Sonderabdruck aus

SCHWEIZERISCHE ZEITSCHRIFT FUR HYDROLOGIE

BIRKHÄUSER VERLAG BASEI

$\mathrm{XXV}, 1963$

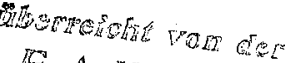
ID. A. W, A. B.
hiss.

\title{
Die Bedeutung des \\ Nannoplanktons im Vergleich zum Netzplankton
}

\author{
Qualitative und quantitatipe Untersuchungen im Züricbsee, \\ Pfäffikersee und anderen Seen
}

Von Marianne Pavoni, dipl. sc. nat.

Manuskript eingegangen am 5. August 1963

\section{INHALT}

A. Einleitung . . . . . . . . . . . . . . . . . . . . . 220

B. Methoden . . . . . . . . . . . . . . . . . . . . . . . . . . . . . 222

C. Das Pbytoplankton des Zürichsees . . . . . . . . . . . . . . . . . . . . 229

I. Allgemeines . . . . . . . . . . . . . . . . . . . . . . . . . . 229

2. Die beobachteten Phytoplankter . . . . . . . . . . 230

a) Artenliste . . . . . . . . . . . . . . . 232

b) Bemerkungen zu einzelnen Organismen . . . . . . . . . . 232

c) Beobachtete Organismen im Vergleich zu früheren Arbeiten . . . . 24I

3. Jahreszeitliches Auftreten . . . . . . . . . . . . . . . . 248

4. Die vertikale Verteilung des Phytoplanktons . . . . . . . . . . . . . 249

5. Biomasse und prozentuale Verteilung des Phytoplanktons . . . . . . . 249

D. Das Pbytoplankton des Pfäffkersees . . . . . . . . . . . . . . . . . 264

I. Allgemeines . . . . . . . . . . . . . . . . . . . 264

2. Die Artenliste der Phytoplankter . . . . . . . . . . . . . . . 265

3. Jahreszeitliches Auftreten . . . . . . . . . . . . . . . . . . . . . 268

4. Die vertikale Verteilung der Planktonorganismen . . . . . . . . . 27I

5. Biomasse und prozentuale Verteilung des Phytoplanktons . . . . . . . 272

6. Nannoplankton und Stoffkreislauf . . . . . . . . . . . . . . . . . 276

7. Vergleich Zürichsee-Pfäffikersee . . . . . . . . . . . . . . . . . 283

E. Untersuchung des Pbytoplanktons perscbiedener Seen . . . . . . . . . . . . . 285

I. Allgemeines . . . . . . . . . . . . . . . . 285

2. Chemische Charakterisierung der Seen . . . . . . . . . . . . 286

3. Resultate der Planktonproben . . . . . . . . . . . . . . . . 293

a) Brienzersee . . . . . . . . . . . . . . . . . . . . . . . . . . 293

b) Thunersee . . . . . . . . . . . . . . . . 295 
c) Walensee . . . . . . . . . . . . . . . . 297

d) Sempachersee . . . . . . . . . . . . . . . . . . . . . . . . . . 299

e) Zürichsee . . . . . . . . . . . . . . . . . . . . . . . . . . .

f) Hallwilersee . . . . . . . . . . . . . . . . . . . . . . . . . . . . . 303

4. Vergleich der Resultate der untersuchten Seen . . . . . . . . . . 305

a) Qualitative Zusammensetzung des Planktons . . . . . . . . . 305

b) Vertikale Verteilung der Planktonorganismen . . . . . . . . . 315

c) Die Biomasse . . . . . . . . . . . . . . . . . . . . . . . 318

F. Scblussbemerkungen . . . . . . . . . . . . . . . . . . . . .

I. Nannoplankton und Zusammensetzung des Phytoplanktons . . . . . . 320

2. Nannoplankton und Biomasse . . . . . . . . . . . . . . 32I

3. Nannoplankton und Individuenzahlen . . . . . . . . . . . . . . . . 325

4. Nannoplankton und Stoffkreislauf . . . . . . . . . . . . . . . . . . 327

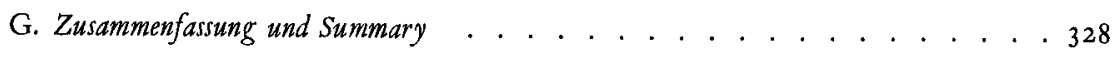

Literaturperzeicbnis . . . . . . . . . . . . . . . . 332

\section{A. Einleitung}

Mit dem Begriff «Nannoplankton» umschrieb LoHMANN [3s] die Gesamtheit jener kleinsten Schwebeorganismen, welche durch Planktonnetze nicht mehr erfasst werden können und die erst durch den feinen Fangapparat der Appendikularien und durch die Zentrifuge erschlossen worden sind. Die Entdeckung des Nannoplanktons durch LoHMANN brachte eine völlig neue Welt äusserst kleiner und zarter Organismen mit sich. In den folgenden Jahren erschienen dann eine Reihe von Arbeiten, die zeigten, wie gross der Anteil des Nannoplanktons am Gesamtplankton ist $[35,54,56,58]$, welche Bedeutung ihm bei der Primärproduktion [2I] und für die Ernährung des Zooplanktons zukommt [33] und mit welchen Methoden diese Nannoplankter am besten erfasst werden können $[74,75]$.

Auch in der Schweiz erfuhr die Planktonforschung durch die neuen Erkenntnisse einen Auftrieb. So verarbeitete LANTZSCH, um die Beziehung zwischen Zentrifugen- und Netzplankton und Zooplankton festzustellen [33], Proben aus dem Zugersee. BachManN untersuchte, hauptsächlich in qualitativer Hinsicht, das Zentrifugenplankton des Vierwaldstättersees [3] und des Rotsees [4]. Während FLÜCK [16] einen Beitrag zum Phytoplankton des Brienzersees lieferte, in welchem er die $\mathrm{zu}$ untersuchenden Proben zentrifugiert hatte, liegt in der Arbeit von COSANDEY [I3] eine ausführliche hydrobiologische Studie über den Lac de Bret vor. COSANDEY schätzte die Verteilung der Organismen aus dem 
Zentrifugenruickstand von Wasserproben. Die neueste Arbeit, in der das Nannoplankton beriicksichtigt wurde, erschien von CHRISTEN [I2] über die Hauserseen. In ihr sind chemische und biologische Resultate mehrerer Untersuchungsjahre dargestellt und das gesamte Plankton bearbeitet. Neben einer weitaus grösseren Zahl einzelner Arbeiten von kurzfristigen Planktonuntersuchungen in Schweizer Seen - eine Zusammenstellung derselben finden wir in MÄrKI [4I] - blieb es jedoch in bezug auf die Formen des Nannoplanktons bei den erwähnten Veröffentlichungen.

Systematische Untersuchungen über das Nannoplankton im Vergleich zum üblichen Netzplankton von Schweizer Seen liegen eigentlich nicht vor. Und so kann man sich bei biologischen Untersuchungen, bei denen nur Netzfänge ausgeführt wurden, eines unsicheren Gefühls nicht erwehren, nämlich, ob man nun wirklich die wichtigsten und den grössten Teil der Planktonorganismen erfasst hat, gerade weil man von anderen, gründlichen Arbeiten weiss, dass die kleinen Organismen oft einen wesentlichen Teil am Gesamtplankton ausmachen $[21,35,54,56,58]$. Die Erfahrung hat wohl gezeigt, dass jeder See einen eigenen Lebensraum mit seinen charakteristischen Umweltsbedingungen darstellt und daher Resultate nur mit Vorsicht verallgemeinert werden dürfen. Es ist also gut möglich, dass im einen See fast reines Nannoplankton vorliegt, in einem andern hingegen zu gleicher Zeit neben kleinen, vorwiegend grössere Formen vorkommen. Wir empfinden es jedoch als Lïcke oder Nachlässigkeit, von vorneherein anzunehmen, dass die kleinen Organismen nicht berücksichtigt $\mathrm{zu}$ werden brauchen, und zwar gerade heute im Zusammenhang mit der zunehmenden Gewässerverschmutzung durch Abwässer.

In der vorliegenden Arbeit setzten wir uns zum Ziel, die qualitative Zusammensetzung des Nannoplanktons in Schweizer Seen zu prüfen und insbesondere seinen quantitativen Anteil am Gesamtplankton zu bestimmen, um daraus zu ermitteln, ob das Nannoplankton für die Gesamtproduktion eines Sees von Bedeutung und bei Planktonuntersuchungen zu berücksichtigen ist. Für eine möglichst umfassende Abklärung dieser Probleme hätte eine grosse Anzahl verschiedener Seen untersucht werden sollen; es zeigte sich jedoch sehr bald, dass es für einen einzelnen Bearbeiter fast unmöglich ist, mehrere Seen nebeneinànder regelmässig zu besuchen und die laufenden Probeserien innert nützlicher Zeit $\mathrm{zu}$ bearbeiten. So blieben von dem anfänglich umfangreichen Programm nur noch Untersuchungen am Zürichsee, welche in den Jahren 1958/59 durchgeführt worden sind. Die Wahl fiel auf diesen See, weil er dem Arbeits- 
platz am nächsten liegt, ferner weil die Probenahme in Verbindung mit den regelmässigen Erhebungen des Chemischen Laboratoriums der Stadt Zürich stattfinden konnte. Ausserdem stand uns das Zahlenmaterial der EAWAG von ausgezählten Schöpfproben aus dem Pfäffikersee vom Jahre I961 zur Verfügung. Ferner wurden zur Zeit der Sommerstagnation I96I in sechs verschiedenen Seen chemische und biologische Proben erhoben.

Meinem verehrten Lehrer, Herrn Prof. Dr. O. JAAG, Direktor der Eidg. Anstalt für Wasserversorgung, gebührt mein aufrichtiger Dank für sein wohlwollendes Entgegenkommen und seine verständnisvolle Förderung meiner Arbeit. Er ermöglichte mir unter anderm auch einen viermonatigen, unvergesslichen Studienaufenthalt an der Biologischen Station Lunz in Niederösterreich. Ganz besonderen Dank schulde ich Herrn Dr. H. Ambühl, Leiter der limnologischen Abteilung der Eidg. Anstalt für Wasserversorgung. Er stellte seine planktologischen und chemischen Analysenresultate des Pfäffikersees zur Verfügung und bereinigte bereitwillig das Manuskript; vor allem aber unterstützte und ermunterte er mich stets mit Rat und Tat und vielen wertvollen Hinweisen. Gerne gedenke ich der Gespräche mit Herrn PD Dr. K. Wuhrmann, dem ich manch kritische, wohldurchdachte Bemerkung verdanke. Sodann ist es mir eine angenehme Pflicht, den Mitarbeitern des Chemischen Laboratoriums der Stadt Zürich, speziell Herrn Dr. P. Zimmermann und den Herren H. Gasser und B. Kim, für all die. Wasserproben des Zürichsees, die sie mir im Laufe der Jahre I958 und I959 in entgegenkommender Weise geholt haben, meinen aufrichtigen Dank auszusprechen. Herrn dipl. ing. agr. W. Rüegg möchte ich für seine hilfreichen Dienste bei Exkursionen an verschiedene Seen ebenfalls danken. Frau P. Weber danke ich herzlich für ihre zuverlässige Zählarbeit des Pfäffikersee-Planktons. Schliesslich gilt mein Dank allen, welche meine Arbeit in irgendeiner Weise gefördert haben.

\section{B. Methoden}

Für die quantitative Untersucbung des Planktons sind schon zahlreiche Methoden ausgearbeitet worden. Mit Hilfe der einen versuchte man die Organismen getrennt zu erfassen $[74,75]$, mit anderen wiederum auf schnellem und einfachem Weg ein Bild von der Produktion in einem See zu erhalten $[39,60]$. Mehrere Autoren befassen sich eingehend mit all den möglichen Bestimmungsarten, indem sie dieselben kritisch beleuchten 
und neue Methoden vorschlagen [7, Io, 38, 40, 52]. Die gründlıchste Methode, die uns ein einigermassen zutreffendes Bild rom biologischen Zustand eines Sees gibt, ist bis heute immer noch die Auszählmethode im Umkehrmikroskop nach UTERMöHL [74, 75]. Allerdings entstehen auch bei dieser Methode von der Probenahme bis zum Schlussresultat einige Fehler, die bei der Beurteilung der Ergebnisse, welche ja nie absolute Werte darstellen, vorsichtige Formulierung verlangen.

Eine erste Fehlerquelle liegt schon beim Erheben der Stichproben im See. Je nach Art der Planktonform und Situation der Witterung entstehen verschieden dichte Ansammlungen der Organismen, so dass, um gesicherte Durchschnittswerte zu erhalten, eigentlich an mehreren Stellen Proben genommen werden müssten. Diese Tatsache kommt in einer

Tabelle 1

Individuenzablen je Liter aus 10 Flaschenzügen

\begin{tabular}{lrrrr}
\hline Zürichsee, 21. Juli 1961 & max. & min. & \multicolumn{1}{c}{$x$} & \multicolumn{1}{c}{ s } \\
\hline Oscillatoria rubescens & 315400 & 244700 & 282900 & 271000 \\
Oscillatoria obliqueacuminata & 66800 & 35900 & 53000 & 14800 \\
Rhodomonas lacustris & 982200 & 448900 & 573960 & 304000 \\
Phacotus lenticularis & 105200 & 800 & 54200 & 47500 \\
Chlorella pyrenoidosa & 22631000 & 9342000 & 12378000 & 4760000 \\
Actinastrum hantzschii & 4600 & 1200 & 2800 & 1200 \\
\hline
\end{tabular}

einmaligen Probeserie vom Zürichsee zum Ausdruck (vgl. Tab. I). Dazu wurden an einem windstillen Tag mit einem Friedingerschen Wasserschöpfer an der gleichen Stelle aus $5 \mathrm{~m}$ Tiefe zehn Proben erhoben, von denen je $50 \mathrm{ml}$ in Absetzkammern gebracht wurden. Sechs häufig vorkommende Organismen von unterschiedlicher Form wurden ausgezählt, nämlich: zwei Flagellaten (Rbodomonas lacustris und Pbacotus lenticularis), zwei fädige (Oscillatoria rubescens und Oscillatoria obliqueacuminata), eine kugelige, unbewegliche (Cblorella pyrenoidosa) und eine koloniebildende Form (Actinastrum bantzscbii). Begreiflicherweise weist Pbacotus die grösste Streuung auf, da diese Form eine relativ starke Eigenbewegung besitzt und zu Schwarmbildung neigt, was schon beim lebenden Material unter dem Mikroskop in der Kammer festgestellt werden kann. THOMas beschrieb das Auftreten eines Phacotusschwarmes im Zürichsee infolge Sprungschichtneigung nach einem Sturm [66]. Selbst in der Schöpfflasche konnte Phacotus dichtere Ansammlungen bilden, was aus Tab. 2 ersichtlich ist, in welcher die Individuenzahlen derselben Organismen aus $5 \times 50 \mathrm{ml}$ Wasser aus einer einzigen Stichprobe zusammengestellt 
Tabelle 2

Individuenzablen je Liter, bestimmt aus $5 \times 50 \mathrm{ml}$ Wasser desselben Flascbenzuges

\begin{tabular}{lrrrr}
\hline Zürichsee, 21. Juli 1961 & \multicolumn{1}{c}{ max. } & \multicolumn{1}{c}{ min. } & \multicolumn{1}{c}{ s } & \multicolumn{1}{c}{ s } \\
\hline Oscillatoria rubescens & 388000 & 268700 & 306100 & 20900 \\
Oscillatoria obliqueacuminata & 65800 & 48400 & 55200 & 7600 \\
Rhodomonas lacustris & 595600 & 447800 & 538700 & 136600 \\
Phacotus lenticularis & 46600 & 850 & 20500 & 23300 \\
Chlovella pyrenoidosa & 16726000 & 11500000 & 13023000 & 2119000 \\
Actinastrum hantzschii & 3300 & 2100 & 2500 & 1400 \\
\hline
\end{tabular}

sind. Rhodomonas zeigt eine viel geringere Eigenbewegung und dementsprechend auch ein ausgeglicheneres Verteilungsbild. Auffallend gleichmässig verteilt sind die fädigen Formen, während die protococcale, kugelige Form stark streuende Zahlen bildete. Diese Abweichungen sind wohl auf die hohe Individuenzahl zurückzuführen, welche erforderte, dass die Proben verdünnt werden müssten. Aus den Zahlen beider Tabellen ist deutlich zu sehen, dass bei quantitativen Planktonuntersuchungen mit Schwankungen der Organismenzahlen gerechnet werden muss, doch ergeben die Zahlen mit wenigen Ausnahmen (z. B. Phacotus) ein durchschnittliches Bild über das quantitative Auftreten der Organismen, ob sie nun in Tausenden (Actinastrum), Hunderttausenden (Oscillatoria, Rbodomonas) oder Millionen (Cblorella) pro Volumeneinheit zu finden sind. Schon RUTTNER [60] schreibt, dass «Schwankungen von ${ }^{\circ} \%$ oder $20 \%$ in der Planktonstatistik nichts besagen» (S. 146). Obgleich man während der Arbeit, besonders beim Berechnen und Auswerten, an den Ergebnissen manchmal zweifeln möchte und oft wünschte, absolutere Zahlenwerte vor sich zu haben, muss man sich immer wieder bewusst sein, dass die mit dieser Methode erhaltenen Resultate trotzdem noch die sicherste Grundlage für die biologische Beurteilung der Seen bildet.

Ein Nachteil bei der Methode UTERMöHL ist allerdings der grosse Zeitaufwand, den sie beansprucht. Man braucht sich daher nicht zu wundern, weshalb wohl ein Grossteil der Seen - und dazu gehören auch die Schweizer Seen - biologisch nicht gründlicher untersucht worden sind. Häufig nimmt man lieber gewisse Fehler in Kauf und sucht immer wieder nach einer Methode, die den eher mühsamen Arbeitsgang des Auszählens, insbesondere der kleinen Formen, abkürzt. Ein solcher Versuch wurde zum Beispiel bei Routineuntersuchungen in schweizerischen Seen durchgeführt, bei denen man, neben den chemischen Analysen, auf möglichst einfachem Weg und in möglichst kurzer Zeit auch ein Bild vom biologischen Zustand der betreffenden Gewässer zu erhalten hoffte. Dabei wurden 
geschöpfte Wasserproben durch einen Trichter mit eingespanntem Phytoplanktonnetzchen filtriert und der Rückstand in Utermöhl-Absetzkammern ausgezählt. Diese Proben hatten gegenüber den gewöhnlichen Netzproben den Vorteil, dass man die filtrierte Wassermenge genau kannte.

Der Vergleich solcher «Trichterproben» mit unveränderten Schöpfproben ist in den Tabellen 3 und 4 zusammengestellt. Diese beiden Aufstellungen zeigen, dass die kleinen Formen zum Teil vollständig durch die Maschen schlüpfen; aber auch die grösseren Formen, vor allem fädige

Tabelle 3

Vergleich zmiscben Scböpfproben und Tricbterproben

\begin{tabular}{|c|c|c|c|c|c|c|}
\hline $\begin{array}{l}\text { Pfäffikersee, } \\
\text { 24. Febr. } 1961\end{array}$ & $\begin{array}{l}5 \mathrm{~m} \\
S\end{array}$ & $T$ & $\% 1$ & $\begin{array}{l}10 \mathrm{~m} \\
S\end{array}$ & $T$ & $\%$ \\
\hline Kephyrion spp. & 9300 & - & - & 29100 & - & - \\
\hline Ochromonas sp. & 280000 & - & - & 84800 & 1600 & 0,5 \\
\hline Rhodomonas lacustris & 731400 & 5500 & 0,5 & 560000 & 5100 & 0,9 \\
\hline Cryptomonas ovata & 124400 & 1200 & 1,0 & 114200 & 700 & 0,2 \\
\hline Mallomonas sp. & 73300 & 240 & 0,3 & 22900 & 850 & 3,7 \\
\hline Gymnodinium helveticum & 3300 & 6 & 0,2 & 2200 & 60 & 2,7 \\
\hline Peridinium cinctum & - & 52 & - & - & 16 & - \\
\hline cf. Ellipsoidion sp. & 16545200 & 6 & - & 23971900 & - & - \\
\hline Staurastrum sp. & - & 28 & - & - & - & - \\
\hline Stephanodiscus hantzschii & 4443400 & 26200 & 0,6 & 3995500 & 61100 & 1,5 \\
\hline Melosira granulata var. ang & & 60 & - & - & - & - \\
\hline A sterionella formosa & 1000 & 3300 & 275 & 2800 & 2300 & 82,0 \\
\hline$S$ Schöpfprobe & terprobe & 1) $T$ in & von $S$ & & & \\
\hline
\end{tabular}

Tabelle 4

Vergleicb zmiscben Scböpfproben und Tricbterproben

\begin{tabular}{|c|c|c|c|c|c|c|}
\hline $\begin{array}{l}\text { Zürichsee, 29. Sept. } 1958 \\
.\end{array}$ & $\begin{array}{l}2,5 \mathrm{~m} \\
S\end{array}$ & $T$ & $\left.\%{ }^{1}\right)$ & $\begin{array}{l}5 \mathrm{~m} \\
S\end{array}$ & $T$ & $\%$ \\
\hline Oscillatoria rubescens & 258100 & 12100 & 4,7 & 163000 & 9000 & 5,5 \\
\hline Oscillatoria obliqueacuminata & 3839700 & 9200 & 0,2 & 1966600 & 5900 & 0,3 \\
\hline Pseudanabaena catenata & 43700 & - & - & 28500 & - & - \\
\hline Anabaena planctonica & 300 & $\mathbf{1}$ & 0,3 & 400 & 5 & 1,2 \\
\hline Platymonas cordiformis & 80 & - & - & + & - & - \\
\hline Katablepharis ovalis & 72800 & - & - & 56300 & - & - \\
\hline Rhodomonas lacustris & 2256500 & - & - & 600000 & - & - \\
\hline Cryptomonas ovata & 64400 & 60 & 0,1 & 31000 & - & - \\
\hline Gymnodinium helveticum & 700 & - & - & 1400 & - & - \\
\hline Ceratium hirundinella & 1400 & 660 & 40,0 & 31000 & - & - \\
\hline Chlorella pyrenoidosa & 311300 & - & - & 238400 & - & - \\
\hline Planctomyces bekefii & 153800 & - & - & + & - & - \\
\hline Asterionella formosa & 2800 & 3300 & 118,0 & 4400 & 3600 & 83,0 \\
\hline Fragilaria crotonensis & 5000 & 9500 & 190,0 & 15800 & 11600 & 73,0 \\
\hline Schöpfprobe & rprobe & in 9 & ron $S$ & & & \\
\hline
\end{tabular}


Algen (Oscillatoria rubescens) gehen verloren ${ }^{1}$ ). Es entsteht nicht nur ein Bild, das proportional unterschiedliche Individuenzahlen pro Volumeneinheit aufweist, sondern wir erhalten überhaupt Zahlen, die eine irreführende quantitative Planktonzusammensetzung ergeben.

Für unsere Untersuchungen des Nannoplanktons erwies sich das direkte Auszählen der Organismen als das geeignetste Verfahren, mit welchem die Arten getrennt erfasst werden können, obgleich wir dadurch nur den momentanen «standing crop» bekommen und obgleich man heute mehr und mehr auf chemisch-physikalischem Wege, zum Beispiel mit der $\mathrm{O}_{2}$ - und vor allem der neuesten, der $\mathrm{C}_{14}$-Methode die Produktion messen und einen Einblick in die Aktivität der Organismen erhalten kann [I9, 60].

Für unsere Untersuchungen wurden vom Dezember 1957 bis zum Dezember 1959 an der tiefsten Stelle des Zürichsees (134 m) Proben geholt, und zwar im ersten Jahr mit wenigen Lücken alle vierzehn Tage, im zweiten nur noch alle vier bis sechs Wochen. Um die vertikale Verteilung des Planktons zu erfassen, wurden soweit möglich in folgenden Tiefen Stichproben erhoben und verarbeitet: $0,2,5,5,7,5$, 10, I5, 20, 30, 60, I0O, I34 $\mathrm{m}$. Von jeder Tiefenstufe wurden IOO $\mathrm{ml}$ für die quantitative Untersuchung abgefüllt und sofort mit JKJ-Lösung nach UTERMÖHL fixiert. Um Schöpf- und Trichterproben miteinander zu vergleichen, wurden während einiger Monate 21 Wasser aus den entsprechenden Tiefen durch den obenerwähnten Filtertrichter filtriert und der Rückstand mit Formol fixięrt. Ferner dienten jeweils einige Tiefenproben zur sofortigen Untersuchung der lebenden Organismen, da sich dieselben durch das Fixieren, vor allem durch Quellungserscheinungen, bis zur Unkenntlichkeit verändern können, zum Beispiel Gymnodiniumarten, kleine Flagellaten oder auch koloniebildende Formen, wie Uroglena, die beim Fixieren vollständig in die einzelnen Zellen zerfallen, oder auch die Dinobryonzellen, die zum grossen Teil stark deformiert aus ihren Bechern schlüpfen. Dazu wurden jeweils Is ml Wasser der unfiltrierten Wasserprobe während dreier Minuten bei etwa I600-I800 Umdrehungen pro Minute zentrifugiert, und zwar in Zentrifugengläsern, wie sie schon LOHMANN [36] beschrieben hat. Das Sediment des in der Spitze hängenden Tropfens wurde im Umkehrmikroskop in einer Utermöhl-Kammer betrachtet.

1) Auffallend sind die Zahlen der beiden charakteristischen, grossen Netzplanktonorganismen Asterionella und Fragilaria, die in den Trichterproben zum Teil in grösserer Menge vorhanden waren als in den entsprechenden Schöpfproben. Diese Unterschiede können damit erklärt werden, dass die Formen in zu geringer Anzahl in den rund $50 \mathrm{ml}$ einer Wasserprobe (wie sie für die Absetzproben gebraucht wurden) enthalten waren, somit nicht genügend, um gesicherte Werte zu erhalten. 
Auf diese Weise musste kein Deckglas gebraucht, und die Organismen konnten, ohne zerdrückt zu werden, längere Zeit als unter dem gewöhnlichen Lichtmikroskop beobachtet werden. Dies ist eine gute Methode, die RUTTNER in seinen Kursen an der Biologischen Station in Lunz immer empfohlen hatte. Die systematische Bestimmung der Phytoplankter erfolgte hauptsächlich nach den üblichen Bestimmungswerken $[9$, I8, 26, 49, 62, 63], wobei das vorzügliche Werk Skujas in erster Linie für die Bestimmung der kleinen Formen diente. Die quantitative Bestimmung erfolgte, wie schon erwähnt, durch Auszählen der Organismen. Dazu wurden jeweils $50 \mathrm{ml}$ Wasser in Röhren-Verbundkammern abgefüllt. Die gefüllten Röhren wurden 48 Stunden stehengelassen, so dass sich alle Organismen auf dem Deckglasboden vollständig sedimentieren konnten. Das Auszählen der Organismen erfolgte im Zeiss-Umkehrmikroskop nach UTERMöHL, je nach Grösse der Formen, mit I6-, 40- oder IOOObjektiv.

Die ausgezählten Organismen warden auf Individuenzahlen im Liter umgerechnet. $\mathrm{Da}$ aber die Individuenzahlen wegen der sehr unterschiedlichen Grösse der Planktonorganismen kein Bild der tatsächlichen Biomasse zu vermitteln vermögen, schien es zweckmässiger, wie schon LOHMANN [35] und RUTTNER [ $54,55,56,58,59$ ] und später auch GRIM [20, 2I] und WuLÉN [76-78], das Planktonvolumen zu bestimmen, obwohl man sich dabei bewusst war, dass diese umständliche Art von Berechnung Ungenauigkeiten und grosse Mehrarbeit mit sich bringt. Die Volumenbestimmung wurde durch Messen der verschiedenen Dimensionen der Organismen und durch Berechnung eines dem Organismus geometrisch ähnlichen Körpers ausgeführt. Berücksichtigt wurde auch wie RUTTNER [55] schon darauf hingewiesen hatte, dass viele Arten, wie zum Beispiel Stepbanodiscus, Rhodomonas, Oscillatoria, je nach Jahreszeit verschiedene Zellausmasse besitzen. So wurden diese Grössen nicht nur einmal, sondern monatlich überprüft und gemessen, und ein Durchschnittsvolumen für die Massenbestimmung verwendet. Auf diese Weise erhielten wir zum Beispiel für einige Organismen des Zürichsees die Volumina, wie sie in Tab. 5 aufgeführt sind.

Ein Vergleich dieser Volumina untereinander zeigt eindrücklich den Unterschied, der entsteht, wenn die Zählergebnisse in Individuenzahlen sowie in Volumen pro Volumeneinheit zur Darstellung kommen.

Für die Totalvolumina wurden die Individuenzahlen mit den Einzelvolumen multipliziert und die Resultate in $10^{6} \mu^{3} / 1$ angegeben. Wenn man das spezifische Gewicht der Planktonorganismen ungefähr gleich I 
Tabelle 5

Volumina einiger Planktonorganismen

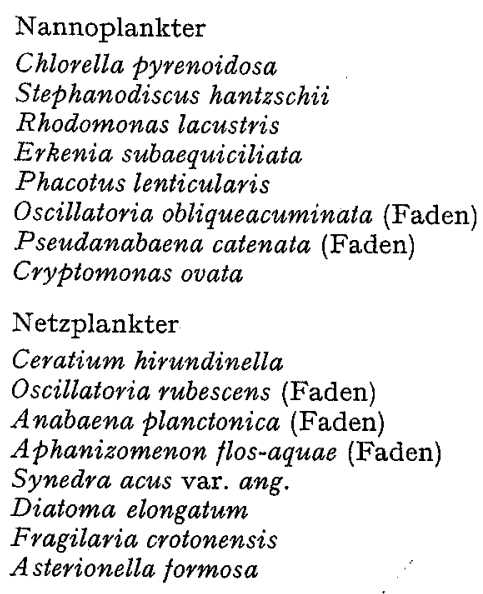

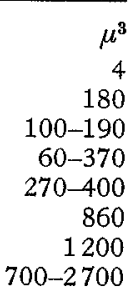

setzt, bedeuten diese Zahlen dann zugleich die Biomasse. So entsprechen ${ }^{I} O^{6} \mu^{3}$-Organismen einer Masse von I $\mu \mathrm{g} / \mathrm{l}$ oder I mg/m $\mathrm{m}^{3}$. Der Gebrauch dieser Masseinheiten ist von Vorteil, wenn chemische und biologische Resultate miteinander verglichen werden. Aus den berechneten Volumina kann der Planktongehalt oder die Biomasse der einzelnen Tiefenstufen oder, durch Interpolation der Tiefenstufenmengen, sogar der Planktongehalt einer ganzen Wassersäule von der Oberfläche bis zum Grund unter einer Flächeneinheit der Oberfläche bestimmt werden, zum Beispiel die Biomasse oder «standing crop», die unter I $\mathrm{cm}^{2}$ Seeoberfläche zur Zeit der Probenahme vorhanden war.

Um die Resultate einzelner Seeuntersuchungen in Kapitel E besser miteinander vergleichen zu können, wurden dort die Begriffe der «Halbwerttiefe» und der « unteren Verbreitung» angewendet, wie sie schon RUTTNER [58] in seinen Arbeiten eingeführt hatte. Nach RUTTNER ist die Halbwerttiefe und untere Verbreitung die Tiefe, wo noch die Hälfte der Biomasse $z u$ finden ist, bzw. noch $10 \%$ der maximalen Individuenzahl vorhanden sind.

Der Begriff Nannoplankton. Wie wir bereits in der Einleitung kurz hingewiesen haben, sind nach LOHMANN Nannoplankter die kleinen Formen, die durch die Maschen des feinen Phytoplanktonnetzes hindurchschlüpfen. «Die kleinsten Formen haben eine Länge von nur I $\mu$; ein Durchmesser von $25 \mu$ muss schon als gross gelten" [36]. Es gibt jedoch viele Formen, 
so auch fädige und stäbchenförmige, die durch die Netzmaschen schlüpfen, auch wenn sie too $\mu$ und mehr lang sind. Eine exakte Abgrenzung der Organismen ist somit nicht möglich, so dass die Aufteilung in Nannoplankton und Netzplankton ganz nach eigenem Gutdünken vorzunehmen ist. WILLÉN [76] zum Beispiel zählte unter das Nannoplankton Organismen, die höchstens in einer Richtung noch $60 \mu$ erreichen. Unsere Nannoplankter sind durchschnittlich $\mathrm{I}-30 \mu$ gross, dazu kommen feine, fädige und stäbchenförmige Organismen. Mit dem Kammerverfahren nach UTERMÖHL jedoch können alle Formen erfasst werden, so dass man eigentlich nicht mehr zwischen Nanno- und Netzplanktern unterscheiden muss; in diesem Fall spricht man besser von Absetz- oder Scböpfplankton.

\section{Das Phytoplankton des Zürichsees}

\section{Allgemeines}

Der Zürichsee ist sowohl chemisch-physikalisch als auch planktologisch einer der meist untersuchten Seen der Schweiz. Seit der zweiten Hälfte des vergangenen Jahrhunderts ist eine grosse Anzahl von Arbeiten über Untersuchungen und Beobachtungen erschienen, anhand welcher seine Entwicklung und sein plötzliches Umkippen von einem oligotrophen $z u$ einem eutrophen Gewässer fast lückenlos verfolgt werden können. Der Hauptteil dieser Veröffentlichungen, insbesondere über chemisch-physikalische Untersuchungen sind in der Arbeit von ZIMMERMANN [79] zusammengestellt.

Das Plankton des oberen und unteren Zürichsees wurde Ende des letzten und zu Beginn dieses Jahrhunderts sowohl qualitativ als auch teilweise quantitativ verfolgt. Diese ersten Arbeiten sind bei MINDER [45, 47] und MäRKI [4I] erwähnt; die neueren planktologischen Beiträge sind im Literaturverzeichnis von JärNEFELT und THOMAS [28] $\mathrm{zu}$ finden. Das Plankton des Zürichsees ist den zahlreichen Arbeiten entsprechend recht gut bekannt. Dank der regelmässigen Untersuchungen im Laufe der letzten 70 Jahre liegt heute die interessante Geschichte des Planktons und seiner Entwicklung in Raum und Zeit qualitativ und zum Teil quantitativ vor. Es gibt wohl nur wenige Seen, bei denen das Neuauftreten von Organismen, das häufig in Form von sogenannten Invasionen stattfand [47], und das Verschwinden bereits bekannter Arten über Jahre hindurch beobachtet wurde. Auffallenderweise fehlen in den meisten dieser Planktonlisten die Namen der kleinen Formen, obgleich das Nanno- 
plankton schon um die Jahrhundertwende entdeckt worden ist. Erst in den neueren Zusammenstellungen von MESSIKOMMER [44], JÄrNEFELT und Thomas [28] und THOMas [68] wurden sie beruicksichtigt, allerdings nur qualitativ, und in einzelnen, zufälligen Stichproben. Schon I929 war sich MINDER bei seinen biologischen Untersuchungen dieser Lücke bewusst, und I943 schrieb er: «Das Plankton des Zürichsees ist zwar nicht in allen Teilen gleichmässig untersucht. So ist das Nannoplankton so gut wie nicht bekannt.» Und: «Unsere Beschreibung der auffälligsten Umbildungen im Planktoncharakter muss sich demnach notgedrungen auf die grösseren Formen, die Organismen des Mikroplanktons (Netzplankton) beschränken. Ob und was für Wandlungen auch das Nannoplankton durchgemacht hat, wissen wir nicht.» Da das Netzplankton des Zürichsees gut bekannt und einfach zu charakterisieren ist, möchten wir unsere Ausführungen im wesentlichen auf die Nannoplankter unserer Schöpfproben beschränken und damit das bekannte, vielbearbeitete Netzplankton ergänzen. Wir beabsichtigten nicht, eine möglichst grosse Liste dieser kleinen Formen aufzustellen, sondern legten Gewicht vor allem auf die kleinen Phytoplankter, die während unserer Untersuchungsperiode quantitativ von Bedeutung waren.

\section{Die beobachteten Phytoplankter}

Die im Laufe der Untersuchungen im Zentrifugensediment beobachteten Organismen des Phytoplanktons sind in Abschnitt $2 b$ (S. 232 ff.) und Tab. 6, Kolonne 7, zu finden. Dazu sei bemerkt, dass die Zahl derOrganismen bei weiteren, eingehenderen qualitativen Untersuchungen um einiges vergrössert werden könnte. Viele kleine, hauptsächlich farblose Flagellaten wurden nur bis zur Gattung bestimmt, weil dieselben oft nur in geringer Anzahl in den Proben vorhanden waren, was das exakte systematische Einordnen erschwerte.

In der Liste sind rund I30 Phytoplankter und 8 Bakterien zu finden, davon 70-80 Nannoplankter. Nur der kleinste Teil dieser Organismen ist jedoch quantitativ von Bedeutung. So wurden im ganzen rund so Formen ausgezählt, zur Berechnung der Biomasse 35 berücksichtigt und pro Probeserie durchschnittlich sogar nur I6 für die Berechnung der Biomasse verwendet (davon $6 \mathrm{Netz}-$ und 8 Nannoplankter und 2 oligoaerobe Formen aus dem Hypolimnion). Die jeweils ausgezählten Artenzahlen sind in Abb. I, Netz- und Nannoplanktonformen getrennt, dargestellt. Daraus geht hervor, dass die Artenzahlen der Nanno- und Netz- 

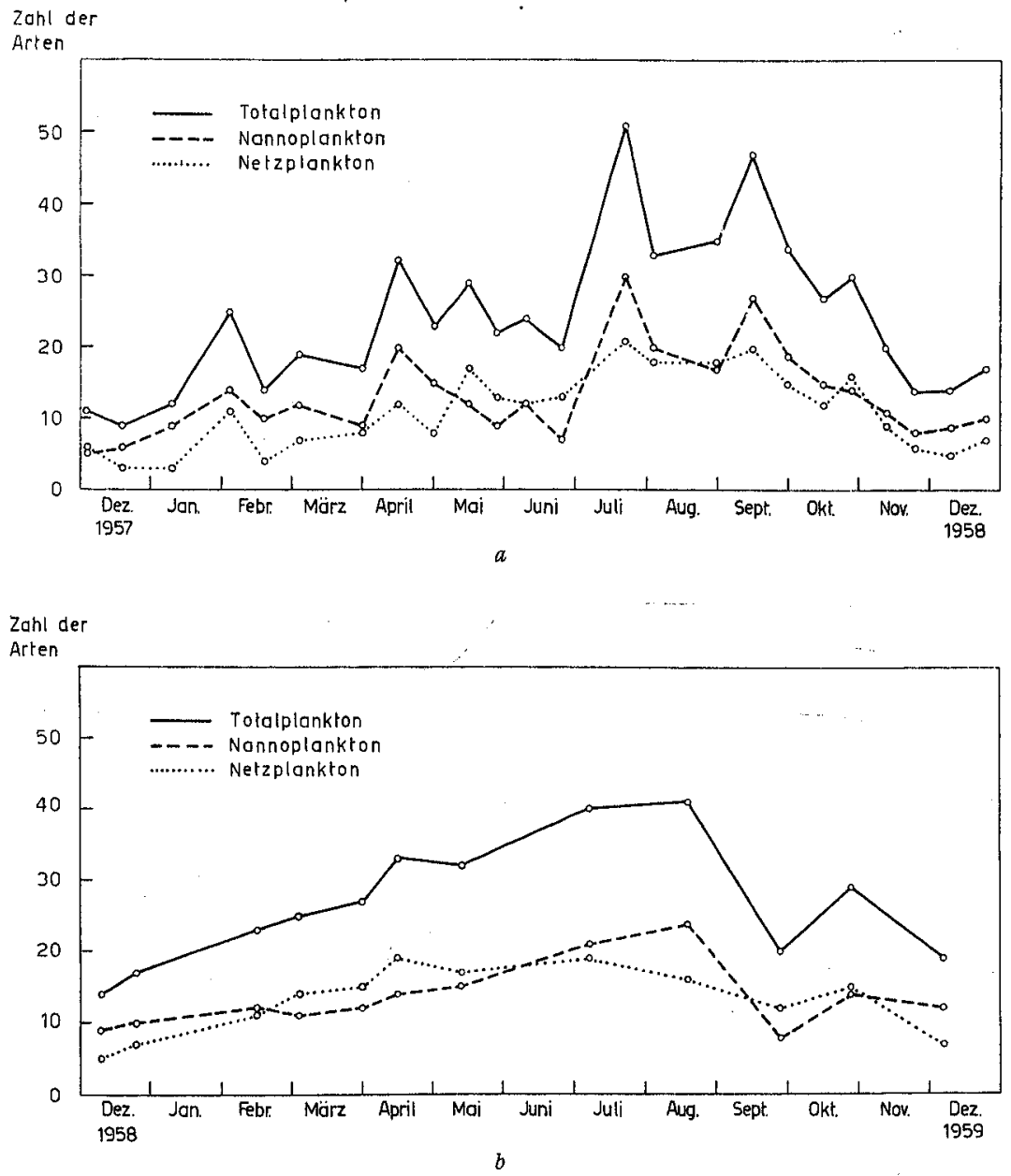

Abbildung $1 a$ und $b$

Zürichsee. Anzahl der ausgezählten Arten. a) Dezember 1957 bis Dezember 1958; $b$ ) Dezember 1958 bis Dezember 1959.

plankter das ganze Jahr hindurch ungefähr gleich gross sind. und dass im Winter beide Gruppen die niedrigsten, im Sommer und frühen Herbst die höchsten Zahlen aufweisen.

Bemerkungen über einzelne Formen bezüglich Systematik, Auftreten und Verteilung, insbesondere der Nannoplankter, wurden in Abschnitt $b$ (S. 232) unter den entsprechenden Organismen angebracht, diese sind nach der heute üblichen Einteilung geordnet. 
a) Artenliste (vgl. Tab. 6 unter c)

\section{b) Bemerkungen zu einzelnen Organismen}

\section{BACTERIOPHYTA}

Formen aus dem Kreise der Bakterien fanden sich hauptsächlich in Grundproben ( $134 \mathrm{~m}$ ), während der Winter- und Frühlingsmonate. Obschon häufig in grosser Zahl vorhanden, fielen sie nie ins Gewicht im Verhältnis zur gesamten Biomasse des Phytoplanktons. Wohl haben wir diese Organismen soweit möglich und bestimmbar ausgezählt, doch darf diesen Werten nicht zu grosses Gewicht beigemessen werden, denn bei den Bakterienzahlen muss vermutlich noch mit viel grösseren Streuungen gerechnet werden als beim Phytoplankton, weil die Grundproben wahrscheinlich nie im gleichen Abstand von der Schlammoberfläche gefasst wurden. Gerade in einer Zone wie der Schlammoberfläche jedoch, wo intensive Abbauvorgänge stattfinden, sind diese Mikroorganismen in kleinsten Abständen verschieden eingeschichtet.

Leptothrix echinata Beger, Abb. I ${ }^{\star 2}$ ): Die Form wurde schon von MINDER eingehend [46] besprochen. Leptotbrix ecbinata trat fast das ganze Jahr hindurch, vor allem aber im Winter und Frühling mehr oder weniger zahlreich, vorwiegend in den Grundproben (I34 m) auf. In den Proben vom Januar bis März I958 war sie in allen Wasserschichten von o-roo $\mathrm{m}$ gleichmässig verteilt; mit einem stark zunehmenden Maximum am Grund (meistens bis in die Millionen pro Liter). Die braunen Sterne lagen oft in unregelmässigen, teilweise dichten Ansammlungen beieinander, was das Auszählen erschwerte und die Zählresultate mit Fehlern belastete. Die. Höchstzahl (9 Mio. Indiv./I) wurde im April r958 ( $134 \mathrm{~m}$ ) gefunden. Der volumenmässige Anteil dieser kleinen Formen ist unbedeutend (Höchstwert $0,047 \mathrm{~mm}^{3} / \mathrm{l}$ ). Meistens wurde sie zusammen mit Leptotbrix sp. angetroffen.

Leptotbrix sp. (cf. pseudovacuolata [Berfiliev] Dorff.), Abb. $2^{\star}$ : Die Fäden sind bis Iro $\mu$ lang, oft kürzer, das Trichom ist I,S-I,7 $\mu$ breit, die Zellen $2,5 \mu$ lang, die Scheide im Vergleich zu den anderen bei SkUjA [62] beschriebenen Arten dünn (Faden mit Scheide . I, $8 \mu$ breit), immer stark inkrustiert mit Eisen oder Mangan. Die Zellen sind an ihren Querwänden leicht eingeschnürt und voneinandergerückt. Endzelle stumpfkegelig. Am besten stimmt die Form mit der von SkUJA [58] beschriebenen Leptotbrix pseudovacuolata überein. Einzig die Scheide ist auffallend dünn ausgebildet. Möglicherweise ist die Breite der Scheide wie bei gewissen fädigen Blaualgen je nach Umweltsbedingungen ein stark variables Merkmal. Die Form trat wie bei Leptotbrix ecbinata hauptsächlich im Winter und Frühling in den Tiefenschichten oder bei Vollzirkulation gleichmässig über die ganze Wassersäule verteilt auf. Die grösste Menge betrug im Mai I $9590,90 \mathrm{~mm}^{3}$, oder $1,54 \mathrm{~mm}^{3}$ unter $\mathrm{I} \mathrm{cm}^{2}$, was $14,4 \%$ des entsprechenden «standing crop» ausmachte.

Planctomyces bekeffi Gimesi, Abb. $3^{\star}$ : Ob Planctomyces zu den Pilzen oder zu den Bakterien gerechnet werden soll, kann auch SKUJA [63] nicht sicher entscheiden. Die äusserst zarten Kolonien sind meist 3-, 4-, 8-, I6- und mehrstrahlig. Am Ende der durchsichtigen, sich verjüngenden, oft bräunlichgelben, glatten, manchmal höckerigen (Eisenablagerung?) Strahlen sitzen kleine, farblose, homogene Kügel-

2) Zahlen mit Stern $\left({ }^{*}\right)$ bedeuten Abbildungen der Organismen auf Tafel 1-5. 
chen von $0,5-0,8-$ I $\mu$ im Durchmesser, oft $2-3$ in einer Reihe (kolonienähnliche Abschnürungen). Die Stiellänge beträgt $2-6,4-12 \mu$. Wie die Vermehrung erfolgt, konnte nicht beobachtet werden. Auffallend häufig wurde die Form auf kugeligen Grünalgen sitzend angetroffen, vor allem auf Gemellicystis neglecta und Spbaerocystis scbröteri, so dass man vermuten könnte, dass Planctomyces tatsächlich keine rein planktische Form ist. Die sternförmigen Kolonien traten hauptsächlich im Spätsommer und Herbst auf. Wir verfolgten ihr Auftreten nicht deshalb, weil sie an der Biomasse des Planktons viel ausmacht, sondern als interessante, noch wenig beachtete Form in der Planktonbiozönose. Die grösste Zahl erreichte sie im August $1958 \mathrm{mit} \mathrm{I}, 2 \mathrm{Mio}$. Indiv. $/ \mathrm{l}\left(=0,006 \mathrm{~mm}^{3} / \mathrm{l}\right)$ in der Tiefe von $9 \mathrm{~m}$. Die maximale Tiefe, in der sie noch festgestellt werden konnte, betrug $30 \mathrm{~m}$. Interessanterweise fiel das Individuenmaximum von Planctomyces oft mit demjenigen von Oscillatoria rubescens zusammen.

Pseudomonas sp. (cf. ariston Skuja), Abb. $4^{\star}$ : Das ganze Jahr hindurch begegneten wir in den Tiefenzonen, hauptsächlich am Grund, einem gutbeweglichen Bakterium. Es besitzt eine elliptische Form, ist $4,5 \mu$ breit und etwa $9,5 \mu$ lang. Die Vermehrung erfolgt durch Querteilung. Der Zellinhalt ist homogen, fein gekörnt, mit JKJ färbt es sich rotviolett an. Die Geisseln wurden erst mit Hilfe einer Färbung sichtbar und sind ein- bis eineinhalb körperlang. Vermutlich ist es eine Pseudomonasart, deren physiologische Merkmale für eine exakte Artbestimmung in Kultur genommen werden müsste. Vergleicht man das Bakterium mit anderen beschriebenen Formen, so stimmt es in Aussehen und Grösse am besten mit $P_{\text {seudomonas ariston }}$ Skuja überein. Die Höchstzahl beträgt 2,6 Mio. Indiv./1 und wurde im Februar I958 gefunden. Auch in den Sommermonaten erreichte diese Form über 2 Mio. Indiv./l.

Spirillum volutans Skuja, Abb. $5^{\star}$ : Sein Aussehen stimmt genau mit der Beschreibung und Abbildung von SKUJA [62] überein. In den Proben war es immer mit Pseudomonas sp. zusammen zu beobachten, besonders dann, wenn Pseudomonas häufig war.

Ocbrobium tectum Perfiliev: Nie zahlreich, zusammen mit Leptotbrix ecbinata und Leptotbrix sp.

Siderocapsa geminata Skuja: Vereinzelt, mit den obenerwähnten Eisenbakterien.

\section{CYANOPHYTA}

Im Zürichsee sind verhältnismässig wenig Blaualgenarten gefunden worden, doch wie schon aus der Literatur zu entnehmen ist [47], prägt eine Blaualge als Charakteralge seit $\mathrm{x} 898$ bis heute das Planktonbild dieses Sees, so dass er nicht nur allgemein als typischer Blaualgensee, sondern nach der Art als «Oscillatoria-rubescens-See» bezeichnet oder typisiert werden kann. Von den 12 Blaualgenarten zählen drei zu den Nannoplanktern, wovon eine im Jahre 1958 in starker Massenentfaltung aufgetreten ist.

Microcystis flos-aquae (Wittr.) Kirchn. em. W.-L.: Sie wurde nur in geringer Individuenzahl in den Planktonproben gefunden, vor allem im August I959.

Apbanotbece clatbrata var. brevis Bachmann, vereinzelt.

Apbanocapsa delicatissima W. et G. S. West, vereinzelt.

Cbroococcus limneticus Lemm., vereinzelt.

Coelosphaerium kützingianum Naegeli: Diese Blaualge wurde nur in der Probeserie vom 5. August 1958 gefunden. Sie erreichte ein Maximum von 438000 Kolonien/1 in $8 \mathrm{~m}$ Tiefe. 
Gomphospbaeria lacustris Chodat, vereinzelt.

Aphanizomenon flos-aquae (L.) Ralfs.

Anabaena planctonica Brunnth.

Die drei letzten Formen traten hauptsächlich im Herbstplankton 1958 auf, doch nie in grosser, für die Produktion massgebender Zahl.

Pseudanabaena catenata Lauterb., Abb. $7^{\star}$ : Die Zellen sind $1,8-2-2,4 \mu$ breit, 3,2 bis $5,6 \mu$ lang, im Längsschnitt abgerundet rechteckig, durch starke Einschnürung deutlich voneinander getrennt. Die Zellen sind länger als diejenigen des Typus und breiter als bei der von SkUJA [62] beschriebenen Form. Das Ektoplasma ist homogen, das Entoplasma feinkörnig. Neben normal ausgebildeten Fäden, bei denen nur je I-2 kleine Gasvakuolen an den Zellwänden ausgebildet waren, gab es Fäden mit zum Teil zahlreichen, stark lichtbrechenden, unregelmässig zerstreuten Körnern

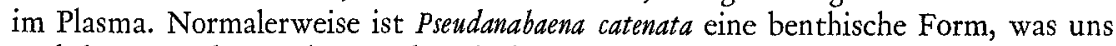
auch heute noch unsicher macht, ob diese freischwimmenden, oft zahlreich vorhandenen Trichome tatsächlich mit Pseudanabaena catenata identifiziert werden dürfen, obgleich Diagnose und Abbildung am besten mit dieser Art ibereinstimmen. Auch andere Autoren (vgl. SKUJA I956, S. 70) haben diese Fäden - obgleich mit einigen Zweifeln erfüllt - unter diese Art eingeordnet und beobachtet, dass benthische Formen leicht in die oberen Wasserschichten aufsteigen und -sich dort als planktische Form weiterentwickeln können. Wie die meisten planktischen Blaualgen trat sie in den Herbstmonaten in den oberen Wasserschichten auf, mit einem Maximum von 265000 Fäden/l im August 1959, in 2,5 m Tiefe.

Oscillatoriu rubescens D.C.: Diese weitverbreitete, bekannte Form wird in einem der folgenden Abschnitte (s. S. 249 ff.) im Zusammenhang mit der Biomasseentwicklung eingehender besprochen.

Oscillatoria obliqueacuminata Skuja, Abb. $8^{\star}$ : Trichome freischwimmend, an 'den Enden nicht verjüngt. Endzelle zugespitzt, teilweise fast krallenartig gebogen, stark vakuolisiert. Trichome nicht oder manchmal ganz leicht eingeschnürt. An den Querwänden beiderseits eine verschieden grosse, unregelmässig geformte Gasvakuole. In der Mitte der langen Zellen oft eine feine Gasvakuole, vermutlich an der Stelle, wo die neue Querwand gebildet wird. Zellen bläulichblass, Chromatoplasma homogen, vom feinkörnigen Ektoplasma getrennt. Zellen $4-6,4-8 \mu$ lang, Trichome I,6-2 $\mu$ breit. Die Form zeigt grosse Ähnlichkeit mit Oscillatoria obliqueacuminata, doch sind die Zellen der Zürichseeform viel schwächer eingeschnürt und die Endzellen stärker zugespitzt. Die Form steht aber auch Oscillatoria Redeckei van Goor (SKUJa [63], S. 63) nahe, doch unterscheidet sie sich deutlich von derselben durch die unterschiedliche Endzelle. Wir fanden die Form in den Schöpfproben vom August und September in den oberen Wasserschichten, zusammen mit Oscillatoria rubescens und Pseudanabaena catenata bis 3,8 Mio. Fäden $/ 1$ in 2,5 m Tiefe am 29. 9. 58 . In den Netzfängen ist sie nur ganz vereinzelt anzutreffen, so dass sie unter die Nannoplankter zu rechnen ist, wenngleich ihre Fadenlänge häufig Iso $\mu$ erreicht.

\section{CHLOROPHYTA}

Die Grünalgen waren quantitativ sozusagen unbedeutend. Die meisten Algen traten sprunghaft in den Sommermonaten auf, um nachher wieder vollständig zu verschwinden. 
Polyblepharidinae

Collodictyon triciliatum Carter: Trat vor allem im Juli und August in den Oberfächenschichten auf, jedoch nie zahlreich.

Euchlorophyceae

Nepbroselmis angulata (Korschikow) Skuja: Vorkommen in den frühen Frühlingsmonaten, doch nie zahlreich.

Chlamydomonas spp.: Die grösste Dichte betrug 222 ooo Indiv./l (24. Juni I958).

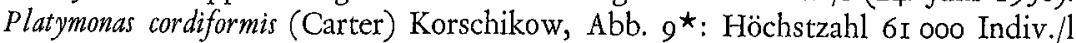
(2. März I959).

Phacotus lenticularis Ehrnb.: Höchstzahl 54000 Indiv./1 (22. Juli I958).

Endorina elegans Ehrnb.: Vereinzeltes Auftreten.

Pandorina morum (Müller) Berg: Vereinzelt.

Gemellicystis neglecta Teiling em. Skuja.

Gloeococcus schroeteri (Chod.) Lemm.: Vereinzelt.

Glococystis bacillus Teiling: Vereinzelt.

Characium gracilipes F. D. Lambert, Abb. I I*: Vereinzelt.

Lambertia judayi (G. M.Smith) Korschikow.

Pediastrum spp.: Alle Pediastrumarten (vgl.' Tab. 6) traten nur vereinzelt auf.

Oocystis spp.: Die Arten (vgl. Tab. 6) waren nie in bemerkenswerter Menge unter den anderen Phytoplanktern zu finden.

Chlorella pyrenoidosa Chick, Abb. Io*: Zellen kugelig $\mathrm{I}, 6-4,8 \mu$ im Durchmesser, wandständiger, ausgeschnittener Chromatophor mit grossem, lateralem Pyrenoid. Mutterzelle teilt sich in vier, wobei die gesprengte Muttermembran häufig noch an einer der vier Zellen hängenbleibt. Diese Form trat meistens mit anderen klẹinen, kugeligen Grünalgen, vor allem mit Coccomyxa minor Skuja und Sticbococcus atomus Skuja (im Text werden diese Formen oft unter dem Begriff « $\mu$-Algen» zusammengefasst) zusammen, auf. Im Sommer 1958 erreichte sie 87,3 Mio. Indiv./1 ( 5 . August I958).

Tedrä̈dron minimum var. opiculato-scrobulatum Skuja: Trat vor allem im Juni auf, und zwar nur vereinzelt.

Treubaria triappendiculata Bern.: Höchstzahl I9 500 Indiv./1 (22. Juli 1958).

Scenedesmus spp.: Nie zahlreiches Auftreten.

Micractinium pusillum Frés.

Ankistrodesmus spp. : Nie zahlreich.

Conjugatae

Nicht von Bedeutung.

\section{EUGLENOPHYTA}

Euglena sanguinea Ehrbg.: Vereinzelt.

Tracbelomonas polvocina Ehrbg.: Vereinzelt.

Menoidium incurvum (Frés.) Klebs: In den Grundproben nie häufig.

Astasia katbemerios Skuja: In den Grundproben nie häufig.

\section{CHRYSOPHYTA}

Chrysophyceae

In ansehnlicher Artenzahl vertreten, spielen die Chrysophyceen sowohl zahlenals auch volumenmässig nur eine geringe Rolle im Zürichseeplankton, im Gegen- 
satz zu den ostalpinen-, ostholsteinischen-, schwedischen- und vielen unserer Alpenrandseen, wo sie sich wenigstens zu gewissen Jahreszeiten in reicher Massenentfaltung entwickeln.

Cbromulina sp. Abb. I6*: Zellen rund, 5-6,4 $\mu$ Durchmesser, ein wandständiger Chromatophor, ein roter Augenfleck in der vorderen Zellhälfte. Im hinteren Zellteil fällt ein grosses, starkes, lichtbrechendes Korn auf, das fast ein Drittel des Zellraumes einnimmt. Eine pulsierende Vakuole ebenfalls in der hinteren Zellhälfte. Geissel halb so lang als der Körper. Die Form bewegt sich in langsamer Wellenbewegung hin und her schwankend vorwärts. Sie wurde nur in den Sommermonaten vereinzelt in den Oberflächenschichten angetroffen.

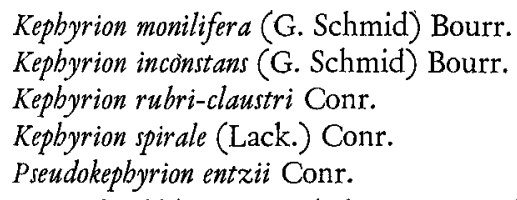

Diese fünf kleinen, zierlichen Formen (Abb. I8-20*) wurden nie getrennt gezählt, da die einzelnen Arten immer nur vereinzelt angetroffen wurden und nie nur eine Art im. Plankton vorhanden war. Am häufigsten waren Kepbyrion monilifera und Kepbyrion inconstans. Es sind ausgesprochene Frühlings- und Winterformen, und erreichten ihre maximale Entfaltung im April 1958 in $\mathrm{I} 5 \mathrm{~m}$ Tiefe mit 61 200 Indiv./1. Volumenmässig bedeutungslos.

Chrysococcus rufescens Klebs (cf. biporus Skuja), Abb. 21*: Die Form stimmt mit der Beschreibung von SKUJA [63] weitgehend überein, nur unterscheidet sie sich durch ihren kleineren Durchmesser von durchschnittlich $6-7 \mu$ und durch das stete Vorhandensein eines gut ausgebildeten, gleich grossen Antapikalporus. Vielleicht handelt es sich auch um Cbrysococcus biporus. Ausser im März I959 wurde die Form nur noch im Mai 1958 beobachtet.

Sphaeroeca polvox Lauterb.: In den JKJ-Proben waren die Kolonien in Einzelzellen zerfallen. Nur im September I958 trat diese Form in grösserer Menge auf: 856000 Zellen/l in o $\mathrm{m}$.

Erkenia subaequiciliata Skuja, Abb. 22*: Eine typische Nannoplanktonform, die sich zur Zeit unserer Untersuchung in den Sommer- und Herbstmonaten, aber auch im Frühjahr im Plankton zeigte. Als wir diesen kleinen Chrysoflagellaten im Zentrifugenplankton bemerkten, brauchte es noch einige Zeit, um ihn richtig einzuordnen. Anfänglich wurde er beim Auszählen nicht berücksichtigt, sondern erst, als er in auffallender Anzahl erschien. Kennt man ihn einmal, dann kann man ihn in den meisten Seen beobachten, in denen er mehr oder weniger häufig vertreten ist. Wegen seiner Kleinheit spielt dieser Organismus volumenmässig nur eine untergeordnete Rolle, obgleich er sich oft in grosser Zahl unter den andern Planktern vorfindet. Die zarten Zellen sind 4-5 $\mu$ lang, 3-4-6 $\mu$ breit und $2,5-3 \mu$ dick, Sie besitzen zwei braungelbe, wandständige Chromatophoren mit zwei stark

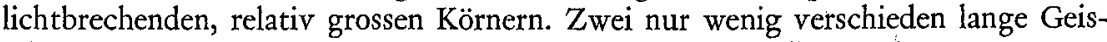
seln, von denen die längere $2-2^{1} / 2$ mal so lang als die Zelle ist, dienen zur Fortbewegung.

Uroglena polvox Ehrnb.: Diese Form war nie häufig vorhanden. Leider zerfallen die Kolonien sehr schnell in die einzelnen Zellen, vorwiegend beim Fixieren mit 
JKJ. Dadurch ist uns diese Form sicher oft entgangen. Wäre sie andererseits in grosser Anzahl vorgekommen, wäre das sofort ins Auge gefallen.

Dinobryon sociale Ehrnb.

Dinobryon divergens Ehrnb.

Dinobryon sertularia Ehrnb.

Dinobryon sociale var. stipitatum (Stein) Lemm.

Die Dinobryonarten wurden bei der quantitativen Auswertung immer zusammen berücksichtigt. Dinobryon fanden wir hauptsächlich in den Monaten Mai bis September und, weniger häufig, im März bis April. Eine bestimmte Reihenfolge im Auftreten der einzelnen Arten konnte nicht beobachtet werden. Auffallend war nur das gemeinsame Vorkommen von Dinobryon sociale, Dinobryon divergens und Dinobryon sertularia im August und September 1958 und im Juli I959. Im JKJ-Präparat waren die Kolonien häufig in die einzelnen Gebäuse zerfallen und der Flagellat selber aus jenen herausgelöst.

Mallomonas caudata Iwan.

Mallomonas acaroides Perty.

Mallomonas elongata Reverdin.

Die Mallomonasarten waren nie in beträchtlicher Zahl zu finden, weshalb wir sie nicht quantitativ auswerteten. Meistens waren die Panzer der fixierten Organismen in die einzelnen Schüppchen und Nadeln zerfallen und bis zur Unkenntlichkeit verändert. Nur in den Zentrifugenproben sind die drei verschiedenen Arten systematisch bestimmt worden. Deutlich zeigte sich dabei, dass Mallomonas caudata eine Früuhlingsform ist, Mallomonas acaroides die wärmeren Temperaturen (Juli) vorzieht und Mallomonas elongata hauptsächlich im Winter und Frühling das Plankton bereichert.

Bicoeca cf. multiannulata Skuja, Abb. 26*: Die Form ist sehr ähnlich der von SkUJA beschriebenen, Sie besitzt jedoch ein grösseres Gehäuse, bis $24 \mu$ lang (bei SkUJA 8-is $\mu$ ), ferner eine gut ausgebildete, undulierende Membran, wie zum Beispiel Bicoeca planctonica, und im Gegensatz zu Bicoeca multiannulata Skuja zwei pulsierende Vakuolen am Grunde der Zellen. Die Zellen selber sind 8,6 $\mu$ lang (bei SKUJA $5-7 \mu$ ). Im Zürichsee wurde sie vereinzelt im September und August gefunden, ihr braungelbes, wunderschönes Gehäuse in den Winterproben oft am Grund.

Pseudopedinella erkensis Skuja, Abb. $23^{\star}$ : Dieser eigenartige, kleine Chrysoflagellat fällt meistens durch sechs Chromatophoren auf. Es gelang uns erst im Jahre I96I, sie lebend zu beobachten und nach SKUJA [62] zu bestimmen. Wir fanden diesen Nannoplankter vor allem in den Sommermonaten und im He1bst, jedoch nie sehr zahlreich. Er scheint wie Erkenia in den meisten unserer Seen vertreten zu sein, nur wird er wegen seines kleinen und zarten Baues gerne übersehen.

Monas sp.

Bodo sp.

Cercobodo sp.

Ocbromonas sp., Abb. 25*.

Heterocbromonas sp., Abb. 28*.

Bei der quantitativen Auswertung wurden diese Flagellaten zusammen berücksichtigt, da wir die Arten nicht genügend sicher bestimmen konnten. Bodo sp. und Ocbromonas sp. waren das ganze Jahr hindurch in den Proben zu finden; Ocbromonas 
sp. entwickelte sich hauptsächlich im September 1958 und 1959, wo an der Oberfläche 948000 Indiv./l (1958) festgestellt wurden. Bodo sp. trafen wir eher in den tieferen Schichten, zum Teil auch in den Grundproben.

\section{Diatomeae}

Die Diatomeen sind neben der Blaualge Oscillatoria rubescens jene Algen, die im Phytoplankton des Zürichsees am meisten ins Gewicht fallen, jedoch nie eine ähnlich riesige Masse bildeten wie Oscillatoria rubescens.

Cyclotella comensis Grun.

Cyclotella comta (Ehrnb.) Kütz.

Cyclotella stelligera $\mathrm{Cl}$. und Grun., Abb. $30^{\star}$.

Cyclotella pseudostelligera Hustedt, Abb. $3 \mathrm{I}^{\star}$.

Cyclotella operculatu (Ag.) Kg., Abb. $32^{\star}$.

Cyclotella bodanica Eulenst.

Stephanodiscus bantzscbii Grun.

Die zentrische Diatomee Stepbanodiscus bantzscbii war zur Zeit unserer Untersuchungen wohl der wichtigste Nannoplankter des Zürichsees. Er trat nicht nur zahlenmässig (27 Mio. Indiv./l in 2,5 m, März 1959) dominierend in Erscheinung, sondern erreichte zur selben Zeit auch weitaus die grösste Biomasse $\left(6,6 \mathrm{~mm}^{3}\right.$ unter

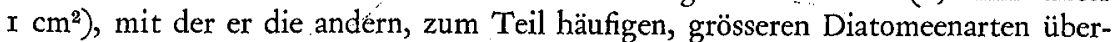
traf. Seine üppigste Vegetationszeit herrschte im Frühling vor. In späteren Monaten war er nur noch vereinzelt in den Proben zu finden.

Stephanodiscus alpinus Hust.: Im Gegensatz zum Frühling 1959, wo Stepbanodiscus alpinus sozusagen nie zu beobachten war, entwickelte er sich im Frühling 1958 in beachtlichen Mengen.

Stephanodiscus astraea (E.) Grun., nur ganz vereinzelt gefunden.

Diatoma elongatum Agardh.: Mit Tabellaria zusammen Hauptdiatomeenart des Monats Mai.

Nitzscbia acicularis W. Sm.: Das ganze Jahr hindurch im Plankton zu finden, jedoch von geringer Bedeutung für das Plankton.

Fragilaria crotonensis Kitton: Trat nie in auffallender Menge unter den Planktern hervor. Höchstentfaltung im April und Mai 1958, wo sie bis zu to ooo Zellen/1 bildete.

Fragilaria capucina Desm.: Immer nur vereinzelte Bänder.

Tabellaria fenestrata (Lyngb.) Kg. var. asterionelloides Grun.: Wie in den meisten Seen war sie auch im Zürichsee eine charakteristische Frühlingsform (und Frühsommer) mit der Höchstzahl von 2.17 00o/l im Juni 1958 bei $9 \mathrm{~m}$ Tiefe.

Tabellaria flocculosa (Roth.) Kg.: Wenige Zickzackbänder im Sommer, die vermutlich vom Walensee herrühren, wo sie als ausgeprägte Massenform das Planktonbild beherrschen kann.

Melosira islandica var. belpetica $\mathrm{O}$. Müller.

Melosira italica (E.) Kg.

Melosira varians $\mathrm{C}$. A. Agardh.

Alle drei Arten waren nur vereinzelt unter den anderen Planktern anzutreffen.

Synedra acus var. angustissima Grun.

Synedra acus var. delicatissima (W. Sm.) Grun.

Synedra ulna (Nitzsch.) Ehrnb. var. danica (Kg.) Grun. 
Von den drei verschiedenen Synedren war Synedra acus var. del. die häufigste Form. Asterionella formosa Hassal.: Sie erreichte ihre maximalen Entwicklungen im Mai I958 mit I,7 Mio. Zellen/l in Io m, 2,5 Mio. Zellen/l in $20 \mathrm{~m}$ und im März 1959 mit $\mathrm{I}, 5$ Mio. Zellen $/ 1$ in o m. Nach einer Entwicklungspause im Sommer begann sie sich im Herbst wieder zu entwickeln und war sonst das ganze Jahr hindurch mehr oder weniger stark im Plankton vertreten.

\section{PYRROPHYTA}

\section{Cryptophyceae}

Die Cryptophyceen umfassen kleinere, zarte Formen, die alle zu den Nannoplanktern gerechnet werden können. In Netzzügen beachtet man sie vereinzelt nur, wenn grosse Entfaltungen derselben im Wasser stattfanden. Die Arten, die wir im Zürichsee feststellten, sind weitverbreitete, in all unseren Seen und zu allen Jahreszeiten auftretende Flagellaten. Das Bestimmen derselben bereitete Mühe, da sie nur relativ kurze Zeit lebend beobachtet werden konnten, sich innert kurzer Zeit deformierten oder platzten. Ja, es bereitete sogar manchmal Mühe, die Gattungen Rhodomonas und Cryptomonas voneinander $\mathrm{zu}$ unterscheiden. ForT [I7] weist mit Recht darauf hin, dass den verschiedenen Formen dieser Gattungen vermehrte Aufmerksamkeit geschenkt werden und dass man sie exakter beschreiben und zeichnen sollte, um abzuklären, welche Formen wohl nur Lokalrassen darstellen und im Grunde genommen zusammengehören, ferner, welche Merkmale wirklich als konstant und damit als Bestimmungsmerkmale gebraucht werden dürfen (z. B. Farbe, Grösse).

Rbodomonas lacustris Pascher et Ruttner, Abb. $33^{\star}$ : Dieser Organismus ist zahlenmässig wohl einer der wichtigsten Nannoplankter des Zürichsees, wo er, mit Ausnahme einer Probeserie im August 1958, immer zu finden war. Im Jahre I958 zeigte er ein ausgesprochenes Frühjahrsmaximum und ein kleineres in den Herbstmonaten. Im Juli/August jedoch fielen die Zahlen fast auf Null zurück. Im Jahre r959 konnte eine maximale Entwicklung im frühen Frühjahr (März) festgestellt werden, die im April allerdings schon auf das Minimum zurückfiel. Die nächste starke Vermehrung erfolgte dann, im Gegensatz zum Vorjahr, im Mai und Juli. Dafür wurde in den Herbstmonaten keine auffällige Bildung der Biomasse mehr beobachtet. Wie schon erwähnt, waren die beiden Untersuchungsjahre schwer miteinander zu vergleichen, da erstens das Wetter im Jahre I95 8 abnormal kalt und regnerisch, im Jahre I959 überdurchschnittlich sonnenreich war, und zweitens, da im Jahre 1959 nicht mehr so viele Proben untersucht werden konnten. In bezug auf die vertikale Verteilung wies Rhodomonas unterschiedliche Bilder auf. Bis auf die Sommermonate erreichte er im allgemeinen ziemlich grosse Tiefen. Die höchste Individuenzahl wurde am 2. März I959 in $5 \mathrm{~m}$ Tiefe erreicht mit 3,8 Mio. Indiv./1, ferner am 29. April I958 in ro $\mathrm{m}$ Tiefe mit $1,8 \mathrm{Mio}$. Indiv./ 1 und am 7. Juli 1959 in $5 \mathrm{~m}$ Tiefe mit 1,9 Mio. Indiv./l und 2,2 Mio. Indiv./1 am 29. September 1958 in $2,5 \mathrm{~m}$. Am ro. Juni I958 mit $\mathrm{I}, 4$ Mio. Indiv. $/ 1$ in o $\mathrm{m}$.

Rhodomonas lens Pascher et Ruttner: Diese Rbodomonasart war im Zürichseeplankton vorhanden, jedoch immer in sehr viel kleinerer Zahl als Rhodomonas lacustris, so dass diese Form mit Rbodomonas lacustris zusammengezählt wurde.

Cryptomonas ovata Ehrnb., Abb. 34*: Dieser Flagellat war das ganze Jahr unter den Planktonformen des Zürichsees zu finden. Zusammen mit Cryptomonas erosa und 
den beiden Rbodomonasarten, Rbodomonas lacustris und Rbodomonas lens, erreichte er das Maximum am 27. Mai i958 mit 259000 Indiv./1 in $5 \mathrm{~m}$ Tiefe.

Cbilomonas cryptomonadoides Skuja, Abb. $36^{\star}$ : Die Monade zeigt weitgehend Ähnlichkeit mit von SKUJa beschriebenen Cbilomonas cryptomonadoides. Nur reichte der Schlund nur bis zur Mitte der Zelle oder war noch etwas kürzer. Stärkekörner konnten sowohl auf der apikalen Dorsalseite als auch auf der ganzen Ventralseite nachgewiesen werden. Ferner sind feine Längslinien zu erkennen. Wir fanden die Form auf dem Grund des Zürichsees, vor allem in der Probeserie vom I4. April I958.

Katablepharis ovalis Skuja, Abb. $37^{\star}$ : Dieser kleine, zarte, farblose Kryptoflagellat war das ganze Jahr hindurch in den Wasserproben zu finden. Besonders zahlreich, jedoch nie von grosser Bedeutung für die Biomasse, nur während der ersten Frühjahrsentfaltung. Dieser Nannoflagellat fiel durch sein eigenartiges Vorwärtsbewegen auf, indem er seine beiden langen Geisseln nach hinten gerichtet hat. Lange Zeit war er unbestimmbar, da die kleinen, wenigen Trichozyten meistens durch viele, stark lichtbrechende Körner nicht zu beobachten waren. Zelle 7,2-I2 $\mu$ lang, 4,8-6 $\mu$ breit, oval bis ellipsoidisch, hinten abgerundet, vorn leicht abgerundet zugespitzt, Geisseln zwei, ungleich lang, seitlich inseriert, die längere etwa I6 $\mu$, die kleinere etwa $9 \mu$ lang. Meistens sind einer bis mehrere braune bis orangefarbene Körper vorhanden und ein grösseres, lichtbrechendes, weissliches Korn. Der Organismus ist weit verbreitet, in Gewässern von verschiedenem Trophiegrad.

Cyatbomonas truncata (Fres.) Fisch., Abb. $38^{\star}$ : Mit 4,8-7;2 $\mu$ Breite und 8,8-10 $\mu$ Länge sind die Ausmasse unserer Form etwas kleiner als diejenigen der beschriebenen Form. Im übrigen stimmen die Formen gut mit dem Typus überein. Dieser Flagellat wurde hauptsächlich in den Sommermonaten unter den andern Planktonformen gefunden, doch nie in ausserordentlicher Entfaltung.

\section{Peridineae}

Ampbidinium turicense Huber-Pestalozzi: Diese kleine Peridinee war nur im Dezember 1957 und Januar 1958 im Plankton aufgetreten.

Gymnodinium belpeticum Penard: Eine typische Form, vorwiegend des Metalimnions, liegt vor in der Peridinee Gymnodinium belpeticum, die wir fast das ganze Jahr, hauptsächlich aber im Herbst und Winter, in unseren Proben vorfanden. Die vertikale Verteilung stimmt weitgehend mit den Beobachtungen RUTTNERs (Lunzer Seen) überein.

Gymnodinium lantzscbii Utermöhl, Abb. 39*: Zellen $13-(20,8-23,4) \mu$ lang und I3-(20,6-26) $\mu$ breit. Apikalteil flach bis flach-kegelförmig abgerundet, meistens etwas kleiner als der Antapikalteil. Querfurche deutlich, Längsfurche auf der Hypovalva schwach angedeutet. Hyalines Plasma mit stark lichtbrechenden, kleinen Körnern. Chromatophor fehlt, doch ist meistens ein gelbbraunes oder orangefarbenes Korn vorhanden (Reservestoffe?), Zellkorn gross, befindet sich oft seitlich in der Nähe der Querfurche oder in der Hypovalva. Längsgeissel ungefähr körperlang. Leider ist der Organismus nur kurze Zeit unter dem Mikroskop zu beobachten, da er sehr schnell aufhört, sich zu bewegen und sich dann gleich abrundet. Am besten passt dieser Flagellat mit dem Gymnodinium lantzscbii zusammen. Im Zürichsee trat er vor allem im Frühling in Erscheinung. Am 2. März I959 bis zu I34 000 Indiv. $/ 1$ in $2,5 \mathrm{~m}$ Tiefe.

Peridinium cinctum (Müller) Ehrnb.

Peridinium millei Huitf.-Kaas. 
Peridinium inconspicuum Lemm.

Ceratium birundinella (O. F.) Schwank.

Alle vier obenerwähnten Formen, wovon Peridinium inconspicuum einziger Nannoplankter, waren im Sommerplankton des Zürichsees, nie sehr zahlreich, vertreten.

\section{c) Beobacbtete Organismen im Vergleich zu früberen Arbeiten}

Das Plankton des Zürichsees wurde im Laufe der vergangenen 70 Jahre wiederholt qualitativ und quantitativ untersucht. Es ist deshalb nicht uninteressant, sämtliche seit 1897 (SCHRÖTER) in der Literatur erschienenen Angaben über das Phytoplankton zu vergleichen. In Tab. 6 sind die betreffenden Phytoplankter systematisch und nach Autoren in chronologischer Ordnung zusammengestellt, wobei Algennamen der heute gültigen Bestimmungsliteratur (vgl. S. 227) angeglichen wurden.

In dieser Aufstellung kommen einerseits die verschiedenen Untersuchungsmethoden deutlich zum Ausdruck. SCHRÖTER [6I] und LOZERON [37] beobachteten vorwiegend die mit Hilfe von Netzzügen angereicherten Organismen, womit sie im wesentlichen nur die grösseren und in belangloser Zahl die kleinen Formen erfassten, und diese auch nur dann; wenn sie in starker Entfaltung im Plankton vertreten waren. STEINER [64] und Minder [45] zählten Schöpfproben in Kolkwitzkammern aus. Diese Autoren bekamen dadurch wenigstens ein quantitativ richtiges Bild von den grösseren Formen; die kleinen Organismen, vor allem die kleinen Flagellaten, konnten jedoch wegen der Dicke der Kammer nicht bestimmt oder überhaupt nicht beobachtet werden. Mit beiden Methoden also können zur Hauptsache nur Netzplankter verarbeitet werden. MESSIKOMMER [44] bestimmte aus Netzzügen, Kratz- und Schlammproben sowohl die Litoral- als auch die Planktonalgen des Zürichsees. Seiner Probenahmetechnik entsprechend finden wir in seiner Arbeit die pflanzlichen Planktonorganismen zahlreicher vertreten, darunter auch kleinere Organismen, vor allem Diatomeen, die im Schlamm besser als andere Algen erhalten bleiben. In der zweitletzten Kolonne in Tab. 6 finden sich Organismen aufgeführt, die aus zwei Arbeiten stammen (THOMAS [68]; Järnefelt und Thomas [28]). Da beide Probenahmen in Form. von Schöpfproben, in denen die kleinen Formen systematisch in Betracht gezogen worden sind; erfolgten, ergaben sich eine ganze Reihe neuer Nannoplankter. Andererseits spiegelt sich in dieser Aufstellung sicher auch die allgemeine Entwicklung des Phytoplanktons im Zürichsee während der letzten Jahrzehnte wider, wobei besonders die Zunahme der Artenzahl der Grünalgen ins Auge springt. 
Tabelle 6

Pbytoplankton des Zürichsees

BACTERIOPHY TA

$\mathrm{Na*}$ Planctomyces bekefii Gimesi

CYANOPHYTA

Microcystis flos-aquae (Wittr.)

em. W. L. Teiling Kirchn.

$N a *$ Aphanocapsa delicatissima

W. und G. S. West

Aphanothece clathrata var. brevis

Bachmann

* Chroococcus limneticus Lemm.

* Gomphosphaeria lacustris Chod.

Coelosphaerium kïtzingianum Naeg.

$N a *$ Pseudanabaena catenata Lauterb.

Anabaena flos-aquae (Lyngb.) Bréb.

Anabaena planctonica Brunnth.

Aphanizomenon flos-aquae L. Ralfs

Oscillatoria rubescens D.C.

$\mathrm{Na} *$ Oscillatoria cf. obliqueacuminata Skuja

$\mathrm{Na}$ * Oscillatoria cf. planctonica Wol.

Oscillatoria subuliformis

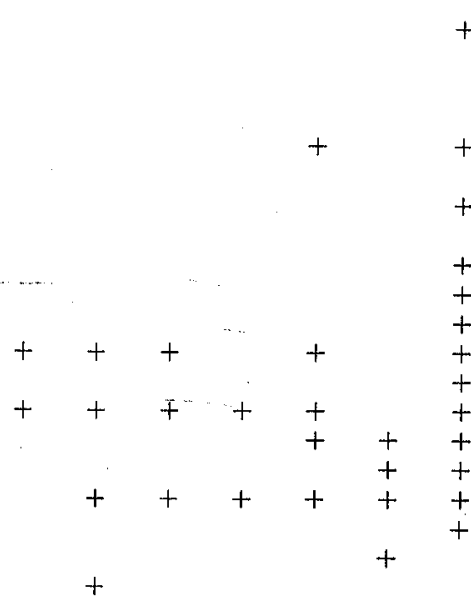

CHLOROPHYTA

Polyblepharidinae

Na* Collodictyon triciliatum Carter

Euchlorophyceae

$\mathrm{Na}$ * Nephroselmis angulata (Korschikow) Skuja

Na Carteriasp.

$\mathrm{Na}$ * Platymonas cordiformis (Carter)

Korschikow

$\mathrm{Na}$ Chlamydomonas spp.

$\mathrm{Na}$ Chlorogonium sp.

$\mathrm{Na}$ Phacotus lenticularis Ehrnb. Pandorina morum (Müller) Bory Eudorina elegans Ehrnb.

Na Gemellicystis neglecta Teiling em. Skuja Gloeococcus schroeteri (Chod.) Lemm. Gloeocystis bacillus Teiling.

$N a^{*}$ Characium gracilipes F. D. Lambert Pediastrum duplex Meyen.

Pediastrum boryanum ('Turp.) Menegh.

$\mathrm{Na}$ * Pediastrum tetras (Ehrnb.) Ralfs

$\mathrm{Na}$ * Chlorella pyrenoidosa Chick

$\mathrm{Na}$ Brachionococcus chlovelloides Naum. Chodatella citriformis Snow

$\mathrm{Na}$ Oocystis marssonii Lemm.

$\mathrm{Na}$ Oocystis lacustris Chod.

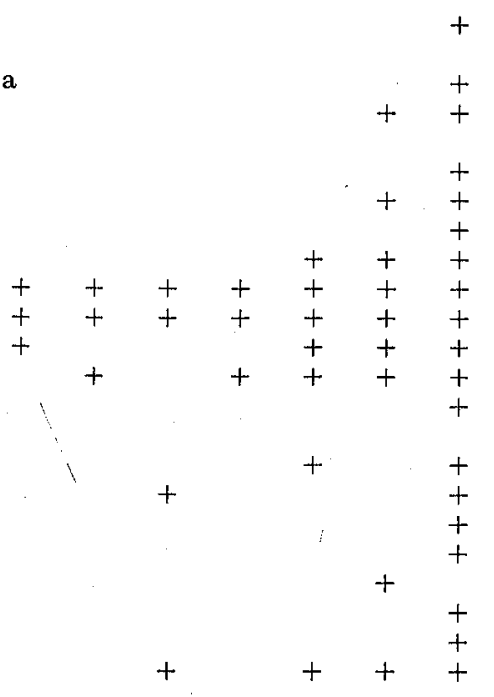


Tabelle 6 (Fortsetzung)

$\begin{array}{lllllll}1 & 2 & 3 & 4 & 5 & 6 & 7\end{array}$

$\mathrm{Na}$ Oocystis borgei Snow

$\mathrm{Na}$ Oocystis parya West et West

Nephrocytium agardhianum Naeg.

$\mathrm{Na}$ * Tetraëdron minimum apiculato-

scrobulatum Skuja

$N a *$ Treubaria triappendiculata Bern.

Scenedesmus quadricauda Turp. em. Chod.

Scenedesmus arcuatus Lemm.

Scenedesmus falcatus Chod.

Scenedesmus armatus f. bicaudatus Chod.

$\mathrm{Na*}$ Actinastrum hantzschii var. fluviatile

Schröder

Crucigenia quadrata Morren

* Kirchneriella lunaris (Kirchn.) Moeb.

Dictyosphaerium pulchellum Wood

Dictyosphaerium elegans Bachm.

Dictyosphaerium ehrenbergianum

$\mathrm{Na*}$ *elenastrum minutum (Naeg.) Collins

Ankistrodesmus falcatus (Corda) Ralfs

$\mathrm{Na}$ Ankistrodesmus falcatus var. setiformis Nyg.

$N a *$ Ankistrodesmus falcatus var. acicularis

(A. Br.) G. S. West

$N a *$ Ankistrodesmus falcatus var. mirabile

W. et G. S. West

Coelastrum microporum Naeg.

Coelastrum reticulatum (Dang.) Senn.

Elakatothrix gelatinosa Wille

$N a *$ Lambertia judayi (G. M. Smith) Korschik.

Hormidium sp.

$\mathrm{Na*}$ Coccomyxa minor Skuja

$\mathrm{Na}$ * Stichococcus atomus Skuja

Conjugatae

Mougeotia sp.

$\mathrm{Na}$ Closterium acutum var. variabile

(Lemm.) Krieger

* Closterium aciculare West

Closterium gracile Bréb.

$\mathrm{Na}$ Cosmarium phaseolus Bréb.

$\mathrm{Na}$ Cosmarium depressum var.

planctonicum Rev.

Cosmarium scenedesmus Delp.

Staurastrum cingulum (W. und G. S.

West) G. H. Smith

Staurastrum gracile Ralfs

Staurastrum pingue Teiling

Staurastrum sebaldi var. ornatum Nordst.

$+$

+
+
+

$+$

$\begin{array}{rr}+ & + \\ + & + \\ + & +\end{array}$

$+\quad+$

$++$

$+$

$+$

+
$+\quad+$

$+$

$+$

$++$

+
$+\quad+$

$+$

$+$

EUGLENOPHYTA

Na Euglena viridis Ehrnb.

$\mathrm{Na}$ Trachelomonas volvocina Ehrnb.

$\mathrm{Na}$ * Menoidium incurvum (Fres.) Klebs

$\mathrm{Na}$ * Astasia kathemerios Skuja

Na* Distigma sp.

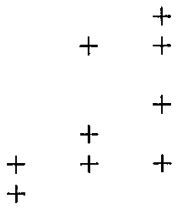

$+\quad+$

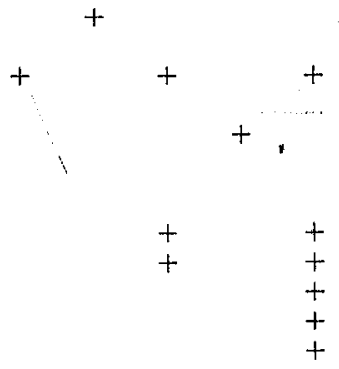




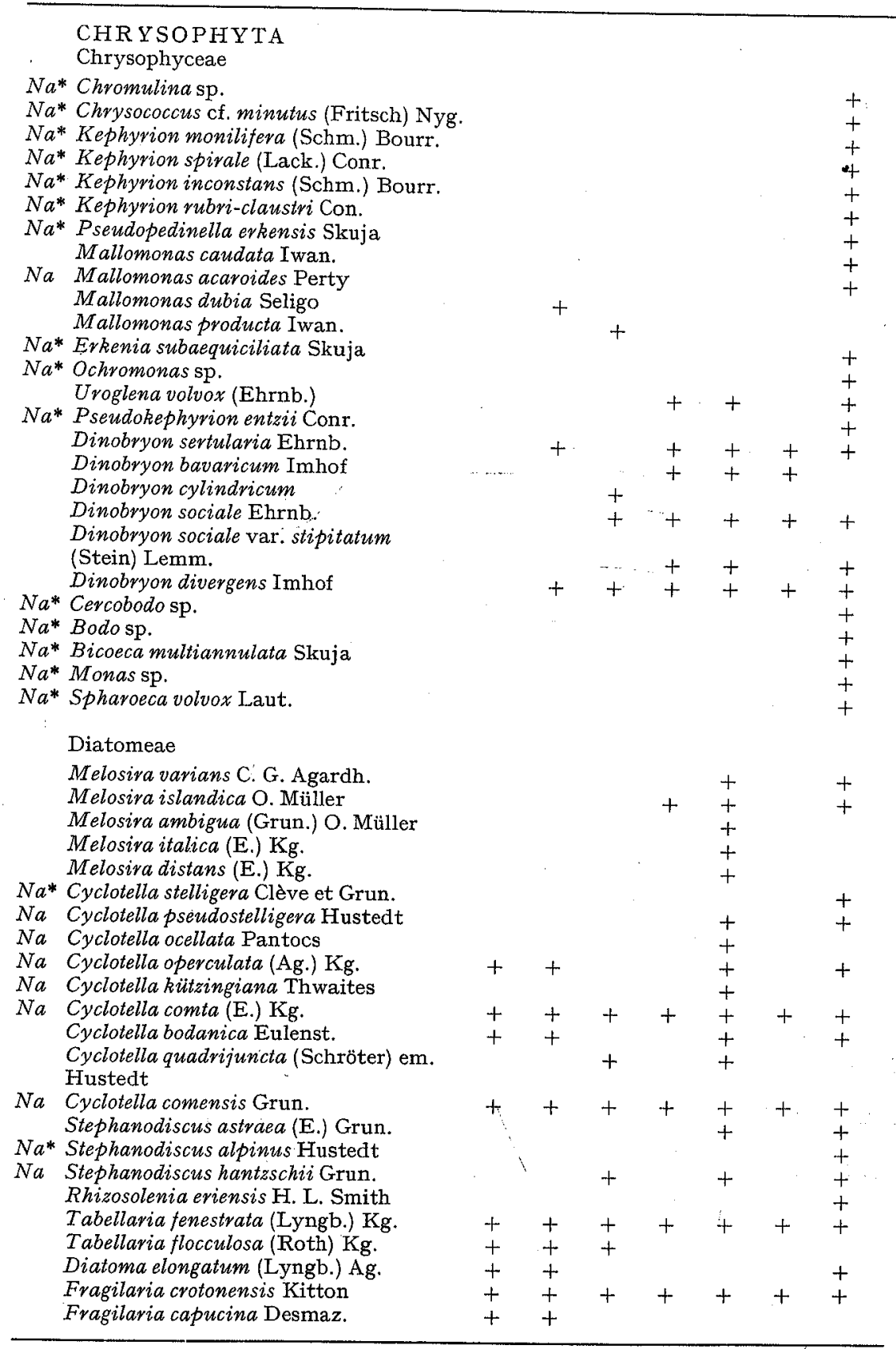




\begin{tabular}{|c|c|c|c|c|c|c|c|c|}
\hline Tabe & lle 6 (Fortsetzung) & 1 & 2 & 3 & 4 & 5 & 6 & 7 \\
\hline & Asterionella formosa Hasall & + & + & + & + & + & + & + \\
\hline & Synedra acus var. angustissima Grim. & + & + & + & + & + & + & + \\
\hline & Synedra acus var. delicatissima & & & & & & & \\
\hline & (W. Sm.) Grun. & + & + & + & + & + & & + \\
\hline$N a$ & Synedra nana Meister & & & & & + & + & + \\
\hline & Synedra ulna (Nitzsch) Ehrnb. & + & + & & & + & & + \\
\hline & Cymatopleura elliptica W. Sm. & + & + & + & & & & + \\
\hline & Cymatopleura solea W. Sm. & + & + & + & & & & + \\
\hline & Heterocontae & & & & & & & \\
\hline & Botryococcus braunii $\mathrm{Kg}$. & + & + & & & + & + & + \\
\hline & $\begin{array}{l}\text { PYRROPHYTA } \\
\text { Cryptophyceae }\end{array}$ & & & & & & & \\
\hline $\mathrm{Na}$ & Cryptochrysis commutata Pascher & & & & & + & & \\
\hline$N a^{*}$ & Rhodomonas lacustris Pascher et Ruttner & & & & & & & + \\
\hline$N a^{*}$ & Rhodomonas lens Pascher et Ruttner & & & & & & & + \\
\hline $\mathrm{Na}$ & Cryptomonas ovata Ehrnb. & & & & & $\cdot \cdot$ & + & + \\
\hline$N a$ & Cryptomonas erosa Ehrnb. & & & & & & & + \\
\hline $\mathrm{Na}$ & Cryptomonas erosa var. reflexa Marsson. & & & & & & & + \\
\hline$N a^{*}$ & Chilomonas cryptomonadoides Skuja & & & & & & - & + \\
\hline$N a^{*}$ & Cyathomonas truncata (Frés.) Fisch. & & & & & & & + \\
\hline$N a^{*}$ & Katablepharis ovalis Skuja & & & & & & & + \\
\hline$N a^{*}$ & Katablepharis sp. & & & & r. & & & + \\
\hline & Peridineae & & & & & & & \\
\hline$N a$ & Amphidinium turicense Huber-Pestalozzi & & & & & & & + \\
\hline$N a^{*}$ & Gymnodinium lantzschii Utermöhl & & & & & & & + \\
\hline $\mathrm{Na}$ & Gymnodinium helveticum Penard & & & & & + & & + \\
\hline $\mathrm{Na}$ & Peridinium inconspicuum Lemm. & & & & & & + & + \\
\hline & Peridinium cinctum (Müller) Ehrnb. & + & + & + & + & + & + & + \\
\hline & $\begin{array}{l}\text { Peridinium willei Huitf.-Kaas } \\
\text { Peridinium volzii Lemm. }\end{array}$ & & & & + & $\begin{array}{l}+ \\
+\end{array}$ & + & + \\
\hline $\mathrm{Na}$ & Peridinium pusillum (Pen.) Lemm. & + & + & + & & & + & + \\
\hline & Peridinium bipes var, tabulatum (E.) Lef. & & & + & & & & \\
\hline & $\begin{array}{l}\text { Ceratium hirundinella (O. F. Müller) } \\
\text { Schrank }\end{array}$ & + & + & + & + & + & + & + \\
\hline
\end{tabular}

In unseren Untersuchungen der Jahre 1958 und I959 wurden rund 40 Formen, fast durchwegs Nannoplankter, im unteren Zürichsee neu gefunden, unter denen hauptsächlich die Anzahl der Chrysoflagellaten und Cryptophyceen auffielen. Bemerkungen zu den einzelnen Arten sind auf S. I2 ff. zu finden. Darüber hinaus figurieren in den Arbeiten früherer Autoren Formen, die wir im Laufe unserer Untersuchungen nie beobachtet haben. Möglicherweise sind sie unserer Aufmerksamkeit entgangen, besonders wenn sie nur in einzelnen Exemplaren auftraten. Daneben scheinen gewisse Organismen von den verschiedenen Autoren verschieden benannt worden zu sein, dies ist namentlich für zwei Algen der Fall: JäRNEFELT fand in der Probe vom 2. August I955 Oscillatoria 
Tabelle 7

Qualitative Zusammensetzung der bäufigsten Phytoplankter im Züricbsee nom Dezember 1957 bis Dezember $1959^{3}$

\begin{tabular}{|c|c|c|c|c|c|c|c|c|c|c|c|c|}
\hline & 1957 & & & & & & & & & & & 1958 \\
\hline Monate & XII & I & II & III & IV V & $\mathrm{V}$ VI & VII & VIII & I IX & $\mathrm{X}$ & $\mathrm{XI}$ & $\mathrm{XII}$ \\
\hline Planctomyces bekefii & & & & & & & & ++ & +++ & ++ & + & \\
\hline Pseudanabaena catenata & & & & & & & & & & + & + & \\
\hline Oscillatoria obliqueacuminata & & & & & & & & + & + & +++ & + & \\
\hline Oscillatoria rubescens & ++ & ++ & ++ & ++ & ++ & + & ++ & + & ++ & +++ & +++ & +++ \\
\hline $\begin{array}{l}\text { Chlamydomonas } \mathrm{sp} \text {. } \\
\text { Platymonas cordiformis }\end{array}$ & & & & & & + & $\begin{array}{l}+++ \\
+\end{array}$ & $\begin{array}{l}++ \\
+\end{array}$ & & & $\begin{array}{l}+ \\
+\end{array}$ & \\
\hline Phacotus lenticularis & & & & & & + & ++ & +++ & & ++ & + & \\
\hline Pandorina morum & & & & & & + & ++ & + & & + & & \\
\hline Sphaerocystis schroeteri & & & & & & & +++ & & & + & & \\
\hline Gemellicystis neglecta & & & & & & + & ++ & ++ & & & & \\
\hline Dictyosphaerium pulchellum & & & & & & + & + & ++ & & & & \\
\hline Micractinium pusillum & & & & & & & & + & & + & & \\
\hline Treubaria triappendiculata & & & & & & & & ++ & & & & \\
\hline Lambertia judayi & & & & & & & +++ & + & + & & & \\
\hline Elakatothrix gelatinosa & & & & & & & & + & & & & \\
\hline Chlorella pyrenoidosa & & & & & + & & +++ & ++ & +++ & ++ & + & \\
\hline $\begin{array}{l}\text { Mougeotia sp. } \\
\text { Erkenia subaequiciliata }\end{array}$ & + & & + & + & + & & ++ & + & + & & + & + \\
\hline Kephyrion spp. & & & + & + & ++ & + & & + & & + & & \\
\hline Dinobryon spp. & & & & & & ++ & & + & ++ & +++ & & \\
\hline Farblose Flagellaten & & + & + & & + & + & ++ & ++ & + & +++ & ++ & ++ \\
\hline Cyclotella spp. & & & & & & + & + & + & +++ & ++ & ++ & + \\
\hline Stephanodiscus hantzschii & & & + & ++ & +++ & ++ & + & & & & & \\
\hline Synedra acus var. delicatissima & & & + & & +++ & + & ++ & + & + & ++ & + & + \\
\hline Fragilaria crotonensis & & & + & & ++ & +++ & + & + & & ++ & + & + \\
\hline Diatoma elongatum & & & & & ++ & +++ & + & & & & & \\
\hline Tabellaria fenestrata & + & + & + & & ++ & $++t$ & ++ & ++ & ++ & + & + & + \\
\hline A sterionella formosa & & + & + & & ++ & +++ & + & & & +++ & ++ & + \\
\hline $\begin{array}{l}\text { Rhodomonas lacustris und } \\
\text { Rhodomonas lens }\end{array}$ & + & + & + & ++ & +++ & ++ & ++ & + & & +++ & ++ & + \\
\hline $\begin{array}{l}\text { Cryptomonas ovata und } \\
\text { Cryptomonas erosa }\end{array}$ & + & + & + & + & ++ & ++ & +++ & ++ & + & +++ & ++ & ++ \\
\hline Gymnodinium helveticum & + & + & + & + & + & + & + & ++ & + & + & + & + \\
\hline Gymnodinium lantzschii & + & + & + & $+t$ & ++ & ++ & & & + & + & + & \\
\hline Peridinium cinctum & & & & & & & + & + & & + & + & \\
\hline 3) + vorhanden & +++ & hr & häu & fig & & & & & & & & \\
\hline
\end{tabular}

planctonica Wol. In unseren Herbstproben vom Jahre 1958 und 1959, aber auch in der einmaligen Probenahme von 196r, waren meistens. zwei fädige Blaualgenarten enthalten, die in unserer Liste unter dem Namen Oscillatoria obliqueacuminata Skuja und Pseudanabaena catenata Lauterb. aufgeführt sind. Vermutlich wurde mit den Namen Oscillatoria planctonica und Oscillatoria obliqueacuminata (oder Pseudanabaena catenata) dieselbe Blaualge gekennzeichnet. JÄRNEFELT und THOMAS [28] waren mit SKUJA [63] der Meinung, dass Oscillatoria planctonica identisch sei mit Oscillatoria 
Tabelle 7

(Fortsetzung)

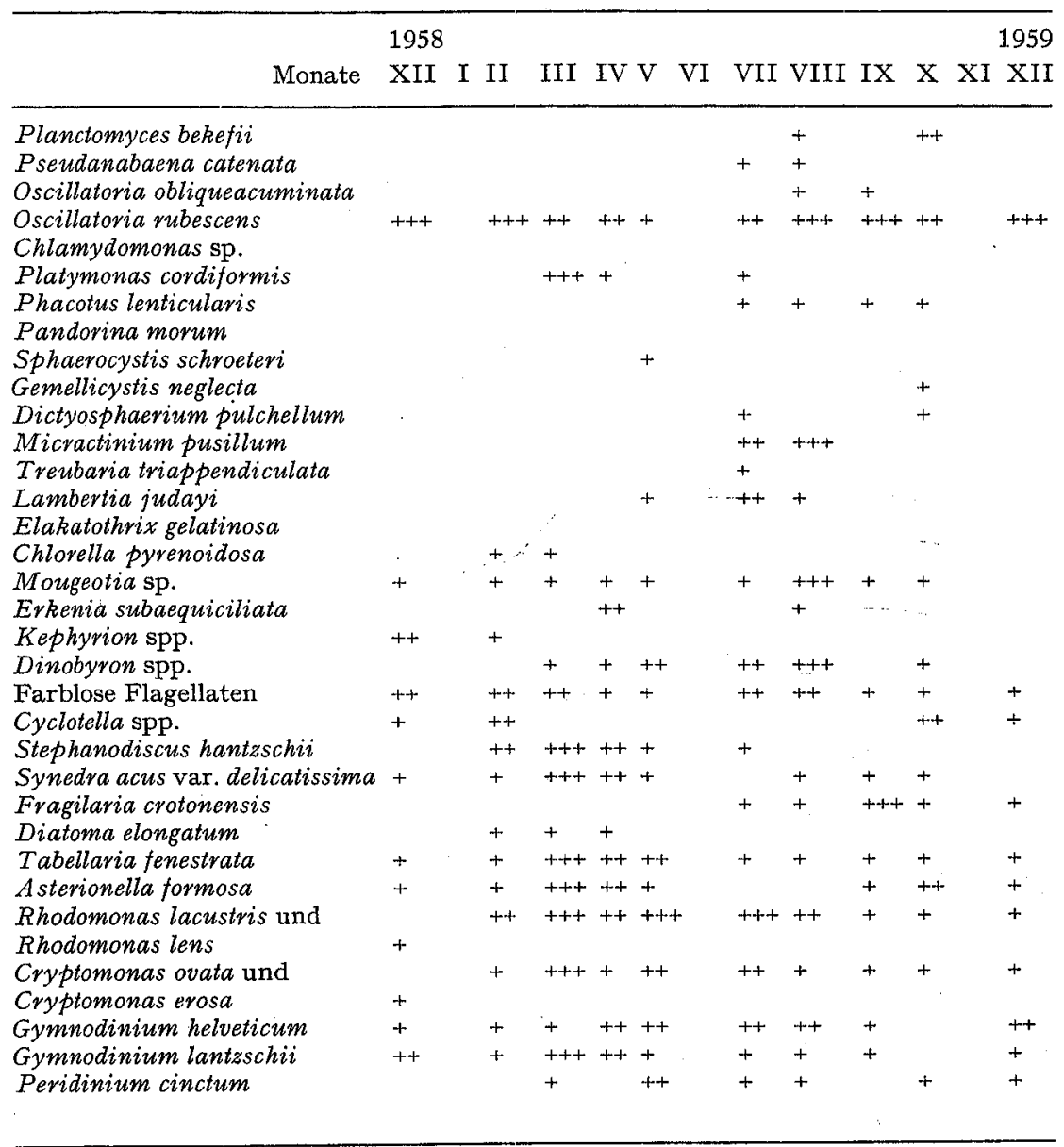

redeckei. Die Form im Zürichsee ist jedoch nicht Oscillatoria redeckei, da ihre Endzellen einseitig zugespitzt und nicht abgerundet sind, wie für Oscillatoria redeckei notwendig wäre (vgl. S. I5). Die Form, die wir als Pseudanabaena catenata bestimmt haben, kann ebenfalls kaum als Oscillatoria redeckei benannt werden (vgl. S. I4). Die zweite Alge, die sich auch in der Probe vom 2. August I95s befand, wurde von JÄRNEFELT als Bracbionococcus cblorelloides Naum. bestimmt. In unseren Proben der entsprechenden Zeiten fiel die Massenentfaltung einer kleinen, kugeligen Grün- 
alge auf, die wir als Cblorella pyrenoidosa Chick (vgl. S. I6) bestimmt hatten. Wahrscheinlich ist mit diesen Namen wiederum ein und dieselbe Form bezeichnet worden.

\section{Jahreszeitliches Auftreten}

In Tab. 7 wurde das monatliche Auftreten der ausgezählten Organismen im Laufe der beiden Untersuchungsjahre eingetragen und ihre Häufigkeit durch ein, zwei oder drei Kreuze angegeben. Dadurch erhält man einen guten Überblick über das jahreszeitliche Auftreten und Verschwinden der einzelnen Formen.

Beim Betrachten dieser Zusammenstellung fallen in erster Linie zwei Gruppen von Organismen auf: solche, die das ganze Jahr hindurch in mehr oder weniger grosser Entfaltung im Plankton vorhanden, und solche, die in ihrem Auftreten an eine bestimmte Zeit gebunden waren. Sozusagen perennierende Formen waren Oscillatoria rubescens (Abb. 2), Synedra acus var. delicatissima, Tabellaria fenestrata, Mougeotia sp., Cryptomonas opata, Rhodomonas lacustris, Gymnodinium belpeticum, Gymnodinium lantzscbii und ein Monas sp., wobei die fünf zuletzt genannten Formen Vertreter des Nannoplanktons darstellen und Cryptomonas und Rbodomonas ausserdem zu den wichtigsten Nannoplanktern des Zürichsees gehören. Dabei erreichte Oscillatoria rubescens in den Herbst- und Wintermonaten ihre maximalen und in den Monaten Mai bis Juli ihre minimalen Entwicklungen. Tabellaria und Synedra entfalteten sich im Frühling am stärksten, Mougeotia trat im Juni 1958 und im August 1959 vor allem in Erscheinung, Cryptomonas wies im Juni und September I958 und im März I959 ein Entwicklungsmaximum auf und Rbodomonas zeichnete sich durch Höchstentfaltungen im April und September I958 und im März, Mai und August I959 aus. Die beiden zuletzt genannten Formen zeigen demnach eine gewisse Unregelmässigkeit in ihrem Auftreten (Abb. S). Keine auffälligen Unterschiede betreffend das jahreszeitliche Vorkommen liessen sich bei Gymnodinium belpeticum beobachten, und Gymnodinium lantzschii schien die Frühlingsmonate vorzuziehen. Ein einziges Maximum und ein Auftreten in nur ein bis vier Monaten finden wir bei den meisten Grünalgen (Abb. 3), darunter auch fünf Nannoplankter, Cblamydomonas sp., Pbacotus lenticularis, Gemellicystis neglecta, Lambertia judayi, Treubaria triappendiculata. Ihre Vegetationszeiten entfielen auf die Monate Mai bis August. In den übrigen Monaten waren sie teilweise vollständig aus dem Blickfeld verschwunden.

Unter den drei Chrysophyceen Dinobryon spp., Kephyrion spp. und Erkenia subaequiciliata traten die Dinobryonarten hauptsächlich im Mai 1958 und 
Mai 1959, September 1958 und August I959 auf, die verschiedenen Kepbyrion- und Pseudokephyrionarten waren im April und Dezember 1958 in grösserer Zahl zu finden und Erkenia subaequiciliata im September 1958, April I959 und August 1958.

Die Diatomeen (Abb. 4) waren, wie bekannt, zur Hauptsache Frühlingsformen mit einer kleinen Herbstspitze. Cyclotella operculata und comta erreichten ihr Maximum hauptsächlich im Herbst und Winter.

Zu erwähnen sind noch die drei Peridineen Peridinium cinctum, Peridinium inconspicuum und Ceratium birundinella, drei Hochsommerformen, wobei das Auftreten von Peridinium inconspicuum vorwiegend auf zwei Monate beschränkt war, nämlich August und September I9s 8 und Juli und August 1959. Die kleinen, kugeligen Grünalgen, die sogenannten « $\mu$-Algen», traten während der zwei Untersuchungsjahre sehr unregelmässig auf (Abb. 2). Im Jahre I958 ausgesprochen in den Sommer- und Herbstmonaten, zum Teil Vegetationsfärbungen verursachend, im Jahre 1959 hingegen wurden sie nur im Februar und März in den Zählproben in vernünftiger Menge gefunden.

\section{Die vertikale Verteilung des Phytoplanktons}

Um die charakteristische vertikale Verteilung der einzelnen Organismen zu erfassen, wurden jeweils die Halbwertstiefen derselben berechnet und ihre vertikale Verteilung in Form von Kugelkurven graphisch dargestellt. Anhand dieses ausgewerteten Zahlenmaterials konnten in grossen Zügen die allgemeingültigen und bekannten Merkmale der verschiedenen Netzund Nannoplanktonformen bezüglich ihrer vertikalen Verteilung $[45,55$, $60,73]$ beobachtet werden, so dass es nicht notwendig erschien, dieses umfangreiche Beobachtungsmaterial an dieser Stelle zu wiederholen (vgl. in diesem Zusammenhang S. 27I und S. 3 I5 ff.).

\section{Biomasse und prozentuale Verteilung des Phytoplanktons}

In Abb. 6 sind die Zahlen der berechneten Biomassen (vgl. auch Tab. 8) graphisch dargestellt. Da die Blaualge Oscillatoria rubescens als dominierende, grosse Phytoplanktonform einen riesigen Teil der Biomasse ausmachte, wurden ihre Werte, ferner diejenigen des restlichen Netzplanktons und des gesamten Nannoplanktons in getrennten Kurvenbildern wiedergegeben. Auffallend für die Kurven des Jahres 1958 sind die ausgeprägten Spitzen von Oscillatoria rubescens. Ausserdem tritt die allgemein bekannte, jahreszeitliche Entwicklung dieser Blaualge klar hervor, ihre Maximalentfal- 


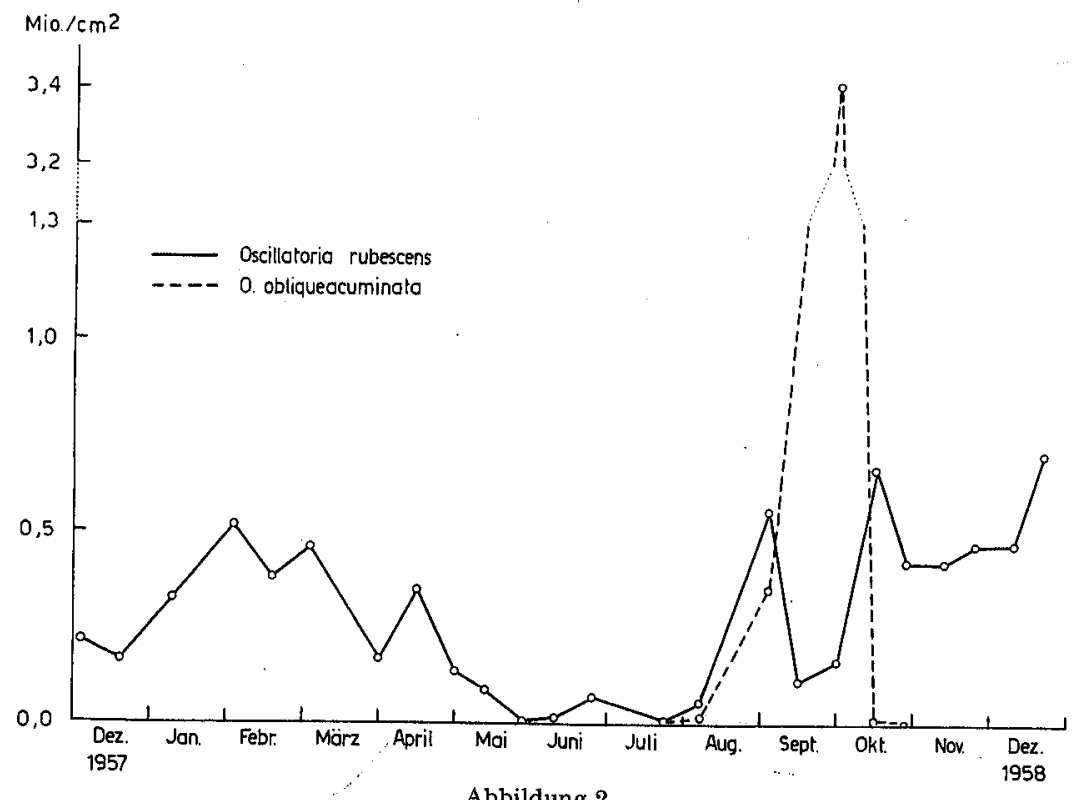

Zürichsee. Jahreszeitliches Auftreten der wichtigsten Blaualgen Oscillatoria rubescens und Oscillatoria obliqueacuminata (Dezember 1957 bis Dezember 1958), in Individuenzahlen/ $/ \mathrm{cm}^{2}$.

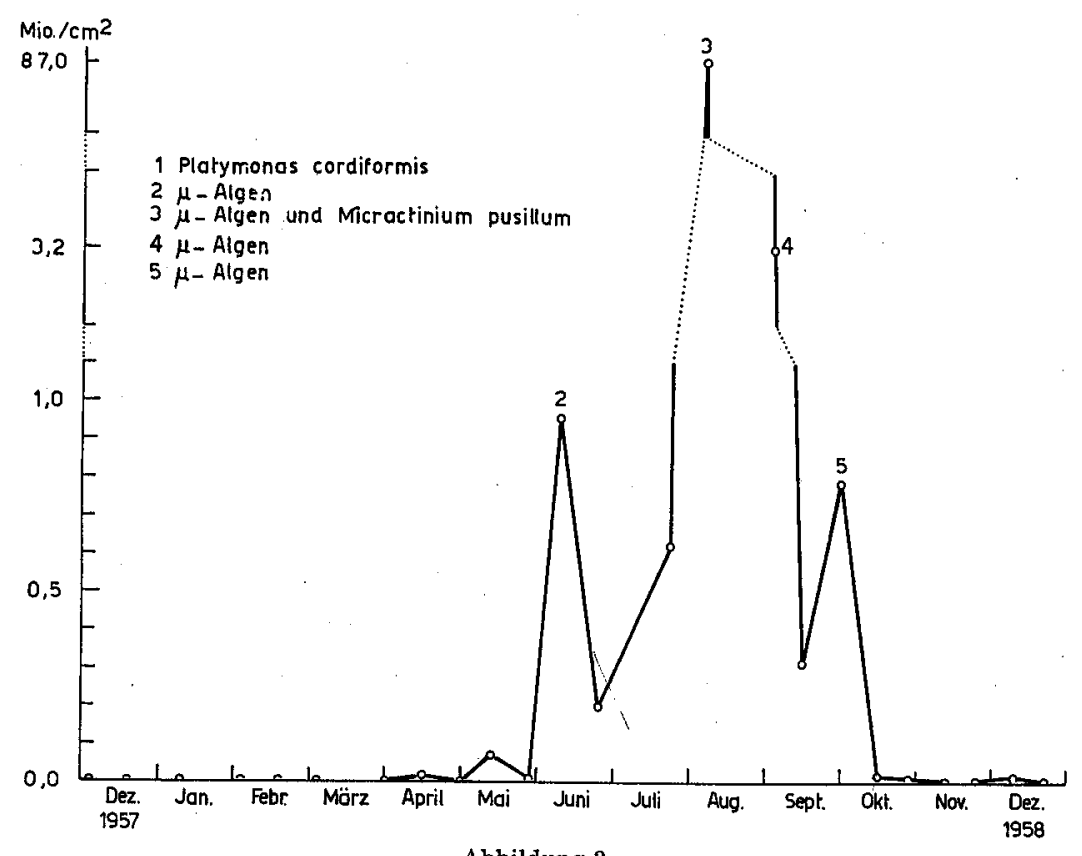

Zürichsee. Jahreszeitliches Auftreten der Grünalgen (Dezember 1957 bis Dezember 1958), in Individuenzahlen $/ \mathrm{cm}^{2}$. Spitze 2 wurde ausser $\mu$-Algen noch durch eine Entwicklung von Lambertia judayi verursacht. 


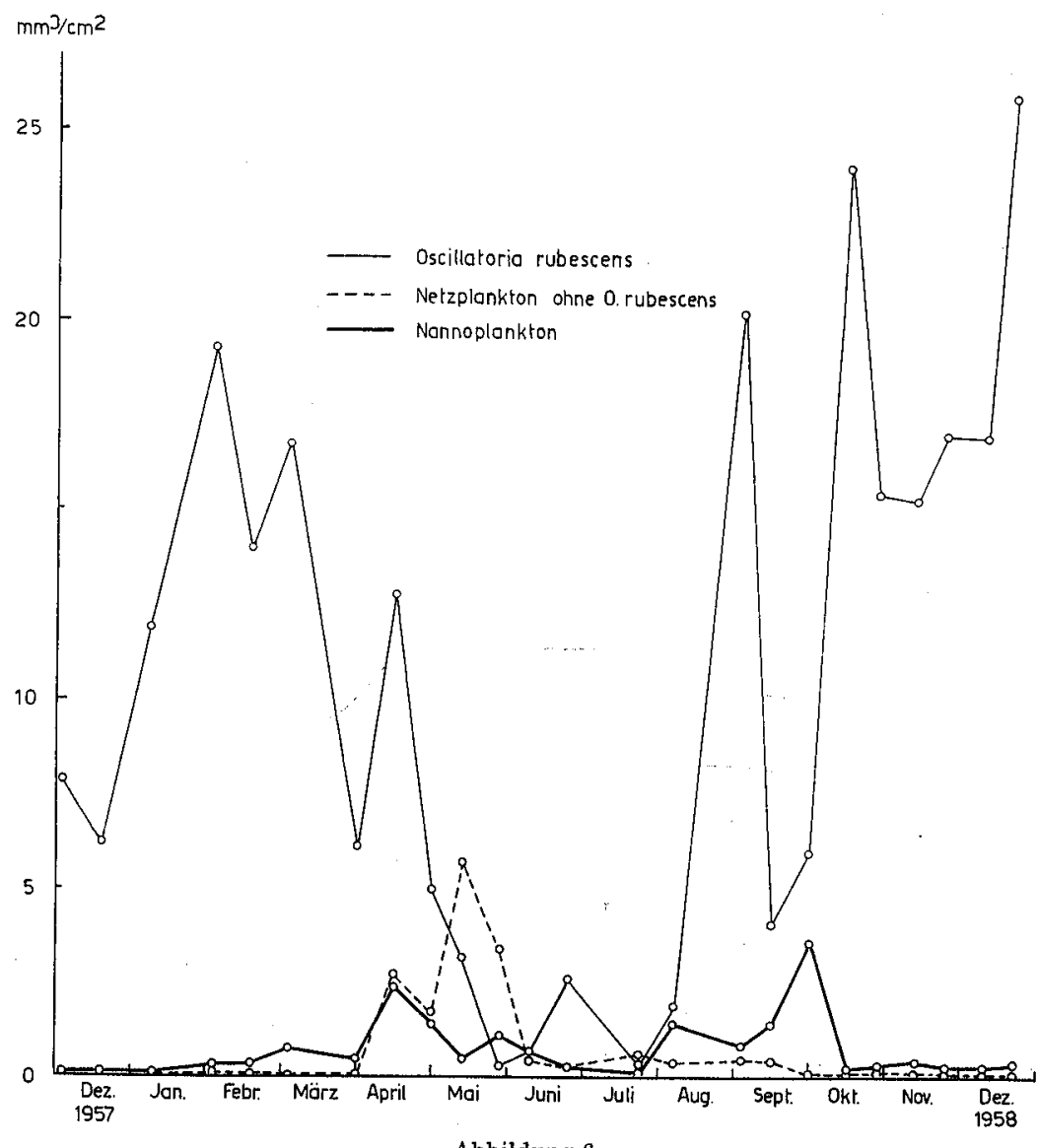

Abbildung 6

Zürichsee. Biomasse des Nannoplanktons im Vergleich zur Biomasse des Netzplanktons (Dezember 1957 bis 1958 ), in $\mathrm{mm}^{\mathrm{a}} / \mathrm{cm}^{2}$. Der dominierende Netzplankter Oscillatoria rubescens wurde getrennt berücksichtigt.

tungen vom Herbst bis in den frühen Frühling und ihre Ruhepausen in den Sommermonaten. Das «restliche Netzplankton» begann sich erst relativ spät, im April, stärker zu entwickeln, und erreichte im Mai seine grösste Biomasse des Jahres mit $5,7 \mathrm{~mm}^{3}$ unter $\mathrm{r} \mathrm{cm}^{2}$. In den anschliessenden Monaten fällt die Kurve stark $a b$ und bleibt konstant auf rund $0,4 \mathrm{~mm}^{3}$ unter $\mathrm{I} \mathrm{cm}^{2}$, um dann in den drei letzten Monaten wie zu Beginn des Jahres wieder fast auf Null abzusinken.

Die Nannoplankter hingegen begannen ihre Entfaltung schon im Februar. Ihre erste Spitze $\left(2,3 \mathrm{~mm}^{3} / \mathrm{cm}^{2}\right)$ fiel in den Monat April (die Nannoplanktonentwicklung setzte also vor dem Frühlingsmaximum des Netz- 

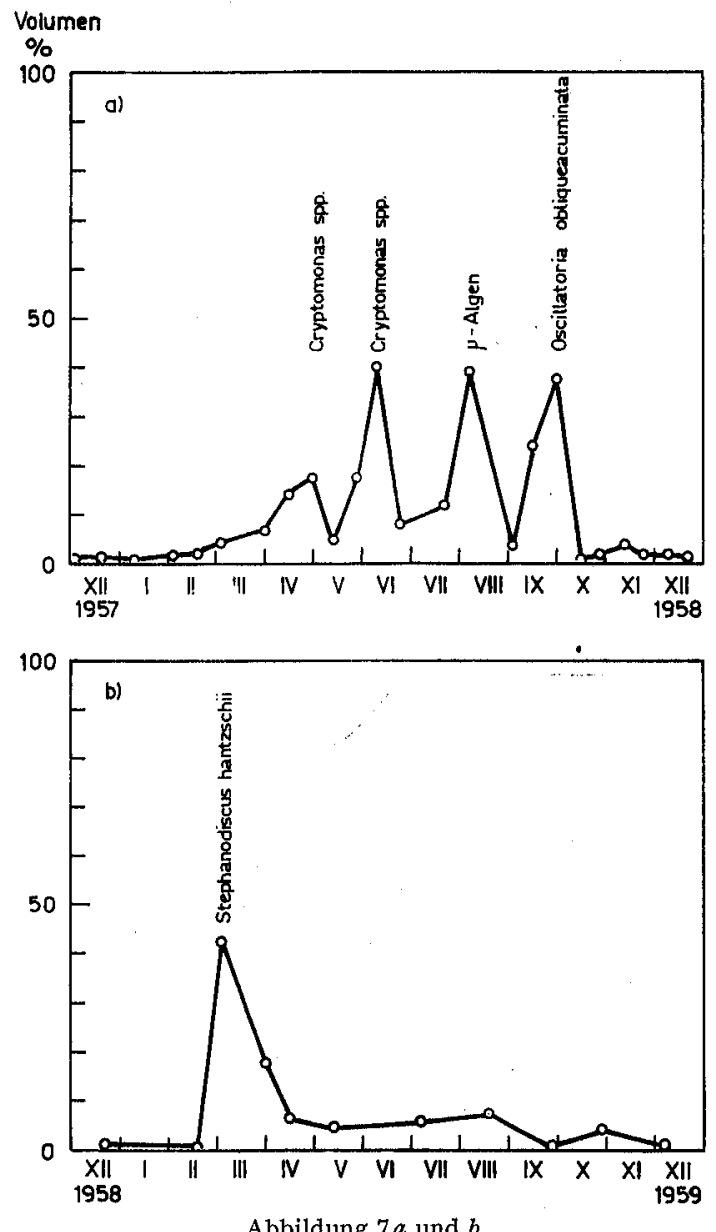

Zürichsee. Prozentualer Biomasseanteil des Nannoplanktons am gesamten Phytoplankton. a) Dezember 1957 bis Dezember 1958. b) Dezember 1958 bis Dezember 1959.

planktons ein), eine zweite, kleinere $\mathrm{I} \mathrm{mm}^{3} / \mathrm{cm}^{2}$ war Ende Mai zu verzeichnen. Nach einer längeren Zeit mit niedrigen Werten erfolgte im August ein höherer Ertrag von $\mathrm{I}, 4 \mathrm{~mm}^{3} / \mathrm{cm}^{2}$, und die grösste Nannoplanktonmasse im Jahre 1958 wurde im September gefunden $\left(3,6 \mathrm{~mm}^{3} /\right.$ $\mathrm{cm}^{2}$ ). Es waren also insgesamt vier Entwicklungsmaxima zu verzeichnen, für welche aber nicht die gleichen, sondern verschiedene Nannoplankter die Ursache waren. Das erste Maximum im April ging in erster Linie auf Rbodomonas lacustris und Cryptomonas opata zurïck. Ende Mai bildete Cryptomonas opata die Hauptmasse, die starke Entwicklung anfangs August 
wurde von Cblorella pyrenoidosa und Coccomyxa minor (« $\mu$-Algen») verursacht und das vierte, auffälligste Maximum Ende September war die Folge einer Massenentwicklung der feinen Blaualge Oscillatoria obliqueacuminata (vgl. auch Abb. 7a).

Wie aus Abb. 6 und Tab. 8 zu ersehen ist, betrug die Biomasse des totalen Netzplanktons ein Vielfaches derjenigen des Nannoplanktons. In keiner Probeserie des Zürichsees konnte im Vergleich zum Netzplankton eine grössere Nannoplanktonmasse bestimmt werden. Die Biomasse des Netzplanktons war im Jahre I958 durchschnittlich fünfzehnmal und im Jahre I959 zehnmal grösser als die Nannoplanktonmasse. In 2 I von 34 Probeserien (etwa $62 \%$ ) lag die Biomasse des Nannoplanktons nur zwischen o und $0,5 \mathrm{~mm}^{3} / \mathrm{cm}^{2}$, während in 22 Probeserien (etwa 65\%) die Erträge des Netzplanktons zwischen 5,0 und $20,0 \mathrm{~mm}^{3} / \mathrm{cm}^{2}$ variierten. Die höchste Netzplanktonmasse ergab den extremen Wert von $69,7 \mathrm{~mm}^{3} / \mathrm{cm}^{2}$ im Februar I959, während der Herbstertrag des Nannoplanktons beinahe zwanzigmal kleiner war. Diese enormen Massenunterschiede sind eindeutig auf die massgebende Oscillatoria rubescens zurückzuführen, die im Jahre 1958 , mit vier Ausnahmen, immer höhere Biomassewerte als das « restliche Netzplankton» erreicht hatte. Abb. 8 gibt den Eindruck, dass eine Beziehung besteht zwischen der Entwicklung von Oscillatoria rubescens und den übrigen Phytoplanktonformen, indem sich die beiden Kurven durch eine gewisse Gegenläufigkeit auszeichnen. Im Frühling I958 war es neben dem Nannoplankton vor allem das «restliche Netzplankton", im Herbst 1958 das Nannoplankton allein, welche gegenüber Oscillatoria rubescens eine gegenläufige Bewegung aufzeigten. -- Auch im Jahre I959 war eine solche Beziehung von Oscillatoria rubescens gegenüber den anderen pflanzlichen Planktern teilweise zu beobachten. Besonders klar kommt diese gegenseitige Einwirkung auf die Entwicklung der Algen im März zum Vorschein, wo sich Stephanodiscus bantzschii explosionsartig entfaltet hatte (vgl. Abb. $7 b$ und Tab. 8 und ro). Oscillatoria rubescens wies auch den Sommer über relativ hohe Biomassewerte auf. Überhaupt kein Zusammenhang zwischen der Biomasse von Oscillatoria rubescens und den übrigen Algen war im Herbst festzustellen.

Die beiden Untersuchungsjahre sollen kurz einander gegenübergestellt werden (Abb. 7 und Tab. 7 und 8). Dabei ist allerdings zu berücksichtigen, dass im Jahre I959 nur halb so viele Proben untersucht wurden. Es ist deshalb wohl möglich, dass Spitzenentwicklungen nicht oder unvollständig erfasst worden sind. Auffallend ist, dass die Biomasse der Oscillatoria rubescens im Jahre I959 dreimal grösser war als im Vorjahr. Ferner blieb Oscilla- 


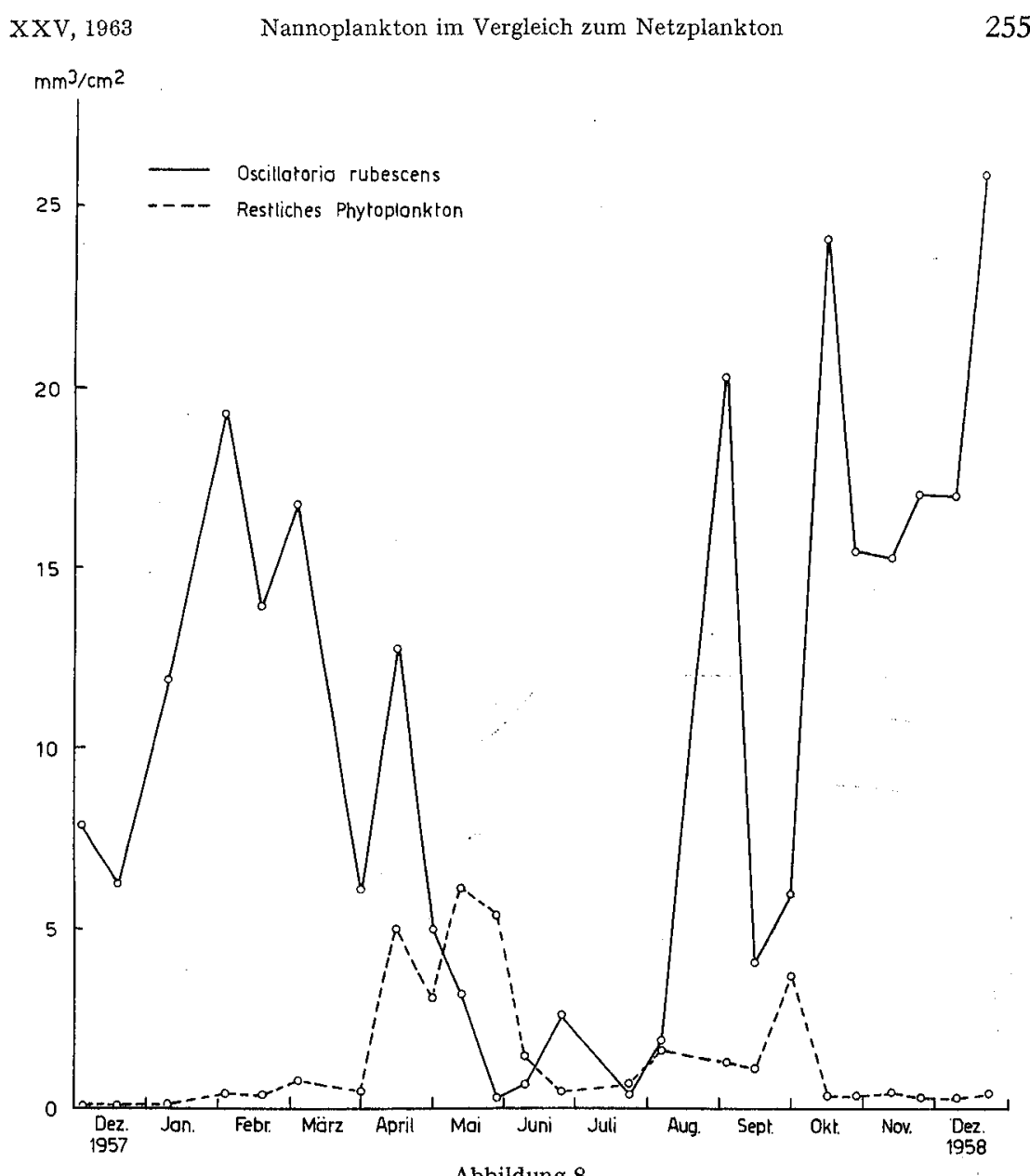

Zürichsee. Die Biomasse von Oscillatoria rubescens im Vergleich zur Biomasse der übrigen Phytoplanktonorganismen (Dezember 1957 bis Dezember 1958 ), in $\mathrm{mm}^{3} / \mathrm{cm}^{2}$.

toria rubescens - gegen die sonstige Erfahrung - nach einem schwachen Rückgang, der auf die riesige Februarentwicklung gefolgt war, den Sommer I959 hindurch auf höheren Werten als im Sommer 1958 und wies erst Ende Oktober eine stärkere Abnahme auf. Auch Minder [45] hat in seinen langjährigen Untersuchungen im Zürichsee abnorme Entwicklungsjahre für Oscillatoria rubescens beobachtet. Ferner setzten die Frühjahrsmaxima I959 des Nanno- und Netzplanktons einen Monat früher und heftiger ein mit einer Vegetationsfärbung von Stephanodiscus bantzscbii. Während der restlichen Monate des Jahres 1959 konnten 
Tabelle 8

Phytoplanktonvolumen des Zürichsees in $10^{6} \mu^{3}$ unter $1 \mathrm{~cm}^{2}$

\begin{tabular}{|c|c|c|c|c|c|c|c|}
\hline & \multicolumn{2}{|c|}{3.12 .57} & 17.12 .57 & 8.1 .58 & 4.2 .58 & 18.2 .58 & 4.3 .58 \\
\hline $\begin{array}{l}\text { Bacteriophyta } \\
\text { Cyanophyta }\end{array}$ & \multicolumn{2}{|c|}{7841,2} & $\begin{array}{r}+ \\
19,9\end{array}$ & $\begin{array}{r}162,1 \\
11882,2\end{array}$ & $\begin{array}{r}340,4 \\
19273,5\end{array}$ & $\begin{array}{r}350,4 \\
13991,5\end{array}$ & $\begin{array}{r}988,1 \\
16731,4\end{array}$ \\
\hline Euchlorophyceae & \multicolumn{2}{|c|}{0,1} & - & - & 0,1 & -3 & $\begin{array}{r}10101,4 \\
0,3\end{array}$ \\
\hline Desmidiales & \multicolumn{2}{|c|}{0,2} & - & - & 1,0 & 6,4 & 12,4 \\
\hline Chrysophyceae & \multicolumn{2}{|r|}{-} & - & - & 4,1 & 14,5 & 16,9 \\
\hline Kleine Flagellaten & \multicolumn{2}{|c|}{$\overrightarrow{-}$} & - & + & 44,4 & 4,5 & - \\
\hline Diatomeae & \multirow{2}{*}{\multicolumn{2}{|c|}{$\begin{array}{r}7,5 \\
48,4\end{array}$}} & 3,8 & 17,7 & 140,5 & 68,1 & 115,7 \\
\hline Cryptophyceae & & \multicolumn{2}{|r|}{55,3} & 64,6 & 105,4 & 161,9 & 419,9 \\
\hline Peridineae & \multicolumn{2}{|c|}{32,0} & 7,5 & 25,8 & 92,9 & 84,4 & 157,1 \\
\hline Netzplankton & & & 11899,9 & 19372,6 & 14017,5 & 16744,4 \\
\hline Nannoplankton & \multirow{2}{*}{\multicolumn{2}{|c|}{$\begin{array}{c}81,0 \\
+\end{array}$}} & 62,8 & 90,4 & 289,3 & 313,7 & 709,4 \\
\hline Bacteriophyta & & + & + & 162,1 & 340,4 & 350,4 & 988,1 \\
\hline \multirow[t]{2}{*}{ Total } & \multicolumn{2}{|c|}{7930,0} & 86,5 & 12152,4 & 20002,3 & 14681,7 & 18441,9 \\
\hline & 1.4 .58 & 15.4 .58 & 29.4 .58 & 13.5 .58 & 27.5 .58 & 10.6 .58 & 24.6 .58 \\
\hline Bacteriophyta & 199,5 & 288,6 & 165,2 & 25,3 & 155,7 & - & $\overrightarrow{-}$ \\
\hline Cyanophyta & 6074,2 & 12721,1 & 4993,5 & 3135,3 & $-252,0$ & 634,9 & 2567,1 \\
\hline Euchlorophyceae & - & 0,8 & 40,5 & 56,4 & 0,3 & 211,4 & 104,9 \\
\hline Desmidiales & 0,2 & - & - & - & - & - & 2,7 \\
\hline Chrysophyceae & 20,1 & 65,8 & 0,7 & 34,9 & 0,5 & 45,1 & 0,2 \\
\hline Kleine Flagellaten & 2,7 & 98,0 & 8,3 & 13,6 & 6,5 & - & 9,8 \\
\hline Diatomeae & 111,0 & 3360,6 & 2363,1 & 5722,9 & 4440,8 & 662,7 & 235,3 \\
\hline Cryptophyceae & 267,5 & 347,0 & 340,9 & 247,4 & 830,7 & 372,7 & 57,9 \\
\hline Peridineae & 77,1 & 110,0 & 262,4 & 37,7 & 64,0 & 125,7 & 92,0 \\
\hline Netzplankton & 6106,2 & 14362,3 & 6613,2 & 8810,0 & 4620,9 & 1341,6 & 2827,2 \\
\hline Nannoplankton & 446,7 & 2340,9 & 1396,2 & 438,1 & 973,9 & 710,9 & 242,6 \\
\hline Bacteriophyta & 199,5 & 288,6 & 165,2 & 25,3 & 155,7 & - & - \\
\hline Total & 6752,4 & 16991,8 & 8174,6 & 9273,4 & 5750,4 & 2052,5 & 3069,78 \\
\hline & 22.7 .58 & 5.8 .58 & 2.9 .58 & $8 \quad 16.9 .58$ & 29.9 .58 & 14.10 .58 & 28.10 .58 \\
\hline Bacteriophyta & 0,6 & 98,4 & & 29,2 & 4,1 & - & - \\
\hline Cyanophyta & 340,5 & 1883,6 & 20524,0 & 4974,5 & 9087,6 & 24095,3 & 15422,7 \\
\hline Euchlorophyceae & 48,5 & 1312,5 & 42,4 & 199,1 & 17,3 & 3,3 & 0,5 \\
\hline Desmidiales & 6,9 & 11,9 & 0,5 & 1,5 & 0,3 & 0,4 & 0,3 \\
\hline Chrysophyceae & 0,2 & 13,3 & 352,7 & 203,6 & 21,8 & - & 0,8 \\
\hline Kleine Flagellaten & 12,4 & 1,0 & 4,1 & 21,9 & 35,5 & 3,9 & 34,7 \\
\hline Diatomeae & 525,6 & 316,2 & 34,1 & 122,6 & 41,5 & 89,4 & 34,8 \\
\hline yceae & 40,2 & 6,4 & 175,7 & 114,9 & 277,9 & 151,4 & 167,6 \\
\hline Peridineae & 23,7 & 73,9 & 328,5 & 179,0 & 68,2 & 37,1 & 82,1 \\
\hline Net & 873,4 & 2215,2 & 20665,0 & 4444,4 & 5986,8 & 24170,8 & 15452,4 \\
\hline kton & 114,9 & 1411,2 & 801,9 & 1376,3 & 3567,1 & 206,6 & 291,2 \\
\hline Bacteriophyta & 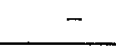 & 90,1 & - & 25,5 & - & - & - \\
\hline otal & 987,3 & 3716,5 & 21466,9 & 5846,2 & 9553,2 & 24377,4 & 15743,6 \\
\hline
\end{tabular}


Tabelle 8 (Fortsetzung)

\begin{tabular}{|c|c|c|c|c|c|c|c|}
\hline & 11.11 .58 & 27.11 .58 & 9.12 .58 & 23.12 .58 & 17.2 .59 & 3.3 .59 & 31.3 .59 \\
\hline Bacteriophyta & - & 10,2 & 27,1 & 87,3 & 66,9 & - & - \\
\hline Cyanophyta & 15258,8 & 17042,0 & 16952,3 & 25860,2 & 68763,6 & 9341,4 & 21808,7 \\
\hline Euchlorophyceae & - & - & - & - & - & 63,8 & 18,6 \\
\hline Desmidiales & - & 0,1 & 2,4 & 1,9 & 5,3 & 0,5 & 0,8 \\
\hline Chrysophyceae & - & - & 19,2 & 8,4 & - & 10,3 & 13,9 \\
\hline Kleine Flagellaten & 10,4 & 14,9 & 7,1 & 35,5 & 19,6 & 145,4 & 49,9 \\
\hline Diatc & 30,4 & 13,6 & 7,8 & 28,2 & 181,2 & 8048,3 & 6257,3 \\
\hline yceae & 281,5 & 70,8 & 44,6 & 41,7 & 130,2 & 768,2 & 142,2 \\
\hline Peric & 93,5 & 189,8 & 188,5 & 257,8 & 79,8 & 194,6 & 36,9 \\
\hline & 3,5 & 17052,4 & 16962,5 & 5888,5 & 68896,8 & 0740,1 & 3369,1 \\
\hline on & 9,0 & 278,7 & 259,3 & 345,0 & 282,8 & 7838,4 & 959,1 \\
\hline Bacte & - & 10,2 & 27,1 & 87,3 & 66,9 & - & - \\
\hline \multirow[t]{2}{*}{ Total } & 15674,5 & 17341,3 & 17248,9 & 26320,8 & 69246,5 & 18578,5 & 28328,2 \\
\hline & 14.4 .59 & 13.5 .59 & 7.7 .59 & 18.8 .59 & 29.9 .59 & 27.10 .59 & 8.12 .59 \\
\hline$a c t$ & 57,4 & 1543,9 & 67,7 & 72,0 & - & 87,9 & 77,2 \\
\hline & 14192,8 & 7641,5 & 6717,0 & 8389,3 & 7868,9 & $1653 ; 0$ & 463,5 \\
\hline Euchlorophyceae & 4,2 & 0,2 & 28,1 & 114,5 & 0,8 & 0,2 & - \\
\hline Desmidiales & - & 0,1 & 1,5 & 52,8 & 0,4 & 0,9 & - \\
\hline Chrysophyceae & 62,5 & 11,5 & 144,1 & 262,6 & - & 18,3 & 0,2 \\
\hline Kleine Flagellaten & 65,1 & 16,3 & 28,7 & 24,1 & 1,8 & 23,4 & 6,9 \\
\hline Diatomeae & 1504,2 & 1129,9 & 228,7 & 56,8 & 115,7 & 152,4 & 27,8 \\
\hline Cryptophyceae & 37,5 & 281,1 & 262,3 & 150,5 & 4,6 & 20,9 & 34,1 \\
\hline Peridineae & 644,9 & 74,1 & 369,4 & 306,5 & 1,8 & 127,7 & 68,0 \\
\hline & 5515,7 & 8770,2 & 7300,8 & 8717,3 & 7985,4 & 891,8 & 16491,3 \\
\hline ston & 961,2 & 386,7 & 477,9 & 640,1 & 8,6 & 72,0 & 109,1 \\
\hline Bacteriophyta & 57,4 & 1543,9 & 67,7 & 72,0 & - & 87,7 & 77,2 \\
\hline otal & 16533,9 & 0700,8 & 7846,4 & 9429,4 & 7994,0 & 2051,5 & 16677,6 \\
\hline
\end{tabular}

zur Zeit der Probenahme keine weiteren auffälligen Nannoplanktonspitzen, wie zum Beispiel von « $\mu$-Algen» oder Oscillatoria obliqueacuminata im Jahre 1958, erfasst werden. Wie jedoch aus Tab. 7 und 8 hervorgeht, unterschieden sich die beiden Probenahmejahre weniger in qualitativer als in quantitativer Hinsicht. Sicher ist ein Teil dieses Unterschiedes mit der extrem unterschiedlichen Witterung während dieser beiden Jahre zu erklären, welche auch eine zeitliche Verschiebung im Auftreten der einzelnen Formen bewirkt hatte. Das Jahr I958 war auffallend niederschlagsreich und kalt, besonders im Frühjahr, Sonne gab es vor allem im September und Dezember. Das Jahr r959 hingegen kann als sehr niederschlagsarm und sonnig gekennzeichnet werden.

Die Verteilung der Biomasse auf die wichtigsten Algengruppen (Abb. 9, Tab. 8-II): 
Tabelle 9

Aufstellung über die Anzabl der ausgezäblten Arten (A) und prozentualer Anteil am Planktonpolumen $(A V)$ des Zürichsees

\begin{tabular}{|c|c|c|c|c|c|c|c|c|c|c|c|c|}
\hline & \multicolumn{2}{|c|}{3.12 .57} & \multicolumn{2}{|c|}{17.12 .57} & \multicolumn{2}{|c|}{8.1 .58} & \multicolumn{2}{|c|}{4.2 .58} & \multicolumn{2}{|c|}{18.2 .58} & \multicolumn{2}{|c|}{4.3 .58} \\
\hline & A & AV & A & $\mathrm{AV}$ & & $\mathrm{AV}$ & A & $\mathrm{AV}$ & A & $\mathrm{AV}$ & A & AV \\
\hline Bacteriophyta & 2 & -. & 2 & - & 3 & 1,3 & 4 & 1,7 & 2 & 2,4 & 5 & 5,4 \\
\hline Cyanophyta & 1 & 98,9 & 1 & 98,9 & 1 & 97,9 & 1 & 96,4 & $\overline{1}$ & 95,3 & 1 & 90,8 \\
\hline Euchlorophyceae & 1 & - & - & - & - & - & 3 & + & - & - & - & + \\
\hline Desmidiales & 1 & - & - & - & - & - & 3 & + & 2 & + & 2 & + \\
\hline Chrysophyceae & - & - & - & - & 1 & + & 2 & + & 1 & 0,1 & 1 & 0,1 \\
\hline Kleine Flagellaten & $-1+$ & $+2)-$ & $(+1)$ & - & $1(+$ & $-2) 0,2$ & 1 & 0,2 & 1 & + & - & - \\
\hline Diatomeae & 3 & 0,1 & 2 & 0,1 & 2 & 0,1 & 7 & 0,7 & 3 & 0,5 & 4 & 0,6 \\
\hline ophyceae & 2 & 0,6 & 2 & 0,9 & 2 & 0,5 & 2 & 0,5 & 2 & 1,1 & 2 & 2,3 \\
\hline Peridineae & 1 & 0,4 & 2 & 0,1 & 2 & 0,2 & 2 & 0,5 & 2 & 0,6 & 3. & 0,3 \\
\hline Netzplankton & 6 & 99,0 & 3 & 99,0 & 3 & 98,0 & 11 & 96,9 & 4 & 95,5 & 7 & 30,8 \\
\hline kton & 3 & 1,0 & 4 & 1,0 & 6 & 0,7 & 10 & 1,4 & 8 & 2,1 & 7 & 3,8 \\
\hline Bacter & 2 & - & 2 & - & 3 & 1,3 & 4 & 1,7 & 2 & 2,4 & 5 & 5,4 \\
\hline \multirow[t]{3}{*}{ Total } & 11 & 100,0 & 9 & 100,0 & 12 & 100,0 & 25 & 100,0 & 14 & 100,0 & 19 & 100,0 \\
\hline & \multirow{2}{*}{\multicolumn{2}{|c|}{$\begin{array}{l}1.4 .58 \\
\mathrm{~A} \mathrm{AV}\end{array}$}} & \multicolumn{2}{|r|}{15.4 .58} & \multicolumn{2}{|c|}{29.4 .58} & \multicolumn{2}{|c|}{13.5 .58} & \multicolumn{2}{|c|}{27.5 .58} & \multicolumn{2}{|c|}{10.6 .58} \\
\hline & & & & A AV & & $\mathrm{AV}$ & & $\mathrm{AV}$ & & $\mathrm{AV}$ & & $\mathrm{AV}$ \\
\hline Bacteriof & & 2,9 & 4 & 1,7 & 4 & 2,0 & 1 & 0,3 & 3 & 2,7 & 2 & + \\
\hline Cyanophyta & & 1. 90,0 & 1 & 74,9 & 1 & 61,0 & 1 & 33,8 & 1 & 4,4 & 1 & 30,9 \\
\hline Euchlorophyceae & & + & 4 & + & 2 & 0,5 & 7 & 0,6 & 3 & + & 7 & 10,3 \\
\hline $\mathrm{De}$ & & + & 4 & + & - & - & 2 & + & 1 & + & 2 & + \\
\hline ceae & & 0,3 & 1 & 0,4 & 1 & + & 3 & 0,4 & 2 & 0,1 & 1 & 2,2 \\
\hline Kleine Flagellaten & & + & 3 & 0,6 & 1 & 0,1 & 1 & 0,1 & 1 & - & - & - \\
\hline Diatomeae & & 1,6 & 9 & 19,8 & 9 & 28,9 & 8 & 61,7 & 7 & 77,2 & 7 & 32,3 \\
\hline Cryptophyceae & & 4,0 & 4 & 2,0 & 3 & 4,2 & 2 & 2,7 & 2 & 14,5 & 2 & 18,2 \\
\hline Peridineae & & 1,1 & 2 & 0,6 & 2 & 3,2 & 4 & 0,4 & 2 & 1,1 & 2 & 6,1 \\
\hline et & & 890,5 & 12 & 84,5 & 8 & 80,9 & 17 & 95,0 & 13 & 80,4 & 12 & 65,4 \\
\hline Nannoplankton & & 6,6 & 16 & 13,8 & 11 & 17,1 & 11 & 4,7 & 6 & 16,9 & 10 & 34,6 \\
\hline Bacterio & & 2,9 & 4 & 1,7 & 4 & 2,0 & 1 & 0,3 & 3 & 2,7 & 2 & + \\
\hline \multirow[t]{3}{*}{ Total } & \multicolumn{2}{|c|}{17100,0} & \multicolumn{2}{|c|}{32100,0} & \multicolumn{2}{|c|}{23100,0} & \multicolumn{2}{|c|}{29100,0} & \multicolumn{2}{|c|}{22100,0} & \multicolumn{2}{|c|}{24100,0} \\
\hline & & 24.6 .58 & & 22.7 .58 & & .8 .58 & & 9.58 & & 5.9 .58 & & .9 .58 \\
\hline & & $\mathrm{AV}$ & & AV & & $\mathrm{A} \mathrm{AV}$ & & $\mathrm{AV}$ & A & AV & A & $\mathrm{AV}$ \\
\hline ta & & - & & + & 6 & 2,4 & 3 & + & 6 & 0,4 & 6 & + \\
\hline Cya & & 183,7 & & 34,5 & 3 & 50,8 & 5 & 95,6 & 4 & 85,1 & 4 & 95,1 \\
\hline Euchlorophyceae & & 3,5 & 22 & 4,6 & 13 & 35,7 & 7 & 0,2 & 12 & 3,4 & 5 & 0,2 \\
\hline Desmidiales & 1 & + & & + & 4 & + & 3 & + & 3 & + & 1 & + \\
\hline Chrysophyceae & 1 & + & 3 & + & 2 & 0,4 & 4 & 1,6 & 5 & 3,5 & 4 & 0,2 \\
\hline Kleine Flagellaten & 2 & 0,3 & 2 & 1,2 & 1 & + & 1 & + & 3 & $0,4 \cdots$ & 2 & 0,4 \\
\hline Diato & & 7,7 & & 53,1 & 4 & 8,5 & 5 & 0,2 & 5 & 2,1 & 5 & 0,4 \\
\hline Cryp & 2 & 1,9 & 2 & 4,1 & 2 & 0,2 & 2 & 0,8 & 2 & 2,0 & 2 & 2,9 \\
\hline Peridineae & & 3,0 & & 2,4 & 3 & 2,0 & 5 & 1,5 & 5 & 3,1 & 5 & 0,7 \\
\hline Netzp & 13 & $3 \quad 92,1$ & 21 & 188,4 & 18 & 59, & 18 & 96,3 & 20 & 76,0 & 15 & 62,6 \\
\hline Nannop & & 7,9 & 28 & $8 \quad 11,6$ & 14 & 38,0 & 14 & 3,7 & 21 & 23,6 & 13 & 37,4 \\
\hline Bacteriophyta & - & - & 2 & + & 6 & 2,4 & 3 & + & 6 & 0,4 & 6 & + \\
\hline otal & 20 & 0100,0 & 51 & 1100,0 & 38 & 100,0 & 35 & $.100,0$ & 47 & $1.00,0$ & 34 & 100,0 \\
\hline
\end{tabular}


Tabelle 9 (Fortsetzung)

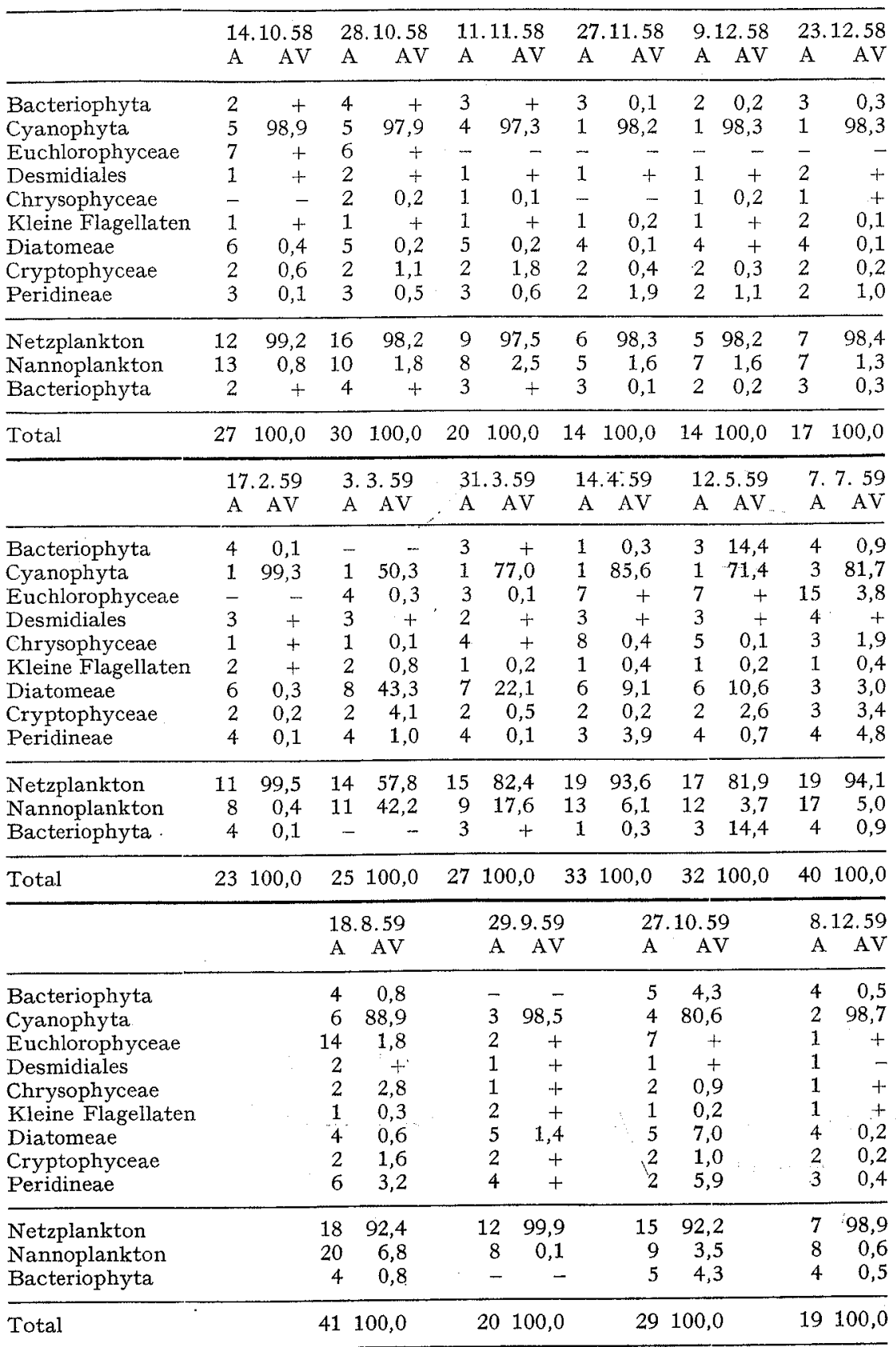


Volumen

$\%$
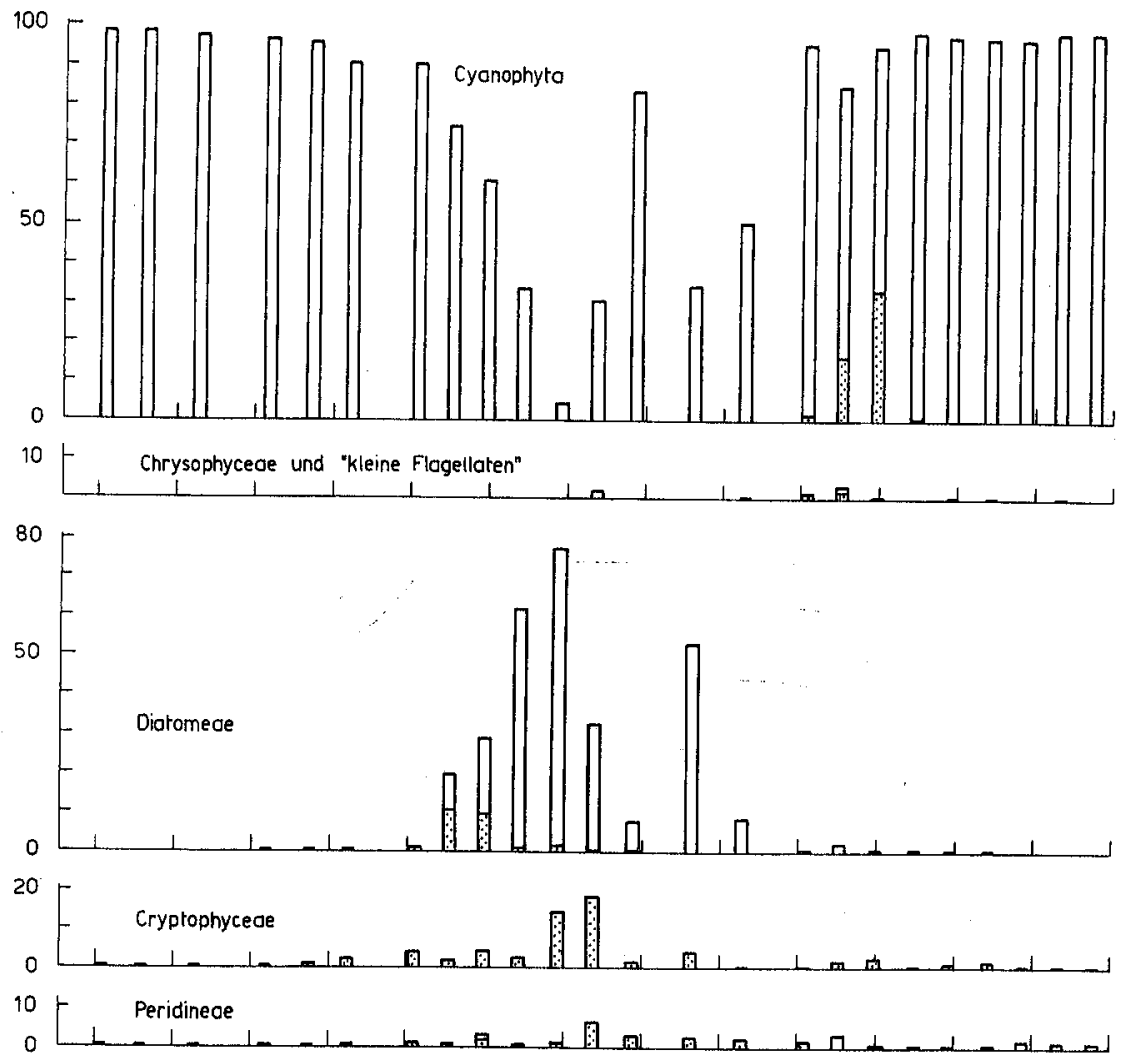

$405 \square$ Nezzplankton

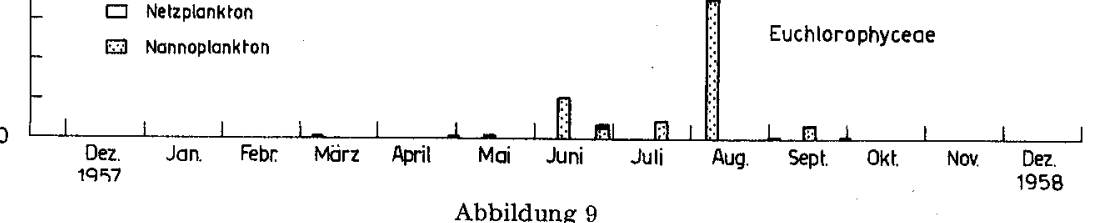

$$
\text { Abbildung } 9
$$

Zürichsee. Prozentualer Biomasseanteil der verschiedenen Algengruppen am Gesamtplankton, unter Berücksichtigung des Netz- und Nannoplanktons (Dezember 1957 bis Dezember 1958).

Cyanophyta. Als ausgesprochener Oscillatoria-rubescens-See liess der Zürichsee von vorneherein erwarten, dass der grösste Anteil der Biomasse auf die Blaualgen entfallen würde. In 23 von 34 Probeserien machten die Blaualgen denn auch mehr als $90 \%$ der Biomasse aus; der niedrigste Anteil betrug im März I959 immer noch $58 \%$. In I7 Probeserien war die 
Biomasse grösser als Io $\mathrm{mm}^{3} / \mathrm{cm}^{2}$ und in 9 Serien lag die Masse zwischen 5 und $10 \mathrm{~mm}^{3} / \mathrm{cm}^{2}$. Im September 1958 wurde mehr als ein Drittel des Blaualgenanteils von der kleinen Form Oscillatoria obliqueacuminata ( $33 \%$ $=3,2 \mathrm{~mm}^{8} / \mathrm{cm}^{9}$ ), übrigens der einzigen für die Biomasse wesentlichen nannoplanktischen Blaualge, geliefert.

Cbloropbyta. Der prozentuale Biomasseanteil der Grünalgen fiel nur im Sommer 1958 ins Gewicht in Form von sozusagen reinem Nannoplankton. Eine auffallende Spitze war im August I958 zu verzeichnen, wo eine Massenentfaltung von Cblorella pyrenoidosa fast $40 \%$ der Biomasse des Phytoplanktons ausgemacht hatte.

Chrysophyceae. Die Chrysophyceen waren während der ganzen Untersuchungszeit nie in auffallender Menge hervorgetreten; I958 waren sie sogar nur in äusserst geringer Zahl vorhanden. So stellten 3,5\% Volumenanteil $\left(=0,1 \mathrm{~mm}^{3} / \mathrm{cm}^{2}\right)$ im September 1958 die maximale Entwicklung der Chrysophyceen dar, gebildet von Dinobryon divergens, Dinobryon sociale und Dinobryon sertularia. Die Nannoplankter, meistens sehr kleine Formen, wie Kepbyrion- und Pseudokepbyrionarten, Pseudopedinella und Erkenia, überschnitten nur ein einziges Mal, nämlich im September 1958, die Grenze von einem Prozent $\left(=0,08 \mathrm{~mm}^{3} / \mathrm{cm}^{2}\right)$.

Kleine Flagellaten (Bodo, Ochromonas, Heterochromonas, Katablepharis). Wie der Formenkreis der Chrysophyceen sind auch diese Organismen von geringer Bedeutung für die Biomasse.

Diatomeae. Die Diatomeen bildeten im jahreszeitlichen Verlauf und in der Biomassebildung gleichsam die Antagonisten der Blaualgen, indem sie sich namentlich im Frühjahr, während der Minimalentwicklung von Oscillatoria rubescens, vermehrten. Stephanodiscus, die einzige Nannoform unter den die Biomasse beeinflussenden Kieselalgen, lieferte im Jahre 1958 (April) eine Masse von $1,7 \mathrm{~mm}^{3} / \mathrm{cm}^{2}$ und im Jahre 1959 (März) sogar $6,7 \mathrm{~mm}^{3} / \mathrm{cm}^{2}$, ein Biomasseanteil, den sogar alle Netzplankter zusammen überhaupt nie erreicht hatten.

Cryptophyceae. Die Formen dieser Gruppe, alles Nannoplankter, waren das ganze Jahr über prozentual meistens verhältnismässig schwach vorhanden. Am stärksten vertreten waren sie im Mai bis Juni 1958 mit I4,5 und I $8,2 \%$, sonst überschnitt ihre Biomasse nie $5 \%$. Ihre grösste Menge fiel in den Juni 1958 und März 1959.

Peridineae. Zwar waren Vertreter aus dieser Gruppe das ganze Jahr hindurch zu finden, doch nur in unwesentlichen Anteilen für das Zürichseeplankton. Im Winter waren es hauptsächlich Gymnodinium belveticum 
Tabelle 10

Nannoplanktonvolumen des Züricbsees in $10^{6} \mu^{3}$ unter $1 \mathrm{~cm}^{2}$

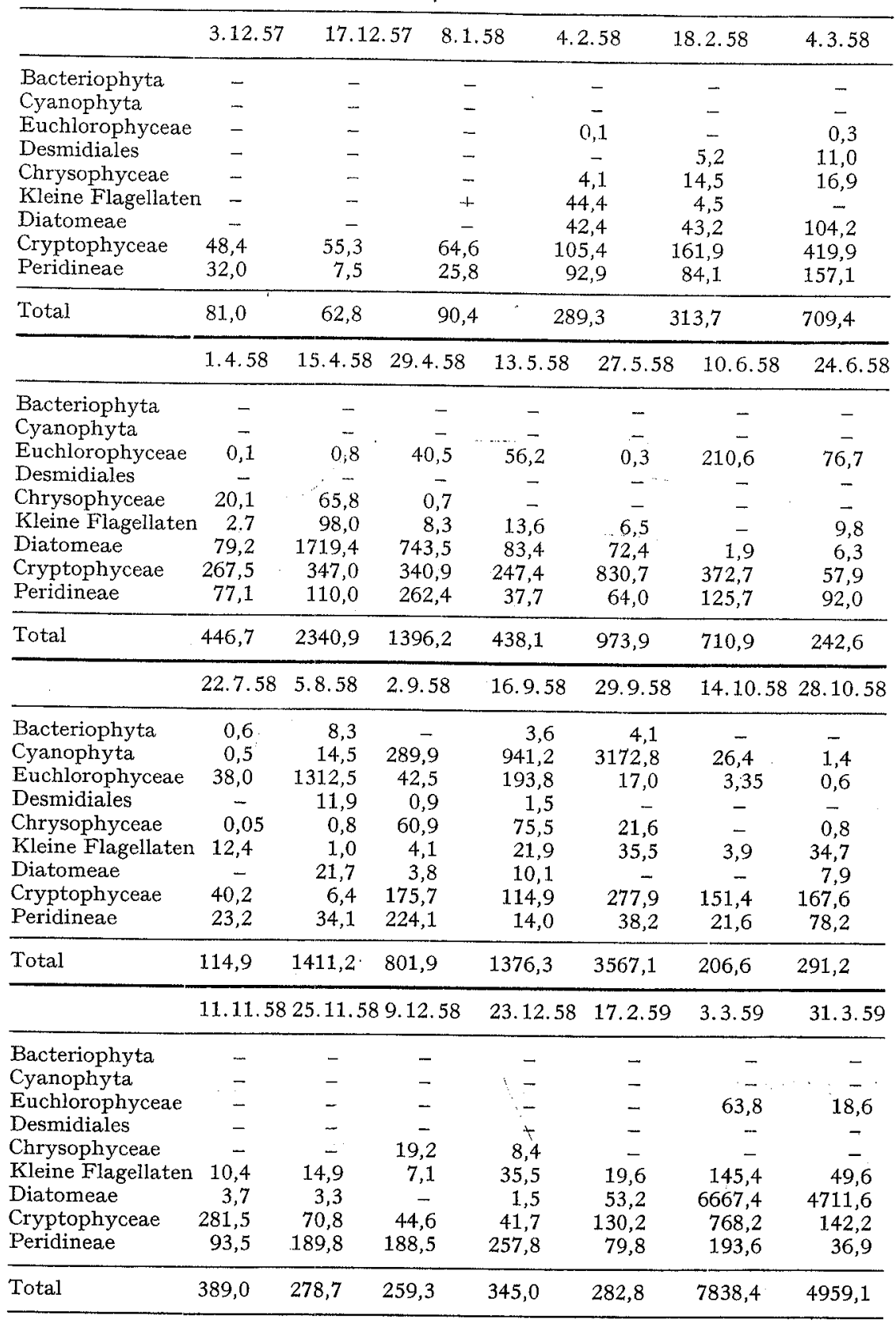


Tabelle 10 (Fortsetzung)

\begin{tabular}{lcrrrrrr}
\hline & 14.4 .59 & 13.5 .59 & 7.7 .59 & 18.8 .59 & 29.9 .59 & 27.10 .59 & 8.12 .59 \\
\hline Bacteriophyta & - & - & - & 0,3 & - & 0,1 & - \\
Cyanophyta & - & - & 2,2 & 216,4 & 0,4 & - & - \\
Euchlorophyceae & 4,2 & - & 28,1 & 0,3 & - & - & - \\
Desmidiales & - & - & - & - & - & - & - \\
Chrysophyceae & 27,6 & - & - & 25,9 & - & 18,3 & 0,2 \\
Kleine Flagellaten & 65,1 & 16,3 & 28,7 & 24,1 & 1,8 & 5,12 & 6,9 \\
Diatomeae & 183,5 & 29,4 & 94,3 & - & - & 27,6 & - \\
Cryptophyceae & 37,5 & 281,1 & 262,3 & 150,5 & 4,6 & 20,9 & 34,1 \\
Peridineae & 643,3 & 59,9 & 62,3 & 222,7 & 1,9 & - & 68,0 \\
\hline Total & 961,2 & 386,7 & 477,9 & 640,1 & 8,6 & 72,0 & 109,1 \\
\hline
\end{tabular}

Tabelle 11

Nannoplanktonoolumenprozente des Züricbsees

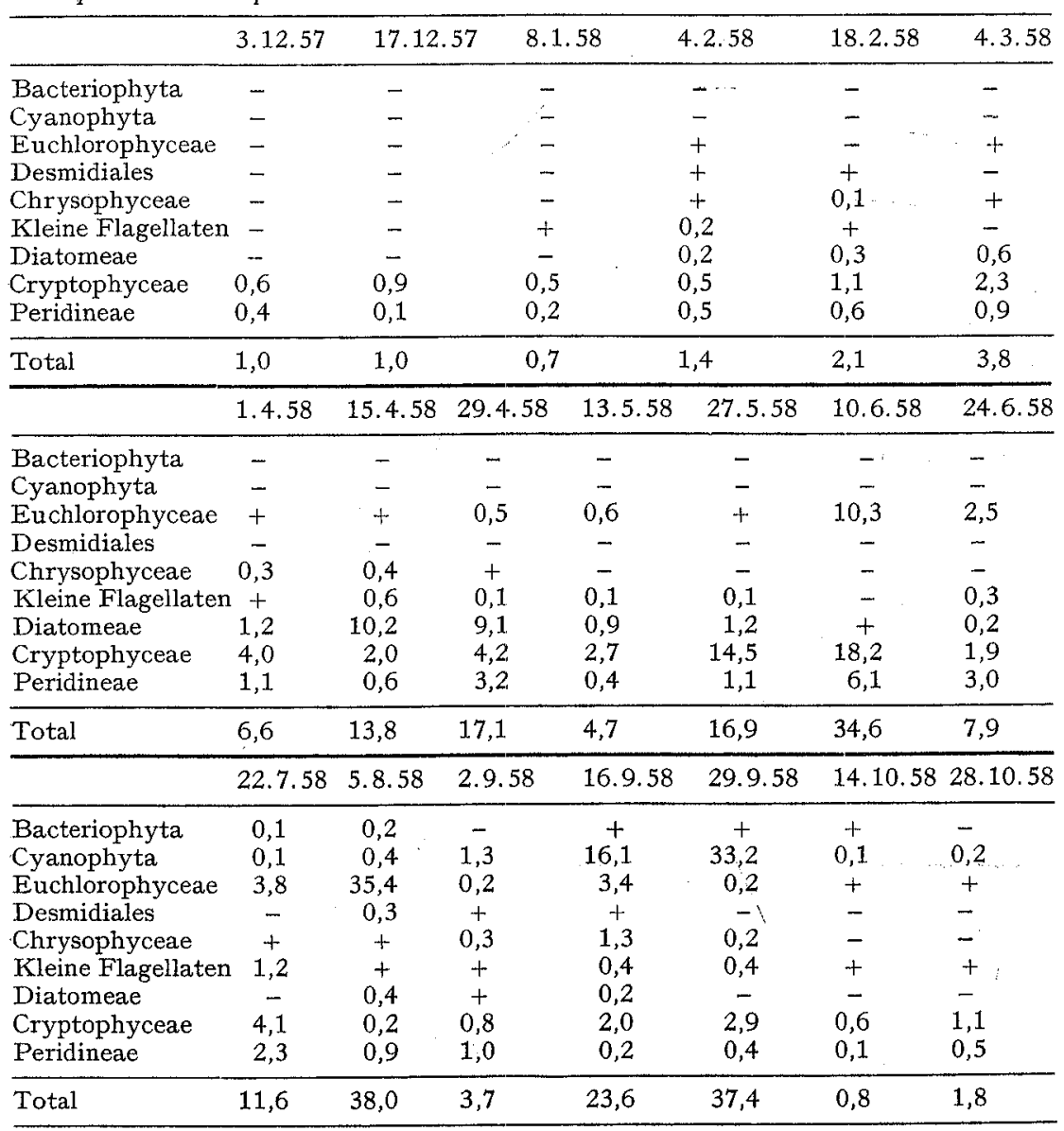


Tabelle 11 (Fortsetzung)

\begin{tabular}{|c|c|c|c|c|c|c|c|}
\hline 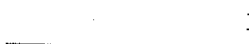 & \multicolumn{3}{|c|}{11.11 .5825 .11 .589 .12 .58} & 23.12 .58 & 1.7 .2 .59 & 3.3 .59 & 31.3 .59 \\
\hline Bacteriophyta & - & - & - & - & - & - & - \\
\hline Cyanophyta & - & - & - & - & - & - & - \\
\hline Euchlorophyceae & - & - & - & - & - & 0,3 & 0,1 \\
\hline Desmidiales & - & - & - & - & - & - & - \\
\hline Chrysophyceae & - & - & 0,2 & + & - & - & + \\
\hline Kleine Flagellaten & + & 0,2 & + & 0,1 & + & 0,8 & 0,2 \\
\hline Diatomeae & + & - & - & - & 0,1 & 35,9 & 16,7 \\
\hline Cryptophyceae & 1,8 & 0,4 & 0,3 & 0,2 & 0,2 & 4,1 & 0,5 \\
\hline Peridineae & 0,6 & 1,0 & 1,1 & 1,0 & 0,1 & 1,0 & 0,1 \\
\hline \multirow[t]{2}{*}{ Total } & 2,5 & 1,6 & 1,6 & 1,3 & 0,4 & 42,2 & 17,6 \\
\hline & 14.4 .59 & 13.5 .59 & 7.7 .59 & 18.8 .59 & 29.9 .59 & 27.10 .59 & 8.12 .59 \\
\hline Bacteriophyta & - & - & - & + & - & + & $\rightarrow$ \\
\hline Cyanophyta & - & - & - & 2,3 & + & - & - \\
\hline Euchlorophyceae & + & - & 0,4 & + & - & - & - \\
\hline Desmidiales & - & - & - & - & $\rightarrow$ & - & - \\
\hline Chrysophyceae & 0,2 & - & - & 0,3 & - & 0,9 & + \\
\hline Kleine Flagellaten & 0,4 & 0,2 & 0,4 & 0,3 & + & 0,2 & + \\
\hline Diatomeae & 1,1 & 0,3 & 1,2 & - & - & 1,3 & - \\
\hline Cryptophyceae & 0,2 & 2,6 & 3,3 & 1,6 & + & 1,0 & 0,2 \\
\hline Peridineae & 3,9 & 0,6 & 0,8 & 2,3 & + & + & 0,4 \\
\hline Total & 5,8 & 3,7 & 6,1 & 6,8 & 0,1 & 3,5 & 0,6 \\
\hline
\end{tabular}

und Gymnodinium lantzscbii, zwei Nannoplankter, während im Sommerplankton Peridinium cinctum und Peridinium inconspicuum sowie Ceratium birundinella die Biomasse der Peridineen bestimmten.

\section{Das Phytoplankton des Pfäffikersees}

\section{Allgemeines}

Im Pfäffikersee haben in den letzten fünfzig Jahren auffallende chemische und biologische Veränderungen stattgefunden, hauptsächlich bedingt durch die zunehmende Eutrophierung durch Abwasser. So weist MessIKOMMER [42] auf folgende Verschiebungen in der Zusammensetzung des Planktons hin: «Eine Anzahl Kieselalgen, wie zum Beispiel die Cyclotellen, die Melosiren, Synedra acus var. angustissima, sind gegenüber früher mengenmässig erheblich zurückgegangen. Fragilaria crotonensis trat vor 40 Jahren spärlich, vor I5-18 Jahren reichlich auf. Neuestens scheint sie wieder zurückzugehen. Eudorina elegans hat vor vier Dezennien fast ganz. gefehlt. Ihre bessere Vertretung hat sich erst im Laufe der letzten 20 Jahre gesichert. Dinobryon divergens hat gegenüber früher an Bedeutung. 
stark eingebüsst.» Heute wird der Pfäffikersee biologisch durch sprunghafte Massenentfaltungen des Planktons, die sogar Vegetationsfärbungen und Wasserblüten verursachen, charakterisiert.

Im Zusammenhang mit technischen Versuchen zur künstlichen Belüftung (erste Resultate darüber bei AмBüHL [2]) bot sich uns die Gelegenheit, das Zahlenmaterial der Planktonproben zu verwerten, wiederum mit dem Ziel, Netz- und Nannoplankton miteinander zu vergleichen sowie die vorliegenden Resultate soweit möglich denjenigen des Zürichsees gegenüberzustellen.

\section{Artenliste der Phytoplankter}

Da das Plankton nicht in regelmässigen Abständen lebend untersucht worden ist, konnten in der folgenden Aufstellung hauptsächlich nur ausgezählte (konservierte) Organismen berücksichtigt werden. In qualitativer Hinsicht waren demnach einzelne Lücken ünvermeidbar. Das Ziel bei der Verarbeitung des Materials war jedoch, die Hauptformen quantitativ zu erfassen.

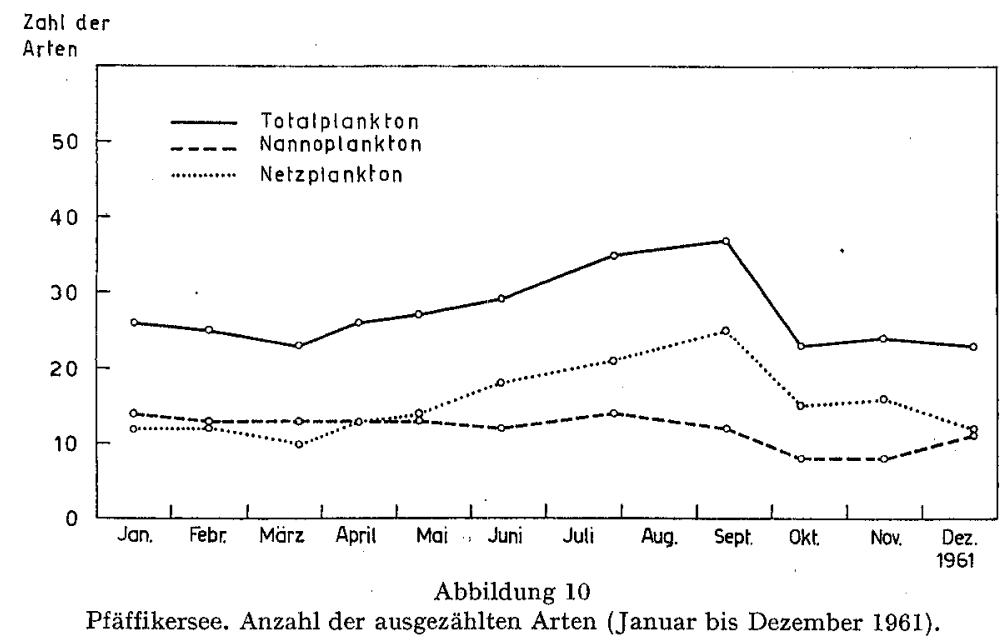

Die Artenzahlen sind in Abb. Io und Tab. I3 wiedergegeben. Rund 80 Formen wurden im Laufe der Untersuchung gefunden, davon etwa 40 Nannoplanktonformen. Pro Monat wurden durchschnittlich is Netzund I2 Nannoplankter ausgezählt. Die wichtigsten Zählformen des Nannoplanktons waren Cryptomonas spp., Rbodomonas spp., Stephanodiscus bantzscbii, kleine, kugelige Formen (Cblorella, Coccomyxa und Ellipsoidion, 
vgl. Abb. $29^{\star}$ ), kleine Flagellaten (Erkenia, Pseudopedinella, Ocbromonas, Bodo, Monas, Heterocbromonas), Selenastrum minutum, Phacotus lenticularis, Lambertia judayi. Unter den Netzplanktonformen seien erwähnt: Apbanotbece clatbrata var. brevis, Aphanizomenon flos-aquae, Fragilaria crotonensis, Asterionella formosa, Melosira granulata var. angustissima, Ceratium birundinella.

\section{CYANOPHYTA}

\section{Artenliste des Pfäffikersees}

Microcystis pulperea (Wood) Forti

Microcystis flos-aquae (Wittrock) Kirchner

Apbanocapsa delicatissima W. et G. E. West

Apbanotbece clatbrata var. brevis Nordstedt Apbanocapsa elacbista W. et G. S. West

Anabaena flos-aquae (Lyngbye) Brébisson

Anabaena planctonica Brunnthaler

Aphanizomenon flos-aquae (L.) Ralfs

Cbroococcus limneticus Lemm.

Coelosphaerium naegelianum Unger

Coelosphaerium kützingianum Nägeli

Gomphosphaeria lacustris Chodat

\section{CHLOROPHYTA}

Euchlorophyceae

Pbacotus lenticularis Ehrenberg

Pandorina morum Bory

Eudorina elegans Ehrenberg

Sphaerocystis scbroeteri Chodat

Gemellicystis neglecta Skuja

Chlorella pyrenoidosa Chick

Pediastrum boryanum (Turpin) Menegh.

Pediastrum duplex Meyen

Oocystis lacustris Chodat

Oocystis marssonii Lemmermann

Nepbrocytium agardbianum Naegeli

Scenedesmus spp.

Actinastrum bantzscbii var. flupiatile Schröd.

Crucigenia rectangularis (A. Braun) Gay

Selenastrum minutum (Naeg.) Cool.

Ankistrodesmus conpolutus Corda

Lambertia judayi (G. M. Smith) Korschik.

Quadrigula pfitzeri Schroeder

Elakatotbrix gelatinosa Wille

Coelastrum reticulatum (Dangeard) Senn.

Coelastrum microporum Naegeli 
Conjugatae

Closterium acutum var. pariabile (Lemm) Krieger

Closterium pronum Bréb.

Cosmarium sp.

Staurastrum gracile Ralfs

CHRYSOPHYTA

Chrysophyceae

Cbrysococcus rufescens Klebs

Erkenia subaequiciliata Skuja

Uroglena volpox Ehrenberg

Kepbyrion inconstans (Schm.) Bourrelly

Kepbyrion moniliferum (Schm.) Bourrelly

Kepbyrion spirale (Lackey) Bourrelly

Dinobryon divergens Imhof

Dinobryon sertularia Ehrenberg

Dinobryon sociale Ehrenberg

Pseudopedinella erkensis Skuja

Bodo sp.

Monas sp.

Heterocbromonas sp.

Diatomeae

Melosira granulata var. angustissima O. M.

Cyclotella comensis Grun.

Cyclotella operculatu (Ag.) Kg.

Cyclotella comta (E.) Kg.

Stephanodiscus bantzscbii Grun.

Tabellaria fenestrata (Lyngb.) Kg.

Diatoma vulgare Bory

Fragilaria crotonensis (Edw.) Kitt.

Fragilaria capucina Desm.

Asterionella formosa Hassall

Synedra acus var. delicatissima (W. Sm.) Grun.

Melosira islandica O. Müller

Diverse Diatomeen

Heterocontae

Ellipsoidion cf. oocystoides Pascher

PYR ROPHYTA

Cryptophyceac

Rbodomonas lacustris Pascher et Ruttner

Rhodomonas lens Pascher et Ruttner

Cryptomonas ovata Ehrenberg

Cryptomonas erosa Ehrenberg 
Cryptomonas erosa var. reflexa Marsson Cyathomonas truncata (Fres.) Fischer Katablepbaris ovalis Skuja

\section{Peridineae}

Gymnodinium lantzschii Utermöhl Gynmodinium beloeticum Penard Peridinium cinctum (Müller) Ehrenberg Peridinium millei Huitf.-Kaas. Ceratium birundinella Schrank

\section{Jahreszeitliches Auftreten}

Qualitativ stimmt die jahreszeitliche Entwicklung des Planktons weitgehend mit dem allgemein bekannten Jahreszyklus eines eutrophen Flachlandsees unseres Gebietes überein. Wie für den Zürichsee ist das Auftreten der Formen während eines.Jahres in Tabelle I2 zusammengestellt (vgl. auch Abb. I3). In den beiden ersten Monaten, Januar und Februar, begannen Cryptomonas ovata und Rhodomonas lacustris zahlreich aufzutreten (Abb. II). Im Februar wurde das Bild von einer kleinen, kugeligen Heterokonten (Abb. 29*) beherrscht. Ausserdem war ein Ocbromonas (Abb. $25^{\star}$ ) und ein Bodo in bemerkenswerter Menge vorhanden. Gegen Ende März hatte eine ausserordentliche Vermehrungsaktivität der obenerwähnten Nannoplankter eingesetzt, die zu einer bräunlichgrünen Vegetationsfärbung geführt hat. Diese starke Entfaltung fand vor allem in den oberen $5 \mathrm{~m}$ statt und wurde namentlich von Cryptomonas opata, Rhodomonas lacustris (Abb. I2), Stepbanodiscus bantzscbii und einer kugeligen Chrysophycee erzeugt. Begleitformen waren Ocbromonas sp., Cbrysococcus rufescens, Gymnodinium belpeticum und Gymnodinium lantzscbii. Ein ähnliches Planktonbild wie der März - nur etwa fünfmal weniger dicht - wies auch der April auf. Im Mai fiel das Auftreten der kleinen Grünalgen Selenastrum minutum, Lambertia judayi und Pbacotus lenticularis auf. Die Euchlorophyceen erreichten ihr qualitatives und quantitatives Maximum im Juni. Dabei waren von Bedeutung Lambertia judayi, Sphaerocystis schroeteri, Oocystis lacustris und Elakatotbrix gelatinosa. Neben den Grünalgen sind wiederum Cryptomonas und Rbodomonasarten die vorherrschenden Formen. Genannt sei ferner die Netzplanktonform Asterionella formosa. Ausser dem Nannoplankter Stepbanodiscus bantzscbii, der sich bis in den Mai hinein in grosser Menge entfaltet hatte, waren andere Kieselalgen nur in geringer Zahl vorhanden. Ganz vereinzelt fanden sich auch Ocbromonas sp. und Uroglena volpox. In Juli verschwanden die Nannoplankter, dafür erreichten Fragilaria 
Tabelle 12

Qualitatipe Zusammensetzung der bäufigsten Pbytoplankter im Pfäflkersee von Fanuar 1961 bis Dezember 1961

Monate 1961

$I$ II III IV V VI VII VIII IX $\mathrm{X}$ XI XII

Aphanothece clathrata var. brevis

Restliche chroococcale Formen

Aphanizomenon flos-aquae

Anabaena flos-aquae

Phacotus lenticularis

Pandorina morum

Sphaerocystis schroeteri

Oocystis lacustris

Dictyosphaerium pulchellum

Selenastrum minutum

Lambertia judayi

Elakatothrix gelatinosa

Chlorella sp., Ellipsoidion sp.

( $\mu$-Algen $\|)$

Closterium aciculare

Cosmarium phaseolus

Staurastrum gracile

Chrysococcus rufescens

Erkenia subaequiciliata

Kephyrion spp.

Dinabryon spp.

Bicoeca multiannulata

Kleine Flagellaten

Melosira granulata var. ang.

Stephanodiscus hantzschii

Synedra acus var. delicatissima

Fragilaria crotonensis

Fragilaria capucina

Tabellaria fenestrata

A sterionella formosa

Rhodomonas lacustris und

Rhodomonas lens

Cryptomonas ovata und

Cryptomonas erosa

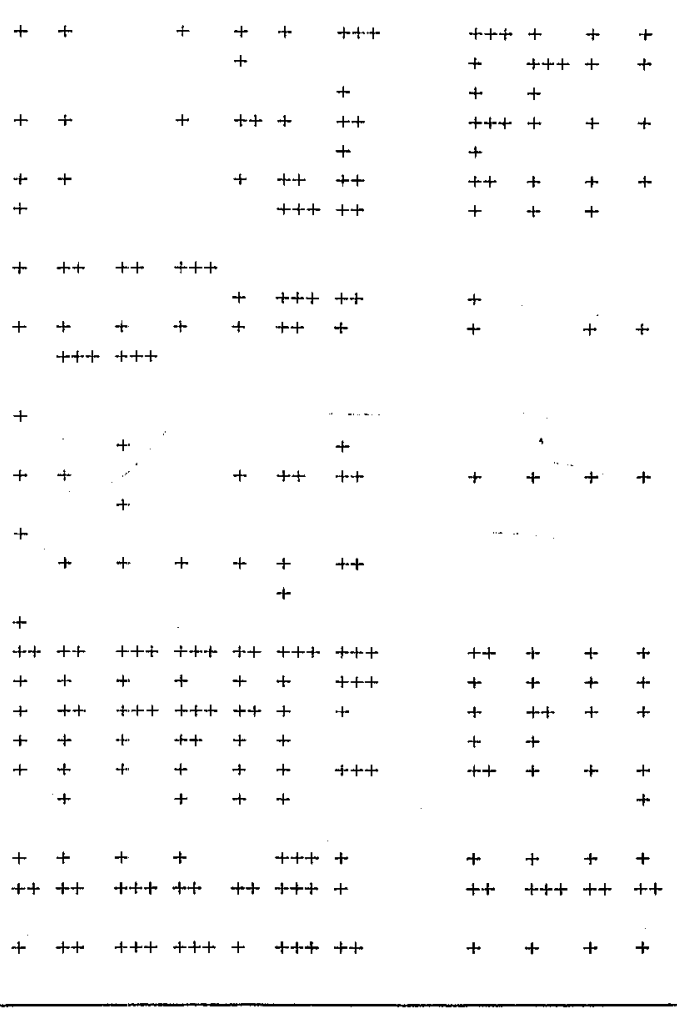

crotonensis und die für den Pfäffikersee charakteristische Melosira granulata var. angustissima ein Entwicklungsmaximum. Eine Anzahl chroococcaler Blaualgen prägten das Planktonbild, so ganz besonders die grossen Kolonien von Aphanotbece clatbrata var. brevis (Abb. II), ferner Microcystis pulverea, Aphanocapsa delicatissima, Coelospbaerium naegelianum, Cbroococcus limneticus und die fädige Form Anabaena flos-aquae.

Die Zusammensetzung des Herbstplanktons änderte sich wesentlich durch die augenfällige Entwicklung des Netzplankters Apbanizomenon flosaquae (Abb. II). Diese Blaualge vermehrte sich schlagartig, so dass im Oktober eine auffallend starke Wasserblüte entstand, die öffentliches Aufsehen 


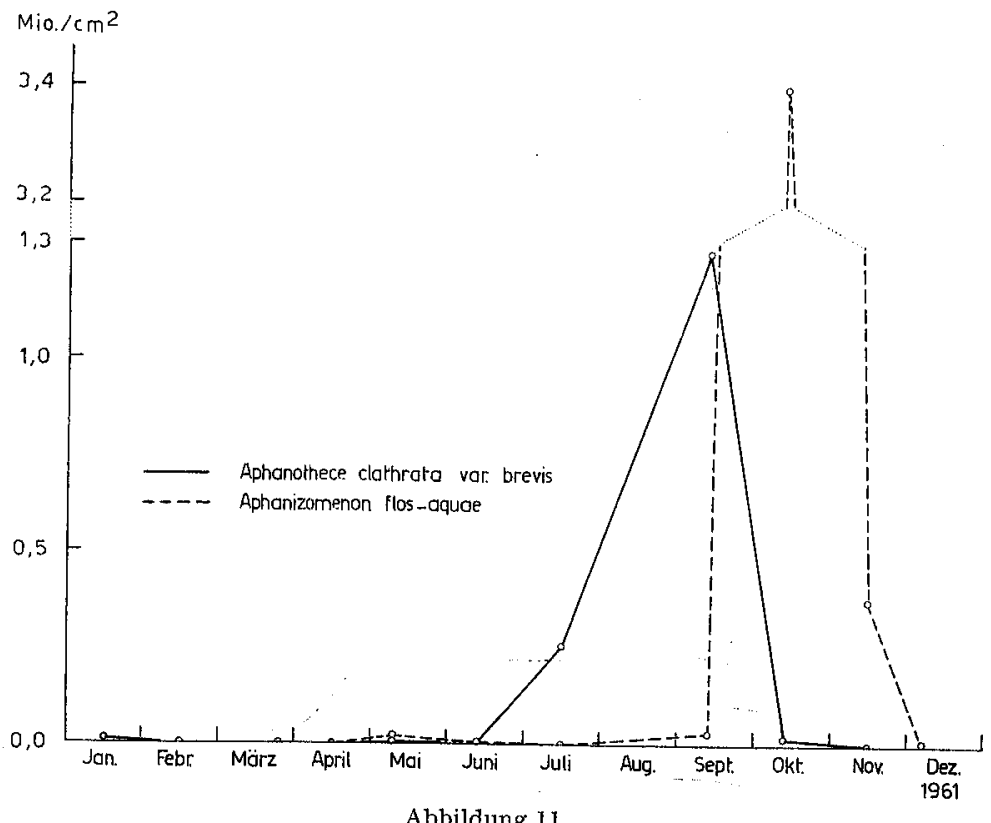

Pfäffikersee. Jahreszeitliches Auftreten der häufigsten Blaualgen Aphanothece clathrata var. brevis und Aphanizomenon flos-aquae (Januar bis Dezember 1961), in Individuenzahlen $/ \mathrm{cm}^{2}$.

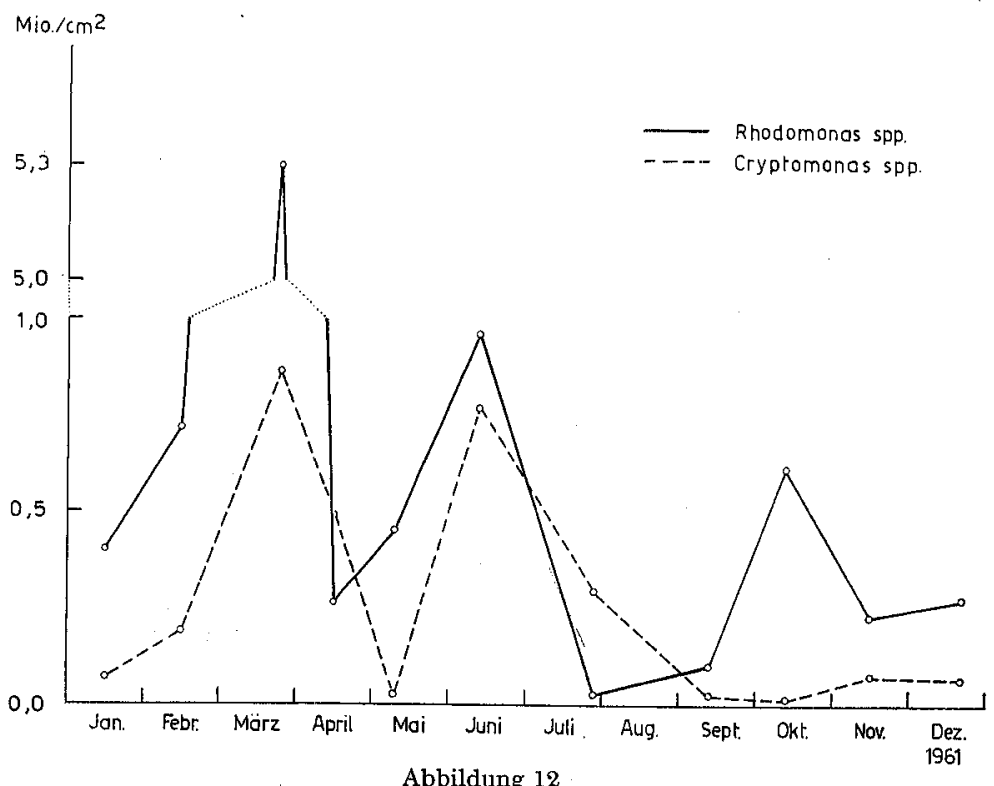

Pfäffikersee. Jahreszeitliches Auftreten der wichtigsten Cryptophyceen Rhodomonas spp. und Cryptomonas spp. (Januar bis Dezember 1961), in Individuenzahlen $/ \mathrm{cm}^{2}$. 


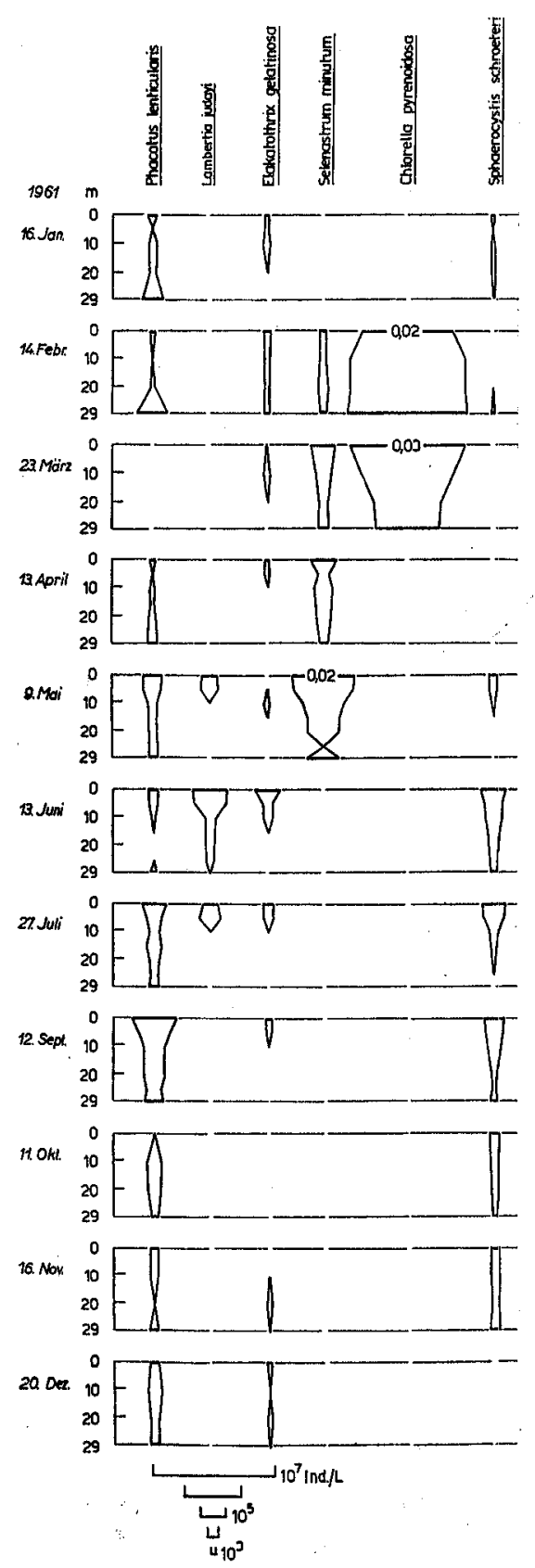


erregte. Die übrigen Planktonformen gingen in dieser Zeit stark zurück. Nur Rhodomonas lacustris - die Allerweltsform - ferner Ceratium birundinella und schon wieder Stephanodiscus bantzschii waren charakteristische Begleitformen dieser Wasserblüte. Während der Wintermonate November und Dezember war Apbanizomenon in geringer Zahl noch vorhanden, Cryptomonas und Rhodomonas rückten wieder in den Vordergrund. Überblicken wir abschliessend noch einmal den Vegetationszyklus des Pfäffikerseeplanktons anhand der Schöpfproben, so können wir das Frühjahrsplankton als reines Nannoplankton, das sogar Vegetationsfärbungen verursachte, mit den Hauptformen Cryptomonas, Rhodomonas, Stephanodiscus, Cblorella und Ellipsoidion, charakterisieren, das im Frühsommer neben den Grünalgen Spbaerocystis und Oocystis vor allem von grösseren Diatomeen wie Fragilaria, Melosira und Synedra abgelöst wurde. Im Sommer und Herbst dominierte das Netzplankton in Form von Blaualgen, wobei Aphanizomenon flos-aquae sich in eindrücklicher Menge als Wasserblüte entwickelt hatte (vgl. auch $A b b$. II, I3).

\section{Vertikale Verteilung der Planktonorganismen}

In Abb. I3 ist die monatliche vertikale Verteilung der wichtigsten pflanzlichen Nanno- und Netzplankter graphisch dargestellt. Die vertikale Verteilung der häufigsten Nannoplankter Rbodomonas und Cryptomonas stimmt auffallend gut mit dem jeweiligen thermischen Zustand des Sees überein. $\mathrm{Zu}$ beachten ist ihr Rückzug ins Epilimnion während der Sommermonate; möglicherweise besteht ein Zusammenhang mit einer gewissen Empfindlichkeit gegenüber niederen Sauerstoffgehalten. Deutlich $\mathrm{zu}$ erkennen ist die bekannte Vorliebe von Gymnodinium belpeticum und Gymnodinium lantzscbii für tiefere Temperaturen. Als typisch epilimnisch erwiesen sich die Grünalgen Lambertia judayi und Elakatotbrix gelatinosa, während die übrigen nannoplanktischen Grünalgen keine prägnanten Schichtungsbilder zeigten. Unter den Netzplanktern ist als einzige auffallend verteilte Alge die Oberflächenform Aphanizomenon flos-aquae hervorzuheben.

Aus den durchschnittlichen Halbwertstiefen geht hervor, dass im Pfäffikersee die stärkste Entwicklung des Nannoplanktons oft in geringerer Wassertiefe stattfand als diejenige des Netzplanktons. Nur zur Zeit der Massenentwicklung von Apbanotbece clatbrata var. brevis im Juli und Apbanizomenon flos-aquae im Oktober waren die Nannoplankter tiefer eingeschichtet als die Netzplankter. 


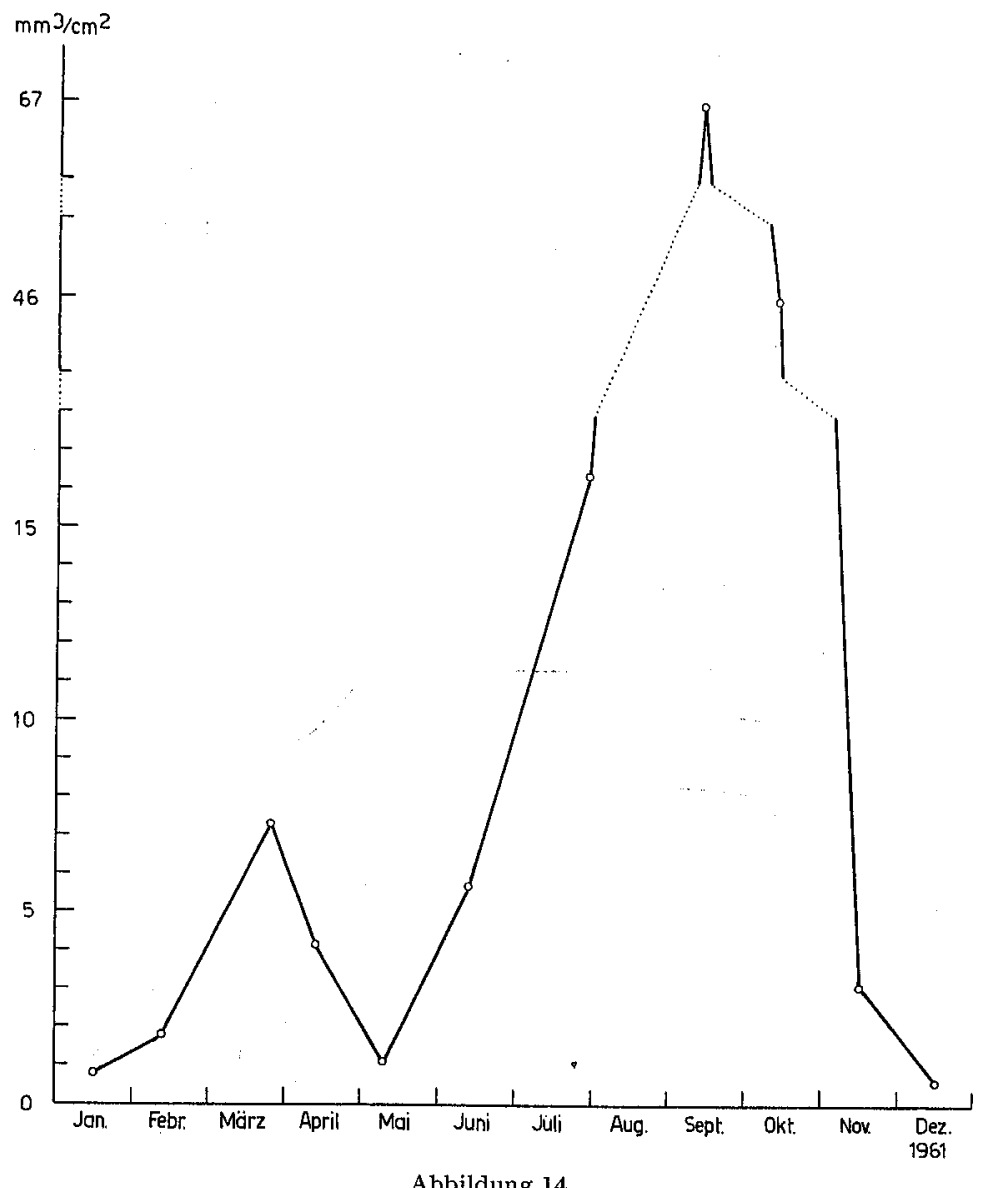

Pfäffikersee. Gesamtbiomasse des Phytoplanktons (Januar bis Dezember 1961), in $\mathrm{mm}^{3} / \mathrm{cm}^{2}$.

5. Biomasse und prozentuale Verteilung des Phytoplanktons

Úberblicken wir die «standing crop»-Kurve des Pfäffikersees im Jahre I96I (Abb. I4), so können wir drei ausgeprägte Biomassemaxima feststellen: eines im Frühling (März), ein höheres im Sommer (Juli) und ein ausserordentliches im Herbst (Oktober). In Abb. Is kommt sehr schön die Gegenläufigkeit Nannoplankton-Netzplankton zum Ausdruck. Dabei beobachtet man eine Nannoplanktonproduktion vor allem in den Frühlingsmonaten bis zum April mit einem Maximum im März und eine zweite, kleine im Juni. In der zweiten Hälfte des Jahres wurde im Vergleich zum Netzplankton nur noch sehr wenig Nannoplankton produ- 


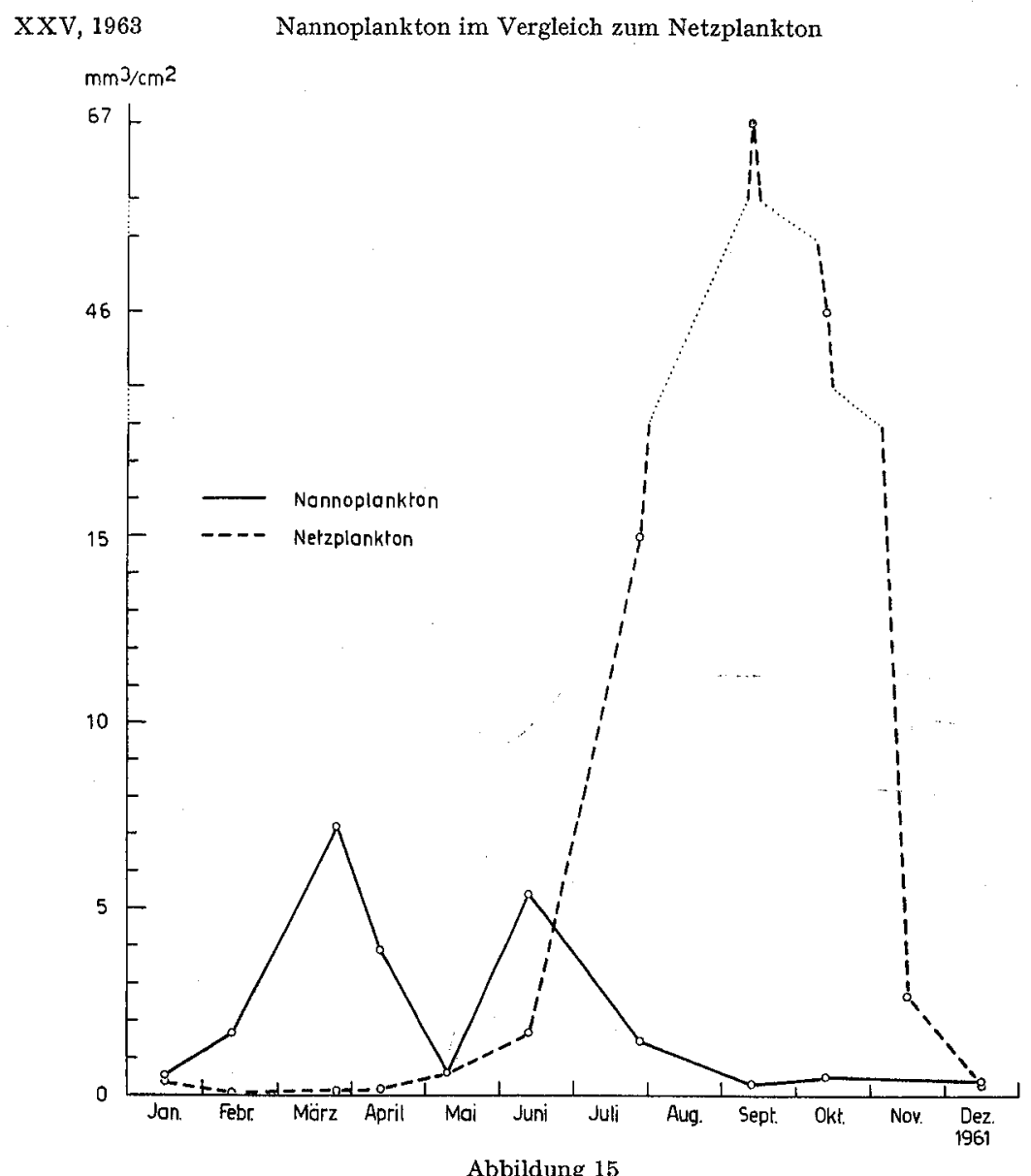

Pfäffikersee. Biomasse des Nannoplanktons im Vergleich zur Biomasse des Netzplanktons (Januar bis Dezember 1961), in $\mathrm{mm}^{3} / \mathrm{cm}^{2}$.

ziert, das Netzplankton hingegen erreichte zwei scharfe Spitzen, die diejenige des Nannoplanktons im Frühling um das Zwei- bis Siebenfache volumenmässig übertrafen. So bildete das Nannoplankton als Jahresmaximum im März $7,2 \mathrm{~mm}^{3}$ organische Substanz unter I $\mathrm{cm}^{2}$, während das Netzplankton im Oktober $45,9 \mathrm{~mm}^{3}$ unter $\mathrm{r} \mathrm{cm}^{2}$ entwickelte. Aus den prozentualen Werten (Abb. I6) und den Individuenzahlen der Nanno- und Netzplankter (Abb. I7) jedoch erkennen wir in eindrücklicher Weise die Bedeutung des Nannoplanktons in der ersten Jahreshälfte.

Es sind vor allem zwei Algengruppen, die diese klar verlaufenden, gegenläufigen Kurvenbilder kennzeichnen. Dies geht aus Abb. I8 hervor: Die Höchstspitzen der Blaualgen fallen genau mit den Biomasse- 


\section{Volumen}

\section{$\%$}

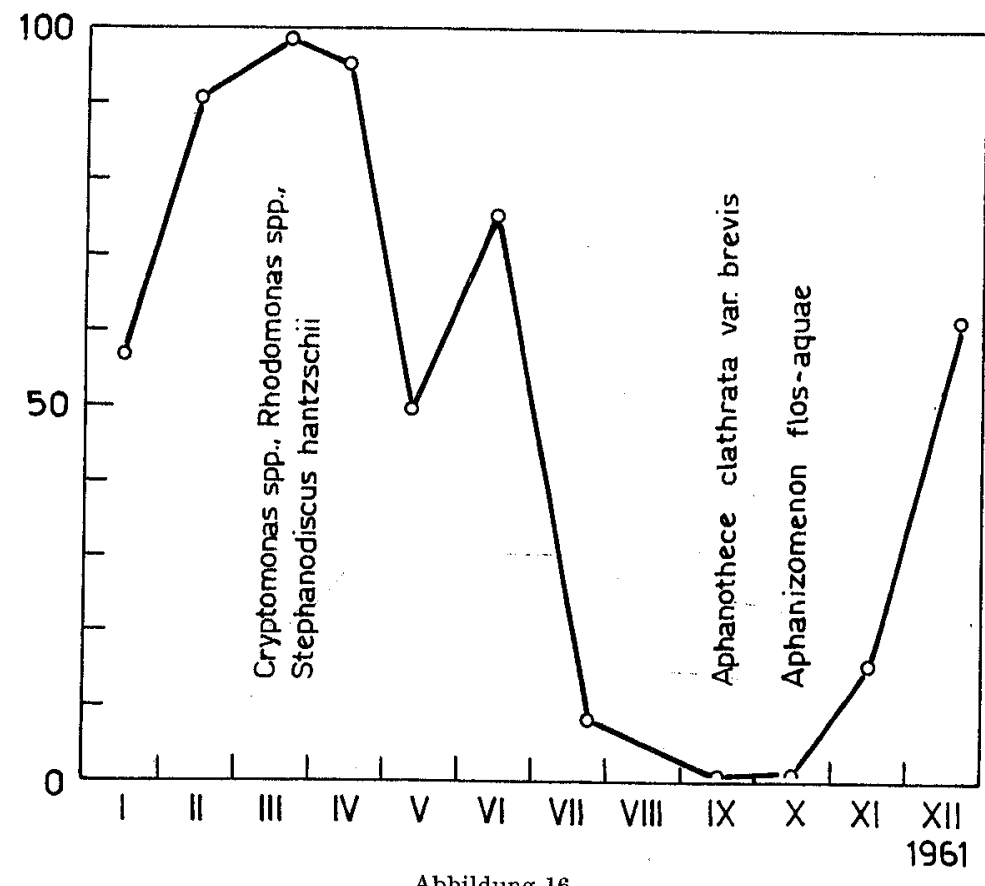

Abbildung 16

Pfäffikersee. Prozentualer Biomasseanteil des Nannoplanktons am Gesamtplankton (Januar bis Dezember 1961).

maxima des Netzplanktons (vgl. auch Abb. 17) im Sommer und Herbst zusammen, während die beiden Nannoplanktonmaxima vor allem durch Cryptophyceae erzeugt wurden.

Die exakten Zahlen der prozentualen Volumenanteile sind in Tab. I3 aufgeführt. Daraus ist ersichtlich, dass die Chrysophyceen volumenmässig überhaupt nicht ins Gewicht fallen. Auch die Euchlorophyceen, von denen bis zu I2 Arten ausgezählt wurden (s. Tab. I3 und I4), machen maximal nur 7,0\% aus und die Diatomeen mit to Zählarten erreichten einen Höchstvolumenanteil von $24,4 \%\left(0,5 \mathrm{~mm}^{3}\right.$ unter $\left.\mathrm{I} \mathrm{cm}^{2}\right)$ im Februar. Die Cryptophyceae jedoch mit nur vier Zählarten bestritten $81,9 \%$ des Gesamtvolumens im März mit $6,0 \mathrm{~mm}^{3}$ unter $\mathrm{I} \mathrm{cm}^{2}$. Der höchste Volumenanteil der Blaualgen, die überhaupt die maximale Biomasse erzeugten, betrug $98,9 \%$ mit $45,4 \mathrm{~mm}^{3}$ unter $\mathrm{I} \mathrm{cm}^{2}$ im Oktober, zur Zeit der Aphanizomenonwasserblüte. Die Desmidiales waren volumenund zahlenmässig unbedeutend, die Peridineae (mit 5 Zählarten), traten 


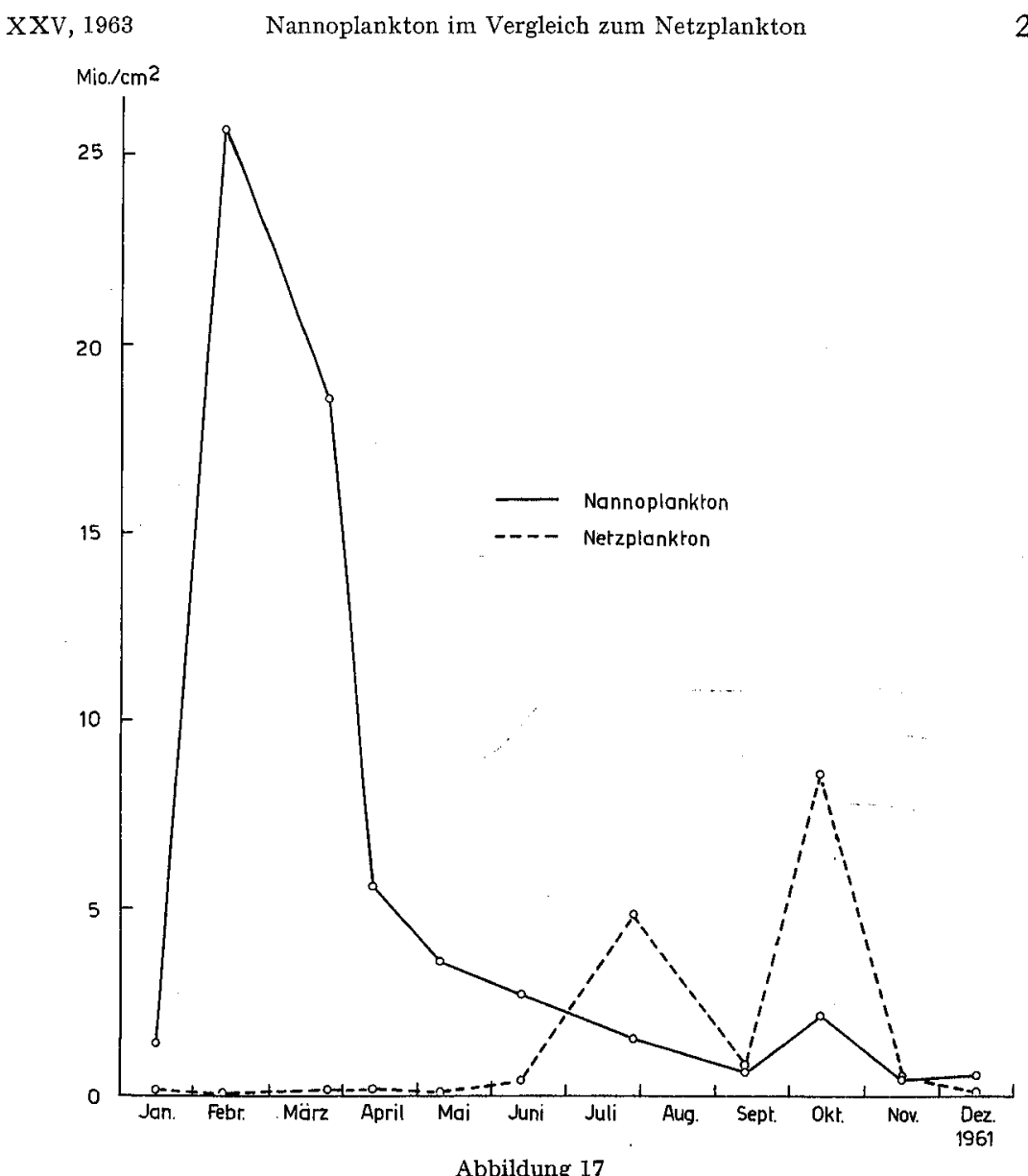

Pfäffikersee. Individuenzahlen des Nannoplanktons im Vergleich zu denjenigen des Netzplanktons (Januar bis Dezember 1961).

mit $17,2 \%$ im April am meisten in Erscheinung und zeigten im September mit $2,7 \mathrm{~mm}^{3} / \mathrm{cm}^{2}$ die grösste Masse. Eine kleine, volumenmässig ebenfalls unwichtige Gruppe wird von einigen kleinen, zum Teil unbestimmbaren Flagellaten (mit Bodo, Monas, Ocbromonas usw.) gebildet.

Um eine Übersicht zu erhalten, wie gross der Anteil des Nannoplanktons in bezug auf die verschiedenen Algengruppen ist, wurden in Abb. I8 die Volumenprozente des Nannoplanktons eingetragen. Die exakten Werte (absolute und prozentuale) sind in Tab. I5 zu finden. Auffallend ist, dass die Cyanophyten reines Netzplankton, die Cryptophyceen und die kleinen Flagellaten reines Nannoplankton darstellen, aber auch die 
Tabelle 13

Aufstellung über die Anzabl der ausgezäblten Arten $(A)$ und prozentualer Anteil derselben am Planktonvolumen $(A V)$ des Pfäffikersees

\begin{tabular}{|c|c|c|c|c|c|c|c|c|c|c|c|c|}
\hline & & & \multicolumn{2}{|c|}{16.1 .61} & \multicolumn{2}{|c|}{14.2 .61} & \multicolumn{2}{|c|}{23.3 .61} & \multicolumn{2}{|c|}{13.4 .61} & \multicolumn{2}{|c|}{9.5 .61} \\
\hline & & & $\mathrm{A}$ & $\mathrm{AV}$ & A & $\mathrm{AV}$ & A & AV & A & $\mathrm{AV}$ & & $\mathrm{AV}$ \\
\hline Bacteriophyta & & & 2 & 0,1 & 1 & + & - & - & 1 & + & 1 & 0,8 \\
\hline Cyanophyta & & & 1 & 33,0 & 1 & 0,2 & - & - & 1 & 0,9 & 2 & 42,8 \\
\hline Euchlorophyceae & & & 4 & 2,2 & 6 & 5,1 & 3 & 0,6 & 4 & 0,1 & 5 & 3,7 \\
\hline Desmidiales & & & 2 & 0,6 & 2 & 0,1 & 2 & - & 1 & 0,2 & 2 & 0,9 \\
\hline Chrysophyceae & & & 2 & - & 1 & - & 1 & - & 1. & - & - & - \\
\hline Kleine Flagellaten & & & 1 & 2,5 & 1 & 2,5 & 1 & 1,6 & 1 & 2,9 & 1 & 4,9 \\
\hline Diatomeae & & & 9 & 9,8 & 9 & 24,4 & 10 & 9,7 & 11 & 15,1 & 10 & 17,9 \\
\hline Cryptophyceae & & & 2 & 46,2 & 2 & 64,1 & 2 & 81,3 & 2 & 63,6 & 2 & 20,3 \\
\hline Peridineae & & & 3 & 5,8 & 2 & 2,6 & 4 & 6,2 & 5 & $5 \quad 17,2$ & 4 & 8.7 \\
\hline Netzplankton & & & 12 & 43,3 & 12 & 9,2 & 10 & 1,5 & 13 & $\begin{array}{ll}3 & 4,7\end{array}$ & 14 & 50,4 \\
\hline Nannoplankton & & & 14 & 56,7 & 13 & 390,8 & 13 & 98,5 & 13 & 395,3 & 13 & 49,6 \\
\hline \multirow[t]{3}{*}{ Total } & & & \multicolumn{2}{|c|}{26100,0} & \multicolumn{2}{|c|}{$25 \quad 100,0$} & \multicolumn{2}{|c|}{23100,0} & \multicolumn{2}{|c|}{$261.00,0$} & \multicolumn{2}{|c|}{27100,0} \\
\hline & \multicolumn{2}{|c|}{13.6 .61} & \multicolumn{2}{|c|}{27.7 .61} & \multicolumn{2}{|c|}{12.9 .61} & \multicolumn{2}{|c|}{11.10 .61} & \multicolumn{2}{|c|}{16.11 .61} & \multicolumn{2}{|c|}{20.12 .61} \\
\hline & A & $\mathrm{AV}$ & A & $\mathrm{AV}$ & A & $\mathrm{AV}$ & A & $\mathrm{AV}$ & A & $\mathrm{AV}$ & $\mathrm{A}$ & $\mathrm{AV}$ \\
\hline Bacteriophyta & 1 & + & 2 & + & 1 & - & 1 & + & 1 & - & - & + \\
\hline Cyanophyta & 2 & 5,5 & 5 & 77,3 & 5 & 95,1 & 3 & 98,1 & 3 & 82,1 & 2 & 32,3 \\
\hline Euchlorophyceae & 6 & 7,0 & 10 & 1,9 & 12 & 0,4 & 4 & + & 5 & 1,1 & 6 & 1,6 \\
\hline Desmidiales & 2 & 1,0 & 3 & 0,1 & 3 & + & 2 & + & 2 & 0,1 & 2 & 0,3 \\
\hline Chrysophyceae & 2 & - & 1 & - & 1 & - & - & - & - & - & - & - \\
\hline Kleine Flagellaten & 1 & 1,0 & 1 & 0,5 & 1 & + & 1 & + & 1 & 0,2 & 1 & 0,9 \\
\hline Diatomeae & 9 & 7,0 & 7 & 11,6 & 9 & 0,3 & 8 & 0,7 & 7 & 1,1 & 8 & 6,3 \\
\hline Cryptophyceae & 2 & 72,2 & 2 & 7,7 & 2 & 0,2 & 2 & 0,6 & 2 & 14,3 & 2 & 50,7 \\
\hline Peridineae & 4 & 6,3 & 4 & 0,9 & 3 & 4,0 & 2 & 0,6 & 3 & 1,1 & 2 & 7,1 \\
\hline Netzplankton & 17 & 24,8 & 21 & 91,4 & 25 & 99,5 & 15 & 98,9 & 16 & 84,4 & 12 & 38,5 \\
\hline Nannoplankton & 12 & 75,2 & 14 & 8,6 & 12 & 0,5 & 8 & 1,1 & 8 & 15,6 & 11 & 61,5 \\
\hline Total & 29 & $1.00,0$ & 351 & 100,0 & 37 & 100,0 & 23 & 100,0 & 24 & 100,0 & 23 & 100,0 \\
\hline
\end{tabular}

Masse der Peridineen das ganze Jahr hindurch hauptsächlich von Nannoplanktern geformt wird, während sich bei den Diatomeen und Euchlorophyceen je nach Monat mehr Netz- oder mehr Nannoplanktonformen entwickeln.

\section{Nannoplankton und Stoffkreislauf}

Wie aus den vorstehenden Darstellungen hervorgeht, entwickelt sich im Pfäffikersee gleich nach der Frühjahrsvollzirkulation und der ersten Erwärmung der Oberflächenschichten fast explosionsartig eine riesige Individuenzahl von sozusagen reinem Nannoplankton. Diese starke Entfaltung ist meistens mit einer Vegetationsfärbung verbunden. Die ausser- 
Tabelle 14

Pbytoplanktonpolumen des Pfäffikersees in $10^{6} \mu^{3}$ unter $1 \mathrm{~cm}^{2}$

\begin{tabular}{|c|c|c|c|c|c|c|}
\hline & & 16.1 .61 & 14.2 .61 & 23.3 .61 & 13.4 .61 & 9.5 .61 \\
\hline Bacteriophyta & & 1,0 & 0,1 & - & - & 9,0 \\
\hline Cyanophyta & & 267,3 & 2,9 & - & 34,6 & 495,2 \\
\hline Euchlorophyceae & & 19,2 & 93,4 & 44,0 & 2,4 & 42,5 \\
\hline Desmidiales & & 2,9 & 2,2 & 0,3 & 7,3 & 9,9 \\
\hline Chrysophyceae & & - & - & - & - & - \\
\hline Kleine Flagellaten & & 19,8 & 45,1 & 115,7 & 119,4 & 57,0 \\
\hline Diatomeae & & 79,2 & 461,9 & 708,6 & 615,2 & 206,6 \\
\hline Cryptophyceae & & 373,2 & 1167,4 & 5975,3 & 2591,0 & 232,6 \\
\hline Peridineae & & 47,2 & 47,7 & 450,3 & 698,4 & 100,7 \\
\hline Netzplankton & & 349,7 & 167,9 & 108,0 & 187,6 & 581,3 \\
\hline Nannoplankton & & 458,1 & 1652,8 & 7186,2 & 3878,7 & 572,2 \\
\hline \multirow[t]{2}{*}{ Total } & & 807,8 & 1820,7 & 7294,2 & 4066,3 & 1153,5 \\
\hline & 13.6 .61 & 27.7 .61 & 12.9 .61 & 11.10 .61 & 16.11 .61 & 20.12 .61 \\
\hline Bacteriophyta & 3,8 & 0,6 & - & 0,02 & - & 0,02 \\
\hline Cyanophyta & 316,3 & 12690,2 & 62909,6 & 45411,2 & 2534,3 & 243,2 \\
\hline Euchlorophyceae & 401,3 & 314,5 & 255,9 & 31,8 & 34,5 & 11,5 \\
\hline Desmidiales & 60,1 & 17,3 & 20,8 & 0,8 & 3,0 & 2,3 \\
\hline Chrysophyceae & - & - & - & - & - & - \\
\hline Kleine Flagellaten & 57,6 & 75,0 & 11,9 & 30,9 & 4,7 & 6,6 \\
\hline Diatomeae & 401,4 & 1910,0 & 179,8 & 310,4 & 33,2 & 51,5 \\
\hline Cryptophyceae & 4156,1 & 1260,5 & 164,6 & 260,8 & 440,6 & 378,5 \\
\hline Peridineae & 368,5 & 141,5 & 2684,0 & 276,1 & 33,7 & 53,2 \\
\hline Netzplankton & 1429,3 & 14994,6 & 66919,7 & 45857,1 & 2604,4 & 287,5 \\
\hline Nannoplankton & 4331,7 & 1408,0 & 306,1 & 464,9 & 479,6 & 459,3 \\
\hline Total & 5761,2 & 16402,6 & 67225,8 & 46322,0 & 3084,0 & 746,8 \\
\hline
\end{tabular}

ordentliche Aktivität der Organismen wird nicht nur in ihrer Dichte, sondern auch in den chemischen Daten sichtbar.

In nachstehender Tab. I6 seien einige Beispiele, in denen die Beziehung zwischen Nannoplankton und Stoffumsatz in prägnanter Weise gezeigt werden, dargestellt.

Der Frühling I96I begann mit auffallend warmem, sonnigem Wetter (Ende Februar bis Mitte März), so dass am 21. 3. 6r die grosse Individuenzahl von rund 28 Mill. Indiv./1 an der Oberfläche festgestellt werden konnte, bei einer Sichttiefe von $2,5 \mathrm{~m}$. In Io $\mathrm{m}$ Tiefe waren noch rund 6 Mio. Indiv./1 vorhanden. Diese Frühjahrsentfaltung von reinem Nannoplankton hatte an der Oberfläche den hohen Sauerstoffgehalt:von I $5,3 \mathrm{mg} / 1$ zur Folge, während am Grund $8,7 \mathrm{mg} / \mathrm{l}$ bestimmt wurden. Beachtenswert war ferner die beträchtliche Zehrung des Nitrats, Phosphats und der Kieselsäure. 


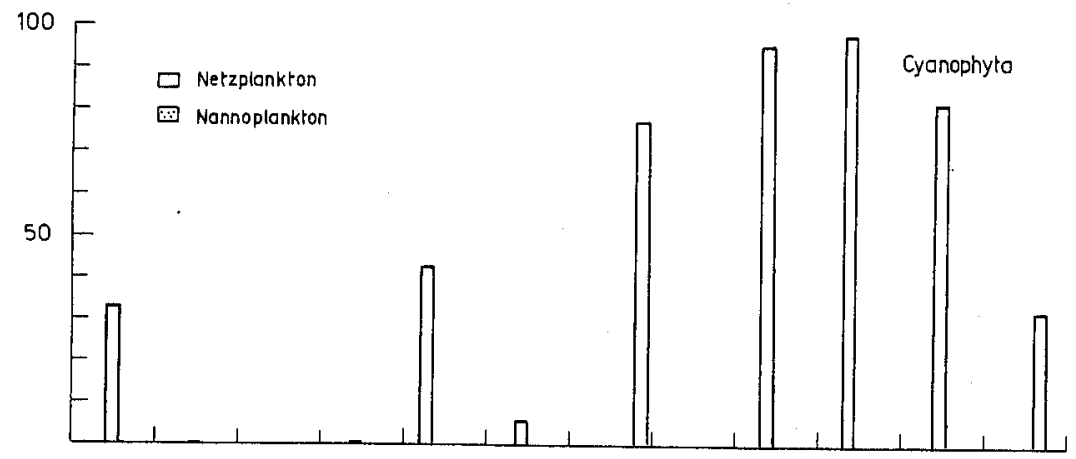

20

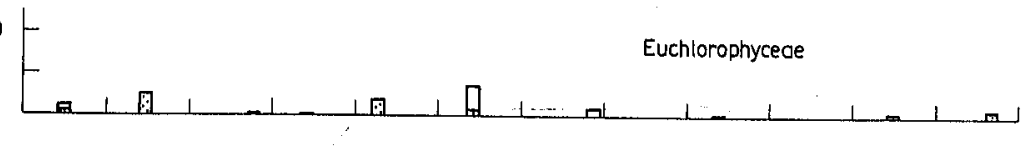

30

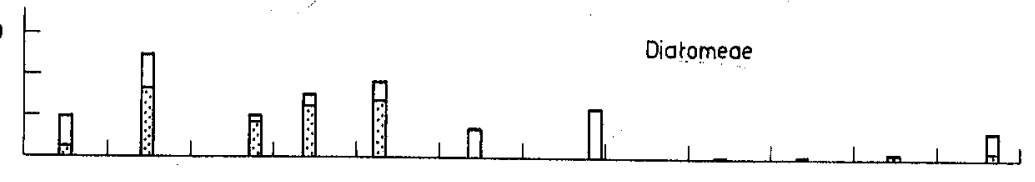

$90+$
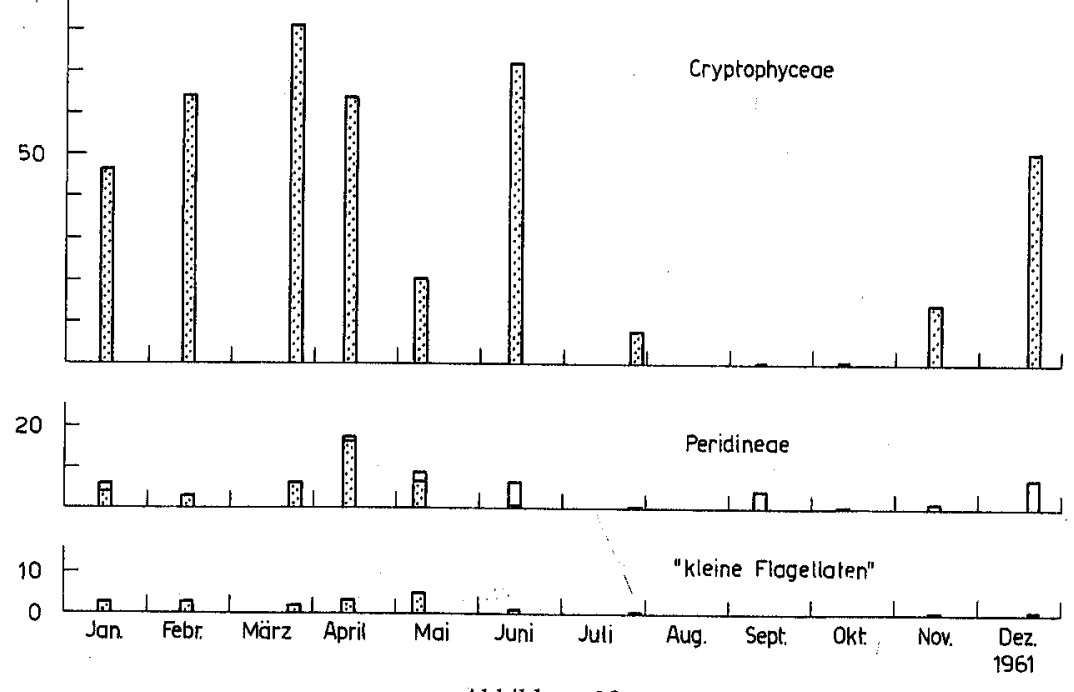

Abbildung 18

Pfäffikersee. Prozentualer Biomasseanteil der verschiedenen Algengruppen am gesamten Phytoplankton, unter Berücksichtigung des Netz- und Nannoplanktons (Januar bis Dezember 1961). 
Tabelle 15 a

Nannoplanktonvolumen des Pfäfikersees in $10^{6} \mu^{3}$ unter $1 \mathrm{~cm}^{2}$

\begin{tabular}{|c|c|c|c|c|c|c|}
\hline & & 16.1 .61 & 14.2 .61 & 23.3 .61 & 13.4 .61 & 9.5 .61 \\
\hline Bacteriophyta & & 0,1 & 0,1 & - & - & 9,0 \\
\hline Cyanophyta & & $\overline{-}$ & $\overline{-}$ & - & - & - \\
\hline Euchlorophyceae & & 9,7 & 92,7 & 44,0 & 2,4 & 36,8 \\
\hline Desmidiales & & - & - & - & - & - \\
\hline Chrysophyceae & & - & - & - & - & $-\overline{0}$ \\
\hline Kleine Flagellaten & & 19,8 & 45,1 & 115,7 & 117,4 & 57,0 \\
\hline Diatomeae & & 21,6 & 299,8 & 613,8 & 501,2 & 159,2 \\
\hline Cryptophyceae & & 373,2 & 1167,4 & 5975,3 & 2591,0 & 232,6 \\
\hline Peridineae & & 32,8 & 47,7 & 437,4 & 666,7 & 77,6 \\
\hline \multirow[t]{2}{*}{ Total } & & 458,1 & 1652,8 & 7186,2 & 3878,7 & 572,2 \\
\hline & 13.6 .61 & 27.7 .61 & 12.9 .61 & 11.10 .61 & 16.11 .61 & 20.12 .61 \\
\hline Bacteriophyta & 3,8 & 0,6 & - & 0,02 & - & 0,02 \\
\hline Cyanophyta & - & - & - & - & - & $\overline{0}$ \\
\hline Euchlorophyceae & 63,2 & 25,2 & 116,3 & 7,2 & 2,9 & 9,9 \\
\hline Desmidiales & - & - & - & - & - & - \\
\hline Chrysophyceae & - & - . & - & 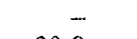 & - & - \\
\hline Kleine Flagellaten & 57,6 & 75,0 & 11,3 & 30,9 & 4,7 & 6,6 \\
\hline Diatomeae & 0,9 & 13,8 & 7,3 & 166,0 & 10,3 & 11,1 \\
\hline Cryptophyceae & 4156,1 & 1260,5 & 164,6 & 260,8 & 440,6 & 378,5 \\
\hline Peridineae & 50,1 & 32,9 & 6,1 & - & 21,1 & 53,2 \\
\hline Total & 4331,7 & 1408,0 & 306,1 & 464,9 & 479,6 & 459,3 \\
\hline
\end{tabular}

Am 9. 5. 61 befand sich an der Oberfläche und in $5 \mathrm{~m}$ Tiefe die viel kleinere Individuenzahl von nur 2,7 Millionen (fast reines Nannoplankton), der Sauerstoffgehalt betrug an der Oberfläche $10,5 \mathrm{mg} / 1$; am Grund war er infolge von Zehrungsvorgängen auf $5 \mathrm{mg} / \mathrm{l}$ zurückgegangen. Noch sprechender waren die Analysenresultate ein Jahr später. Das Frühjahr I962 zeichnete sich durch anhaltend schlechte, kalte Witterung aus im Gegensatz zum Frühjahr I96I. Das kühle Wetter spiegelte sich in der relativ schwachen Planktonentwicklung von $\mathrm{I}, 4 \mathrm{Mio}$. Indiv./l wider und in der von der Oberfläche bis zum Grund gleichförmig verlaufenden Sauerstoffmenge und der übrigen gelösten Stoffe. Im Mai begann dann, wohl etwas verspätet, aber um so heftiger, die Nannoplanktonzeit des Frühjahrs, wobei im Oberflächenwasser 85,7 Mio. Indiv./l gezählt wurden. Der Sauerstoffgehalt betrug daselbst 19,6 mg/l, und die Nitrate, Phosphate und Kieselsäure waren zum grössten Teil aufgebraucht.

Die aufgeführten Beispiele sind besonders klar und eindeutig, da sie aus der Zeit der beginnenden Frühjahrsstagnation stammen, wo kleinste Anderungen in der chemischen Schichtung noch viel besser wahrgenom- 
Tabelle $15 \mathrm{~b}$

Nannoplanktonvolumenprozente des Pfäflikersees

\begin{tabular}{|c|c|c|c|c|c|c|}
\hline & & 16.1 .61 & 14.2 .61 & 23.3 .61 & 13.4 .61 & 9.5 .61 \\
\hline Bacteriophyta & & 0,1 & + & - & - & 0,8 \\
\hline Cyanophyta & & - & - & - & - & - \\
\hline Euchlorophyceae & & 1,2 & 5,1 & 0,6 & 0,1 & 3,2 \\
\hline Desmidiales & & - & - & - & - & - \\
\hline Chrysophyceae & & - & & - & - & - \\
\hline Kleine Flagellaten & & 2,5 & 2,5 & 1,6 & 2,9 & 4,9 \\
\hline Diatomeae & & 2,7 & 16,5 & 8,4 & 12,3 & 13,8 \\
\hline Cryptophyceae & & 46,2 & 64,1 & 81,9 & 63,6 & 20,3 \\
\hline Peridineae & & 4,0 & 2,6 & 6,0 & 16,3 & 6,7 \\
\hline Total & & 56,7 & 90,8 & 98,5 & 95,2 & 49,7 \\
\hline & 13.6 .61 & 27.7 .61 & 12.9 .61 & 11.10 .61 & 16.11 .61 & 20.12 .12 \\
\hline Bacteriophyta & + & + & & + & - & - \\
\hline Cyanophyta & - & - & & - & - & - \\
\hline Euchlorophyceae & 1,1 & 0,2 & 0,2 & + & $\cdot+$ & 1,3 \\
\hline Desmidiales & - & - & & - & - & - \\
\hline Chrysophyceae & - & - & - & - & - & - \\
\hline Kleine Flagellaten & 1,0 & 0,5 & + & 0,1 & 0,2 & 0,9 \\
\hline Diatomeae & + & 0,1 & + & 0,4 & 0,3 & 1,5 \\
\hline Cryptophyceae & 72,2 & 7,7 & 0,2 & 0,6 & 74,3 & 50,7 \\
\hline Peridineae & 0,9 & 0,2 & + & - & 0,7 & 7,1 \\
\hline Total & 75,2 & 8,7 & 0,5 & 1,1 & 15,5 & 61,5 \\
\hline
\end{tabular}

men und erklärt werden können. Schwieriger ist es, ein analoges Beispiel für das Netzplankton darzulegen.

Am II. Oktober I96I war der See überdeckt mit einer Wasserblüte von Apbanizomenon flos-aquae. An der Oberfläche waren r6,6 Mio. Fäden/1 bestimmt worden. Im Monat vorher waren erst wenige Fäden von Apbanizomenon festgestellt worden. Die Sauerstoffwerte waren an der Oberfläche für solche Verhältnisse jedoch erstaunlich niedrig $(8,6 \mathrm{mg} / \mathrm{l})$. Vermutlich hatte schon eine Teilzirkulation stattgefunden (vgl. die Werte des Septembers), doch, trotzdem, schien durch diese Apbanizomenonentwicklung nur wenig Sauerstoff produziert worden zu sein (vgl. Summe des Sauerstoffs von O-I5 m im September und Oktober).

Aber auch im Juli r96I, zur Stagnationszeit, wurde gegenüber dem Nannoplankton viel Netzplankton ( 1,2 Mio. Indiv. und Kol./l) entwickelt. Volumenmässig war eine zweimal so grosse Biomasse vorhanden als zur Zeit der Nannoplanktonentwicklung im März. Die Sauerstoffmengen jedoch waren eher gering ( $14,5 \mathrm{mg} / \mathrm{l}$ ). Dies könnte möglicherweise mit der grossen Menge des zur Zeit der Probenahme vorhandenen 
Tabelle 16

Einige Beispiele von Planktonentwicklungen im Pfäffikersee und entsprecbende cbemiscbe Daten

\begin{tabular}{|c|c|c|c|c|c|}
\hline 21.3 .61 & $0 \mathrm{~m}$ & $5 \mathrm{~m}$ & $10 \mathrm{~m}$ & $20 \mathrm{~m}$ & $30 \mathrm{~m}$ \\
\hline \multicolumn{6}{|l|}{$\begin{array}{l}\text { Wichtigste Planktonorganismen } \\
\text { Indiv./1 }\end{array}$} \\
\hline Chlovella pyr., Ellipsoidion sp. & 8500000 & - & 4300000 & 1600000 & 1400000 \\
\hline Diverse Flagellaten & 1.300000 & - & 629000 & 5500 & 13800 \\
\hline Stephanodiscus hantzschii & 6300000 & - & 437000 & 131000 & 160000 \\
\hline Cryptomonas ovata & 1600000 & - & 51000 & 2500 & 0 \\
\hline Rhodomonas lacustris & 10000000 & - & 219000 & 22300 & 10000 \\
\hline Total & 27700000 & - & 5636000 & 1761300 & 1583800 \\
\hline \multicolumn{6}{|l|}{ Physikalisch-chemische Daten } \\
\hline Temperatur ${ }^{\circ} \mathrm{C}$ & 6,4 & - & 6,0 & 4,4 & 4,3 \\
\hline Sauerstoff $(\mathrm{O})$ & 15,3 & - & 13,6 & 10,5 & 8,6 \\
\hline Nitrat $(\mathrm{N})$ & 0,34 & - & 0,50 & 0,76 & 0,76 \\
\hline Phosphat (P) & 0,060 & - & 0,070 & 0,122 & 0,130 \\
\hline Kieselsäure $\left(\mathrm{SiO}_{2}\right) \mathrm{mg} / \mathrm{l}$ & 2,00 & - & 2,40 & 3,40 & 3,70 \\
\hline Karbonathärte frz. $\mathrm{H}^{\circ}$ & 18,9 & - & 18,9 & 18,7 & 18,8 \\
\hline \multicolumn{6}{|l|}{9.5 .61} \\
\hline \multicolumn{6}{|l|}{$\begin{array}{l}\text { Wichtigste Planktonorganismen } \\
\text { Indiv./1 }\end{array}$} \\
\hline Selenastrum minutum & 1300000 & 1200000 & 341000 & 146000 & 137000 \\
\hline Diverse Flagellaten & 112000 & 131000 & 218000 & 280000 & 287000 \\
\hline Stephanodiscus hantzschii & 593000 & 826000 & 3400 & 0 & 1100000 \\
\hline Rhodomonas lacustris & 702000 & 520000 & 17000 & 5900 & 3200 \\
\hline Total & 2707000 & 2677000 & 579400 & 577900 & 1527200 \\
\hline \multicolumn{6}{|l|}{ Physikalisch-chemische Daten } \\
\hline Temperatur ${ }^{\circ} \mathrm{C}$ & 12,8 & 9,2 & 7,1 & 4,6 & 4,3 \\
\hline Sauerstoff $(O)$ & 10,5 & 10,3 & 7,9 & 6,1 & 3,0 \\
\hline Nitrat $(\mathrm{N})$ & 0,68 & - & 0,86 & 1,20 & 1,20 \\
\hline Phosphat $[\mathrm{P}] \quad \mathrm{mg} / \mathrm{l}$ & 0,060 & - & 0,090 & 0,110 & 0,150 \\
\hline Kieselsäure $\left(\mathrm{SiO}_{2}\right) \mathrm{mg} / \mathrm{l}$ & 1,80 & -- & 2,20 & 3,20 & 4,96 \\
\hline Karbonathärte frz. $\mathrm{H}^{\circ}$ & 19,3 & - & 19,3 & 19,2 & 19,3 \\
\hline \multicolumn{6}{|l|}{27.7 .61} \\
\hline \multicolumn{6}{|l|}{$\begin{array}{l}\text { Wichtigste Planktonorganismen } \\
\text { Indiv./1 }\end{array}$} \\
\hline Aphanothece clathrata var. brevis & 237000 & 314000 & 108000 & 7200 & 8400 \\
\hline Fragilaria crotonensis & 428000 & 225000 & 38200 & 320 & 530 \\
\hline Melosira granulata var. gran. & 253000 & 75400 & 4200 & 430 & \\
\hline Diverse Flagellaten & 108000 & 147000 & 93500 & 111000 & 11700 \\
\hline Total & 1026000 & 761000 & 243900 & 118900 & 20600 \\
\hline \multicolumn{6}{|l|}{ Physikalisch-chemische Daten } \\
\hline Temperatur ${ }^{\circ} \mathrm{C}$ & 21,6 & 18,4 & 16,3 & 10,3 & 8,0 \\
\hline Sauerstoff $(O)$ & 14,5 & 11,0 & 5,2 & 0,7 & 0,7 \\
\hline Nitrat $(\mathrm{N})$ & 0,04 & - & 0,32 & 0,66 & 0,34 \\
\hline Phosphat $(\mathrm{P}) \quad \mathrm{mg} / \mathrm{l}$ & - & - & 0,075 & 0,155 & 0,258 \\
\hline Kieselsäure $\left(\mathrm{SiO}_{2}\right) \mathrm{mg} / 1$ & 0,25 & - & 2,17 & 3,4 & 4,74 \\
\hline Karbonathärte frz. $\mathrm{H}^{\circ}$ & 17,6 & - & 18,9 & 19,3 & 19,5 \\
\hline
\end{tabular}


Tabelle 16 (Fortsetzung)

\begin{tabular}{|c|c|c|c|c|c|}
\hline 12.9 .61 & $0 \mathrm{~m}$ & $5 \mathrm{~m}$ & $10 \mathrm{~m}$ & $20 \mathrm{~m}$ & $30 \mathrm{~m}$ \\
\hline \multicolumn{6}{|c|}{$\begin{array}{l}\text { Wichtigste Planktonorganismen } \\
\text { Indiv./1 }\end{array}$} \\
\hline $\begin{array}{l}\text { Aphanothece clathrata var. } \\
\text { Phacotus lenticularis } \\
\text { Rhodomonas lacustris }\end{array}$ & $\begin{array}{l}118000 \\
485000 \\
166000\end{array}$ & $\begin{array}{r}97900 \\
1.50000 \\
168000\end{array}$ & $\begin{array}{r}109000 \\
55200 \\
2300\end{array}$ & $\begin{array}{r}2200000 \\
49900 \\
0\end{array}$ & $\begin{array}{r}210 \\
37200 \\
2300\end{array}$ \\
\hline Total & 769000 & 415900 & 166500 & 2249900 & 39700 \\
\hline \multicolumn{6}{|c|}{ Physikalisch-chemische Daten } \\
\hline $\begin{array}{ll}\text { Temperatur }{ }^{\circ} \mathrm{C} & \\
\text { Sauerstoff }(\mathrm{O}) & \mathrm{mg} / 1 \\
\text { Nitrat }(\mathrm{N}) & \mathrm{mg} / \mathrm{l} \\
\text { Phosphat }(\mathrm{P}) & \mathrm{mg} / \mathrm{l} \\
\text { Kieselsäure }\left(\mathrm{SiO}_{2}\right) & \mathrm{mg} / \mathrm{l} \\
\text { Karbonathärte frz. } \mathrm{H}^{\circ}\end{array}$ & $\begin{array}{l}19,2 \\
15,3 \\
0,16 \\
0,025 \\
1,20 \\
18,2\end{array}$ & $\begin{array}{l}17,2 \\
8,5 \\
- \\
- \\
-\end{array}$ & $\begin{array}{l}16,5 \\
4,8 \\
0,20 \\
0,042 \\
1,70 \\
18,5\end{array}$ & $\begin{array}{c}11,4 \\
0,2 \\
0,40 \\
0,152 \\
3,80 \\
19,6\end{array}$ & $\begin{array}{l}8,6 \\
0,4 \\
0,14 \\
0,215 \\
4,95 \\
19,9\end{array}$ \\
\hline
\end{tabular}

11.10 .61

Wichtigste Planktonorganismen

Indiv./1

\begin{tabular}{|c|c|c|c|c|c|}
\hline $\begin{array}{l}\text { Aphanizomenon flos-aquae } \\
\text { Stephanodiscus hantzschii } \\
\text { Rhodomonas lacustris }\end{array}$ & $\begin{array}{r}16600000 \\
1400000 \\
1200000\end{array}$ & $\begin{array}{l}- \\
- \\
-\end{array}$ & $\begin{array}{r}0 \\
47800 \\
0\end{array}$ & $\begin{array}{r}10800 \\
266600 \\
0\end{array}$ & $\begin{array}{r}18600 \\
13300 \\
2700\end{array}$ \\
\hline Total & 19200000 & - & 47800 & 277400 & 34600 \\
\hline \multicolumn{6}{|c|}{ Physikalisch-chemische Daten } \\
\hline $\begin{array}{ll}\text { Temperatur }{ }^{\circ} \mathrm{C} \\
\text { Sauerstoff }(\mathrm{O}) & \mathrm{mg} / \mathrm{l} \\
\text { Nitrat }(\mathrm{N}) & \mathrm{mg} / 1 \\
\text { Phosphat }(\mathrm{P}) & \mathrm{mg} / \mathrm{l} \\
\text { Kieselsäure }\left(\mathrm{SiO}_{2}\right) & \mathrm{mg} / 1 \\
\text { Karbonathärte frz. } \mathrm{H}^{\circ}\end{array}$ & $\begin{array}{c}17,7 \\
8,6 \\
0,04 \\
0,14 \\
1,60 \\
17,4\end{array}$ & $\begin{array}{r}16,6 \\
7,8 \\
- \\
- \\
- \\
-\end{array}$ & $\begin{array}{l}16,4 \\
7,0 \\
0,06 \\
0,136 \\
1,56 \\
17,3\end{array}$ & $\begin{array}{c}13,1 \\
0,4 \\
0,14 \\
0,140 \\
3,34 \\
19,6\end{array}$ & $\begin{array}{l}10,3 \\
0,3 \\
0,06 \\
0,142 \\
3,90 \\
19,8\end{array}$ \\
\hline
\end{tabular}

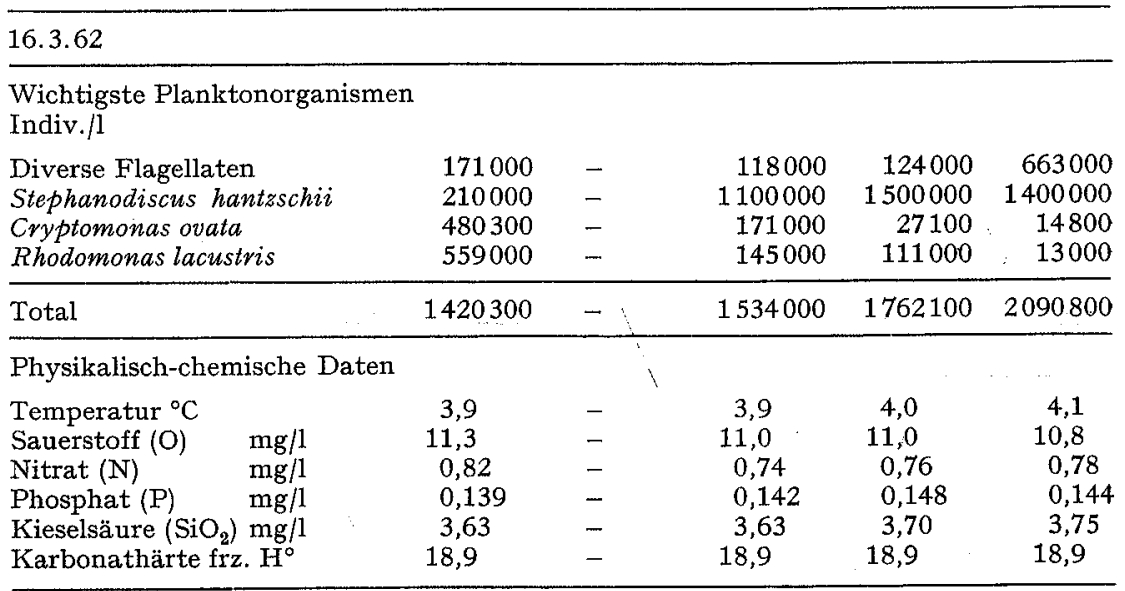


Tabelle 16 (Fortsetzung)

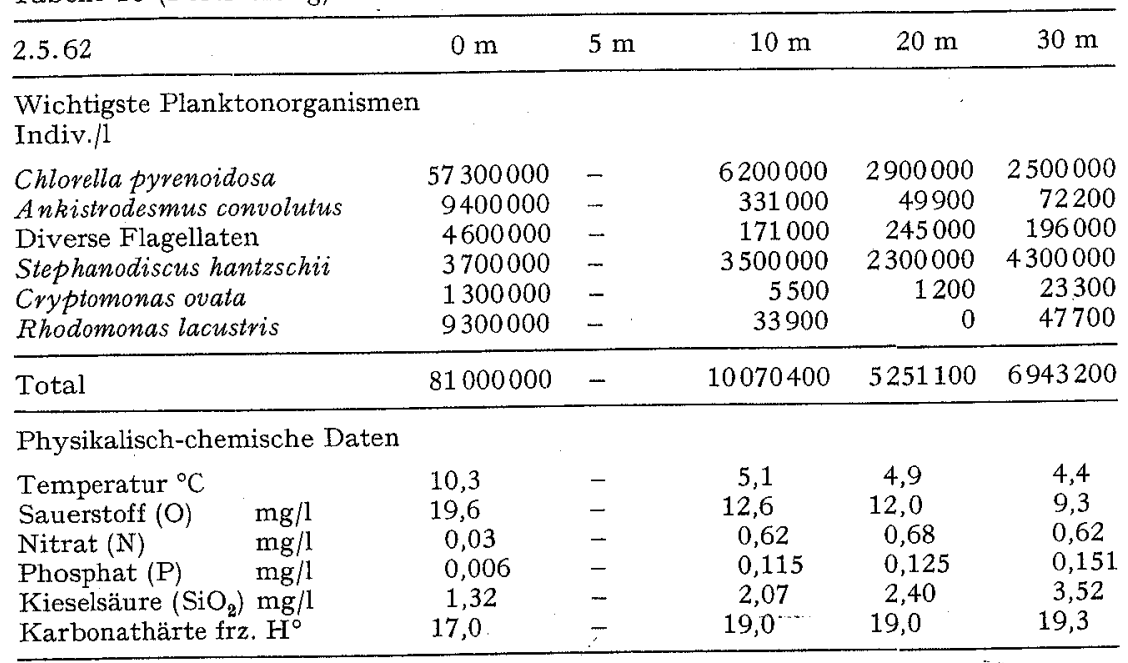

Zooplanktons erklärt werden. Aber auch im Frühjahr war das Zooplankton in grosser Dichte vorhanden, so dass die Vermutung naheliegt, dass das Netzplankton, trotz höherer Wassertemperatur als im Frühling, langsamer wächst als das Nannoplankton.

Bei einer zu grossen Beriicksichtigung der Biomasse besteht somit die Gefahr, dass dem Netzplankton gegenüber dem Nannoplankton zuviel Gewicht beigemessen wird.

So wie sich diese Netzplankter langsam vermehren, werden sie, besonders die Blaualgen, auch entsprechend langsam abgebaut. Dies kam nach der Aphanotbece-clatbrata-var.-brevis-Entwicklung im Juli schön zum Ausdruck (vgl. Abb. I3), wo diese Form sich in $20 \mathrm{~m}$ Tiefe langsam anreicherte und sogar den Winter über zum Teil noch vorhanden war. Dasselbe konnte auch bei Aphanizomenon flos-aquae beobachtet werden (Abb. I3, vgl. auch WILLÉN [77]).

\section{Vergleich Zürichsee-Pfäffikersee}

Bei einem Vergleich des Zürichsee- mit dem Pfäffikerseeplankton ist zu berücksichtigen, dass die beiden Gewässer stark verschieden sind und dass sie nicht in denselben Jahren und auch nicht gleich häufig untersucht wurden. Dagegen sind beide Seen stark eutroph.

Pro Probeserie betrug die durchschnittliche Biomasse für den Pfäffiker-

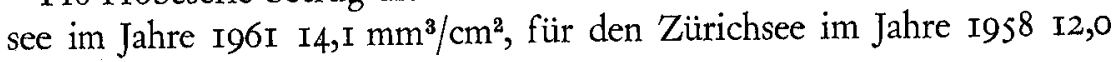


$\mathrm{mm}^{3} / \mathrm{cm}^{2}$. Die Unterschiede zwischen maximalen und minimalen Biomasseerträgen variierten in beiden Seen (Pfäffikersee: $0,8-67,2 \mathrm{~mm}^{3}$ / $\mathrm{cm}^{2}$ im Jahre I96I; Zürichsee: I,0-26,2 $\mathrm{mm}^{3} / \mathrm{cm}^{2}$ im Jahre 1958 und $2,0-69,2 \mathrm{~mm}^{3} / \mathrm{cm}^{2}$ im Jahre I959).

Verschieden jedoch war der Rhythmus, in dem die Biomasse dieser Seen entstanden war. Dies ist in erster Linie auf die Zusammensetzung des Planktons zurïckzuführen. Während die grössten Biomassen des Pfäffikersees von Ende Juli bis Oktober auftraten, fielen sie für den Zürichsee auf Vorfrühling, Herbst und Winter. Auch in bezug auf die Bildung von Nannoplankton unterschieden sich die beiden Seen beträchtlich. So fand sich im Pfäffikersee im Frühjahr und Frühsommer ein stark entwickeltes, reines Nannoplankton vor, während man im Zürichsee den Eindruck gewann, dass diese kleinen Plankter volumenmässig fast durchwegs von grösseren Formen verdrängt waren, mit der Folge, dass das Nannoplankton in keinem Fall auch nur die Hälfte des gesamten Phytoplanktons erreichte. Die grösste Biomasse an Netzplankton wurde im Pfäffikersee am II. IO. 6I mit $90,3 \mathrm{~mm}^{3} / 1$ an der Oberfläche gefunden, im Zürichsee am 2. 9. 58 mit $29,7 \mathrm{~mm}^{3} / 1$ in $8 \mathrm{~m}$ Tiefe. Die grösste Biomasse des Nannoplanktons im Pfäffikersee betrug $12,5 \mathrm{~mm}^{3} / 1$ an der Oberfläche (23. 3. 6I), im Zürichsee $3,9 \mathrm{~mm}^{3} / 1$ in $2,5 \mathrm{~m}$ (29. 9. 58).

An der Zusammensetzung des Planktons fällt auf, dass die Höchstwerte der Biomasse in beiden Seen auf verschiedene Blaualgen-Massenentfaltungen zurückgingen. Während im Zürichsee Oscillatoria rubescens sozusagen das ganze Jahr hindurch die " Grundfarbe» bildete, und im Herbst die nannoplanktischen Blaualgen Oscillatoria obliqueacuminata und Pseudanabaena catenata neben Anabaena planctonica und Apbanizomenon flos-aquae das Blaualgenbild bereicherten, waren im Pfäffikersee an den sprunghaften Sommer- und Herbstentwicklungen vor allem Aphanothece clatbrata var. brepis und Apbanizomenon flos-aquae beteiligt. Waren im Pfäffikersee die Cryptophyceen an zweiter Stelle für die Biomasse ausschlaggebend und machten die Diatomeen einen kleineren Teil aus so bildeten im Zürichsee die letzteren den zweitgrössten Anteil. In jedem der beiden Seen war Stephanodiscus bantzschii ein typischer Frühjahrsnannoplankter, der in bedeutender Anzahl vorkam. An Chrysophyceen wurden im Pfäffikersee sozusagen keine, im Zürichsee hur wenige gefunden, darunter waren in beiden Seen Kephyrionarten, Erkenia subaequiciliata und Heterochromonas sp. mehr oder weniger zahlreich vorhanden. Peridineen und Grünalgen waren im Pfäffikersee in grösserer Masse festzustellen. Trotz diesen Verschiedenheiten waren - ganz allgemein gesehen - an der Zu- 
sammensetzung des Nannoplanktons ungefähr die gleichen Arten beteiligt. Unter Berücksichtigung der quantitativen Verhältnisse könnte der Pfäffikersee als Blaualgen-Cryptophyceen-See, der Zürichsee als BlaualgenDiatomeen-See bezeichnet werden.

\section{E. Untersuchung des Phytoplanktons verschiedener Seen}

\section{Allgemeines}

Um wenigstens eine Vorstellung vom Nannoplankton anderer Schweizer Seen zu erhalten, wurde das Plankton von sechs Seen, die sich in Grösse, Tiefe, ihrem chemisch-physikalischen Verhalten und Trophiegrad unterscheiden, anhand einer einmaligen Untersuchung zur Zeit der Sommerstagnation studiert. Mit diesen Voraussetzungen konnte das Plankton der sechs Seen wenigstens zur Sommerszeit hinreichend gekennzeichnet werden. Dabei waren wir uns völlig bewusst, dass eine einmalige Untersuchung nie ein lïckenloses Bild über das Verhalten, Auftreten und die Zusammensetzung der Planktonorganismen ergibt.

Folgende Seen wurden untersucht: Brienzersee, Thunersee, Walensee, Zürichsee, Sempachersee, Hallwilersee. Zudem wurden Resultate von Proben aus dem Pfäffikersee teilweise berücksichtigt. Während die drei erstgenannten Seen Vertreter des oligotrophen Typus darstellen, sind die übrigen drei unter die meso- bis eutrophen Typen einzureihen. Diese Seen können nach verschiedenen Gesichtspunkten miteinander verglichen werden. Einmal besteht die Möglichkeit, die drei oligotrophen oder die drei eutrophen Seen oder beide Typen einander gegenüberzustellen. Zum anderen können über Seen ähnlicher Lage Vergleiche angestellt werden, über Brienzer- und Thunersee, die durch die Aare verbunden, ein einheitliches System bilden, oder über Walen- und Zürichsee, welche durch den Linthkanal und den Obersee miteinander in Verbindung stehen. Nahe beieinander, allerdings nicht im gleichen Einzugsgebiet, liegen ferner Sempacher- und Hallwilersee. Zu erwähnen ist eine ökologische Gruppe: nämlich Seen mit Oscillatoria rubescens, wie der Hallwilerund Zürichsee, in denen die Blaualge so stark dominiert, dass man von eigentlichen Oscillatoria-rubescens-Seen spricht. In spärlicher Anzahl wurde diese Form auch im Thunersee gefunden, ausserdem erwähnte sie FLüCK [16] in der Planktonliste des Brienzersees; in unseren Proben war sie nicht vorhanden. Und Seen obne Oscillatoria rubescens hingegen wie der Walensee, Sempachersee und der stark eutrophe Pfäffikersee. 
Zur Charakterisierung der untersuchten Seen in bezug auf ihre Lage und Morphologie sind die wichtigsten Daten in Tab. I7 zusammengestellt. Datum und Stelle der Probenahme sind der Tab. I8 zu entnehmen.

Abschliessend seien Autoren genannt, die diese Seen vor allem in planktologischer Hinsicht untersucht haben. Erste Planktonbeobachtungen im Brienzersee wurden von Heuscher [25] festgehalten. Eine weitere Planktonarbeit, in der sogar das Nannoplankton berïcksichtigt wurde, hat FLÜCK [I6] veröffentlicht. NyDEGGER [48] machte Beobachtungen über das Lichtklima dieses Sees. In der gleichen Arbeit liegen unter anderem Resultate über das Lichtklima des Thuner-, Walen-, Zürichund Sempachersees vor. Utber das Plankton des Thunersees fand sich ausser der Arbeit von Heuscher [25] keine Veröffentlichung. HuBERPEsTALOzZI [27] vertiefte sich während der Jahre 1930-35 in das Studium des Planktons des Walensees anhand von Netzzügen. Seine Resultate stellte er früheren Planktonuntersuchungen des Walensees gegenüber. Autoren des Zürichsees sind auf Seite Io erwähnt. Wiederum in einer Veröffentlichung von HEUSCHER [24] findet man einige Planktonangaben über den Sempachersee; THEILER [65] und GROBE [22] bearbeiteten das Zooplankton desselben. Leider bestehen keine schriftlich niedergelegten Untersuchungen über das Phytoplankton dieses Sees, so dass kein sicheres Bild über seine Entwicklung in den vergangenen Jahren entsteht. Anhand von Sauerstoffprofilen und besonders eindrücklich anhand von Bohrprofilen kann eine vermehrte Planktonentwicklung und ein biologisch gestörtes Gleichgewicht festgestellt werden [80]. Schon Du Bors und GEIGY [I4] kamen auf Grund von Oligochätenbestimmungen zum Schluss, dass sich der Sempachersee im Übergangsstadium vom oligotrophen zum eutrophen Seetypus befindet. Über den Hallwilersee erschien die früheste Arbeit, speziell über das Plankton, von BRUTSCHY [II]; KELLER [3I] führte limnologisch-chemische Untersuchungen durch und BACHOFEN [ $s$ ] versuchte den Stoff kreislauf mit Hilfe von Sedimentpfannen genauer abzuklären. Im Zusammenhang mit der zunehmenden Eutrophierung des Hallwilersees durch Einleitung von Abwässern hat dieser See in den vergangenen Jahren vermehrte Aufmerksamkeit auf sich gezogen $[\mathrm{r}, 6]$. Das Schrifttum des Pfäffikersees ist auf Seite $264 \mathrm{ff}$. zu finden.

2. Chemische Charakterisierung der Seen

Um trotz einmaliger Untersuchung ein klares Bild vom Zustand der Seen zu erhalten, wurde parallel zu den quantitativen Planktonbestimmungen Wasser aus den entsprechenden Tiefenstufen chemisch analy- 


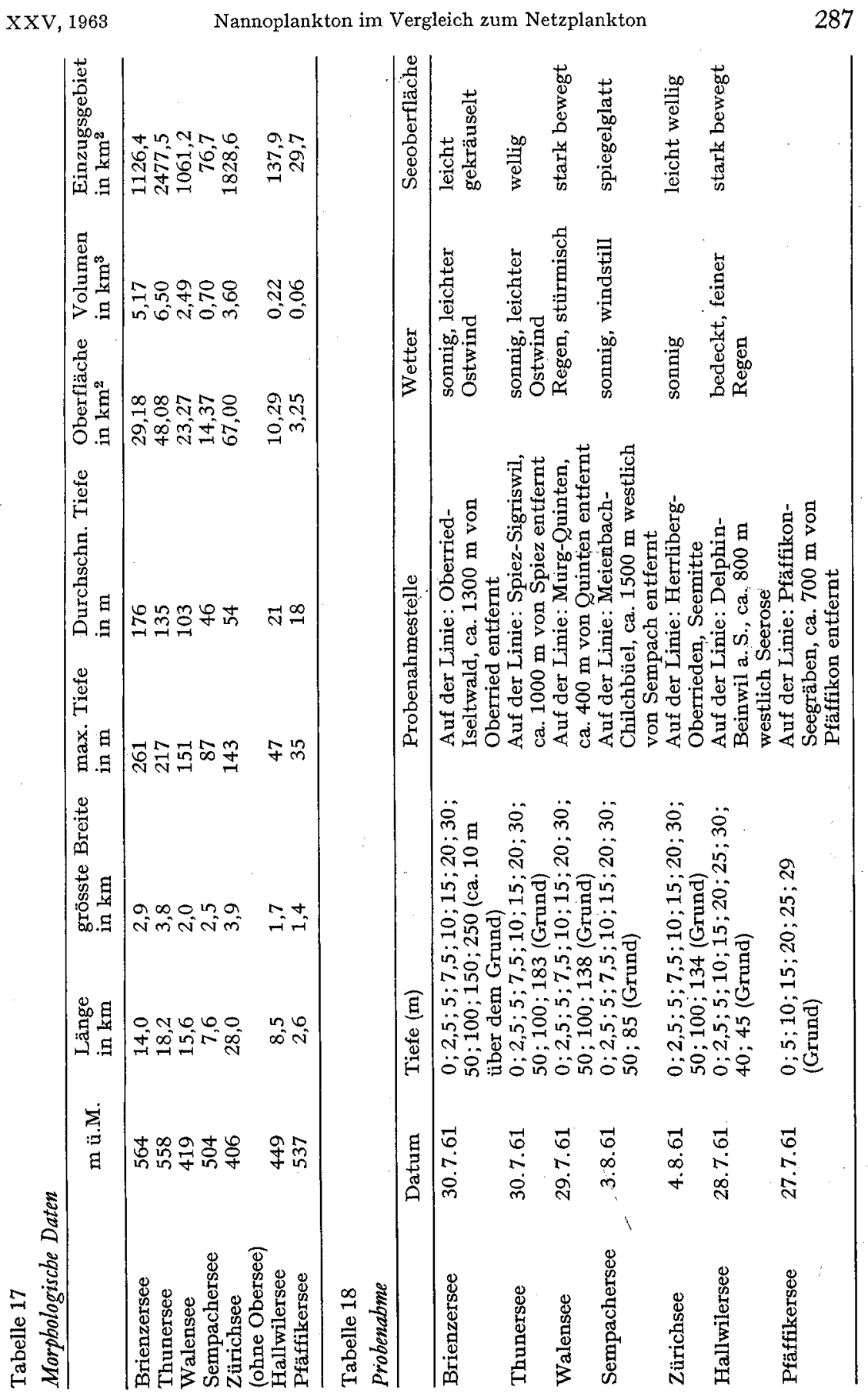


Tabelle 19 a-c

Cbemiscb-pbysikaliscbe Daten

a) Brienzersee

\begin{tabular}{cccllllll}
\hline $\begin{array}{c}\text { Tiefe } \\
\mathrm{m}\end{array}$ & $t{ }^{\circ} \mathrm{C}$ & $\begin{array}{l}\mathrm{O}_{2} \\
\mathrm{mg} / \mathrm{I}\end{array}$ & $\begin{array}{l}\mathrm{CO}_{2} \\
\mathrm{mg} / \mathrm{l}\end{array}$ & $\begin{array}{l}\mathrm{NH}_{3}(\mathrm{~N}) \\
\mathrm{mg} / \mathrm{l}\end{array}$ & $\begin{array}{l}\mathrm{NO}_{2}(\mathrm{~N}) \\
\mathrm{mg} / \mathrm{l}\end{array}$ & $\begin{array}{l}\mathrm{NO}_{3}(\mathrm{~N}) \\
\mathrm{mg} / 1\end{array}$ & $\begin{array}{l}\mathrm{PO}_{4}(\mathrm{P}) \\
\gamma / 1\end{array}$ & $\begin{array}{l}\mathrm{SiO}_{2} \\
\mathrm{mg} / \mathrm{I}\end{array}$ \\
\hline 0 & 15,5 & 11,0 & 0,0 & 0,02 & 0,010 & 0,10 & 5 & 0,42 \\
2,5 & 15,3 & 11,0 & 0,0 & 0,02 & 0,005 & 0,03 & 0 & 0,44 \\
5 & 14,7 & 11,9 & 0,0 & 0,02 & 0,010 & 0,10 & 5 & 0,77 \\
7,5 & 12,9 & 11,5 & 0,0 & 0,02 & 0,010 & 0,10 & 0 & 0,78 \\
10 & 11,8 & 10,7 & 0,0 & 0,02 & 0,010 & 0,14 & 5 & 0,86 \\
15 & 10,3 & 10,1 & 0,0 & 0,01 & 0,005 & 0,04 & 5 & 0,92 \\
20 & 8,5 & 10,0 & 0,0 & 0,01 & 0,005 & 0,24 & 5 & 1,33 \\
30 & 6,0 & 10,4 & 0,0 & 0,02 & 0,005 & 0,29 & 5 & 1,68 \\
50 & 4,8 & 10,0 & 0,0 & 0,01 & 0,005 & 0,19 & 5 & 1,80 \\
100 & 4,8 & 10,0 & 0,0 & 0,01 & 0,005 & 0,28 & 5 & 1,91 \\
150 & - & 9,6 & 0,0 & 0,02 & 0,000 & 0,12 & 5 & 1,80 \\
240 & 4,8 & 9,7 & 0,0 & 0,02 & 0,000 & 0,12 & 5 & 2,12 \\
\hline
\end{tabular}

b) Thunersee

\begin{tabular}{ccccccccc}
$\begin{array}{l}\text { Tiefe } \\
\mathrm{m}\end{array}$ & $t^{\circ} \mathrm{C}$ & $\begin{array}{l}\mathrm{O}_{2} \\
\mathrm{mg} / 1\end{array}$ & $\begin{array}{l}\mathrm{CO}_{2} \\
\mathrm{mg} / 1\end{array}$ & $\begin{array}{l}\mathrm{NH}_{3}(\mathrm{~N}) \\
\mathrm{mg} / \mathrm{l}\end{array}$ & $\begin{array}{l}\mathrm{NO}_{2}(\mathrm{~N}) \\
\mathrm{mg} / \mathrm{l}\end{array}$ & $\begin{array}{l}\mathrm{NO}_{3}(\mathrm{~N}) \\
\mathrm{mg} / \mathrm{l}\end{array}$ & $\begin{array}{c}\mathrm{PO}_{4}(\mathrm{P}) \\
\gamma / 1\end{array}$ & $\begin{array}{l}\mathrm{SiO}_{2} \\
\mathrm{mg} / \mathrm{l}\end{array}$ \\
\hline 0 & $\mathbf{1 7 , 5}$ & $\mathbf{1 0 , 6}$ & 0,0 & 0,00 & 0,011 & 0,17 & 15 & 0,20 \\
$\mathbf{2 , 5}$ & $\mathbf{1 7 , 4}$ & 10,5 & 0,0 & 0,00 & 0,012 & 0,15 & 6 & 0,12 \\
$\mathbf{5}$ & $\mathbf{1 6 , 2}$ & $\mathbf{1 0 , 8}$ & 0,0 & 0,00 & 0,011 & 0,16 & 12 & 0,12 \\
7,5 & 15,1 & 11,1 & 0,0 & 0,00 & 0,011 & 0,18 & 9 & 0,33 \\
10 & 14,0 & 10,3 & 0,0 & 0,00 & 0,012 & 0,20 & 9 & 0,55 \\
15 & $\mathbf{1 2 , 3}$ & 9,7 & 0,0 & 0,00 & 0,010 & 0,25 & 6 & 0,85 \\
20 & 10,3 & 9,4 & 0,0 & 0,00 & 0,006 & 0,30 & 9 & 1,0 \\
$\mathbf{3 0}$ & 6,8 & 9,3 & 0,0 & 0,00 & 0,004 & 0,37 & 6 & 1,32 \\
50 & 5,1 & 8,8 & 0,0 & 0,00 & 0,005 & 0,40 & 11 & $\mathbf{1}, 65$ \\
100 & 4,9 & 8,7 & 0,0 & 0,00 & 0,003 & 0,40 & 9 & 1,80 \\
183 & 4,9 & 6,8 & 0,0 & 0,00 & 0,007 & 0,40 & 9 & 2,75 \\
\hline
\end{tabular}

c) $W$ alensee

\begin{tabular}{ccccccccc}
\hline $\begin{array}{l}\text { Tiefe } \\
\mathrm{m}\end{array}$ & $t{ }^{\circ} \mathrm{C}$ & $\begin{array}{l}\mathrm{O}_{\mathbf{2}} \\
\mathbf{m g} / 1\end{array}$ & $\begin{array}{l}\mathrm{CO}_{2} \\
\mathrm{mg} / \mathrm{l}\end{array}$ & $\begin{array}{l}\mathrm{NH}_{3}(\mathrm{~N}) \\
\mathrm{mg} / \mathrm{l}\end{array}$ & $\begin{array}{l}\mathrm{NO}_{2}(\mathrm{~N}) \\
\mathrm{mg} / \mathrm{l}\end{array}$ & $\begin{array}{l}\mathrm{NO}_{3}(\mathrm{~N}) \\
\mathrm{mg} / 1\end{array}$ & $\begin{array}{l}\mathrm{PO}_{4}(\mathrm{P}) \\
\gamma / 1\end{array}$ & $\begin{array}{l}\mathrm{SiO}_{2} \\
\mathrm{mg} / 1\end{array}$ \\
\hline 0 & 16,7 & 10,8 & 0,0 & 0,02 & 0,005 & 0,20 & 5 & 0,20 \\
2,5 & 16,7 & 10,7 & 0,0 & 0,01 & 0,005 & 0,20 & 5 & 0,58 \\
5 & 16,2 & 10,8 & 0,0 & 0,01 & 0,005 & 0,21 & 5 & 0,63 \\
7,5 & 15,8 & 10,9 & 0,0 & 0,01 & 0,005 & 0,21 & 5 & 0,54 \\
$\mathbf{1 0}$ & 14,3 & 11,1 & 0,0 & 0,02 & 0,005 & 0,21 & 5 & 0,68 \\
15 & 11,9 & 10,2 & 0,0 & 0,02 & 0,000 & 0,30 & 5 & 0,83 \\
20 & 10,7 & 8,9 & 0,0 & 0,02 & 0,000 & 0,34 & 0 & 1,19 \\
30 & 8,2 & 9,5 & 0,0 & 0,01 & 0,000 & 0,41 & 0 & 1,48 \\
50 & 5,8 & 9,8 & 0,0 & 0,02 & 0,000 & 0,46 & 0 & 1,94 \\
$\mathbf{1 0 0}$ & $\mathbf{5 , 8}$ & - & 0,0 & 0,01 & 0,000 & 0,44 & 5 & 2,22 \\
139 & 5,6 & 8,3 & 0,0 & 0,02 & 0,000 & 0,46 & 5 & 3,10 \\
\hline
\end{tabular}

siert. Temperatur, Leitfähigkeit, pH-Wert, Sauerstoff und Kohlensäure wurden an Ort und Stelle oder unmittelbar nach der Probeerhebung bestimmt; die übrigen chemischen Komponenten aus tiefgekühlten Proben. 
Tabelle $19 \mathrm{~d}-\mathrm{f}$

Chemiscb-pbysikaliscbe Daten

d) Sempacbersee

\begin{tabular}{lccllllll}
\hline $\begin{array}{l}\text { Tiefe } \\
\mathrm{m}\end{array}$ & $t{ }^{\circ} \mathrm{C}$ & $\begin{array}{l}\mathrm{O}_{2} \\
\mathrm{mg} / \mathrm{l}\end{array}$ & $\begin{array}{l}\mathrm{CO}_{2} \\
\mathrm{mg} / 1\end{array}$ & $\begin{array}{l}\mathrm{NH}_{3}(\mathrm{~N}) \\
\mathrm{mg} / \mathrm{l}\end{array}$ & $\begin{array}{l}\mathrm{NO}_{2}(\mathrm{~N}) \\
\mathrm{mg} / \mathrm{l}\end{array}$ & $\begin{array}{l}\mathrm{NO}_{3}(\mathrm{~N}) \\
\mathrm{mg} / \mathrm{l}\end{array}$ & $\begin{array}{l}\mathrm{PO}_{4}(\mathrm{P}) \\
\gamma / 1\end{array}$ & $\begin{array}{l}\mathrm{SiO}_{2} \\
\mathrm{mg} / 1\end{array}$ \\
\hline 0 & 20,4 & 10,0 & 0,0 & 0,00 & 0,004 & 0,00 & 9 & 0,33 \\
2,5 & 20,4 & 10,0 & 0,0 & 0,01 & 0,005 & 0,00 & 0 & 0,14 \\
5 & 20,2 & 9,9 & 0,0 & 0,04 & 0,005 & 0,06 & 2 & 0,14 \\
7,5 & 18,2 & 9,6 & 0,0 & 0,00 & 0,005 & 0,00 & 8 & 0,10 \\
10 & 9,9 & 4,6 & 0,0 & 0,05 & 0,004 & 0,16 & 0 & 0,30 \\
15 & 7,6 & 3,9 & 3,6 & 0,00 & 0,004 & 0,35 & 2 & 0,65 \\
20 & 6,2 & 6,0 & 3,6 & 0,00 & 0,006 & 0,38 & 0 & 0,98 \\
30 & 5,2 & 6,2 & 3,7 & 0,00 & 0,006 & 0,42 & 21 & 1,17 \\
50 & 4,7 & 5,8 & 3,6 & 0,00 & 0,004 & 0,42 & 29 & 1,63 \\
85 & 4,3 & 0,7 & 6,7 & 0,00 & 0,004 & 0,53 & 90 & 3,2 \\
\hline
\end{tabular}

e) Zïrichsee

\begin{tabular}{cccccccrr}
\hline $\begin{array}{l}\text { Tiefe } \\
\mathrm{m}\end{array}$ & $t^{\circ} \mathrm{C}$ & $\begin{array}{c}\mathrm{O}_{2} \\
\mathrm{mg} / \mathrm{l}\end{array}$ & $\begin{array}{l}\mathrm{CO}_{2} \\
\mathrm{mg} / 1\end{array}$ & $\begin{array}{l}\mathrm{NH}_{3}(\mathrm{~N}) \\
\mathrm{mg} / 1\end{array}$ & $\begin{array}{l}\mathrm{NO}_{2}(\mathrm{~N}) \\
\mathrm{mg} / 1\end{array}$ & $\begin{array}{l}\mathrm{NO}_{3}(\mathrm{~N}) \\
\mathrm{mg} / 1\end{array}$ & $\begin{array}{c}\mathrm{PO}_{4}(\mathrm{P}) \\
\gamma / 1\end{array}$ & $\begin{array}{l}\mathrm{SiO}_{2} \\
\mathrm{mg} / \mathrm{l}\end{array}$ \\
\hline 0 & 21,6 & $\mathbf{1 0 , 9}$ & 0,0 & 0,00 & 0,005 & 0,00 & 9 & 0,15 \\
2,5 & 20,2 & 11,5 & 0,0 & 0,00 & 0,006 & 0,00 & 11 & 0,03 \\
5 & 19,5 & 10,8 & 0,0 & 0,00 & 0,002 & 0,00 & 8 & 0,03 \\
7,5 & 18,8 & 10,1 & 0,0 & 0,00 & 0,006 & 0,00 & 15 & 0,05 \\
10 & 14,6 & 4,8 & 0.0 & 0,00 & 0,007 & 0,22 & 12 & 0,35 \\
15 & 7,5 & 4,2 & 6,1 & 0,00 & 0,006 & 0,53 & 60 & 1,95 \\
20 & 6,4 & 4,7 & 6,1 & 0,00 & 0,006 & 0,55 & 77 & 2,25 \\
30 & 5,6 & 5,6 & 5,8 & 0,00 & 0,008 & 0,56 & 95 & 1,53 \\
50 & 4,6 & 6,2 & 5,3 & 0,00 & 0,006 & 0,57 & 100 & 2,42 \\
100 & 4,3 & 2,1 & 8,3 & 0,00 & 0,004 & 0,60 & 140 & 2,85 \\
136 & 4,3 & 0,3 & 10,6 & 0,27 & 0,067 & 0,20 & 232 & 4,78
\end{tabular}

f) Hallwilersee

\begin{tabular}{lcrllllll}
\hline $\begin{array}{l}\text { Tiefe } \\
\mathbf{m}\end{array}$ & $t{ }^{\circ} \mathrm{C}$ & $\begin{array}{l}\mathrm{O}_{2} \\
\mathrm{mg} / 1\end{array}$ & $\begin{array}{l}\mathrm{CO}_{2} \\
\mathrm{mg} / \mathbf{l}\end{array}$ & $\begin{array}{l}\mathrm{NH}_{3}(\mathrm{~N}) \\
\mathrm{mg} / 1\end{array}$ & $\begin{array}{l}\mathrm{NO}_{2}(\mathrm{~N}) \\
\mathrm{mg} / 1\end{array}$ & $\begin{array}{l}\mathrm{NO}_{3}(\mathrm{~N}) \\
\mathrm{mg} / 1\end{array}$ & $\begin{array}{l}\mathrm{PO}_{4}(\mathrm{P}) \\
\gamma / 1\end{array}$ & $\begin{array}{l}\mathrm{SiO}_{2} \\
\mathrm{mg} / \mathbf{l}\end{array}$ \\
\hline 0 & 21,4 & 11,8 & 0,0 & 0,02 & 0,000 & 0,00 & 5 & 0,73 \\
2,5 & 21,4 & 11,9 & 0,0 & 0,02 & 0,005 & 0,00 & 5 & 0,68 \\
5 & 18,2 & 9,7 & 0,0 & 0,02 & 0,000 & 0,00 & 5 & 1,00 \\
7,5 & 15,0 & 0,8 & 8,2 & 0,02 & 0,000 & 0,00 & 5 & 2,44 \\
10 & 9,8 & 0,3 & 8,1 & 0,02 & 0,065 & 0,00 & 30 & 2,98 \\
15 & 7,5 & 2,0 & 8,1 & 0,03 & 0,005 & 0,52 & 93 & 3,48 \\
20 & 5,7 & 3,1 & 8,4 & 0,02 & 0,000 & 0,55 & 103 & 3,62 \\
25 & 4,5 & 3,5 & 8,1 & 0,02 & 0,000 & 0,57 & 83 & 3,65 \\
30 & 4,0 & 0,2 & 8,4 & 0,16 & 0,052 & 0,38 & 133 & 5,22 \\
40 & 4,0 & 0,2 & 9,9 & 0,17 & 0,055 & 0,36 & $\mathbf{1 2 6}$ & 5,20 \\
45 & 4,0 & 0,2 & 12,1 & 0,22 & 0,059 & 0,38 & 127 & 5,22 \\
\hline
\end{tabular}

Die wichtigsten chemisch-physikalischen Daten sind in der Tab. I9a-f und in den Abb. Ig und 20 zusammengestellt.

Temperatur. Aus den Abb. I9 und 20 sind deutlich zwei Gruppen von 

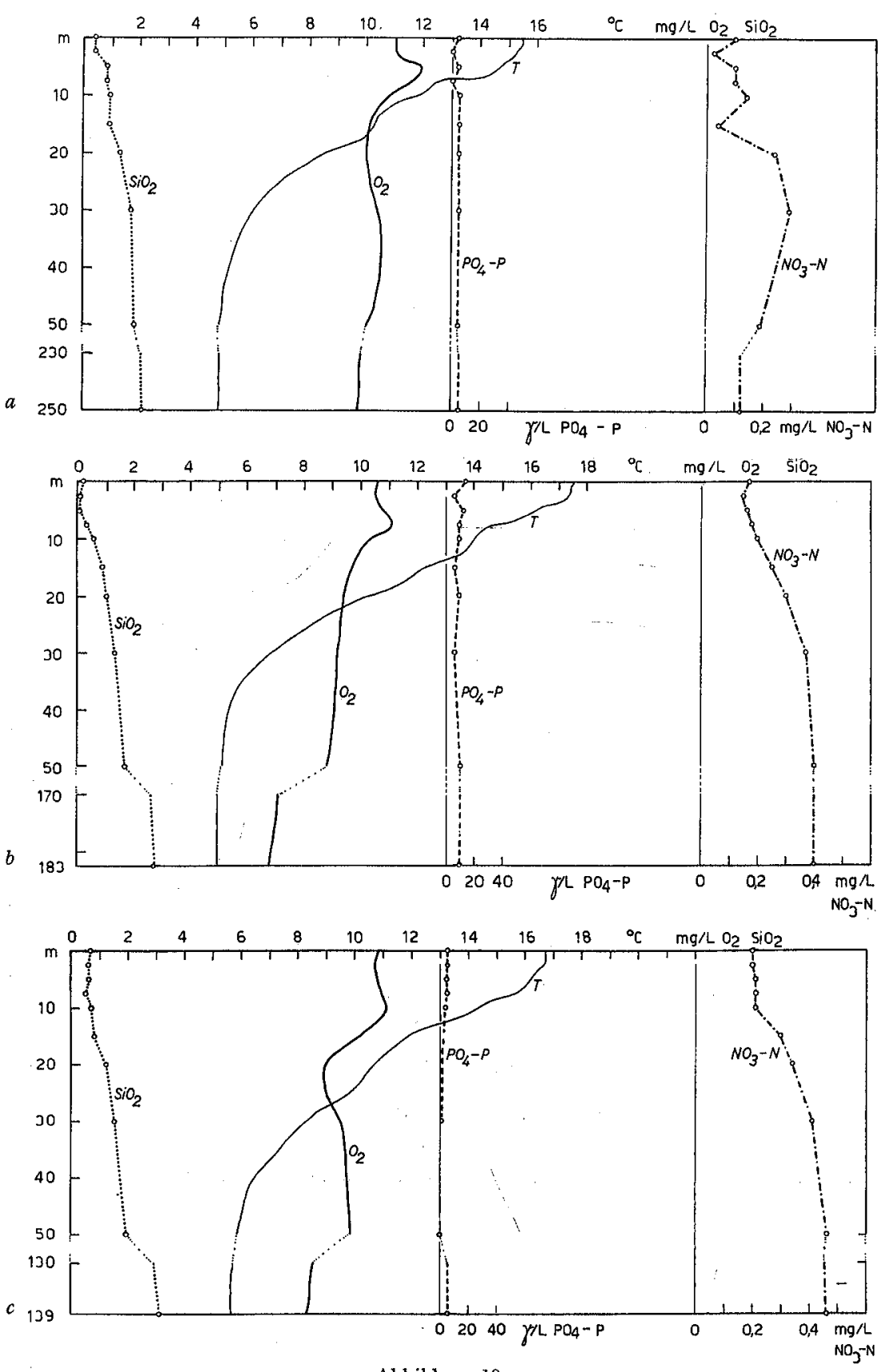

Abbildung $19 a-c$

Vertikaler Verlauf einiger chemisch-physikalischer Komponenten im $a$ Brienzer-, $b$ Thunerund $c$ Walensee. 

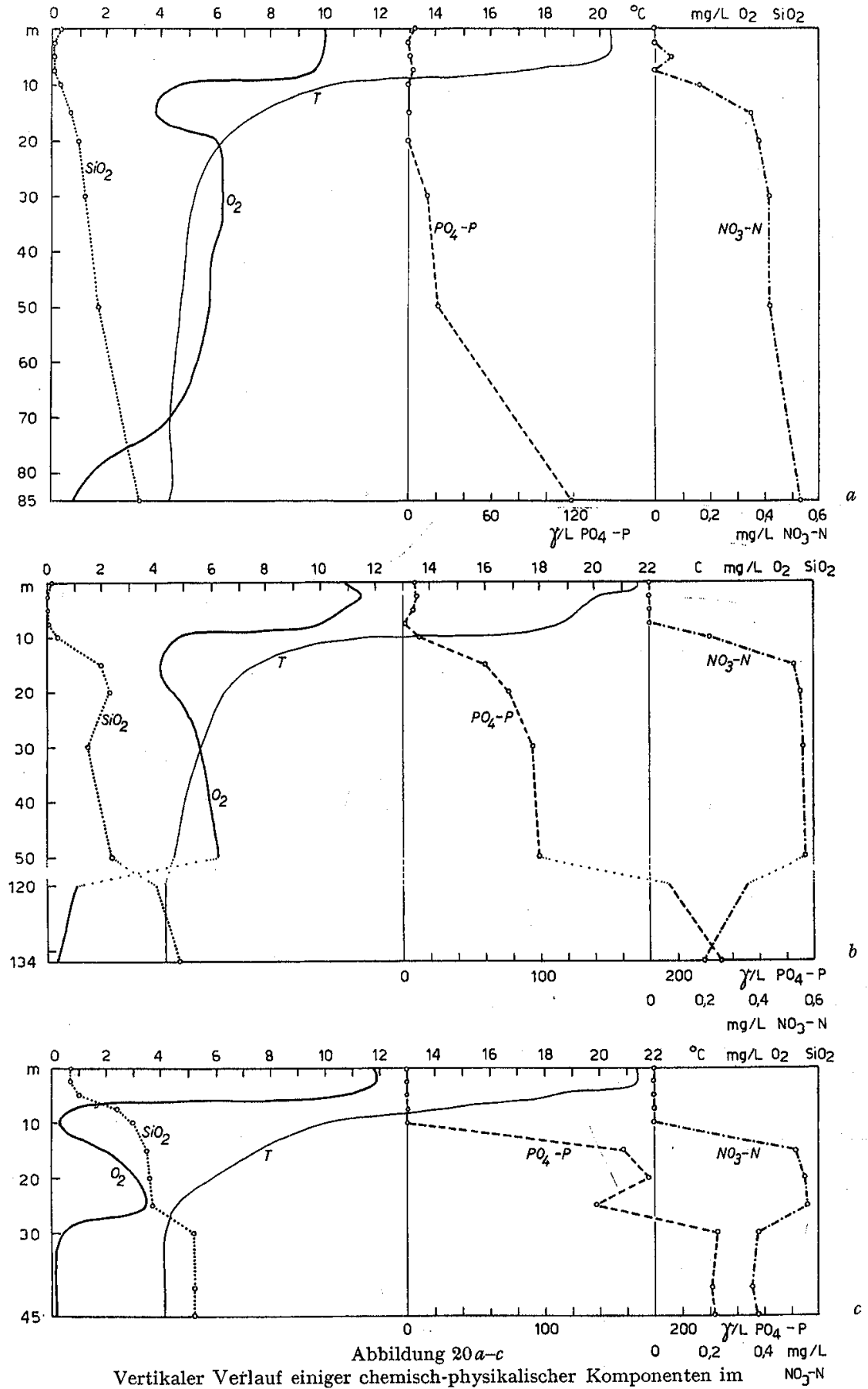

$a$ Sempacher-, $b$ Ziirich- und $c$ Hallwilersee. 
Seen zu erkennen: einerseits Hallwiler-, Sempacher- und Zürichsee mit ausgeprägter Sprungschicht, relativ hohen Oberflächen- und niedrigen Tiefentemperaturen, andererseits Brienzer-, Thuner- und Walensee mit auseinandergezogener Sprungschicht, für die Sommerszeit niedrigen Oberflächen- und relativ hohen Tiefentemperaturen. Diese Unterschiede in ihrem thermischen Verhalten sind vor allem auf die klimatische Lage (Mittelland: Hallwiler-, Sempacher- und Zürichsee; Voralpen: Brienzer-, Thuner- und Walensee) und ihre morphologische Beschaffenheit zurückzuführen.

Sauerstoff. Brienzer-, Thuner- und Walensee stimmen auch im Kurvenverlauf des Sauerstoffs bemerkenswert überein: schwach ausgebildetes Sauerstoffmaximum im Epilimnion, eine unbedeutende Sauerstoffabnahme im Metalimnion und gleichförmiger, beinahe gerader Verlauf im Hypolimnion. Die drei anderen Seen zeigten eine viel ausgeprägtere Sauerstoffschichtung, vor allem der Hallwilersee, der in der Oberflächenschicht überhaupt den höchsten Sauerstoffgehalt, ferner ein eindrückliches metalimnisches $\mathrm{O}_{2}$-Minimum und von $30 \mathrm{~m}$ an ein sauerstofffreies Hypolimnion aufwies, als Folge der ausgesprochen eutrophen Verhältnisse.

Nitrat. Auch die Nitratwerte waren kennzeichnend für den Trophiezustand der verschiedenen Seen, so namentlich für den Hallwilersee, wo Nitrat bis in to $\mathrm{m}$ Tiefe nicht nachweisbar war, anschliessend ein rapider Anstieg im Metalimnion und ein erneuter Abfall im sauerstofffreien Hypolimnion (vgl. auch den $\mathrm{NH}_{3}$-Gehalt von $0,22 \mathrm{mg} /$ auf dem Grund). Einen ähnlichen Verlauf zeigt die Kurve des Zürichsees, während im Sempachersee das Nitrat bis zum Grund hinunter stetig ansteigt. Der Verlauf dieser Kurven steht in Übereinstimmung mit den Feststellungen in den Arbeiten von BACHOFEN [s] und ZIMMERMANN [79].

Phosphat. Die Phosphatkurven der drei oligotrophen Seen bilden, mit Ausnahme von leichten Schwankungen in der trophogenen Schicht, sozusagen eine Gerade von der Oberfläche bis zum Grund, mit Werten ${ }_{\text {f }}$ die im Brienzer- und Walensee nie überschritten wurden. Im Thunersee betrug der höchste Gehalt $\mathrm{I} 4,5 \gamma / 1 \mathrm{P}$ in $\mathrm{O} \mathrm{m}$ und $\mathrm{I} \mathrm{I}, 0 \gamma / 1 \mathrm{P}$ in $50 \mathrm{~m}$ Tiefe. Die Phosphate der eutrophen Seen waren im Grunde bis auf $90 \gamma / 1 \mathrm{P}$ (Sempachersee), I27 $\gamma / 1 \mathrm{P}$ (Hallwilersee) und $232 \gamma / 1 \mathrm{P}$ (Zürichsee) angereichert, während sie im Epilimnion dieser Seen sozusagen aufgebraucht waren.

Silikat. Zwischen gelöster Kieselsäure und der Entwicklung der Diatomeen besteht eindeutig ein Zusammenhang [30, 60]. Interessant waren die Werte der Tiefenproben, wobei sich die Gruppe der eutrophen Seen durch bedeutend höhere Zahlen auszeichneten, ganz besonders der Hall- 
wilersee mit $5,22 \mathrm{mg} / 1 \mathrm{~S}_{1} \mathrm{O}_{2}$. Diese $\mathrm{Zahl}$ und namentlich das starke Gefälle der Kieselsäurekurve besagt, dass der Hallwilersee im Vergleich zu den anderen Seen vermutlich eine intensive Diatomeenentwicklung hinter sich hatte, obgleich er immer noch die höchsten Kieselsäurewerte im Epilimnion aufwies. Aber auch die Kurve des Zürichsees, mit einer rapiden Zunahme an $\mathrm{SiO}_{2}$ in Io m Trefe, und die Kurven des Sempacher- und Thunersees geben den Eindruck, dass die Kieselalgen in den vergangenen Monaten einen ziemlichen Anteil an der Biomasse ausgemacht hatten. Hingegen hatten Brienzer- und Walensee, deren Kurven das schwächste Gefälle aufweisen, wahrscheinlich erst eine geringe Diatomeendichte erreicht, oder es hatten sich kleine, zartere Kieselalgenformen, Nannoplankter, wie vor allem Cyclotellen, aber auch Rbizosolenia, entwickelt, deren Schalen weniger Kieselsäure für den Aufbau benötigen und rascher abgebaut werden, so dass die Kieselsäure jeweils schon in den oberen Wasserschichten während des Absinkens wieder für den Aufbau neuer Zellen frei wurde. So trafen wir beim Auszählen der Brienzerseeproben, in $100 \mathrm{~m}$ Tiefe und nur in dieser Stufe, auffallend rudimentär erhaltene Rbizosoleniaschalen. Im Gegensatz zu den anderen Seen waren im Brienzerund Walensee die Kieselalgen gerade in auffallender Entwicklung begriffen.

\section{Resultate der Planktonproben}

a) Brienzersee

Qualitatip: Zusammensetzung und Volumenprozente:

Cyanophyta: Nicht vorhanden.

Chlorophyta: Cblamydomonas sp., Sphaerocystis scbroeteri, Gloeocystis planctonica, Scbroederia setigera, Elakatotbrix gelatinosa.

Chrysophyta: Pseudopedinella erkensis $(0, \mathrm{I} \%)$, Mallomonas acaroides und Mallomonas producta $(0,2 \%)$, Erkenia subaequiciliata $(0,4 \%)$, Ocbromonas sp. $(0,7 \%)$, Uroglena polvox, Dinobryon divergens und Dinobryon sociale $(\mathrm{T}, \mathrm{0} \%)$, Stelexomonas dichotoma.

Diatomeae: Cyclotella comensis $(0,6 \%)$, Cyclotella operculata ( $14,9 \%)$, Fragilaria crotonensis $(3 \mathrm{I}, 6 \%)$, Synedra acus var. delicatissima, Asterionella formosa $(6,7 \%)$.

Cryptophyceae: Rbodomonas lacustris und Rbodomonas lens $(7,8 \%)$, Cryptomonas opata und Cryptomonas erosa $(34,6 \%)$.

Peridineae: Gymnodinium sp., Gymnodinium belpeticum (0,3\%), Peridinium cinctum, Ceratium birundinella.

Das Phytoplankton des Brienzersees war auffallend arm an Grünalgen, Blaualgen fehlten, dafür dominierten Diatomeen und Cryptophyceen. Seine qualitative Zusammensetzung wurde durch die Massenformen von Cryptomonas opata $(34,6 \%)$, Fragilaria crotonensis $(31,6 \%)$ und Cyclotella operculata (I4,9\%) charakterisiert. Zwei Nannoplanktonorganismen mach- 
ten also fast $50 \%$ der Gesamtmasse aus. Quantitativ von Bedeutung waren ausserdem Asterionella formosa mit 6,7\% und Rbodomonas lacustris und Rhodomonas lens mit $7,8 \%$. Ferner erhielt das Planktonbild des Brienzersees seine besondere Note durch folgende Formen, die allerdings zur Zeit der Probenahme quantitativ nicht ins Gewicht fielen: Diceras cbodati, Stelexomonas dichotoma (s. Abb. $27^{\star}$ ), ein kalt stenothermer Organismus, und Cryptomonas tetrapyrenoidosa (s. Abb. $35^{\star}$ ). Die beiden zuletzt genannten Formen sind deshalb bemerkenswert, weil sie in den anderen untersuchten Seen nicht beobachtet wurden.

Vertikale Verteilung. Dem ausgesprochen oligotrophen Charakter des Brienzersees und seinem tiefen, eher stark durchströmten Becken entsprechend, war auch die vertikale Verteilung der Organismen ausgebildet (s. Abb. 2ra), von denen Cyclotella operculata, Cryptomonas opata und Fragilaria crotonensis bis auf $150 \mathrm{~m}$ hinunter in beträchtlicher Menge gefunden wurden, wobei die Chromatophoren der Zellen noch auffallend schön erhalten waren und gar. nicht den Eindruck von abgestorbenen Zellteilen erweckten. In $250 \mathrm{~m}$ Tiefe jedoch wurden nur noch leere, im Abbau begriffene Zellen festgestellt. Das gesamte Phytoplankton erreichte erst in einer durchschnittlichen Tiefe von $25,5 \mathrm{~m}$ noch $10 \%$ seiner Höchstwerte (= untere Verbreitung, s. S. 228). Berechnet man die untere Verbreitung getrennt für das Nanno- und Netzplankton, so erhält man I6,5 bzw. $25,2 \mathrm{~m}$, also Zahlen von geringem Unterschied. Vor allem sind es Fragilaria crotonensis (ein Netzplankter) und Rbodomonas lacustris (ein Nannoplankter), die mit ihren vertikalen Ausdehnungen von 33,6 bzw. 4I,2 m die Tiefenerstreckung des Netz- und Nannoplanktons dermassen beeinflussten. Bemerkenswert war aber auch das vertikale Auftreten von Cryptomonas ovata (untere Verbreitung I6,9 m), Gymnodinium belpeticum $(45,0 \mathrm{~m})$ und Cyclotella operculata $(\mathrm{I} 6,9 \mathrm{~m})$. Neben diesen weiträumig, eher gleichförmigen Verteilungsbildern von Rbodomonas lacustris und Rbodomonas lens, Cryptomonas opata, Cyclotella operculata, Asterionella formosa und Fragilaria crotonensis heben sich typische, epilimnische Formen heraus, deren untere Verbreitung durchschnittlich 9,7 m betrug. Erwähnt seien einerseits die Nannoplankter Erkenia subaequiciliata, Pseudopedinella erkensis, Ochromonas sp. und Monas sp., andererseits der Netzplankter Dinobryon mit seinen Arten seciale und divergens. Auffallend klein war die Planktonentwicklung an der Oberfläche, was wahrscheinlich mit dem stürmischen Wetter an den der Probenahme vorangegangenen Tagen zu erklären ist. $\mathrm{Zu}$ dieser Zeit schwammen auf der leicht gekräuselten Seeoberfläche kleine und grosse Stücke von Treibholz. 
delicatissima (0, $1 \%)$, Asterionella formosa $(5,7 \%)$, Synedra cf. nana $(0,2 \%)$, Fragilaria crotonensis $(22,3 \%)$, Tabellaria flocculosa $(0,6 \%)$.

Cryptophyceae: Cryptomonas opata und Cryptomonas erosa (4,0\%), Rhodomonas lacustris und Rbodomonas lens $(5,8 \%)$.

Peridineae: Gymnodinium belpeticum $(0,4 \%)$, Gymnodinium sp., Peridinium cinctum $(0,3 \%)$, Ceratium birundinella $(\mathrm{r} 2,2 \%)$.

Wie beim Brienzersee wird der Aspekt des Planktons durch das starke Zurücktreten der Blaualgen und Grünalgen gekennzeichnet. Chrysophyceen und Diatomeen waren zahlreich vertreten. Die häufigsten quantitativen Formen waren Cyclotella operculata ( $19,2 \%)$, Erkenia subaequiciliata $(2,7 \%)$ und Dinobryon sociale $(23,1 \%)$. Für die Masse bestimmend waren ferner Ceratium birundinella (12,2\%), Fragilaria crotonensis (22,3\%), Asterionella formosa $(5,7 \%)$ und Rbodomonas lacustris und Rbodomonas lens $(5,8 \%)$.

Als besondere, eigentlich epiphytische Alge, die nur in den Planktonproben des Thunersees zu beobachten war, sei Hyalobryon mucicola genannt, die meistens losgelöst als freies Individuum und nur selten in Form kleiner Kolonien auf Dinobryon sociale sitzend gefunden wurde. Hervorzuheben ist das Vorkommen der Blaualge Oscillatoria rubescens mit I80o Fäden/l in Is $\mathrm{m}$ Tiefe.

Vertikale Verteilung (Abb. 2I b). Die untere Verbreitungsgrenze (Io\% der Höchstzahl) des Gesamtplanktons betrug $24,7 \mathrm{~m}$, wobei das Nannoplankton I4,5 m, das Netzplankton 26,7 m erreichte. Diese erheblichen vertikalen Ausbreitungen ergaben sich wiederum, wie beim Brienzersee, in erster Linie durch die tief hinuntersteigenden Diatomeen: Fragilaria crotonensis (untere Verbreitung 84,5 m), Asterionella formosa $(27,4 \mathrm{~m}$ ), Synedra acus var. angustissima $(27,0 \mathrm{~m})$ und die Cryptophyceen Cryptomonas opata $(75 \mathrm{~m}$ ) und Rbodomonas spp. ( $80 \mathrm{~m}$ ), ferner durch Gymnodinium belpeticum $(45,0 \mathrm{~m})$. Auch die maximale Volksdichte der Organismen lag zum Teil verhältnismässig tief, hauptsächlich in Io und is $\mathrm{m}$; sogar die typisch epilimnischen Gattungen Dinobryon und Erkenia mit den Höchstzahlen an der Oberfläche, reichten bis $20 \mathrm{bzw}$. Is $\mathrm{m}$ hinunter.

Biomasse. Die Halbwerttiefe wurde im Vergleich zum Brienzersee $(25 \mathrm{~m})$ schon bei $9,3 \mathrm{~m}$ erreicht. Der mittlere Litergehalt mit $0,17 \mathrm{~mm}^{3}$ und die Totalmasse von $3,21 \mathrm{~mm}^{3} / \mathrm{cm}^{2}$ waren zu jenem Zeitpunkt die geringsten der untersuchten Seen. Das Nannoplankton machte mit $1,2 \mathrm{~mm}^{3} /$ $\mathrm{cm}^{2}$ gut $1 / 3$ der Gesamtproduktion $\left(3,2 \mathrm{~mm}^{3} / \mathrm{cm}^{2}\right)$ aus. Ausschlaggebend für diesen Volumenanteil war das Massenvorkommen von Cyclotella operculata $(19,2 \%)$, die schon im Brienzersee mit $14,9 \%$ vertreten war. Sie erreichte im Thunersee ihr Maximum in $7,5 \mathrm{~m}\left(0,5 \mathrm{~mm}^{3} / 1=2,6\right.$ Mio. 
Indiv.(1). Aber auch Cryptomonas ovata und Rhodomonas lacustris mit zusammen $0,3 \mathrm{~mm}^{3} / \mathrm{cm}^{2}$ bestritten den bedeutenden Volumenanteil von 9,8\%. Im Gegensatz zum Brienzersee wurde die Biomasse des Netzplanktons vorwiegend von Dinobryon sociale - ausserdem Dinobryon dipergens und Dinobryon bavaricum - $(23, \mathrm{I} \%)$ und Fragilaria crotonensis $(22,7 \%)$ geformt, ausserdem durch die grosse Form Ceratium birundinella (12,2\%) und Asterionella formosa $(5,7 \%)$. Aus folgender Tabelle, in welcher die durchschnittlichen Litergewichte zusammengestellt sind, ist sehr schön ersichtlich, dass die Produktion vor allem in den oberen Io $\mathrm{m}$ stattfand.

Durchscbnittliches Planktonvolumen je Liter in $\mathrm{mm}^{3}$ (Thunersee)

\begin{tabular}{cccc}
\hline Tiefe $(\mathrm{m})$ & Phytoplankton & Nannoplankton & Netzplankton \\
\hline $0-2,5$ & 2,008 & 0,689 & 1,319 \\
$2,5-5$ & 1,804 & 0,674 & 1,142 \\
$5-7,5$ & 1,625 & 0,735 & 0,889 \\
$7,5-10$ & 1,365 & 0,649 & 0,716 \\
$10-15$ & 0,801 & 0,268 & 0,532 \\
$15-20$ & 0,287 & 0,138 & 0,149 \\
\hline $0-10$ & 1,701 & 0,687 & 1,017 \\
$10-20$ & 0,544 & 0,203 & 0,341 \\
$20-30$ & 0,221 & 0,074 & 0,148 \\
$30-50$ & 0,110 & 0,043 & 0,066 \\
$\mathbf{5 0 - 1 0 0}$ & 0,122 & 0,018 & 0,031 \\
$100-183$ & 0,033 & 0,005 & 0,031 \\
\hline $0-183$ & 0,174 & 0,064 & 0,110 \\
\hline
\end{tabular}

\section{c) Walensee}

Qualitative Zusammensetzung und Volumenprozente:

Cyanophyta: keine.

Chlorophyta: Scbroederia setigera, Sphaerocystis schroeteri, Elakatotbrix gelatinosa, Oocystis lacustris.

Chrysophyceae: Pseudopedinella erkensis $(1,2 \%)$, Mallomonas acaroides, Erkenia subaequiciliata $(0,6 \%)$, Ocbromonas sp., Pseudokepbyrion entzii $(0,1 \%)$, Uroglena polvox $(4,4 \%)$, Dinobryon dipergens und Dinobryon sociale (0,2\%), Cbrysolykos planctonicus, Monas sp. $(0,3 \%)$.

Diatomeae: Cyclotella comensis, Cyclotella stelligera $(0,2 \%)$, Cyclotella pseudostelligera, Stephanodiscus alpinus $(0,1 \%)$, Fragilaria crotonensis (10,3\%), Tubellaria flocculosa $(64,2 \%)$, Synedra acus var. angustissima $(0,4 \%)$, Synedra acts var. radians $(0,2 \%)$, Synedra cf. nana.

Cryptophyceae: Cryptomonas opata und Cryptomonas erosa (12,3\%), Rbodomonas lacustris und Rbodomonas lens $(2,5 \%)$.

Peridineae: Gymnodinium belpeticum $(0,6 \%)$, Peridinium cinctum, Peridinium inconspicuum $(0,6 \%)$, Ceratium birundinella $(18,3 \%)$. 
Das Phytoplankton des Walensees zeigte in qualitativer Hinsicht grosse Ähnlichkeit mit demjenigen des Brienzer- und Thunersees. Blaualgen waren zu dieser Zeit keine vorhanden, Grünalgen nur wenige, vereinzelte Formen. Hingegen wurde das Bild wiederum von Chrysophyceenarten und namentlich von Formen aus der Reihe der Diatomeen zusammengesetzt. Vor allem herrschte eine grössere Art, Tabellaria flocculosa, vor. Weitere wichtige Massenformen waren die Netzplankter Fragilaria crotonensis, Ceratium birundinella und als Nannoplankter Cryptomonas opata und Cryptomonas erosa. Die anderen kleinen, zum Teil äusserst feinen, für den Walensee charakteristischen Formen, wie Cyclotella stelligera, Pseudokephyrion entzii, ferner Peridinium inconspicuum, waren zur Zeit der Entfaltung nur in kleiner Menge vorhanden. Merkwürdig war das Auftreten von Cbrysolykos planctonicus (vgl. Abb. 27 $7^{\star}$ ), die in BOURRELLY [9] beschrieben ist.

Vertikale Verteilung. (Abb. 2I c). Wie im Brjenzer- und Thunersee, wo der auseinandergezogenen Temperaturkurve und chemischen Schichtung entsprechend die Organismen in grosse Tiefen vordrangen, liegt das durchschnittliche untere Auftreten ( $10 \%$ ) der Höchstzahlen der Organismen noch relativ tief bei $19,4 \mathrm{~m}$. In den Verteilungsbildern der einzelnen Arten fallen wiederum die weit auseinandergezogenen, gleichförmig verlaufenden Kurven von Rhodomonas und Cryptomonas auf. Auch Fragilaria crotonensis und Tabellaria flocculosa steigen tief hinunter, allerdings sind die grössten Dichten eindeutig auf die oberen $20 \mathrm{~m}$ konzentriert. Die Vertreter der Cryptophyceen, wie Dinobryon, Pseudopedinella, Erkenia, farblose Flagellaten besiedelten jedoch ziemlich gleichmässig die oberen I0-Is m. Eine extreme Oberflächenform waren Peridinium inconspicuum und Spbaerocystis scbroeteri. Nur bei vier Formen, Dinobryon spp., Synedra acus var. radians, Rbodomonas lacustris und Peridinium inconspicuum, lag das Maximum der Entfaltung an der Oberfläche, bei den anderen Organismen entwickelten sich die grössten Individuenzahlen in den Tiefen zwischen 2,5 und to $\mathrm{m}$.

Biomasse. Die Biomasse des Phytoplanktons betrug $9,0 \mathrm{~mm}^{3} / \mathrm{cm}^{2}$, davon bestritt das Nannoplankton gut $1 / 5(22,2 \%)$. Vor allem war es Cryptomonas ovata, der die Menge des Nannoplanktons bestimmte. Die Hauptmasse des Phytoplanktons machte Tabellaria flocculosa $(64,2 \%)$ aus mit $5,8 \mathrm{~mm}^{3} / \mathrm{cm}^{2}$. Wie aus der Zusammenstellung der durchschnittlichen Planktonvolumen zu sehen ist, fand man in der Wasserschicht zwischen 30 und $50 \mathrm{~m}$ noch einen auffallend hohen Litergehalt von $0,328 \mathrm{~mm}^{3}$, was sonst in keinem der untersuchten Seen der Fall war, und in der Schicht von Io-20 $\mathrm{m}$ wurde der höchste durchschnittliche Gehalt 


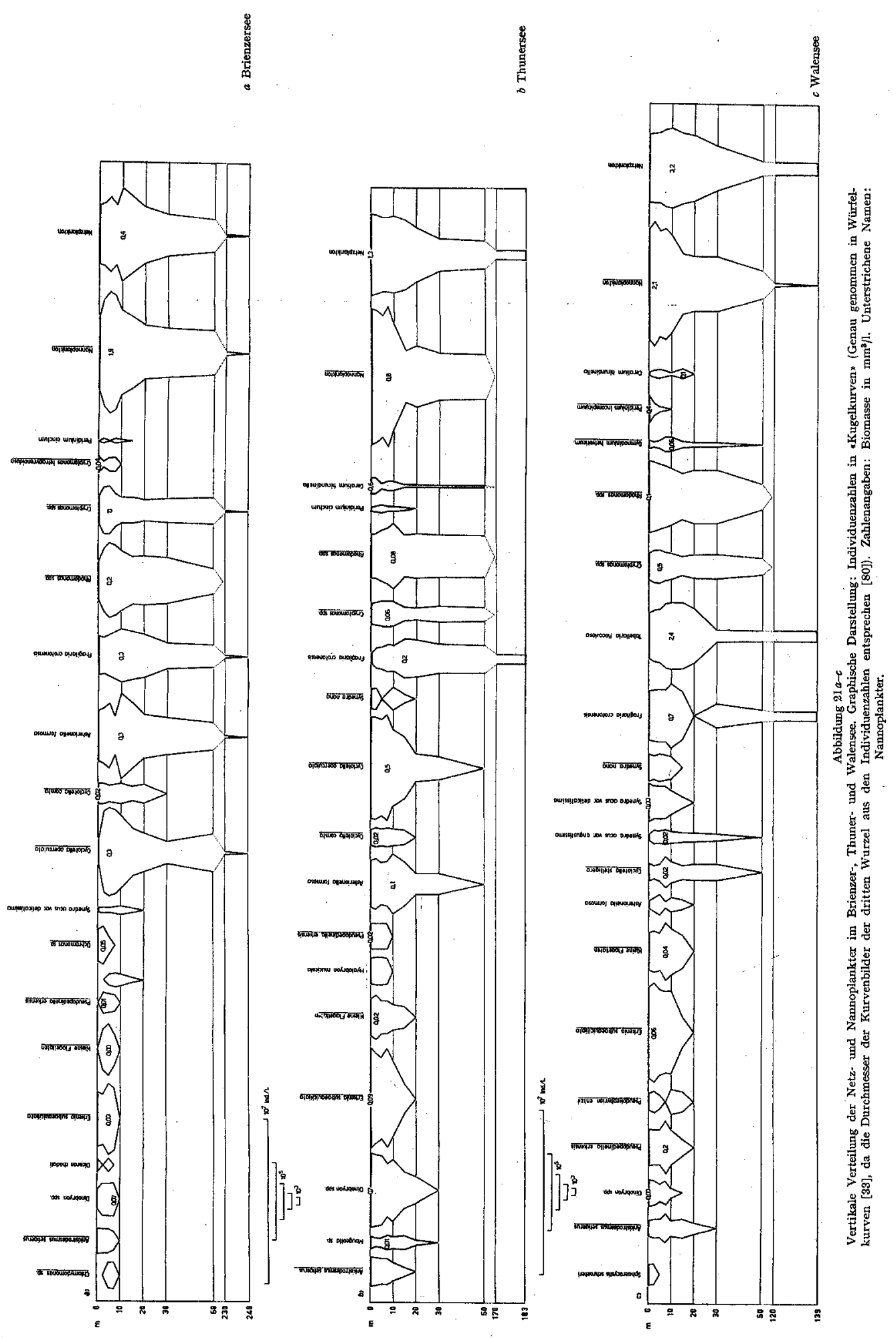


des Walensees, nämlich $3,008 \mathrm{~mm}^{3} / 1$ bestimmt. Dieser Wert wurde vor allem wegen der Massenentfaltung von Tabellaria flocculosa erreicht, die in $10 \mathrm{~m}$ Tiefe in einer Menge von $2,4 \mathrm{~mm}^{3} / 1(=677600$ Zellen/l) auftrat. Diese Massenentfaltung wurde auch im Sauerstoffgehalt sichtbar; der maximale Gehalt von II,06 mg/l befand sich in der Tiefe von $7,5 \mathrm{~m}$. Die relativ mächtige Produktionsschicht kommt auch in der Halbwertstiefe von 12,5 m zum Ausdruck. Wie im Thuner- und Brienzersee entwickelten sich die Nannoplanktonformen im Vergleich zum Netzplankton mehr in den oberen Wasserschichten. So betrug die Halbwerttiefe für das Nannoplankton des Walensees 8, I m, für das Netzplankton hingegen $\mathrm{I} 6,4 \mathrm{~m}$.

Durcbscbnittliches Planktonvolumen je Liter in $\mathrm{mm}^{3}$ (Walensee)

\begin{tabular}{clll}
\hline Tiefe $(\mathrm{m})$ & Phytoplankton & Nannoplankton & Netzplankton \\
\hline $0-2,5$ & 2,858 & 1,535 & 1,322 \\
$2,5-5$ & 1,995 & 1,505 & 0,490 \\
$5-7,5$ & 2,979 & 0,827 & 2,153 \\
$7,5-10$ & 3,533 & 0,649 & 2,884 \\
$10-15$ & 3,219 & 0,331 & 2,888 \\
$15-20$ & 2,797 & 0,189 & 2,608 \\
\hline $0-10$ & 2,841 & 1,129 & 1,712 \\
$10-20$ & 3,008 & 0,260 & 2,748 \\
$20-30$ & 2,317 & 0,231 & 2,087 \\
$30-50$ & 0,328 & 0,115 & 0,202 \\
$50-100$ & 0,053 & 0,003 & 0,049 \\
$100-136$ & 0,013 & 0,001 & 0,012 \\
\hline $0-136$ & 0,660 & 0,123 & 0,516 \\
\hline
\end{tabular}

\section{d) Sempachersee}

Qualitatipe Zusammensetzung und Volumenprozente:

Cyanophyta: Microcystis flos-aquate, Cbroococcus limneticus, Coelosphaerium kützingiana $(47,9 \%)$, Chroococcus minutus var. (4,1\%), Apbanocapsa delicatissima (0,4\%).

Chlorophyta: Carteria sp. $(\mathrm{I}, \mathrm{I} \%)$, Cblamydomonas $\mathrm{sp} .(\mathrm{0}, \mathrm{I} \%)$, Gloeocystis planctonica $(3,3 \%)$, Characium gracilipes, Oocystis marssonii $(5,2 \%)$, Oocystis solitaria, Tetraëdron minimum, Closterium acutum var. pariabile $(0,2 \%)$, Staurastrum gracile $(0,2 \%)$, Cosmarium pbaseolus $(0, \mathrm{I} \%)$, Coelastrum reticulatum, Scenedesmus acuminata, Gemellicystis neglecta.

Chrysophyceae: Erkenia subaequiciliata $(\mathrm{I}, 8 \%)$, Monas sp. $(0, \mathrm{r} \%)$, Spbaeroeca polpox.

Diatomeae: Stephanodiscus bantzscbii, Fragilaria crotonensis $(2,3 \%)$.

Tabellaria fenestrata, Asterionella formosa.

Cryptophyceae: Cryptomonas opata $(2,3 \%)$, Rbodomonas lacustris (2,0\%),

Peridineae: Gymnodinium belpeticum $(0,9 \%)$, Peridinium cinctum $(3,3 \%)$, Ceratium birundinella $(24,4 \%)$. 
Im Sempachersee herrschten die Blaualgen vor, an zweiter Stelle Peridineen, ausserdem fielen die zahlreichen Arten [24] von Grïnalgen, darunter ro Nannoplankter auf. Bemerkenswert an der Planktonzusammensetzung des Sempachersees waren Massenformen, die in den anderen Seen nicht oder nur vereinzelt aufgetreten waren. Unter den Blaualgen war dies für Coelosphaerium küntzingiana, dem stärksten Vertreter überhaupt, und Chroococcus minutus (vgl. Abb. $6^{\star}$ ) der Fall. Die Grünalgen traten durch das zahlreiche Vorhandensein von Oocystis marssonii, Gloeocystis planctonica, ferner Characium gracilipes und je einer Art der Gattungen Carteria und Cblamydomonas besonders hervor. Dafür waren die Diatomeen bis auf Fragilaria nur spärlich und vereinzelt anzutreffen und von den Chrysophyceen war nur Erkenia subaequiciliata stark entwickelt und Monas sp. und Sphaeroeca volvox vorhanden.

Vertikale Verteilung (Abb. 22a). Die untere Verbreitung (IO $\%$ der Höchstzahlen) betrug für das Gesamtplankton noch $\mathrm{I} 5,4 \mathrm{~m}$.

Die Verteilungsbilder der einzelnen Arten zeigen, dass die lang auseinandergezogenen, tief hinuntersteigenden Kurven fehlen. Dies rührt vor allem davon her, dass gerade die Diatomeen, die bis in grosse Tiefen vorzudringen vermögen, fehlten. Ausser Gymnodinium belpeticum war in $30 \mathrm{~m}$ Tiefe nur noch viel Detritus vorhanden. Aber auch Rhodomonas lacustris und Cryptomonas ovata, die in den oligotrophen Seen einen ausgedehnten Tiefenbereich aufwiesen, waren in $20 \mathrm{~m}$ bzw. $30 \mathrm{~m}$ ïberhaupt nicht mehr zu finden. Dies kann vermutlich mit dem Einfluss der ausgeprägten Temperatursprungschicht, und für Rhodomonas mit dem Sauerstoffschwund in Io und I5 m erklärt werden. Ein eigenes Schichtungsbild boten die Blaualgen Cbroococcus minutus, Coelospbaerium kïtzingiana und Aphanocapsa delicatissima, die ihre höchste Individuenzahl in $10 \mathrm{~m}$ gebildet hatten. Eindrücklich war vor allem die scharfe Einschichtung von Chroococcus, der bis und mit $5 \mathrm{~m}$ überhaupt nicht anzutreffen war. Von Io $\mathrm{m}$ an ist in seinem Kurvenbild sowohl nach oben als auch nach unten ein ausserordentlich starkes Gefälle der Bevölkerungsdichte zu beobachten. Worauf diese ausgeprägte Einlagerung chroococcaler Blaualgen, analog zur Blaualge Oscillatoria rubescens in anderen Seen, zurückzuführen ist, ist schwierig zu deuten und kann aus einer einmaligen Untersuchung nicht festgestellt werden. Auch Aphanocapsa delicatissima trat erst in $2,5 \mathrm{~m}$ auf, reicherte sich in Io $\mathrm{m}$ an und verschwand in $\mathrm{I} 5 \mathrm{~m}$ vollständig; Coelosphaerium hingegen war von 0-Io $\mathrm{m}$ fast in gleichmässiger Dichte, mit grösster Zahl in 7,5 m, verteilt, um plötzlich auf wenige Individuen zurückzufallen. Die Maxima der Euchlorophyceae jedoch lagen im Epilimnion 
(vgl. Carteria sp., Tetraëdron minimum, Characium gracilipes, Gloeocystis planctonica und Oocystis marssonii). Besonders erwähnt sei Oocystis marssonii, deren vertikale Schichtung parallel mit der Temperaturschichtung zu verlaufen schien.

Biomasse. Die gesamte Phytoplanktonproduktion konzentrierte sich vorwiegend in den oberen Io $\mathrm{m}$. So fanden sich in 7,I m noch die Hälfte des Totalvolumens von $5,9 \mathrm{~mm}^{3} / \mathrm{cm}^{2}$, in I5 $\mathrm{m}$ aber war nur noch $1 / 18$ des Maximums, und in $20 \mathrm{~m}$ nur mehr $1 / 50$ desselben vorhanden. Dasselbe Bild bringt auch die Zusammenstellung der durchschnittlichen Litervolumen gut zum Ausdruck. Schon in der Schicht zwischen 20 und $30 \mathrm{~m}$ lag nur noch ein Litervolumen von $0,046 \mathrm{~mm}^{3} / 1$ vor. Dafür fand in den oberen Io $m$ eine intensive Produktion statt, was im Litergewicht von 4,338 $\mathrm{mm}^{3} / 1$ erkennbar ist. Volumenmässig war das Netzplankton $(77,9 \%)$ knapp viermal stärker vertreten als das Nannoplankton. Den Volumenanteil des Nannoplanktons bildeten hauptsächlich Oocystis marssonii $(5,2 \%)$, Cbroococcus minutus (4,1\%), Glococystis. planctonia ( $3,3 \%)$, Rbodomonas lacustris und Cryptomonas opata (zusammen 4,3\%), ferner Erkenia subaequiciliata $(\mathrm{I}, 8 \%)$, Gymnodinium belpeticum (2,0\%) und verschiedene kleine Flagellaten. Das Netzplankton bestand in erster Linie aus Coelospbaerium kützingiana $(47,9 \%)$ und den allgemein verbreiteten Formen Ceratium birundinella und Peridinium cinctum (zusammen $28,6 \%$ ).

Durcbschnittlicbes Planktonvolumen je Liter in $\mathrm{mm}^{\mathbf{3}}$ (Sempacbersee)

\begin{tabular}{llll}
\hline Tiefe $(\mathrm{m})$ & Phytoplankton & Nannoplankton & Netzplankton \\
\hline $0-2,5$ & 4,413 & 0,560 & 3,853 \\
$2,5-5$ & 4,105 & 0,549 & 3,555 \\
$5-7,5$ & 4,004 & 0,734 & 3,270 \\
$7,5-10$ & 4,830 & 0,761 & 4,068 \\
$10-15$ & 2,898 & 0,473 & 2,426 \\
$15-20$ & 0,210 & 0,139 & 0,071 \\
\hline $0-10$ & 4,338 & 0,651 & 3,687 \\
$10-20$ & 1,554 & 0,306 & 1,248 \\
$20-30$ & 0,046 & 0,039 & 0,007 \\
$30-50$ & 0,003 & 0,003 & 0,000 \\
$50-85$ & 0,001 & 0,001 & 0,000 \\
\hline $0-85$ & 0,700 & 0,118 & \\
\hline
\end{tabular}

\section{e) Zürichsee}

Qualitatipe Zusammensetzung und Volumenprozente:

Cyanophyta: Anabaena flos-aquae (0,1\%), Pseudanabaena catenata (4,1\%), Apbanizomenon flos-aquae $(0,3 \%)$, Oscillatoria rubescens $(55,0 \%)$, Oscillatoria obliqueacuminata $(0,6 \%)$. 
Chlorophyta: Chlamydomonas sp., Pbacotus lenticularis, Pandorina morum (0,1\%), Actinastrum bantzscbii $(0, \mathrm{I} \%)$, Treubaria triappendiculata, Selenastrum minutum, Scenedesmus

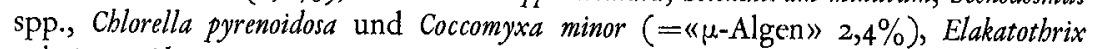
gelatinosa, Closterium acutum var. variabile, Ankistrodesmus falcatus.

Chrysophyceae: Erkenia subaequiciliata $(0,4 \%)$, Uroglena polvox $(0,3 \%)$, Dinobryon sertularia, Dinobryon dipergens, Dinobryon sociale $(3,4 \%)$, Monas $\mathrm{sp}$.

Diatomeae: Cyclotella comensis, Cyclotella pseudostelligera $(0,4 \%)$, Stepbanodiscus bantzscbii $(7,9 \%)$, Stephanodiscus astraea, Synedra acus var. delicatissima $(8,0 \%)$, Synedra acus var. angustissima, Tabellaria flocculosa $(4,3 \%)$, Tabellaria fenestrata $(0,2 \%)$, Fragilaria crotonensis, Asterionella formosa (0,1\%).

Cryptophyceae: Rbodomonas lacustris ( $\mathrm{I}, 7 \%)$, Cryptomonas ovata $(\mathbf{2}, \mathbf{2} \%)$.

Peridineae: Gymnodinium belpeticum $(3,0 \%)$, Peridinium inconspicuum $(0,1 \%)$, Peridinium cinctum, Ceratium birundinella $(7,0 \%)$.

Die Planktongemeinschaft ist durch fädige Blaualgen gekennzeichnet, zu denen zwei Nannoplankter, Oscillatoria obliqueacuminata und Pseudanabaena catenata gehören. Neben den uiblichen Diatomeen sind zahlreiche Arten von Chlorophyceen vorhanden, unter denen qualitativ Actinastrum bantzscbii, Treubaria triappendiculata, Selenastrum minutum und, bezüglich Individuenzahlen, die kleinen kugeligen Grünalgen ( $\mu$-Algen») Cblorella pyrenoidosa und Coccomyxa minor als Nannoplankter auffallen. Im übrigen zeichnete sich das Plankton durch keine Besonderheiten aus.

Vertikale Verteilung. (Abb. 22, b). Die untere Verbreitung aller Planktonalgen betrug 9,8 m; für das Nannoplankton 9,8, für das Netzplankton 9,6 m. Die kleinen Formen waren, mit Ausnahme von Cryptomonas opata, bei to $\mathrm{m}$ überhaupt nicht mehr vorhanden. Die maximale Individuenzahl lag in $7,5 \mathrm{~m}$ Tiefe, bedingt durch die Blaualgen Oscillatoria rubescens, Oscillatoria obliqueacuminata und Pseudanabaena catenata. Typische Oberflächenentwicklung war bei Peridinium inconspicuum, Ceratium birundinella und Erkenia subaequiciliata der Fall. Es sei noch speziell auf das vertikale Auftreten von Rbodomonas aufmerksam gemacht, der im Gegensatz zu den oligotrophen Seen nur noch in der Schicht von 0-7,5 m zu finden war, was wahrscheinlich wie im Sempachersee vor allem auf den Sauerstoffschwund zwischen 7,5 und to $m$ zurückzuf ühren ist. Erwähnenswert ist die extrem hohe Individuenentwicklung der « $\mu$-Algen» im Epilimnion, die sogar eine leicht grünliche Vegetationsfärbung erzeugten (Sichttiefe: $\mathrm{I}, 9 \mathrm{~m}$ ). In Io $\mathrm{m}$ Tiefe waren nur noch ganz vereinzelte $« \mu$-Algen» zu finden. Die grosse Entfaltung der Tabellaria flocculosa im Walensee trat auch im Zürichsee in Erscheinung, wo sie ihr Individuenmaximum in $20 \mathrm{~m}$ Tiefe erreichten.

Biomasse. Der Zürichsee wies eine erstaunlich geringe Planktonproduktion auf mit nur $3,7 \mathrm{~mm}^{3} / \mathrm{cm}^{2}$ und einem durchschnittlichen Litergehalt 
von $2,2 \mathrm{~mm}^{3}$. Der grösste Litergehalt $\left(3,0 \mathrm{~mm}^{3}\right)$ wurde in $7,5 \mathrm{~m}$ Tiefe gefunden. Das Nannoplankton umfasste knapp $1 / 3$ der Biomasse. Die Halbwerttiefe betrug noch $8,7 \mathrm{~m}$. Die Blaualgen machten $60,1 \%$ aus, die Diatomeen gut $20 \%$ und an den restlichen Volumenprozenten waren Chlorophyten, Peridineen und Cryptophyceen beteiligt. Von der totalen Biomasse des Nannoplanktons entfallen 4,9\% auf die beiden feinen, fädigen Blaualgen, ferner 7,9\% auf Stepbanodiscus bantzscbii, 3\% auf Gymnodinium belveticum, 2,4\% auf die kugeligen Grünalgen und $\mathrm{I}, 9 \%$ auf Rbodomonas und Cryptomonas.

Durcbschnittliches Planktonvolumen je Liter in $\mathrm{mm}^{3}$ (Züricbsee)

\begin{tabular}{clll}
\hline Tiefe $(\mathrm{m})$ & Phytoplankton & Nannoplankton & Netzplankton \\
\hline $0-2,5$ & 2,237 & 0,833 & 1,403 \\
$2,5-5$ & 1,732 & 1,180 & 0,552 \\
$5-7,5$ & 2,507 & 1,279 & 1,228 \\
$7,5-10$ & 1,923 & 0,653 & 1,270 \\
$10-15$ & 0,706 & 0,061 & 0,644 \\
$15-20$ & 0,441 & 0,015 & 0,426 \\
\hline $0-10$ & 2,099 & 0,986 & 1,113 \\
$10-20$ & 0,573 & 0,038 & 0,535 \\
$20-30$ & 0,164 & 0,011 & 0,150 \\
$30-50$ & 0,123 & 0,009 & 0,114 \\
$50-100$ & 0,122 & 0,009 & 0,113 \\
$100-140$ & 0,038 & 0,002 & 0,036 \\
\hline $0-140$ & 0,267 & 0,078 & 0,188 \\
\hline
\end{tabular}

\section{f) Hallwilersee}

Qualitatipe Zusammensetzung und Volumenprozente:

Cyanophyta: Anabaena flos-aquae, Anabaena planctonica (12,1\%), Pseudanabaena catenata, Aphanizomenon flos-aquae $(9,5 \%)$, Oscillatoria rubescens $(64,4 \%)$, Oscillatoria obliqueacuminata $(\mathrm{I}, \mathrm{O} \%)$.

Chlorophyta: Pbacotus lenticularis, Platymonas cordiformis, Pandorina morum (2,8\%), Dictyosphaerium pulcbellum, Oocystis lacustris, Scenedesmus quadricauda, Tetraëdron minimum, Elakatotbrix gelatinosa, Mougeotia sp., Closterium acutum var. variabile, Staurastrum cingulum.

Chrysophyceae: Erkenia subaequiciliata $(0,4 \%)$, Dinobryon sociale, Dinobryon bavaricum, Dinobryon sertularia, Dinobryon dipergens $(\mathrm{r}, 2 \%)$, Monas sp. $(0,1 \%)$.

Diatomeae: Cyclotella comensis, Cyclotella kützingiana $(0,3 \%)$, Fragilaria crotonensis $(0,6 \%)$, Synedra acus var. angustissima $(0,3 \%)$, Asterionella formosa $(0,4 \%)$.

Cryptophyceae: Cryptomonas opata, Cryptomonas erosa var. reflexa $(0,4 \%)$.

Peridineae: Gymnodinium belveticum $(0,6 \%)$, Peridinium inconspicuum und peridinium bipes ( $\mathrm{I}, 7 \%)$, Peridinium cinctum $(0,2 \%)$, Ceratium birundinella $(3, \mathrm{I} \%)$. 
Wie beim Zürichsee herrschten im Phytoplankton des Hallwilersees die hormogonalen Blaualgen vor. Charakteristisch waren ausserdem Cyclotella kützingiana, Cryptomonas erosa var. reflexa, Peridinium bipes, drei Nannoplankter, und zahlreiche Arten von Chlorophyten.

Vertikale Verteilung. (Abb. 22 c). Sowohl in der chemischen Schichtung als auch in der vertikalen Verteilung des Phytoplanktons kommt die starke Eutrophierung des Hallwilersees zum Ausdruck. Die untere Verbreitungsgrenze (10\% der Höchstzahlen) - die geringste der untersuchten Seen - liegt allerdings noch in $12,8 \mathrm{~m}$ Tiefe. Diese wurde erzeugt durch die bis in grössere Tiefen auftretenden Diatomeen Synedra acus, Asterionella formosa und Fragilaria crotonensis. Daneben waren Formen wie Erkenia subaequiciliata, Ceratium birundinella, verschiedene Arten von Dinobryon und Peridinium teilweise schon in $7,5 \mathrm{~m}$ nicht mehr vorhanden. Unter den Blaualgen erreichten Anabaena planctonica, Apbanizomenon flos-aquae und Oscillatoria obliqueacuminata ihre Maxima ebenfalls an der Oberfläche. Oscillatoria rubescens hingegen zeigte wieder das übliche "geflügelte» Kurvenbild, wobei die Einschiebung auffallend hoch in $5 \mathrm{~m}$ erfolgte. Dies rührte wahrscheinlich davon her, dass die enorm scharfe Sauerstoffabnahme zwischen 5 und $7,5 \mathrm{~m}$ (genau zwischen 5 und $6 \mathrm{~m}$ ) erfolgte, und zwar von $9,68 \mathrm{mg} / 1 \mathrm{O}_{2}$ auf $0,761 \mathrm{O}_{2}$. Es 1st deshalb denkbar, dass nicht mehr Temperatur oder Licht, sondern in erster Linie der Sauerstoffgehalt für diese abweichende Schichtung von Oscillatoria rubescens massgebend war. Erwähnenswert ist ferner die prägnante Einschichtung von Pandorina in $5 \mathrm{~m}$ Tiefe.

Biomasse. Die Biomasse von $\mathrm{I} 4 \mathrm{~mm}^{3} / \mathrm{cm}^{2}$ war ansehnlich, insbesondere wenn man bedenkt, dass diese Menge innerhalb der oberen ro $\mathrm{m}$ produziert worden war, was einem durchschnittlichen Litergehalt von 12,8 $\mathrm{mm}^{3}$ in der Wassersäule von o-1o $\mathrm{m}$ entspricht. Die Halbwerttiefe lag bei 4,3 m, und die weitaus stärkste Planktonentwicklung mit $26,3 \mathrm{~mm}^{3} / 1$ befand sich in $5 \mathrm{~m}$ und fiel mit dem Oscillatoria-rubescens-Maximum von $2 \mathrm{I}, 8 \mathrm{~mm}^{3} / 1$ zusammen. In $7,5 \mathrm{~m}$ war jedoch nur noch $1 / 7$, in Io $\mathrm{m}$ noch $1 / 13$ des Planktonmaximums vorhanden. Oscillatoria rubescens stellte mit $64,6 \%$ des Gesamtphytoplanktonvolumens die Hauptmassenform dar. Mit rund $76 \%$ lag ein typisches Blaualgenmaterial vor uns. Nannoplanktonformen, 20 an der Zahl, waren volumenmäss̀ig äusserst schwach entwickelt und hätten beim Hallwilersee mit $5 \%$ Volumenanteil (oder $0,7 \mathrm{~mm}^{3} / \mathrm{cm}^{2}$ ) bei der Biomasseberechnung des Sees ebensogut vernachlässigt werden können. Die stärkste Nannoplanktonentwicklung von $0,7 \mathrm{~mm}^{3} / 1$ fand an der Oberfläche statt. Diese Masse wurde hauptsächlich von Erkenia 


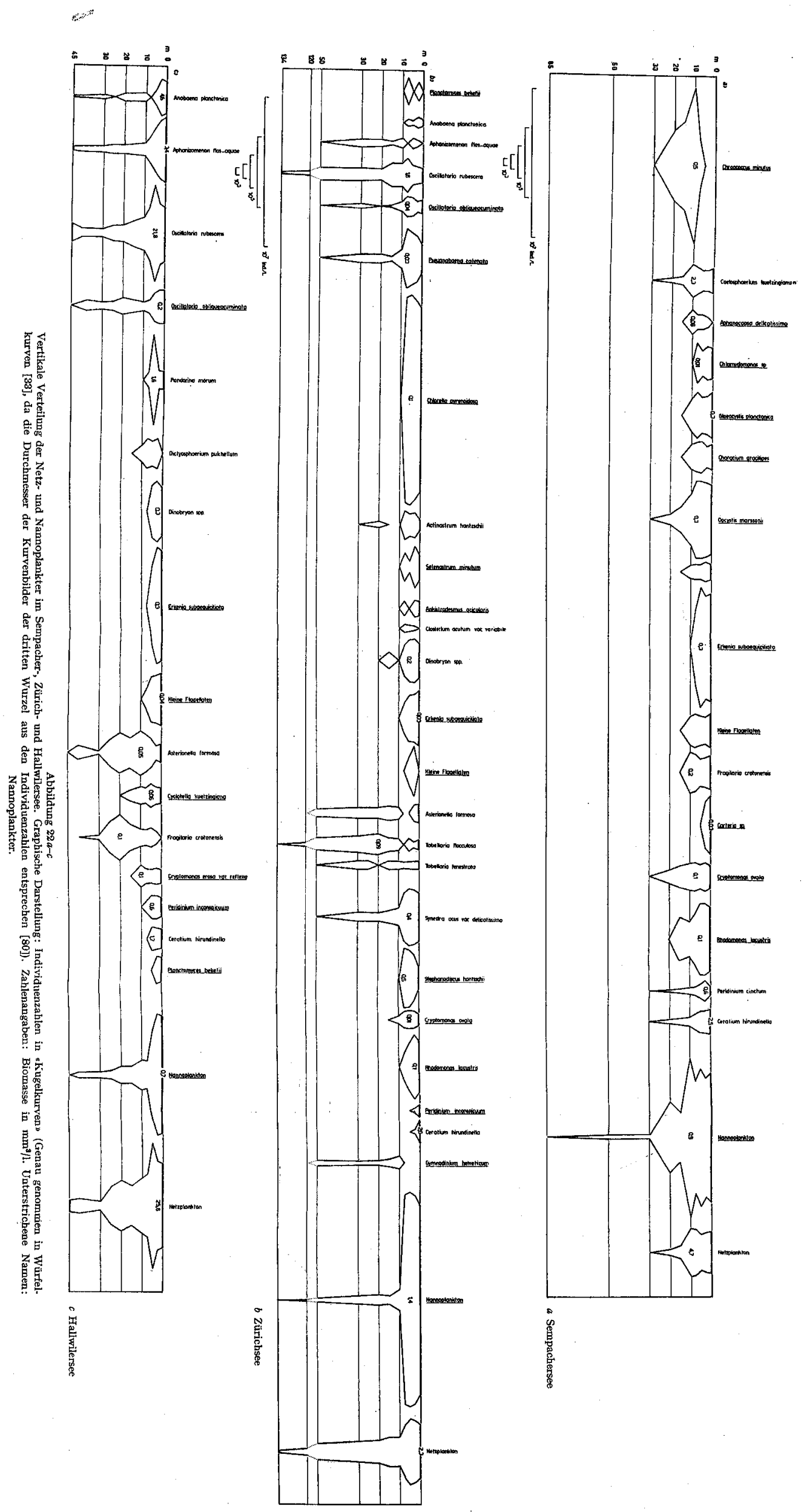


subaequiciliata, Peridinium inconspicuum und Peridinium bipes, ferner von der feinfädigen Oscillatoria obliqueacuminata gebildet.

Durcbschnittlicbes Planktonvolumen je Liter in $\mathrm{mm}^{3}$ (Hallwilersee)

\begin{tabular}{llll}
\hline Tiefe $(\mathrm{m})$ & Phytoplankton & Nannoplankton & Netzplankton \\
\hline $0-2,5$ & 13,068 & 0,868 & 12,200 \\
$2,5-5$ & 21,124 & 0,792 & 20,336 \\
$5-7,5$ & 14,112 & 0,292 & 14,820 \\
$7,5-10$ & 2,972 & 0,116 & 2,856 \\
$10-15$ & 1,346 & 0,139 & 1,206 \\
$15-20$ & 0,506 & 0,082 & 0,424 \\
$20-25$ & 0,274 & 0,041 & 0,232 \\
$25-30$ & 0,108 & 0,015 & 0,094 \\
$30-45$ & 0,048 & 0,023 & 0,025 \\
\hline $0-10$ & 12,819 & 0,517 & 12,302 \\
$10-20$ & 0,925 & 0,111 & 0,815 \\
$20-30$ & 0,244 & 0,028 & 0,163 \\
\hline $0-45$ & 3,112 & 0,152 & $\cdots$ \\
\hline
\end{tabular}

4. Vergleich der Resultate der untersuchten Seen

In den folgenden Abschnitten werden die Ergebnisse der analysierten Planktonproben miteinander verglichen, und zwar in erster Linie in bezug auf das Nannoplankton.

\section{a) Qualitative Zusammensetzung des Planktons}

Aus Tab. 20, in der die Phytoplankter der untersuchten Seen zusammengestellt sind, ist zu entnehmen, dass in diesen einmaligen Probenahmen 57 Nannoplankter (6I\%) und 36 Netzplankter $(39 \%)$ erfasst wurden. In den einzelnen Seen wurden 30-40 Phytoplankter beobachtet, wobei der Artenbestand des Nannoplanktons im Brienzer-, Walen- und Sempachersee etwa $70 \%$, der des Thunersees etwa $60 \%$, des Zürichsees etwa $50 \%$, des Hallwiler- und Pfäffikersees etwa $45 \%$ ausmachte. Schlüsse hinsichtlich der Artenzahlen des Nannoplanktons verschiedener Seetypen können jedoch aus diesen vereinzelten Stichproben nicht gezogen werden, obgleich es auf Grund dieser Zahlen scheinen will, dass das Nannoplankton oligotropher Seen zur Zeit der Sommerstagnation prozentual artenreicher ist als das Netzplankton.

Die Arten der Nannoplankter entstammen vornehmlich zwei Algengruppen (vgl. Tab. 2I), den Chrysophyceen (I2 Arten) und den Euchlorophyceen (19 Arten), ausserdem den Cryptophyceen, die nur Nanno- 
Tabelle 20

Die Pbytoplankter der untersucbten Seen (in Volumenprozenten der Totalmasse unter I $\mathrm{cm}^{2}$ der einzelnen Seen)

\begin{tabular}{|c|c|c|c|c|c|c|c|}
\hline Art & $\mathrm{Br}$ & Th & Wa & $\mathrm{Se}$ & $Z \ddot{u}$ & $\mathrm{Ha}$ & Pf \\
\hline Nannoplankter & & & & & & & \\
\hline Chroococcus cf. minutus (Kütz.) Naeg. var. & & & & 4 & & & \\
\hline Aphanocapsa delicatissima W. u. G. S. West & & & & + & & & \\
\hline Oscillatoria obliqueacuminata Skuja & & & & & 1 & 1 & \\
\hline Pseudanabaena catenata Lauterb. & & & & & 4 & + & \\
\hline Chlamydomonas spp. & + & & & + & & & \\
\hline $\begin{array}{l}\text { Carteria sp. } \\
\text { Platymonas corditormis (Carter) Korschikow }\end{array}$ & & & + & + & & & \\
\hline $\begin{array}{l}\text { Phacotus lenticularis Ehrenberg } \\
\text { Phas (Carter) Korschikow }\end{array}$ & & & & & + & $\begin{array}{l}+ \\
+\end{array}$ & + \\
\hline $\begin{array}{l}\text { Gloeocystis planctonica (W. u. G. S. West) Lem } \\
\text { Chlorella pyrenoidosa Chick und }\end{array}$ & & & & 3 & + & & + \\
\hline Coccomyxa minor Skuja & & + & + & & 2 & & \\
\hline $\begin{array}{l}\text { Oocystis lacustris Chodat } \\
\text { Oocystis marssonii Lemm. }\end{array}$ & & & + & 5 & & + & + \\
\hline Scenedesmus spp. & & & + & + & & + & \\
\hline Tetraëdron minimum (A. Br.) Hansg. & & & & + & & + & \\
\hline Treubaria triappendiculata Bernard & & & & & + & & \\
\hline Selenastrum minutum (Naeg.) Collins & & + & & & + & & \\
\hline Characium gracilipes F. D. Lambert & & & + & + & & & \\
\hline Ankistrodesmus falcatus (Corda) Ralfs & & & + & & + & & \\
\hline Ankistrodesmus longissimus (Lemm.) Wille & & & & & + & & \\
\hline $\begin{array}{l}\text { Elakatothrix gelatinosa Wille } \\
\text { Lambertia judayi (G. M. Smith) Korschikow }\end{array}$ & + & + & + & + & + & + & + \\
\hline $\begin{array}{l}\text { Lambertia judayi (G. M. Smith) Korschilow } \\
\text { Actinastrum hantzschii Lagerh. }\end{array}$ & & & & & + & & + \\
\hline $\begin{array}{l}\text { Closterium acutum var. (Lemm.) Krieger } \\
\text { Cosmarium phaseolus }\end{array}$ & & & & + & + & + & + \\
\hline $\begin{array}{l}\text { Cosmarium phaseolus } \\
\text { Ochromonas sp. }\end{array}$ & 1 & & & + & & & + \\
\hline $\begin{array}{l}\text { Ochromonas sp. } \\
\text { Erkenia subaequiciliata Skuja }\end{array}$ & + & 3 & $\begin{array}{r}+ \\
1\end{array}$ & & & & \\
\hline & + & 1 & $\begin{array}{l}1 \\
1\end{array}$ & 2 & + & + & + \\
\hline $\begin{array}{l}\text { Pseudopedinella erkensis Skuja } \\
\text { Kleine Flagellaten }\end{array}$ & + & + & $\begin{array}{r}1 \\
+\end{array}$ & & & & \\
\hline & & & $\begin{array}{l}+ \\
+\end{array}$ & + & + & + & 1 \\
\hline Diceras chodati Reverdin & + & + & & & & & + \\
\hline Hyalobryon mucicola Pascher & & + & & & & & \\
\hline Chrysolykos planctonicus Mack & & + & + & & & & \\
\hline Mallomonas acaroides Perty & + & 1 & & & & & \\
\hline Uroglena americana Calkins & + & 1 & 4 & & + & & \\
\hline Sphaeroeca volvox Lauterborn & & & & + & & & \\
\hline Stelexomonas dichotoma Lackey & + & & & & & & \\
\hline Cyclotella kittzingiana Thwaites & & & & & & + & \\
\hline Cyclotella operculata (Ag.) $\mathrm{Kg}$. & 15 & 19 & & & & & \\
\hline Cyclotella comta (E.) Kg. & 1 & 1 & & & & & \\
\hline $\begin{array}{l}\text { Cyclotella comensis Grun. } \\
\text { Cyclotella stelligera Cleve et Grun. }\end{array}$ & + & + & + & & + & + & \\
\hline $\begin{array}{l}\text { Cyclotella stelligera Cleve et Grun. } \\
\text { Cyclotella pseudostelligera Hustedt }\end{array}$ & & & $\begin{array}{l}+ \\
+\end{array}$ & & + & & \\
\hline Stephanodiscus hantzschii Grun. & & & & + & 8 & & + \\
\hline Stephanodiscus alpinus Hustedt & . & & + & & & & \\
\hline Synedra nana Meister & $\vdots$ & + & + & & & & \\
\hline $\begin{array}{l}\text { Rhodomonas lacustris Pascher et Ruttner } \\
\text { Rhodomonas lens Pascher et Ruttner }\end{array}$ & 8 & 6 & 3 & 2 & 2 & & + \\
\hline $\begin{array}{l}\text { Cryptomonas ovata Ehrenberg } \\
\text { Cryptomonas erosa Ehrenberg }\end{array}$ & 35 & 4 & 12 & 2 & + & + & 8 \\
\hline Cryptomonas erosa. var reflexa Marsson & & & & & & + & \\
\hline
\end{tabular}


Tabelle 20 (Fortsetzung)

\begin{tabular}{|c|c|c|c|c|c|c|}
\hline Art & $\mathrm{Br}$ & Th & Wa & $\mathrm{Se}$ & $Z \ddot{u}$ & $\mathrm{Ha}$ \\
\hline Cryptomonas cf. tetrapyrenoidosa Skuja & + & & & & & \\
\hline Gymnodinium helveticum Penard & + & + & 1 & 1 & 3 & 1 \\
\hline Gymnodinium lantzschii Utermöhl & + & & & + & & \\
\hline $\begin{array}{l}\text { Peridinium inconspicuum Lemm. } \\
\text { Peridinium bipes Stein }\end{array}$ & & & 1 & & + & + \\
\hline Gymnodinium spp. & + & + & & & & \\
\hline
\end{tabular}

Netzplankter

Microcystis flos-aquae (Wittr.) Kirchn, em. W.-L.

Coelosphaerium kütaingianum Naeg.

Aphanothece clathrata var. brevis Bachm.

Chroococcus limneticus Lemm.

Oscillatoria rubescens D.C.

Anabaena planctonica Brunnth.

Anabaena flos-aquae (Lyngb.) Bréb.

Aphanizomenon flos-aquae (L.) Ralfs.

Pandorina morum (Müller) Bory

Eudorina elegans Ehrenberg

Gloeococcus schroeteri (Chod.) Lemm.

Pediastrum duplex Meyen.

Pediastrum boryanum (Turp.) Menegh.

Dictyosphaerium pulchellum Wood.

Coelastrum reticulatum (Dang.) Senn,

Chodatella citriformis Snowa.

Botryococcus braunii Kütz.

Hormidium sp.

Mougeotia sp.

Staurastrum gracile Ralfs.

Closterium aciculare $\mathrm{T}$. West

Mallomonas producta Iwan.

Dinobryon sociale Ehrnb.

Dinobryon divergens Imhof

Dinobryon bavaricum Imhof

Dinobryon sertularia Ehrnb.

Rhizosolenia eriensis H. L. Smith

Melosira granulata var. angustissima Müller

Stephanodiscus astraea (E.) Grim)

A sterionella formosa Hassall

Tabellaria flocculosa (Roth) Kg.

Tabellaria fenestrata (Lyngb.) Kg.

Fragilaria crotonensis Kitton

Synedra acus var. angustissima Grim.

Synedra acus var. delicatissima (W.Sm.) Grun.

Peridinium willei Huitf.-Kaas

Peridinium cinctum (Müller) Ehrnb.

Ceratium hirundinella (O. F. Müller) Schrank

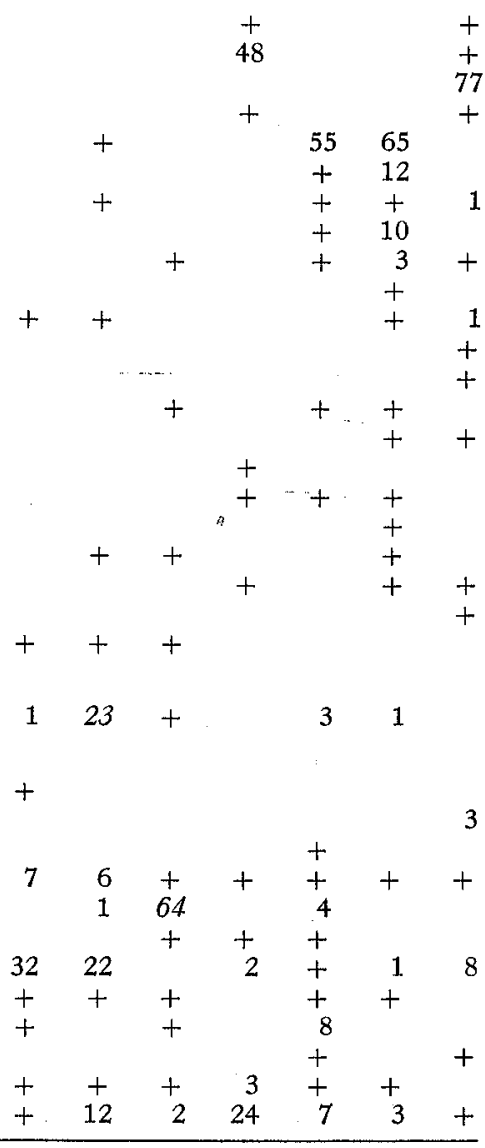

planktonformen umfassen. Unter den Cyanophyceen überwiegen die Formen des Netzplanktons, während sich die Diatomeen etwa zu gleichen Teilen auf Netz- und Nannoplankton aufteilen. Dieses Resultat ist im Grunde genommen einleuchtend, da unter den planktischen Blaualgen die meisten Formen relativ grosse Kolonien oder Fäden ausbilden, die Chloro- 
phyceen, ganz besonders jedoch die Chrysophyceen und Cryptophyceen: für die reiche Vielfalt an kleinen, oft geisseltragenden, einzelligen Organismen bekannt sind. Die Verbreitung der Formen ist ebenfalls aus Tab. 2I zu entnehmen. So gab es 6 Nannoplankter (gegenüber 2 Netz. planktern), die in allen Seen auftraten, 20 Nannoplankter (gegenübe: II Netzplanktern), die nur in einem der untersuchten Seen beobachte wurden, 26 Nannoplankter (gegenüber I8 Netzplanktern), die in 2-: der untersuchten Seen festgestellt wurden, und 5 Nannoplankter (gegen über 8 Netzplanktern), die in $4-6$ Seen vorhanden waren. Am auffallend sten vielleicht war die verhältnismässig grosse Zahl an Organismen, di nur in einem See anzutreffen waren. Die Ursache dieser Erscheinung lieg vermutlich im unterschiedlich ökologischen und regionalen Charakter de Seen, wie weiter unten noch dargelegt wird. Es fanden sich demnac. stenöke als auch weitverbreitete Netz- und Nannoplanktonorganismer wobei die Zahl der Nannoplankter meistens etwas grösser war (wa jedoch noch nichts aussagt über das quantitative Auftreten dieser Nannc planktonformen).

Was die Zahl der Massenformen anbelangt, das heisst von Formen, di mindestens in einem See wenigstens $0,5 \%$ Volumenanteil erreichten, git Tab. 2I in der letzten Kolonne wieder. Nur $42 \%$ aller Arten erfüllte diese Bedingung, davon 20 Nannoplankter (gegenüber I 9 Netzplanktern' Über 10\% Volumenanteil wurde nur von 2 Nannoplanktern und 8 Net: planktern (zusammen II \% aller Arten) erreicht. Den höchsten Volumer anteil bildete ein Netzplankter: Aphanotbece clathrata var. brevis m $77,3 \%$. Zwei weitere Blaualgen, Oscillatoria rubescens und Coelosphaeriu kützingianum, waren mit $64,5 \%$ bzw. $47,9 \%$ und die beiden Kieselalge Tabellaria flocculosa und Fragilaria crotonensis mit $64,2 \%$ bzw. $31,6 \%$ b teiligt. Nur zwei Nannoplankter hingegen, Cyclotella operculata ur Cryptomonas opata, bestritten mehr als $10 \%$ der Biomasse (vgl. auch $\mathrm{Ta}$ 20 und 2I). Obgleich also die Netzplankter prozentual ärmer an Arts waren, fielen sie zur Sommerszeit durch 8 besonders «leistungsfähige Formen volumenmässig stärker ins Gewicht als die Nannoplankter, vı denen nur zwei Organismen die Grösse der Biomasse in signifikant Weise zu beeinflussen vermochten.

Nach diesen mehr allgemeinen Feststellungen hinsichtlich Artenzahl und Massenformen von Netz- und Nannoplanktonorganismen ist vielleicht nützlich, einige Einzelheiten näher zu erörtern. In Tab. 2 wo die Algengruppen der einzelnen Seen nach Artenzahl und Volume anteil auseinandergehalten sind, treten die Besonderheiten ihrer Vert 


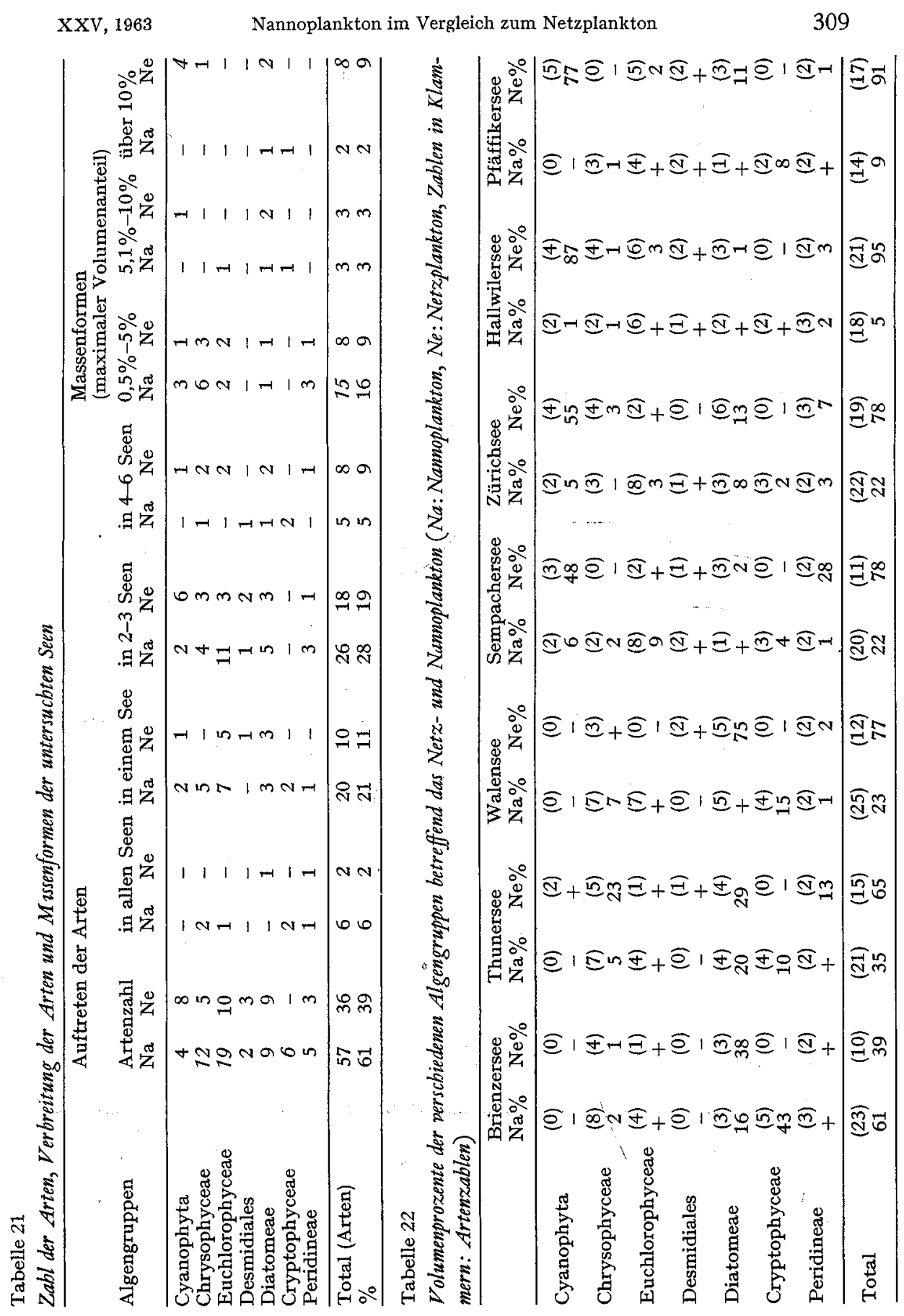


lung klar hervor. Schon die Artenzablen lassen teilweise Unterschiede erkennen, jedoch ergäben diese Zahlen für sich allein betrachtet ein falsches Bild über die effektive Bedeutung der einzelnen Algengruppen an der Zusammensetzung des Planktons (vgl. z. B. die Artenzahlen und die Volumenprozente der Euchlorophyceen mit denjenigen der Cyanophyten und Diatomeen in Tab. 22). Hingegen kommen in der prozentual unterschiedlichen Verteilung (Tab. 22) der Algengruppen, analog $\mathrm{zu}$ den chemischen Resultaten, wiederum deutlich die oligotrophen (Brienzer-, Thuner-, Walensee) und die eutrophen (Sempacher-, Hallwiler-, Zürich-, Pfäffikersee) Seetypen zum Ausdruck. In der Reihe der eutrophen Seen herrschten die Blaualgen vor, während sie unter den oligotrophen Seen nur im Thunersee, zudem in unbedeutender Menge, vorhanden waren. Dafür zeichnete sich das Planktonbild der letzteren durch das Hervortreten der Diatomeen, Cryptophyceen und teilweise der Chrysophyceen aus, Algengruppen, die in den vier eutrophen Seen zur Untersuchungszeit stark zurücktraten. Die Euchlorophyceen, zum grössten Teil Nannoplanktonformen, bildeten in allen Seen nur einen kleinen Massenanteil. In den eutrophen Seen wurden sie wohl etwas artenreicher vertreten.

Weitere interessante Vergleichsmöglichkeiten ergaben das Auftreten der einzelnen Nannoplankter in den untersuchten Seen (vgl. Tab. 20):

Cyanophyta. Vier Blaualgenvertreter, zwei chroococcale, Apbanocapsa delicatissima und Cbroococcus minutus, und zwei hormogonale, Oscillatoria obliqueacuminata und Pseudanabaena catenata, kennzeichneten das gefundene Nannoplankton. Die beiden chroococcalen Arten wurden nur im Sempachersee beobachtet. Apbanocapsa delicatissima allerdings ist eine verbreitete, doch nie zahlreich auftretende Form, die wir schon im Zürich-, Pfäffiker-, Vierwaldstätter- und Bodensee vereinzelt festgestellt hatten. Cbroococcus cf. minutus hingegen wurde von uns zum erstenmal in den Proben des Sempachersees bestimmt, wo sie sowohl als Charakter- als auch Massenform dem Planktonbild einen eigenen Aspekt verlieh. Die beiden fädigen Blaualgen hingegen bildeten zwei interessante Charakter- und Massenformen des Hallwiler- und Zürichsees. Eutrophe Gewässer fördern wahrscheinlich das Wachstum dieser hormogonalen Nannoplankter.

Cbloropbyta. Obgleich die grösste Zahl von Nannoplanktern von den Grünalgen gestellt wurde, waren nur drei Formen auch quantitativ von Bedeutung, nämlich Cblorella pyrenoidosa im Zürichsee, Gloeocystis planctonica und Oocystis marssonii im Sempachersee. Charakterformen waren Treubaria triappendiculata und Actinastrum buntzscbii im Zürichsee, Scbroe- 
deria setigera in den oligotrophen Seen und Lambertia judayi im Pfäffikersee. Die restlichen Formen waren mehr oder weniger in allen Seen zu finden.

Cbrysopbyceae. Von der relativ grossen Anzahl [12] der Nannoplankter aus dieser Algengruppe waren zwei Formen in allen untersuchten Seen zu finden, sogar zum Teil als Massenformen, Erkenia subaequiciliata und ein Monas sp. Eine andere Chrysophycee, Pseudopedinella erkensis, fand sich zur Zeit der Probenahme als Massenform in den drei oligotrophen Seen vor. Im Thuner- und Brienzersee waren Diceras chodati und Mallomonas acaroides verbreitet. Ein für den Brienzersee kennzeichnender Chrysoflagellat stellte Stelexomonas dichotoma (s. Abb. $27^{\star}$ ), für den Thunersee Hyalobryon mucicola dar, und für den Walensee waren Kepbyrion entzii und vor allem Chrysolykos planctonicus (s. Abb. 24*) typisch. Nur im Sempachersee wurde zur Zeit der Probenahme Sphaeroeca polpox angetroffen.

Unter den Nannoplanktern der Chrysophyceen kommt der allgemeine ökologische Charakter dieser Algengruppe zum Ausdruck. Es gibt wenige ökologisch und regional indifferente Formen (Erkenia subaequiciliata), die Mehrzahl der Formen zieht kühleres Wasser vor und wurde deshalb auch nur in den drei oligotrophen Alpenrandseen, die sich im Vergleich zu den anderen Seen durch tiefere Temperaturen auszeichneten, gefunden, so zum Beispiel Pseudopedinella erkensis, Diceras cbodati, Cbrysolykos planctonicus, Stelexsmonas dichotoma, Kephyrion entzii. In diesem Zusammenhang ist zu bemerken, dass Diceras chodati wahrscheinlich nicht unbedingt nur auf kälteres Wasser, sondern eher auf reines Wasser angewiesen ist, im Gegensatz zu Pseudopedinella, bei welcher vor allem der Temperaturfaktor die Entwicklung beeinflusst, denn wir fanden diese Form auch im Zürichsee, Pfäffikersee und Untersee (Seen des Mittellandes), vorwiegend im frühen Frühjahr.

Diatomeae. Die Nannoplanktonformen der Diatomeen unserer Breiten umfassen hauptsächlich zentrische Formen, die oft nur vereinzelt, dann aber auch wieder in grossen Massen in den Seen auftreten können. So prägte Cyclotella operculata den Gesamtaspekt des Planktons im Thunerund Brienzersee, während sie in den anderen Seen fehlte. Dazu war Cyclotella comta in den beiden Seen reichlich entwickelt. Neben den dominierenden Blaualgen trat im Hallwilersee Cyclotella kützingiana als typische Form zahlreich in Erscheinung; im Walensee fiel die eher seltene kleine Cyclotella stelligera als Charakterform auf. Daneben lagen vereinzelte Zellen von Cyclotella pseudostelligera, die im Zürichsee zu jener Zeit sporadisch in $5 \mathrm{~m}$ Tiefe auftauchte, vor. Typisch für den Walensee war ferner Stepha- 
nodiscus alpinus, der weder im Brienzer- noch im Thunersee festgestellt werden konnte, und Synedra nana, die auch im Thunersee zu finden war. Stephanodiscus bantzschii war im Sempacher- und Zürichsee vorhanden, während sie in den anderen Seen nicht nachgewiesen werden konnte.

Cryptopbyceae. Als weitverbreitete und häufigste Nannoplankter unserer Seen spielen einzelne Arten der Cryptophyceen oft die Rolle von Massenformen, so namentlich Cryptomonas ovata und Rbodomonas lacustris, weniger Cryptomonas erosa und Rbodomonas lens. Cryptomonas ovata wurde in allen untersuchten Seen beobachtet. Im Brienzersee bildete er mit Cryptomonas erosa zusammen gut einen Drittel der Gesamtmasse. Im Brienzersee trat ferner Cryptomonas cf. tetrapyrenoidosa auf und im Hallwilersee charakterisierte vor allem Cryptomonas erosa var. reflexa als Cryptophycee das Plankton, wo sie sich hauptsächlich im Metalimnion aufhielt.

Peridineae. Von den wenigen beobachtëten Arten sei nur das Auftreten von Peridinium bipes im Hallwilersee erwähnt.

Immer wieder fühlt man sich versucht, analog zu den Pflanzengesellschaften der Makrophyten, die Zusammensetzung des Phytoplanktons der Seen zu charakterisieren, indem Massenformen und ökologische Charakterformen zu Assoziationsgruppen vereinigt werden [12, 72]. Dies ist nicht ganz einfach, da nur einmalige Probenahmen für die Kennzeichnung der Planktongemeinschaften vorliegen, und die Seen sich regional und ökologisch - vor allem durch Temperatur- und Trophiefaktoren unterscheiden. Ausserdem sind die autökologischen Merkmale der Planktonorganismen nur teilweise bekannt. Immerhin bilden die physikalisch-chemischen Untersuchungen der Seen und die quantitative Auswertung der Planktonproben eine sichere Grundlage, um die vorgefundene Planktongemeinschaft einigermassen vernünftig und kurz zu benennen.

Die wichtigsten Merkmale des Planktons der oligotrophen Seen: In jedem der untersuchten Seen waren eine bis zwei Kieselalgen neben einer Chrysophycee oder Cryptophycee mit mindestens 10\% Volumenanteil unter den Hauptformen vertreten. Im Brienzer- und Thunersee finden sich dieselben Hauptkieselalgen, Fragilaria crotonensis und Cyclotella operculata. Im Brienzersee überwog Cryptomonas ovata und erosa, im Thunersee Dinobryon sociale (mit Dinobryon bavaricum und Dinobryon dipergens zusammen) und Ceratium birundinella. Möglicherweise rührt dieser Unterschied von der etwas höheren Temperatur des Thunersees her. Beiden Seen gemeinsam waren die Hauptkieselalgen Fragilaria crotonensis und Cyclotella 
operculata und die Nannoplankter Diceras chodati und Pseudopedinella erkensis. Die Planktongemeinschaft des $W$ alensees war eindeutig durch Kieselalgen geprägt, wobei Tabellaria flocculosa mit nahezu 50\% die Hauptform darstellt. Entsprechenden Erfahrungen an anderen Seen zufolge liesse diese Entwicklung der Kieselalgen eigentlich auf einen leicht eutrophen $\mathrm{Zu}$ stand des Sees schliessen, was die chemischen Analysenresultate jedoch nicht bestätigen. Wie bereits erwähnt, war $P_{\text {seudopedinella erkensis, welche }}$ wir auch im Brienzer- und Thunersee fanden, ebenfalls hier vertreten. Ausschliesslich auf den Walensee beschränkt waren dagegen Cyclotella stelligera, Pseudokepbyrion entzii und Cbrysolykos planctonicus, ein äusserst zarter Chrysoflagellat, der nur in vereinzelten Exemplaren in verschiedenen Tiefen $(0,2,5$ und Is $\mathrm{m})$ vorhanden war.

Die eutrophen Seen wurden durch das Massenauftreten von Blaualgen charakterisiert. Eine auffallende Ähnlichkeit zeigten die Planktongemeinschaften des Hallwiler- und des Zürichsees; hier-dominierte Oscillatoria rubescens mit je über $50 \%$ Volumenanteil. Für diese zwei Seen waren ferner die beiden fädigen Blaualgen, Oscillatoria obliqueacuminata und Pseudanabaena catenata und eine epilimnische kleine, zarte Form aus dem Kreis der Bacteriophyta (Planctomyces bekefii) gemeinsam. Unterschiede zeigten sich hingegen in der Zusammensetzung der Grünalgen. So fand sich im Hallwilersee als typische, in grosser Zahl vorhandene Form Pandorina morum zusammen mit Pbacotus lenticularis, im Zürichsee hatten sich im Bereich von o bis $7,5 \mathrm{~m}$ Tiefe Cblorella pyrenoidosa und Coccomyxa minor

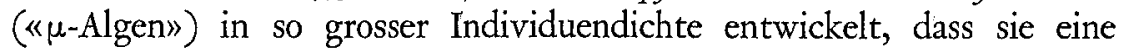
grünliche Vegetationsfärbung verursachten. Ausserdem waren zur Zeit der Untersuchung die Grünalgen Treubaria triappendiculata und Actinastrum bantzschii spezifisch für das Plankton des Zürichsees.

Der Pfäffiker- und der Sempachersee wiesen eine ganz andere Blaualgenzusammensetzung auf. Den Pfäffikersee kennzeichnete eine Massenentfaltung von Aphanothece clatbrata var. brevis, ein Hinweis auf den eutrophen Charakter dieses Gewässers, während im Sempachersee Coelospbaerium kützingianum den grössten Volumenanteil erreichte. Zusammen mit Cbroococcus minutus war diese Form typisch für diesen See. Unter den Grünalgen zeichnete er sich durch das verhältnismässig zahlreiche Hervortreten von Gloeocystis planctonica und Char.ucium gracilipes aus, während im Pfäffikersee die Grünalgen Pbacotus lenticularis und Oocystis lacustris stärker in Erscheinung traten. 'Das sommerliche Phytoplankton der untersuchten Seen könnte demnach mit folgenden Haupt-, Begleit- und Charakterformen umschrieben werden (s. Tab. 23): 
Tabelle 23

Haupt-, Begleit- und Cbarakter-Planktonalgen der untersucbten Seen

\begin{tabular}{|c|c|c|c|}
\hline See & $\begin{array}{l}\text { Hauptformen (mehr als } \\
10 \% \text { Volumenanteil) }\end{array}$ & Begleitformen & Charakterformen \\
\hline Brienzersee & $\begin{array}{l}\text { Cryptomonas ovata } \\
\text { Fragilaria crotonensis } \\
\text { Cyclotella operculata }\end{array}$ & $\begin{array}{l}\text { Rhodomonas lacustris } \\
\text { Rhodomonas lens } \\
\text { Asterionella formosa } \\
\text { Erkenia subaequiciliata } \\
\text { Pseudopedinella erkensis }\end{array}$ & $\begin{array}{l}\text { Cryptomonas } \\
\text { tetrapyrenoidosa } \\
\text { Diceras chodati } \\
\text { Cyclotella comta } \\
\text { Stelexomonas dichotoma }\end{array}$ \\
\hline Thunersee & $\begin{array}{l}\text { Fragilaria crotonensis } \\
\text { Cyclotella operculata } \\
\text { Dinobryon sociale } \\
\text { Ceratium hirundinella }\end{array}$ & $\begin{array}{l}\text { Cryptomonas ovata } \\
\text { Rhodomonas lacustris } \\
\text { Erkenia subaequiciliata } \\
\text { Astorionella formosa } \\
\text { Pseudopedinella erkensis } \\
\text { Dinobryon divergens } \\
\text { Dinobryon bavaricum }\end{array}$ & $\begin{array}{l}\text { Diceras chodati } \\
\text { Hyalobryon mucicola }\end{array}$ \\
\hline Walensee & $\begin{array}{l}\text { Tabellaria flocculosa } \\
\text { Cryptomonas ovata }\end{array}$ & $\begin{array}{l}\text { Erkenia subaequiciliata } \\
\text { Uroglena volvox } \\
\text { Rhodomonas lacustris } \\
\text { Pseudopedinella erkensis. } \\
\text { Peridinium } \\
\quad \text { inconspicuum } \\
\text { Dinobryon sociale } \\
\text { Dinobryon divergens }\end{array}$ & $\begin{array}{l}\text { Pseudokephyrion entzii } \\
\text { Cyclotella stelligera } \\
\text { Stephanodiscus alpinus } \\
\text { Chrysolykos } \\
\quad \text { planctonicus }\end{array}$ \\
\hline $\begin{array}{l}\text { Sempacher- } \\
\text { see }\end{array}$ & $\begin{array}{l}\text { Coelosphaerium } \\
\text { kitzingianum } \\
\text { Ceratium hirundinella }\end{array}$ & $\begin{array}{l}\text { Erkenia subaequiciliata } \\
\text { Fragilaria crotonensis } \\
\text { Gloeocystis planctonica } \\
\\
\text { Characium gracilipes } \\
\text { Cryptomonas ovata } \\
\text { Rhodomonas lacustris } \\
\text { Tetraëdron minimum } \\
\text { Stephanodiscus hantzschii }\end{array}$ & $\begin{array}{l}\text { Chroococcus cf. minutus } \\
\text { Oocystis marssonii } \\
\text { Aphanocapsa } \\
\quad \text { delicatissima }\end{array}$ \\
\hline Zürichsee & Oscillatoria rubescens & $\begin{array}{l}\text { Cryptomonas ovata } \\
\text { Rhodomonas lacustris } \\
\\
\text { Dinobryon sertularia } \\
\text { Erkenia subaequiciliata } \\
\text { Stephanodiscus } \\
\quad \text { hantzschii } \\
\text { Synedra acus var. } \\
\text { Tabellaria flocculosa } \\
\text { Actinastrum hantzschii } \\
\text { "u-Algen" } \\
\text { Selenastrum minutum } \\
\text { Aphanizomenon } \\
\text { flos-aquae } \backslash \\
\text { Peridinium } \\
\text { inconspicuum }\end{array}$ & $\begin{array}{l}\text { Planctomyces bekefii } \\
\text { Oscillatoria } \\
\quad \text { obliqueacuminata } \\
\text { Pseudanabaena } \\
\quad \text { catenata }\end{array}$ \\
\hline Hallwilersee & $\begin{array}{l}\text { Oscillatoria rubescens } \\
\text { Anabaena planctonica }\end{array}$ & $\begin{array}{l}\text { Aphanizomenon } \\
\text { flos-aquae } \\
\text { Anabaena flos-aquae }\end{array}$ & $\begin{array}{l}\text { Planctomyces bekefii } \\
\text { Oscillatoria } \\
\quad \text { obliqueacuminata }\end{array}$ \\
\hline
\end{tabular}




\begin{tabular}{|c|c|c|c|}
\hline See & $\begin{array}{l}\text { Hauptformen (mehr als } \\
10 \% \text { Volumenanteil) }\end{array}$ & Begleitformen & Charakterformen \\
\hline & & $\begin{array}{l}\text { Dinobryon sociale } \\
\text { Erkenia subaequiciliata } \\
\text { Fragilaria crotonensis } \\
\text { A sterionella formosa } \\
\text { Pandorina morum } \\
\text { Phacotus lenticularis } \\
\text { Peridinium } \\
\text { inconspicuum } \\
\text { Peridinium cinctum } \\
\text { Ceratium hirundinella }\end{array}$ & $\begin{array}{l}\text { Pseudanabaena } \\
\quad \text { catenata } \\
\text { Cyclotella kitzingiana } \\
\text { Cryptomonas erosa var. } \\
\quad \text { reflexa } \\
\text { Peridinium bipes }\end{array}$ \\
\hline Pfäffikersee & Aphanothece clathrata & $\begin{array}{l}\text { Anabaena flos-aquae } \\
\text { Fragilaria crotonensis } \\
\text { Cryptomonas ovata } \\
\text { Sphaerocystis schroeteri } \\
\text { Pandorina morum } \\
\text { Ceratium hirundinella }\end{array}$ & $\begin{array}{l}\text { Melosira granulata var. } \\
\text { angustissima }\end{array}$ \\
\hline
\end{tabular}

b) Vertikale Verteilung der Planktonorganismen -

Um die vertikale Verbreitung der Netz- und Nannoplankter innerhalb der untersuchten Seen miteinander zu vergleichen, wurde neben der maximalen Individuendichte der Begriff der «unteren vertikalen Verbreitung» (s. S. 228) herbeigezogen und die berechneten Werte nach Seen und Algengruppen geordnet in Tab. 24 zusammengestellt.

Die untere Verbreitung der Cyano-, Chryso- und Chloropbyceen lagen zwischen 7 und $18 \mathrm{~m}$, ohne dass bedeutende Unterschiede zwischen Nannound Netzplanktonformen in Erscheinung getreten wären. Die Diatomeen erreichten im allgemeinen grössere Tiefen $(28 \mathrm{~m})$, wobei die untere vertikale Verbreitung der Netzplankter durchschnittlich etwas tiefer lag als die der Nannoplankter. Dieser Unterschied rührt vermutlich vom geringeren spezifischen Gewicht und der kleineren Sinkgeschwindigkeit des letzteren her. Bemerkenswerte, doch gut erklärbare Differenzen waren zwischen den Netz- und Nannoplanktern der Peridineen zu beobachten. Die Netzplankter bestanden nämlich hauptsächlich aus Organismen des Epilimnions und der Oberfläche (Ceratium birundinella, Peridinium cinctum usw.), während unter den wenigen Nannoplanktèrn oft Gymnodinium belveticum, eine typisch meta- und hypolimnische Form, neben der charakteristischen Oberflächenform Peridinium inconspicuum dominierte. Vergleichen wir die unteren Verbreitungen des Netz- und Nannoplanktons innerhalb der verschiedenen Seen, so ist besonders auffällig, dass in den oligo- 
trophen Seen das Nannoplankton meistens eine geringere vertikale Verbreitung aufzeigte als das Netzplankton. Dies ist darauf zurückzuführen, dass unter den Netzplanktern bezüglich Individuenzahlen die Diatomeen vorherrschten; im Brienzer- und Thunersee Asterionella formosa (untere vertikale Verbreitung 22,0 bzw. 27,4 m), im Walensee Tabellaria flocculosa (untere vertikale Verbreitung $45 \mathrm{~m}$ ). Die untere vertikale Verbreitung bestimmte im Brienzersee die kleine Cyclotella operculata, im Thunersee das zahlreiche Auftreten von Erkenia subaequiciliata und Cyclotella operculata; und im Walensee wiederum das zahlenmässige Vorherrschen von Erkenia subaequiciliata. Im Sempachersee wurde die untere Verbreitung des Nannound Netzplanktons durch Blaualgen festgelegt, nämlich durch den Nannoplankter Chroococcus cf. minutus und den Netzplankter Coelosphaerium kützingianum, wobei Cbroococcus cf. minutus eher tiefer eingeschichtet war. Im Zürichsee dominierten zahlenmässig nicht die Blaualgen, sondern die Grünalgen (Chlorella, Coccomyxa) und die Chrysophyceen (Dinobryon spp.), und im Hallwilersee hatten für das Nannoplankton wiederum Erkenia subaequiciliata, für das Nannoplankton Oscillatoria rubescens und Pandorina morum die für die untere Verbreitung ausschlaggebenden Individuenzahlen geliefert.

Gewisse, durch die Verhältnisse der Seen bedingte Unterschiede in der unteren vertikalen Verbreitung der einzelnen Algengruppen innerhalb der untersuchten Seen lassen sich nur bei den Cryptophyceen und Chrysophyceen beobachten. So steigen sie in den oligotrophen Seen teilweise tiefer hinunter als in den eutrophen, was wohl mit der Lage und der Mächtigkeit des Metalimnions zusammenhängt. Besonders zu erwähnen sind die prägnanten, stark streuenden Werte der unteren vertikalen Verbreitung der Cryptophyceen, die mit $80 \mathrm{~m}$ (Thunersee) überhaupt die grösste untere vertikale Erstreckung aufwiesen. Diese Zahlen sind so eindrücklich, dass man sich fragt, ob sich in diesen Tiefen nur abgesunkene Organismen befanden oder ob hier die Umweltsverhältnisse den Organismen tatsächlich noch ein Weiterleben gestattet hätten, denn diese zarten, auf äussere Umweltsveränderungen meist negativ reagierenden Flagellaten waren in den Proben der oligotrophen Seen noch erstaunlich gut erhalten. Im Zürichsee lag die untere Verbreitungsgrenze dieser Formen erheblich höher. Begrenzender Faktor schien, vor allem für Rbodomonas, das metalimnische Sauerstoffminimum zwischen 7,5 und $5 \mathrm{~m}$ zu sein (s. Abb. 22 b). Im Hallwilersee fehlte Rbodomonas lacustris völlig zur Zeit der Probenahme. Zahlreich wurde in diesem See dafür Cryptomonas erosa var. reflexa beobachtet, wo er sich im Metalimnion angereichert 


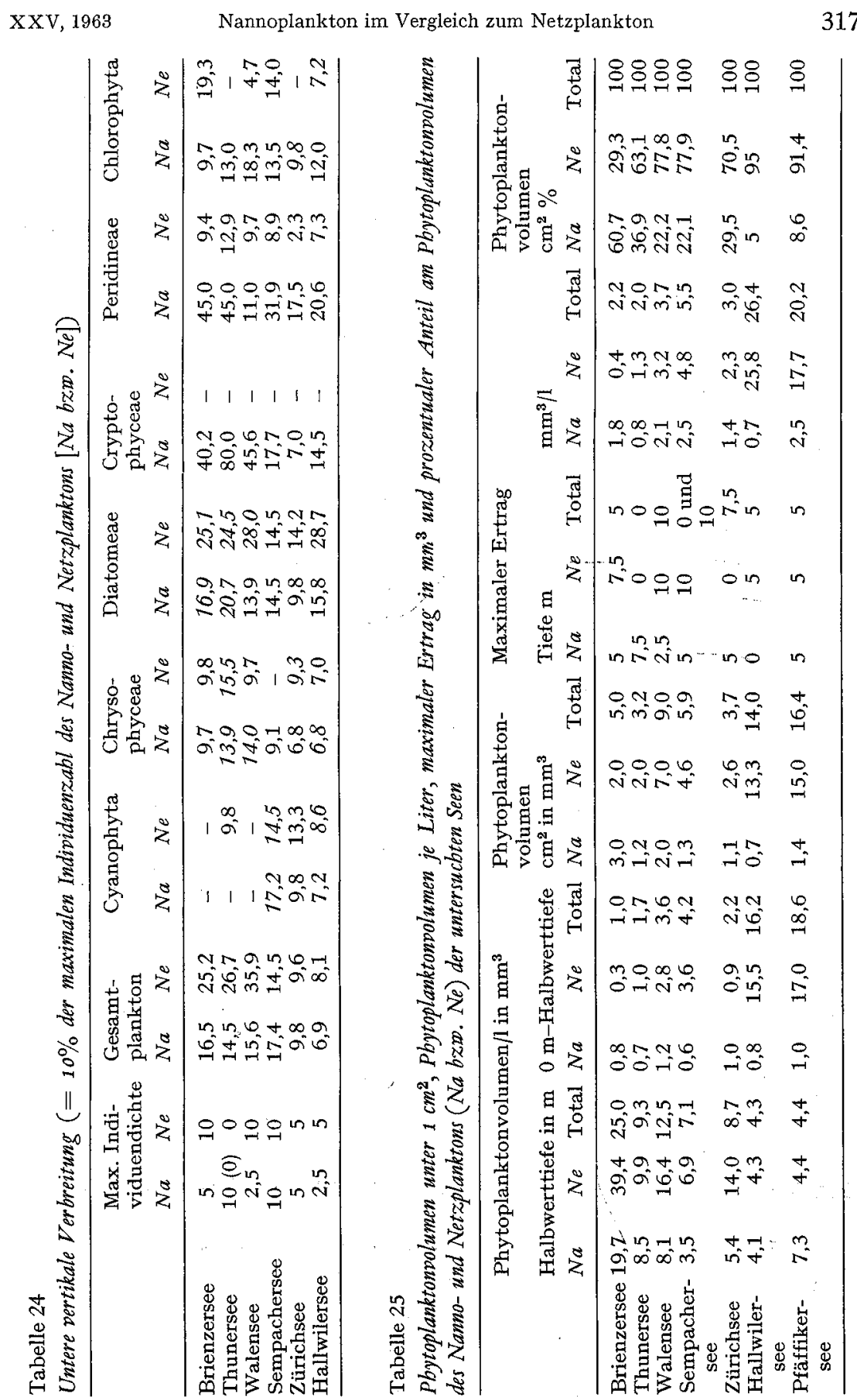


hatte. Im Gegensatz zu Rhodomonas lacustris scheint diese Art eher resistent zu sein gegenüber Sauerstoffschwund.

Zusammenfassend kann gesagt werden, dass die vertikale Verteilung (vgl. Tab. 24) der Netz- und Nannoplankter keine wesentlichen Unterschiede aufzeigte. Dies ist begreiflich, wenn man bedenkt, dass das Nannowie das Netzplankton aus beweglichen und unbeweglichen, kugeligen, stäbchenförmigen und koloniebildenden, mit Gasvakuolen und Gallerten versehenen Formen zusammengesetzt ist. Ein Unterschied kann höchstens bei den unbeweglichen Planktonorganismen, infolge des unterschiedlichen spezifischen Gewichtes und der Sinkgeschwindigkeit, auftreten.

\section{c) Die Biomasse}

In Tab. 25 (vgl. auch Abb. 23 b) sind die durchschnittlichen Volumina je Liter sowie die maximalen Erträge und Phytoplanktonmassen unter I $\mathrm{cm}^{2}$ des Nanno-, Netz- und Totalphytoplanktons zusammengestellt, wobei die Seen nach steigendem Trophiegrad geordnet wurden.

Wie zu erwarten war, wiesen der Pfäffiker- und Hallwilersee die grössten durchschnittlichen Litervolumen und extreme Höchstwerte auf.

Auffallend niedrig war der Litergehalt des Züricbsees. Ein ähnlicher Tiefpunkt der Biomasse war I958 im Zürichsee (Abb. 6) und im Pfäffikersee im Jahr I96I (Abb. I5) zu beobachten gewesen. Auch FINDENEGG [IS] berichtet von ähnlichen «Atmungspausen» in der Planktonentwicklung der Kärntner Seen. Vermutlich liegt hier ein Zusammenhang mit der Erschöpfung der Nährstoffe in der Produktionsschicht vor. Der durchschnittliche Litergehalt des Nannoplanktons war in allen untersuchten Seen klein und bewegte sich in schwachen Schwankungen zwischen den Werten von 0,6 bis I,2 $\mathrm{mm}^{3} / 1$. Das durchschnittliche Litergewicht des Totalphytoplanktonvolumens wurde demnach durch die teilweise sehr hohen Netzplanktonvolumen verursacht. Nur im Brienzer- und im Zürichsee war das mittlere Nannoplanktonvolumen je Liter etwas grösser als dasjenige des Netzplanktons, was wohl auf die grossen Unterschiede der Halbwerttiefen der Phytoplanktontypen zurückzuführen ist (vgl. Tab. 25, Kolonne Halbwerttiefen). Der durchschnittliche Litergehalt lag, mit Ausnahme desjenigen des Zürichsees, in guter Korrelation zum Trophiegrad, das heisst zum Nährstoffgehalt der produzierenden Schicht, was auch den Feststellungen von FINDENEGG [15] und RUTTNER [60] entspricht.

Die Mächtigkeit der Produktionsschicht, die in den verschiedenen Seetypen stark variieren kann, kam in der Planktonmasse unter $\mathrm{I} \mathrm{cm}^{2}$ der untersuchten Seen zum Ausdruck (Tab. 25, Abb. 23). Der Brienzersee zum 


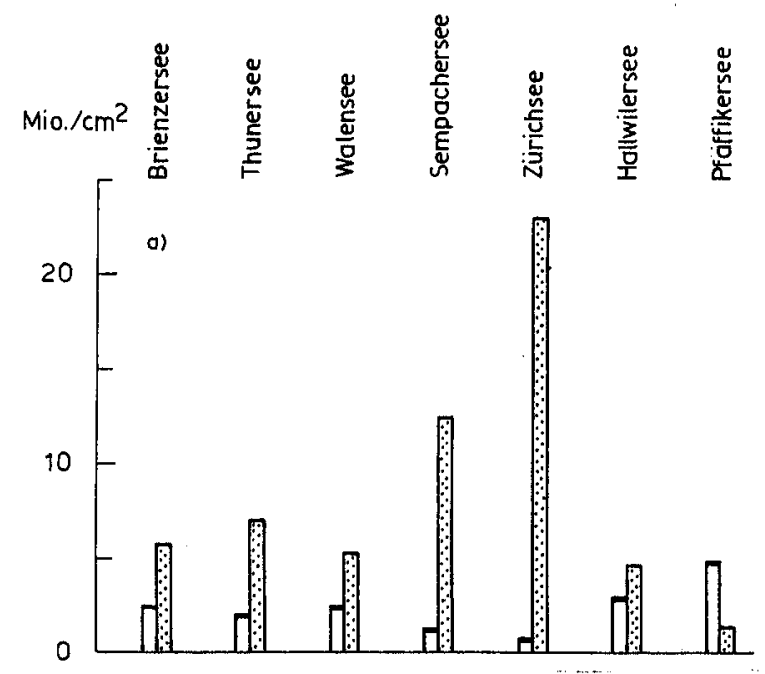

$\mathrm{mm}^{3} / \mathrm{cm}^{2}$

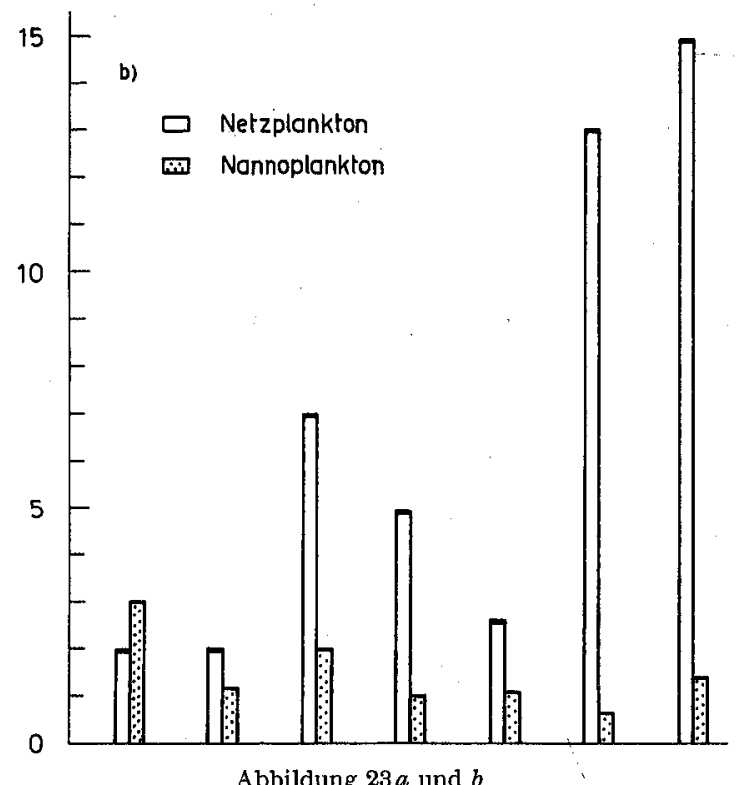

Netz- und Nannoplankton der untersuchten Seen. $a$ ) Individuenzahlen in Mio/ $\mathrm{cm}^{2} . b$ ) Biomasse in $\mathrm{mm}^{3} / \mathrm{cm}^{2}$.

Beispiel hatte trotz kleinstem Litergehalt eine grössere Biomasse als der Zürichsee und der Tbunersee, und der $W$ alensee - aus dem gleichen Grund eine höhere als der Sempachersee. 
Das Nannoplankton erreichte im Brienzersee $\left(3 \mathrm{~mm}^{3} / \mathrm{cm}^{2}\right)$ die stärkste, im Hallmilersee $\left(0,7 \mathrm{~mm}^{3} / \mathrm{cm}^{2}\right)$ die geringste Biomasse.

Gesetzmässigkeiten für die Entwicklung der beiden Planktontypen hinsichtlich «Fruchtbarkeit und Mächtigkeit der Produktionsschicht» analog zum Totalplankton können aus diesen wenigen Zahlen nicht herausgelesen werden, obschon man vom Brienzer- und Walensee den Eindruck gewinnt, dass die Masse des Nannoplanktons zur Sommerszeit in oligotrophen Seen grössere Werte aufweist als in den eutrophen Seen; doch müsste das zuerst in weiteren Untersuchungen abgeklärt werden. Fest steht dagegen, dass zur Zeit der Probenahme das Netzplankton, mit Ausnahme des Brienzersees, wo das Nannoplankton gut $60 \%$ ausmachte, sowohl in den oligo- als auch in den eutrophen Seen dominierte (vgl. auch die Prozentzahlen in Tab. 25). Ursache dafür war die starke Blaualgenentfaltung in den eutrophen, warmen und das Vorherrschen der grösseren Kieselalgen in den oligotrophen, kühleren Seen. Dech war das Nannoplankton, mit Ausnahme des Hallwilersees, in den untersuchten Seen prozentual so stark vertreten, dass es bei der Erfassung der Biomasse nicht hätte vernachlässigt werden können.

\section{F. Schlussbemerkungen}

I. Nannoplankton und Zusammensetzung des Phytoplanktons

Im Laufe der Untersuchungen wurden unter andern aus folgenden Gattungen wichtige Vertreter des Nannoplanktons gefunden: Oscillatoria, Cblamydomonas, Pbacotus, Cblorella, Coccomyxa, Erkenia, Cyclotella, Stephanodiscus, Rbodomonas, Cryptomonas, Katablepharis, Gymnodinium.

Während im ganzen durchschnittlich meistens doppelt so viele Nannoals Netzplanktonformen bestimmt wurden, wurden in dieser Arbeit ungefähr gleich viele Netz- und Nannoplanktonorganismen für die quantitative Auswertung berücksichtigt. Oft gab es unter den Nannoplanktern Organismen, die den Biotop ausgezeichnet charakterisierten, zum Beispiel Stelexomonas dichotoma: kalt-stenotherm, oligotroph (Brienzersee); Cbrysolykos planctonicus: kalt-stenotherm, oligotroph (Walensee); Diceras cbodati: oligotroph (Brienzersee, Thunersee); Oscillatoria obliqueacuminata: warmstenotherm, eutroph (Hallwilersee, Zürichisee, auch Untersee); Planctomyces bekefii: warm-stenotherm, eutroph (Hallwilersee, Zürichsee).

Daraus geht hervor, dass das Nannoplankton bei limnologischen Untersuchungen, wenn auch nicht immer quantitativ, doch wenigstens qualitatip berücksichtigt werden sollte, da es einen wesentlichen Teil einer Plankton- 
gemeinschaft ausmachen kann, und es gerade unter dem Nannoplankton oft sehr charakteristische Formen gibt, die einen See als Lebensraum gut zu kennzeichnen vermögen.

\section{Nannoplankton und Biomasse}

Versucht man, unsere Resultate einigermassen vergleichbaren Biomassewerten aus anderen Arbeiten gegenüberzustellen, so fällt auf, dass der Volumenanteil bzw. die Biomasse des Nannoplanktons zum gesamten pflanzlichen Plankton in den von uns bearbeiteten Seen eher gering ist, dass dagegen der absolute Biomassegehalt pro Flächeneinheit höher liegt. Im Jahre 1958 machte das Nannoplankton des Zürichsees durchschnittlich 5,9\%, im Jahre I959 9,0\% des gesamten Phytoplanktons aus; der Durchschnitt des Pfäffikersees betrug $\mathrm{I} 4 \%$, und die einmalige Untersuchung der übrigen Seen ergab einen Anteil von $18 \%$.

Im Lunzer Untersee hingegen war die jährliche Nannoplanktonmasse dreimal grösser als jene des Netzplanktons [54]. In den ostalpinen Seen wurde sozusagen reines Nannoplankton, vor allem kleine Cyclotellen, gefunden, während Netzformen, wie grössere Diatomeen, stark zurücktraten [56]. GRIM bezeichnete den Bodensee noch als Cyclotellensee [2I].

In den einzelnen Kärntner Seen [Is] herrschten hauptsächlich Cyclotellen vor, in anderen bestimmten Oscillatoria rubescens und Ceratium birundinella das Bild. Durchschnittlich I0\% Nannoplanktonanteil ergaben einmalige Untersuchungen an 6 oberitalienischen Seen [59].

Besonders eindrücklich sind die interessanten Resultate von Untersuchungen an hochalpinen Seen Österreichs durch RoDHE [ $5 \mathrm{I}]$, wo das Nannoplankton den Hauptanteil der Biomasse (z. B. im Schwarzsee 97\%) ausmachte. RUTTNER [58] betont in den Untersuchungsergebnissen des Sundamaterials, dass die meisten pflanzlichen Vertreter zum Nannoplankton gehören. Nahezu 40\% Volumenanteil erreichte das Nannoplankton im schwedischen See Mälaren [76].

Zu diesen Beispielen sei bemerkt, dass erstens das Netz- und Nannoplankton nicht immer getrennt berücksichtigt worden war, zweitens die Resultate von zeitlich und zahlenmässig unterschiedlichen Untersuchungen herstammten und dass zudem, je nach Gutdünken der Autoren, gewisse Grenzformen noch zum Nannoplankton gerechnet wurden, andere wieder nicht.

Dadurch und durch andere ungleiche Voraussetzungen und Durchführungen der vorerwähnten Arbeiten wird der Vergleich natürlich erschwert. Man kann sich beispielsweise fragen, ob Ergebnisse von ein- 
maligen Untersuchungen überhaupt mit durchschnittlichen Jahreszahlen verglichen werden dürfen, besonders wenn man berücksichtigt, wie gross allein die Schwankungen der Biomasse von Probe zu Probe sein können (vgl. Min./Max. Zürichsee-Pfäffikersee, S. 284), und wie sehr das Verhältnis zwischen Netz- und Nannoplankton ändert, je nachdem man einen Organismus noch zur einen oder andern Gruppe zählt (vgl. Coelosphaerium kützingianum im Sempachersee, das rund $48 \%$ des Gesamtvolumens bestreitet. In unseren Untersuchungen als Netzplankter behandelt, könnte man es auch als Nannoplankter berücksichtigen). Äusserst vorsichtig sollte man sein bei klimatisch und ökologisch vollständig verschiedenen Seen (z. B. Tropenseen der Sundainseln oder der durch Brackwasser beeinflusste See Mälaren). Wenn wir aus den Zahlen unserer Untersuchungen im Vergleich zu den anderen Arbeiten trotzdem allgemeine Schlüsse zu ziehen versuchen, so nur mit Vorbehalt und in Form von Vermutungen, welche in weiteren Untersuchungen noch gründlichèr abgeklärt und bewiesen werden müssen.

Die am Anfang dieses Abschnittes genannten, zum Teil auffallend grossen Unterschiede bezüglich Nanno- und Netzplankton in den verschiedenen Seen werden vor allem durch die artenmässige Zusammensetzung bestimmt. In den Seen unseres Gebietes entwickeln sich häufig koloniebildende, grössere Kieselalgen wie Fragilaria crotonensis, Asterionella formosa und Tabellaria fenestrata. Oft entstehen, vor allem in den eutrophen Seen, Massenentfaltungen von Blaualgen wie Microcystis flosaquae, Oscillatoria rubescens und Apbanizomenon flos-aquae, die durch ihre grossen Volumina die Biomasse eines Sees ausschlaggebend erhöhen können (z. B. Pfäffikersee, 28. 7. 6I: Aphanotbece clatbrata var. brepis $\mathrm{I} 2,5 \mathrm{~mm}^{3} /$ $\mathrm{cm}^{2}=250600$ Kolonien $/ \mathrm{cm}^{2}=77 \%$ der gesamten Phytoplanktonmasse; I . Io. 6I: Apbanizomenon flos-aquae: $44,9 \mathrm{~mm}^{3} / \mathrm{cm}^{2}=8,3$ Mio. Fäden/ $\mathrm{cm}^{2}=96,6 \%$. Zürichsee, 2. 2. 59 : Oscillatoria rubescens: $68,7 \mathrm{~mm}^{3} / \mathrm{cm}^{2}$ $=\mathrm{I}, 8 \mathrm{Mio}$. Fäden $/ \mathrm{cm}^{2}=99,4 \%$ ). Während diese grossen Formen somit schon mit relativ kleinen Individuenzahlen beträchtliche Biomasse (vgl. auch die grösste einzellige Phytoplanktonform des Süsswassers: Ceratium birundinella, die mit nur 24200 Individuen schon eine Biomasse von $\mathrm{I}, 4 \mathrm{~mm}^{3}$ formt) ausbilden, vermögen die Nannoplankter nicht einmal zu Zeiten riesiger Volksdichten annähernd ähnliche Biomassen zu erreichen, auch dann nicht, wenn Vegetationsfärbungen und auffallend niedrige Sichttiefen das Gegenteil erwarten liessen (vgl. Zürichsee, 5. 8. 58: Cblorella pyrenoidosa $85,8 \mathrm{Mio} . / \mathrm{cm}^{2}=\mathrm{I}, 2 \mathrm{~mm}^{3} / \mathrm{cm}^{2} ; 3.3$. 59: Stephanodiscus bantzscbii $37 \mathrm{Mio} . / \mathrm{cm}^{2}=6,7 \mathrm{~mm}^{3} / \mathrm{cm}^{2}$ ). 
Nach diesen Hinweisen über die Biomasse des Netz- und des Nannoplanktons ist es begreiflich, dass in Seen, wo koloniebildende Kieselalgen und vor allem grosse Blaualgen vorherrschen - erfahrungsgemäss ist das häufig in den eutrophen Seen der mitteleuropäischen Region der Fall die prozentuale Biomasse des Nannoplanktons im Laufe des Jahres oft bis auf Bruchteile von Prozenten zurückgedrängt werden kann (z. B. war der Anteil des Nannoplanktons im Zürichsee am 8. I. 58:0,8\%, am I4. I0. 58 : 0,8\%, am 17. 2. 59:0,4\%, am 29. 9. 59:0,1\%, am 8. I2. 59:0,7\%, und im Pfäffikersee am I2. 9. 6r: 0,4\%). Daneben aber kann je nach der $\mathrm{Zu}-$ sammensetzung des Planktons eine Hochproduktion von beinahe reinem Nannoplankton eintreten, die jedoch nie die eindrücklichen Biomassen, welche Netzplankter $\mathrm{zu}$ bilden vermögen, erreicht (vgl. Pfäffikersee 23. 3. 6r: Nannoplankton (Cryptophyceen und Stephanodiscus bantzscbii) $7,2 \mathrm{~mm}^{3} / \mathrm{cm}^{2}(=98,5 \%)$; II. IO. 6I : Netzplankton (fast ausschliesslich Aphanizomenon flos-aquae) $45,9 \mathrm{~mm}^{3} / \mathrm{cm}^{2}$ (=99\%). Zürichsee: 3.3 .59 : Nannoplankton (Stephanodiscus bantzscbii) $7,8 \mathrm{~mm}^{3} / \mathrm{cm}^{2}(=42,3 \%$ ), I7. 2 . 59: Netzplankton (Oscillatoria rubescens) $68,9 \mathrm{~mm}^{3} / \mathrm{cm}^{2}(=99,6 \%$ ). In oligotrophen. Seen Mitteleuropas hingegen scheint das Nannoplankton das Netzplankton meistens um ein Mehrfaches an Biomasse zu übertreffen (vgl. Lunzer Untersee, ostalpine Seen). Die grösseren, koloniebildenden Kieselalgen, aber auch Blaualgen des Netzplanktons treten in auffallend kleiner Zahl auf oder finden sich überhaupt nicht in den Artenlisten. Ausdrücklich erwähnt seien nochmals die Untersuchungsresultate RODHES [5I] für hochalpine Seen in Österreich, wo allerdings neben einer extremen Nährstoffarmut auch die für solche Seen typischen tiefen Dauertemperaturen die Auslese der Planktonorganismen bestimmte. In unserer Vergleichsreihe wies der noch am ehesten als oligotroph zu bezeichnende Brienzersee, als einziger eine Nannoplanktonmenge auf (60\%), die grösser war als das Netzplankton, und zwar zu einer Jahreszeit, wo in den eutrophen, wärmeren Seen die Blaualgen des Netzplanktons vorherrschten.

Diese Erläuterungen erwecken den Eindruck, dass die Nannoplankter im Vergleich zu den Netzformen des Phytoplanktons in verschiedenen extremen Lebensbedingungen, wie zum Beispiel in stark oligotrophen Seen, überwiegen, während sie in den eutrophen Seen durch das gehäufte Auftreten von Netzplanktern volumenmässig stark zurückgedrängt werden können. Dem ist entgegenzustellen, dass auch in extrem hypertrophen Gewässern - solche findet man allerdings häufiger unter Teichen als bei tiefen Seen - enorme Algenentwicklungen beobachtet werden können, die aus kleinem Nannoplankton bestehen [73]. 
Die Behauptung, dass ein Zusammenhang besteht zwischen extremen Umweltbedingungen und der Entwicklung von Nannoplankton (vgl. Abb. 24), wartet allerdings noch einer Bestätigung.

Diese Vermutung wird teilweise erklärt und unterstützt, wenn man die einzelnen Algengruppen hinsichtlich planktischer Nanno- und Netzplanktonformen miteinander vergleicht. Es gibt nämlich ganz allgemein viel mehr pflanzliche Nanno- als Netzplankter. Daher ist auch die Wahrscheinlichkeit verhältnismässig gross, dass unter extremen Bedingungen die Nannoplankter den Netzplanktern ökologisch überlegen sind.

Die meisten planktischen Blaualgen sind grössere Formen, die sich hauptsächlich in nährstoffreicherem und warmem Wasser in eindrücklicher Masse entfalten können. Die Euchlorophyceen und Euglenophyten bestehen zum grössten Teil aus Nannoplankton und ziehen im allgemeinen eutrophes Milieu vor. Eine bedeutende Anzahl dieser Formenkreise entwickeln sich in auffallender Menge oft in extrem eutrophen Gewässern, meist kleineren Teichen und häufig in gedüngten Tümpeln. Ein grosser Prozentsatz der Chrysophyceen umfasst kleine Formen, die, um gut zu gedeihen, vorwiegend (abgesehen von den grösseren koloniebildenden Formen wie Dinobryon- und Uroglenaarten) auf reines und eher kühles Wasser angewiesen sind. Die Diatomeen, die ungefähr gleich viele Nanno- und Netzplanktonarten aufweisen, reagieren ökologisch oft ganz unterschiedlich; viele Cyclotellen ziehen oligotrophes Wasser vor, Stephanodiscus bantzschii wiederum bildet Massenentfaltungen in eutrophen Seen, wie auch die meisten Netzformen unter den Kieselalgen. Die Planktonvertreter der Cryptophyceen, alles Nannoplankter, sind durch ökologische Spezialisten, aber auch durch Ubiquisten gekennzeichnet und können sowohl in eutrophen als auch in oligotrophen Seen zahlreich in Erscheinung treten. Die Peridineen, aus Netz- und grösstenteils Nannoplankton bestehend, sind ebenfalls ein ökologisch variierender Formenkreis, der durch Spezialisten für verschiedene Wassertypen und -schichtungen hervortritt.

Zusammenfassend kann festgehalten werden, dass das Plankton der oligotrophen Seen unserer Regionen vor allem aus Nannoplanktern der Chrysophyceen, Diatomeen, Cryptophyceen und Peridineen gebildet ist. Die eutrophen Seen aber sind vorwiegend von Netzplanktern aus den Gruppen der Diatomeen und Blaualgen besiedelt. In den Gewässern jedoch, die noch stärker mit organischen Stoffen belastet sind, treten vorwiegend Nannoplankter aus den Gruppen der Euchlorophyceen und Euglenophyten auf (Abb. 24). 


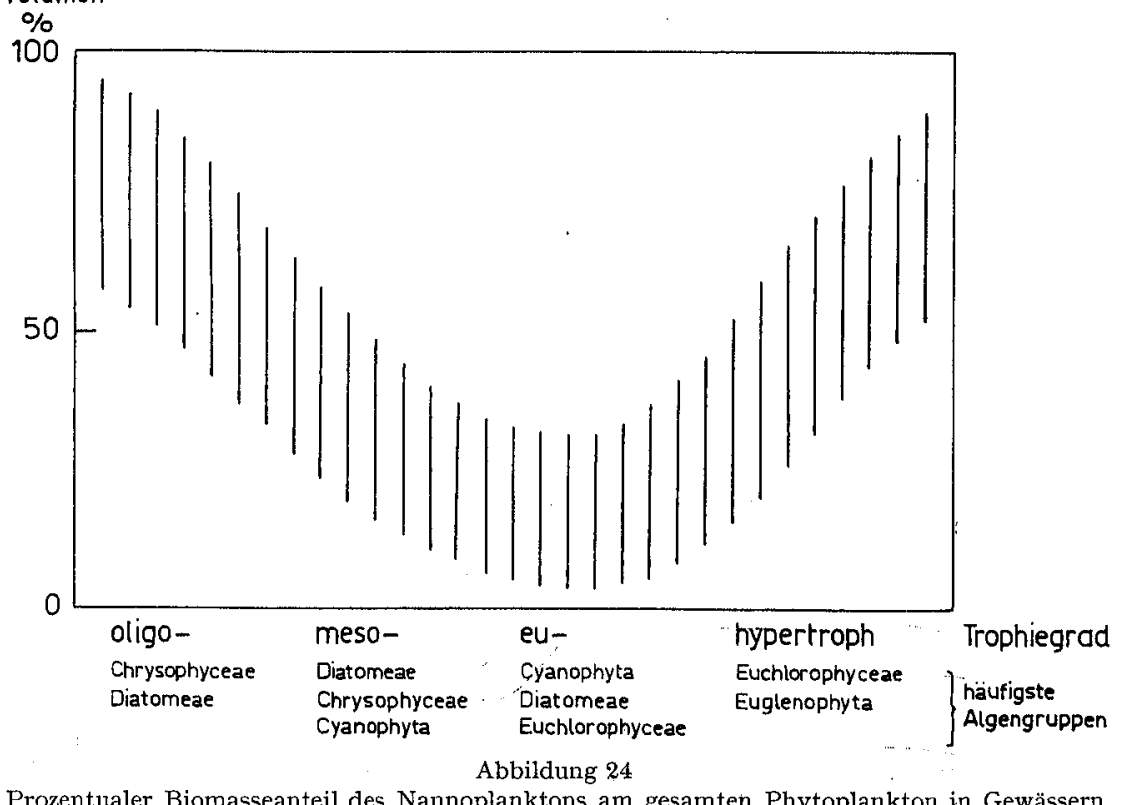

Prozentualer Biomasseanteil des Nannoplanktons am gesamten Phytoplankton in Gewässern von verschiedenem Trophiegrad (schematische Darstellung).

\section{Nannoplankton und Individuenzahlen}

Wie die vorstehenden Ausführungen zeigen, sind die prozentualen Anteile der Biomasse des Nanno- und des Netzplanktons zumindest in den untersuchten Seen stark verschieden, meistens zugunsten des Netzplanktons. Vom praktischen Standpunkt aus läge deshalb der Schluss nahe, dass zur Feststellung der gesamten Biomasse das Nannoplankton manchmal überhaupt vernachlässigt werden könnte. Werden jedoch die absoluten Werte dieser Planktontypen in Betracht gezogen, so erkennt man, dass neben einem verhältnismässig stark entwickelten Netzplankton ebensogut eine an Individuen, aber auch an Volumen bzw. Biomasse nicht unbedeutende Menge Nannoplankton vorhanden sein kann (z. B. Hallwilersee 28. 7. 6r : Nannoplankton $5 \%$ Volumenanteil $=4,8$ Mio. Indiv. $/$ $\mathrm{cm}^{2}=0,7 \mathrm{~mm}^{3} / \mathrm{cm}^{2}$, Netzplankton $95 \%$ Volumenanteil $=2,9$ Mio. Indiv. $/ \mathrm{cm}^{2}=14,0 \mathrm{~mm}^{3} / \mathrm{cm}^{2}$; Zürichsee 7. 7. $59:$ Nannoplankton $5 \%$ Volumenanteil $=2,2$ Mio. Indiv. $/ \mathrm{cm}^{2}=0,5 \mathrm{~mm}^{3} / \mathrm{cm}^{2}$, Netzplankton $95 \%$ Volumenanteil $=0,6$ Mio. Indiv. $/ \mathrm{cm}^{2}=7,3 \mathrm{~mm}^{3} / \mathrm{cm}^{2} ; \mathrm{I3} .5 .59$ : Nannoplankton $\varsigma \%=8,6$ Mio. Indiv. $/ \mathrm{cm}^{2}=8,8 \mathrm{~mm}^{3} / \mathrm{cm}^{2}$ ).

In den ostalpinen Seen bestand der überwiegende Anteil des Planktons 
aus Nannoformen, während das Netzplankton nur in bedeutungslosen Zahlen vorhanden war. Diese Feststellung allein ist indessen unvollständig. So finden wir sowohl im Zürich-als auch im Pfäffikersee und in den übrigen untersuchten Seen trotz überwiegendem Netzplankton für den Nannoanteil immer noch um ein Mehrfaches höhere Maximalliterzahlen und -biomassewerte. Im Lunzer Untersee zum Beispiel erreichte die häufigste Diatomee Cyclotella comta während der Jahre I9II-I9I3 die Höchstzahl von gut 600000 Indiv./l, was überhaupt die grösste beobachtete Dichte darstellte [SI]. Die höchste Biomasse, die bei den Untersuchungen der ostalpinen Seen Österreichs [52] beobachtet wurde, war 4,0 $\mathrm{mm}^{3} / \mathrm{cm}^{2}$. Im Zürichsee betrug die grösste Dichte, die eine Alge erreichte, I29 Mio./l (Cblorella pyrenoidosa), und die grösste Nannoplanktonmasse $\left(7,8 \mathrm{~mm}^{3} / \mathrm{cm}^{2}\right)$ wurde ebenfalls im Zürichsee festgestellt. Es ist deshalb nicht erstaunlich, dass das Zooplankton, welches sich vorwiegend von Nannoplankton ernährt, in eutrophen Seen zahlreicher vorhanden ist als in oligotrophen, obgleich hier das Nannoplankton im Vergleich zum Netzplankton volumenmässig stark zurücktritt.

Dass aber weder prozentuale Volumenzahlen noch absolute Biomassewerte allein genügen, um die Bedeutung des Nannoplanktons zu'beurteilen, kann anhand weiterer Beispiele dieser Untersuchung und aus Literaturangaben gezeigt werden. Betrachten wir die Individuenzahlen des Nannoplanktons, so stellen wir fest, dass sie diejenigen des Netzplanktons oft um ein Vielfaches übersteigen. So waren im Zürichsee die Individuenzahlen des Nannoplanktons in $3 / 5$ von rund so Probeserien höher als diejenigen des Netzplanktons. Durchschnittlich waren sie im Zürichsee fünfmal und im Pfäffikersee viermal grösser als die Netzplanktonzahlen (vgl. auch Abb. 17,23 ).

Beim Vergleich von Individuenzahlen ist allerdings zu bemerken, dass mit dem Begriff «Individuen» nicht immer einzellige Algen, sondern auch mehrzellige Formen bezeichnet werden, wie zum Beispiel Microcystis- und Coelosphaeriumkolonien oder Blaualgenfäden, darunter Oscillatoria rubescens und Oscillatoria obliqueacuminata. Trotzdem glauben wir, dass es wiederum nicht richtig wäre, die durchschnittliche Zellzahl eines Fadens zu berechnen und diese einzelnen Zellen als Individuen zu betrachten. Oscillatoria rubescens zum Beispiel ist eine langsam wachsende Form, so dass diese Zellzahlen eine zu grosse Teilungsaktivität dieser Alge vortäuschen würden im Gegensatz zu den Individuenzahlen der kleinen Flagellaten. Waren letztere in grosser Anzahl vorhanden, zeigten sie nämlich meistens auch eine grosse Teilungsaktivität, was besonders schön in der $\mathrm{O}_{2^{-}}$ 
Produktion und in der Zehrung von Nährstoffen sichtbar wurde (vgl. Tabelle I6).

Ferner kann es auch Fälle geben, in denen es angezeigt ist, die Bedeutung des Nanno- gegenüber dem Netzplankton anhand der Individuenzahlen und nicht der Biomassewerte zu beurteilen. Nach einer Ruhepause in den Sommermonaten 1958 stiegen die Individuenzahlen von Oscillatoria rubescens Ende August stark an, fielen jedoch vierzehn Tage später wieder stark zurück. Möglicherweise ist dieser Rückgang auf die plötzliche Massenentfaltung der feinen, fädigen Blaualgen Oscillatoria obliqueacuminata zurückzuführen, die im September 3,4 Mio. Fäden $/ \mathrm{cm}^{2}$ und eine Höchstliterzahl von 3,8 Mio./l in 2,5 m erreichte gegenüber rund I60000 Fäden $/ \mathrm{cm}^{2}$ der Oscillatoria rubescens (vgl. Abb. 2). Anhand der Biomasse käme die Aktivität und die Konkurrenzfähigkeit dieser feinen Blaualgen nicht zum Ausdruck (Oscillatoria rubescens $5,9 \mathrm{~mm}^{3} / \mathrm{cm}^{2}$, Oscillatoria obliqueacuminata $3, \mathrm{I} \mathrm{mm} / \mathrm{cm}^{2}$ ).

Die Bedeutung der Individuenzahl gegenüber der Biomassezahl wird auch in der starken Entfaltung der « $\mu$-Alge» Chlorella pyrenoidosa im Juli I96I klar, wo diese Form im Zürichsee, in der Schicht von 0-7,5 m ziemlich gleichmässig verteilt; einen durchschnittlichen Litergehalt von 23 Mio./1 erreichte und unter $\mathrm{I} \mathrm{\textrm {cm } ^ { 2 }}$ 2I,3 Mio. Individuen entwickelt hatte. Durch diese Volksdichte wurde die Sichttiefe auf $\mathrm{I}, 9 \mathrm{~m}$ herabgesetzt. Diese kleine Alge schwächte durch ihre hohe Populationsdichte die Lichtintensität der oberen Wasserschichten in bedeutendem Masse, was man sich mit Biomassezahlen nie vorstellen könnte. Der Biomasseanteil betrug nämlich nur $2,4 \%$, während Oscillatoria rubescens mit $55 \%$ nur II 8000 Fäden $/ \mathrm{cm}^{2}$ aufwies.

\section{Nannoplankton - Stoffkreislauf}

Bei diesen Untersuchungen konnten leider nur statische Ejgenschaften der Organismen, wie Individuenzahlen und Biomasse, berücksichtigt werden. Im Abschnitt über Nannoplankton Pfäffikersee-Stoffkreislauf (S. $276 \mathrm{ff}$.) wurde jedoch anhand chemischer Daten auf die Bedeutung des Nannoplanktons für den Stoffkreislauf in einem See hingewiesen. Um seine Wichtigkeit für das limnische Geschehen voll zu erfassen, müsste man beispielsweise seine Dynamik im Vergleich zum Netzplankton beobachten. Dies hat RODHE [50] für den Erkensee mittels der $\mathrm{C}_{14}$-Methode gemacht und festgestellt, dass die Aktivität bzw. die Teilungsgeschwindigkeit der kleinen Organismen (allerdings rechnete er dazu solche bis 
zu Ioo $\mu$ Grösse) um ein Vielfaches grösser ist als beim pflanzlichen Netzplankton. Ferner wäre es ausserordentlich interessant, die Abbaugeschwindigkeit dieser kleinen Organismen zu ermitteln, ferner, in welcher Tiefe diese hauptsächlich stattfindet. GoLTERMANN [20] hat im Labor Abbauversuche durchgeführt und unter anderem festgestellt, dass Phosphate, aber auch Kieselsäure und Nitrate innerhalb kurzer Zeit wieder freigesetzt werden können.

Man kann sich gut vorstellen, dass besonders die kleinen, zarten Flagellaten und « $\mu$-Algen» (weniger die kleinen Kieselalgen) durch ihre grössere Aufbau- und Abbaugeschwindigkeit und kleinere Sinkgeschwindigkeit den Stoffumsatz vor allem eines tieferen Sees im Epi- und Metalimnion stärker beeinflussen als das Netzplankton, dies ganz besonders auch in Zeiten der Teilzirkulationen. Die grösseren Formen indessen, die relativ langsam wachsen, schneller absinken und für ihren Abbau mehr Zeit benötigen, wirken in Zeiten ihrer-Höchstentfaltungen durch Nährstoffentzug und Abgabe von Stoffwechselprodukten auf Epi- und Metalimnion ein, dann aber sind sie hauptsächlich mit dem Zooplankton zusammen an der Schlammbildung beteiligt. Ein grosser Teil der mineralisierten organischen Stoffe, die mit den Vollzirkulationen wieder ins Pelagial gelangen, stammt vermutlich von pflanzlichen Netzplanktern.

In ihrem dynamischen Verhalten stehen wahrscheinlich viele kleine Nannoplankter den Bakterien näher als dem Netzplankton.

Zusammenfassend kann gesagt werden, dass das Nannoplankton sowohl für die qualitative Zusammensetzung des Planktons, für die Biomasse, die Produktion und für den gesamten Stoffkreislauf eines Sees von Bedeutung ist und bei Planktonuntersuchungen nicht vernachlässigt werden darf.

\section{G. Zusammenfassung}

Das pflanzliche Nannoplankton des Zürichsees und Pfäffikersees wurde im Laufe einer zweijh̆rigen bzw. einjährigen Periode qualitativ und quantitativ untersucht, und zwar besonders im Vergleich zum Phytonetzplankton. Daneben liegen Resultate einmaliger Untersuchungen von sechs Seen mit verschiedenem Trophiegrad vor (oligotroph: Brienzer-, Thuner- und Walensee; eutroph: Sempacher-, Hallwiler- und Zürichsee).

Die Organismen wurden mit Hilfe der Zentrifugenmethode nach LoHMANN lebend bestimmt. Die quantitative Bestimmung erfolgte mit der 
Auszählmethode nach UTERmöHL im Umkehrmikroskop und durch Berechnung der Biomasse nach LoHMANN. Im Laufe der Untersuchungszeit wurden in den Proben des Zürichsees rund I30 Phytoplankter, davon etwa 70-80 Nannoplankter bestimmt. Rund 40 Formen, fast durchwegs Nannoplankter, wurden für den unteren Zürichsee neu gefunden. Im Pfäffikersee wurden 80 Formen, davon ungefähr 40 Nannoplankter, und in der einmaligen Untersuchung der obenerwähnten sechs Seen etwa Ioo Phytoplankter (davon etwa 60 Nannoplankter) beobachtet (pro See durchschnittlich 30-40). Der Artenbestand des Nannoplanktons im Vergleich zum Netzplankton war in den oligotrophen Seen prozentual höher als in den eutrophen.

Die jahreszeitliche und vertikale Verteilung der Organismen ist in Tabellen und Abbildungen festgehalten.

Ferner wurden die Individuenzahlen, die Biomasse und der prozentuale Volumenanteil des Netz- und Nannoplanktons tabellarisch und graphisch dargestellt und diskutiert. Fast in allen untersuchten Seen waren die Individuenzahlen des Nannoplanktons wesentlich grösser als die Zahl der Netzplankter. Die Biomasse des Nannoplanktons trat im eutrophen Zürichsee gegenüber dem Netzplankton, das zum grossen Teil durch Oscillatoria rubescens beherrscht wurde, zu gewissen Zeiten stark zuriick. Während der Untersuchungsjahre hat sie nie 50\% der totalen Biomasse erreicht. Im eutrophen Pfäffikersee bestand das Frühjahrs- und Frühsommerplankton sozusagen aus reinen Nannoformen, das Sommer- und Herbstplankton aus reinen Netzformen. Die absolute Biomasse des Netzplanktons war jedoch um ein Mehrfaches grösser. In den anderen, nur einmal untersuchten Seen spielten die Formen des Nannoplanktons zur Zeit der Untersuchung bezüglich der Biomasse nur im oligotrophen Brienzersee eine wichtige Rolle.

Anhand der Untersuchungsresultate und der Arbeiten anderer Autoren gelangte man zur Vermutung, dass der prozentuale Biomasseanteil des Nannoplanktons in oligotrophen Seen Mitteleuropas im allgemeinen grösser, in eutrophen Seen kleiner ist als derjenige des Netzplanktons. Hingegen scheint die absolute Biomasse des Nannoplanktons in oligotrophen Seen kleiner zu sein als in eutrophen.

Aus Vergleichen zwischen Individuenzahlen, Biomasse und chemischen Analysenresultaten aus dem Pfäffikersee zu schliessen, ist die Aktivität des Nannoplanktons gegenüber dem Netzplankton verhältnismässig gross, ebenso seine Wirkung auf den gesamten Stoff haushalt des Sees.

Für die Charakterisierung der Biozönose sowie für die Berechnung der 
Planktondichte, der Biomasse, der Produktion und des Stoffkreislaufs eines Sees ist das Nannoplankton von wesentlicher Bedeutung. Es sollte deshalb bei Planktonuntersuchungen sowohl qualitativ als auch quantitativ berücksichtigt werden.

\section{Summary}

The phytoplankton of the Lakes of Zurich and Pfäffikon was examined for a period of two years (I958 and 1959) and one year (I96I) respectively both qualitatively and quantitatively in relation to the phytonetplankton. Moreover the results of planktonic samples of six lakes (autumn I96I) of different trophic degrees (oligotrophic: Lakes of Brienz, Thun and Walen; eutrophic: Lakes of Sempach, Hallwil, Zurich), were dealt with in this Paper.

The organisms were identified qualitatively by the centrifugal method of LOHMANN [36] from living material, quantitatively by the counting method and inverted microscope of UTERMÖHL [74] and by calculating the volume of the different organisms, the biomass or standing crop respectively [35]. In Tables 3 and 4 unfiltrated and filtrated samples are compared, to demonstrate the enormous loss of algae by filtration.

During the investigations important representatives of nannoplanktonic organisms were found from the following genera (Plates I- -5 ): Oscillatoria, Cblamydomonas, Phacotus, Cblorella, Coccomyxa, Erkenia, Cyclotella, Stepbanodiscus, Rbodomonas, Cryptomonas, Katablepharis, Gymnodinium. We often observed nannoplankton organisms which are characteristic of the biotop; e. g. Stelexomonas dicbotoma: cold-stenothermic oligotrophic (Lake of Brienz); Chrysolykos planctonicus; cold-stenothermic, oligotrophic (Lake of Walen); Diceras cbodati: oligotrophic (Lake of Brienz and Thun); Oscillatoria obliqueacuminata: warm-stenothermic, eutrophic (Lake of Hallwil and Zurich).

About I30 phytoplankton species, 80 of them representing nannoplankters, were recorded in the Lake of Zurich. About 40 species, almost without exception nannoplanktonic forms, were named for the first time in the Lake of Zurich, though it is one of the most thoroughly investigated lakes, both biologically and chemically (Table 6). In the Lake of Pfäffikon about 80 species, 40 of them nannoplanktonic and in the six lakes mentioned above about too phytoplankton organisms ( 60 of them nannoplanktonic) were observed (Table 20). The percentage of nannoplankton species was rather higher in oligotrophic than in eutrophic lakes. The qualitative results show 
on the whole that the nannoplankton constitutes an essential part of the algal plankton community, both numerically and as ecological indicators.

The vertical distribution of some net- and nannoplankton organisms are plotted in Figures I3, 2I and 22. The nannoplankters show no special characteristics in comparison with the netplankton organisms (Table 24).

In nearly all samples examined the numbers of nannoplankton individuals per unit of volume were much greater than those of netplankton (Figs. I7 and 23a). The nannoplankton standing crop in the eutrophic Lake of Zurich was insignificant in comparison with its netplankton. The characteristic and big blue-green alga Oscillatoria rubescens often dominated the net- and nannoplankton (Figs. 6 and 7). The standing crop of the nannoplankton therefore never reached $50 \%$ of the total phytoplankton (Figs. 7 , 9 and Table 9). Notable are the following peaks of nannoplanktonic developments (Figs. 6, 7 and Tables 8, 9), namely in April r958 by Rbodomonas lacustris and Cryptomonas ovata, at the end of May by Cryptomonas opata, in the beginning of August by Cblorella pyrenoidosa and Coccomyxa minor, at the end of September by the little blue-green alga Oscillatoria obliqueacuminata and in February 1959 by Stephanodiscus bantzschii. See also Figs. 2-5, where the seasonal abundance of the most important species and groups are plotted in number of individuals below a unit of area.

In the highly eutrophic Lake of Pfäffikon a great amount of pure nannoplankton was exhibited in spring and early summer. The plankton of summer and autumn represents pure netplankton (Figs. I5-17, Tables 13, I4). The absolute biomass amount however was several times larger than the nannoplanktonic (Fig. I5 and Table I3). The spring development of algae consisted especially of Rbodomonas lacustris and Stephanodiscus bantzscbii, the peaks of netplankton in summer and autumn were caused by the blue-green algae Apbanothece clatbrata var. brevis and Apbanizomenon flos-aquae (Figs. II to I3, I6 and 18). The great nannoplankton development in spring had a considerable influence on the amount of the chemical compounds dissolved (Table I6) and support the idea that nannoplankters are biologically much more active than the netplankton.

Comparing the Lake of Zurich with the Lake of Pfäffikon we can say that the average standing crop in the one does not differ significantly from that of the other. The average biomass of the Lake of Zurich amounted to $12 ; 0$ $\mathrm{mm}^{3} / \mathrm{cm}^{2}$, in the year 1958 and to $\mathrm{I} 4, \mathrm{I} \mathrm{mm} / \mathrm{cm}^{2}$ for the Lake of Pfäffikon in 196I. The difference between the lowest and the highest standing crop varied in both lakes in the same limits (Lake of Zurich: $1,0-26,2 \mathrm{~mm} / \mathrm{cm}^{2}$ in the year I958 and 2,0-69,2 $\mathrm{mm}^{3} / \mathrm{cm}^{2}$ in I959; Lake of Pfäffikon: 0,8-67,2 
$\mathrm{mm}^{3} / \mathrm{cm}^{2}$ in $196 \mathrm{I}$ ). They differed mainly in their rhythm of producing phytoplankton and in their forming nannoplankton. In the other six lakes mentioned the nannoplankton standing crop of the oligotrophic Lake of Brienz alone was significant, with a percentage of 60 (Fig. 23).

The results of the present papers and those of other authors [ $\mathrm{I} 5,2 \mathrm{I}, 5 \mathrm{I}$, 54,59 and 77] lead us to surmise that the percentage biomass of nannoplankton in the oligotrophic lakes of Middle Europe is generally higher than in the eutrophic lakes. Heavy algal developments formed of pure nannoplankton can be observed also in hypertrophic lakes. These facts suggest that there is a close relation between extreme environmental factors and the percentage of nannoplankton. The more extreme the environmental conditions are the greater is the percentage of nannoplankton in relation to the netplankton. This suggestion is supported by the fact that generally there are many more species of nannoplankton than of netplankton. The possibility therefore that under extreme environmental conditions more nannoplankton is produced than netplankton is relatively great. Furthermore, this fact can be explained by comparing the different algal groups with regard to the nannoplanktonic and netplanktonic organisms they produce. The algal plankton community of the oligotrophic lakes of our regions consists mainly of nannoplanktonic species of the groups of the Chrysophyceae, Diatomeae, Cryptophyceae and Peridineae. The eutrophic lakes, on the other hand, are inhabited primarily by netplankton organisms of the groups of the Cyanophyta and Diatomeae. And in the hypertrophic lakes again nannoplankton species of the groups of the Euchlorophyceae and Euglenophyta are particularly developed (Fig. 24).

For the characterization of the plankton bicoenosis, the plankton density, the biomass, the production and the metabolism of a lake the nannoplankton is all important. It ought not to be neglected therefore, both qualitatively and quantitatively, in any planktological examination of a lake.

\section{LITER A TURVERZEICHNIS}

[I] АмвÜHL, H., Die Näbrstoffzufubr zum Hallwilersee, Schweiz. Z. Hydrol. 22, $563-597$ (1960).

[2] AмBய̈HL, H., Die künstlicbe Belüftung des Pfäffkersees, Verbandsber. VSA, Nr. $77 / 2(1963)$

[3] BachmanN, H., Charakterisierung der Planktonpegetation des Viermaldstättersees mittels Netzfängen und Zentrifugenproben, Verh. Naturf. Ges., Basel 35, I48-167 (I923). 
[4] BachmanN, H., Hydrobiologische Untersuchungen am Rotsee, Schweiz. Z. Hydrol. $5,39-8 \mathrm{I}$ (I93I).

[5] BACHOFEN, R., Stoffbausbalt und Sedimentation im Baldegger- und Hallwilersee, Diss. Univ. Zürich, I 18 S. (1960).

[6] BALdinger, F., Das Hallwilersee-Projekt als Beispiel einer grosszügigen Seesanierung, Schweiz. Z. Hydrol. 19, I8-36 (I957).

[7] Ballentine, D., Comparison of the different metbods of estimating nanoplankton, J. Mar. Biol. Assoc. U. K. 38, I29-I 48 (1953).

[8] BORGOROV, B. G., On the standardisation of marine plankton investigation, Internat. Rev. ges. Hydrobiol. 44, 62I-624 (1959).

[9] Bour Reliy, P., Recherches sur les Cbrysopbycées, Rev. algol. Mém. Hors-Série 1, 4I2 S. (I957).

[IO] BRAARUD, T., Counting methods for determination of the standing crop of phytoplankton, Cons. Intern. Explor. Mer 144, I7-20 (1958).

[II] BRUTSCHY, A., Das Plankton des Hallmilersees, Mitt. Aargauischen Naturf. Ges. 12, I4I-I48 (I9II).

[12] Christen, H. R., Limnologiscbe Untersucbungen im Hauserseegebiet, Schweiz. Z. Hydrol. 21, 19-108 (1959).

[13] CosandeY, F., Etude bydrobiologique du Lac de Bret, Schweiz. Z. Hydrol. 17, I-86 (I955).

[14] DU BoIs, A. M., und GEIGY, R., Beiträge zur Ökologie, Fortpflanzungsbiologie und Metamorphose pon Sialis lutaria L., Rev. suisse Zool. 42, I69-248.

[Is] Findenegg, I., Untersucbungen über die Ökologie und die Produktionsperbältnisse des Planktons im Kärntner Seengebiet, Internat. Rev. ges. Hydrobiol. 43, 368-429 (I943).

[16] FLücK, H., Beiträge zur Kenntnis des Pbytoplanktons des Brienzersees, Schweiz. Z. Hydrol. 4, I-70 (I928), I092 S.

[17] Fotr, B., Algenkunde (VEB Fischer-Verlag, Jena 1959), $482 \mathrm{~S}$.

[I8] GEITLER, L., Cyanopbyceae, Rabenborst's Kryptogamenflora, Bd. I4 (Akademische Verlagsgesellschaft, Leipzig I932), I092 S.

[I9] Gessner, F., Hydrobotanik I (I955) und Hydrobotanik II (I959), (VEB Deutscher Verlag der Wissenschaften, Berlin).

[20] Golterman, H. L., Studies on the cycle of elements in fresh mater, Acta Botanica Neerlandica 9, I-58 (1960).

[2I] GRIM, J., Beobachtungen am Pbytoplankton des Bodensees (Obersee) somie deren rechnerische Auspertung, Internat. Rev. ges. Hydrobiol. 39, I93-3 I5 (1939).

[22] Grobe, D., Mebrjäbrige Untersucbungen am Zooplankton des Sempacbersees, Rev. suisse Zool. 65, I-93 (1958).

[23] Heuscher, J., Vorläufiger Bericbt über die Resultate einer Untersucbung des Walensees, Schweiz. Fischereiztg. 1, Beilage $6 \mathrm{zu}$ Nr. 25, 29-36 (1893).

[24] Heuscher, J., Der Sempacbersee und seine Fiscbereiperbältnisse, Schweiz. Fischereiztg. 3, Beilage I 7 zu Nr. 2, I63-213 (I895).

[25] HeusCher, J., Thuner- und Brienzersee, ibre biologischen und Fischereiperbältnisse, Schweiz. Fischereiztg. 2 (I90I).

[26] Huber-PestalozzI, G., Das Pbytoplankton des Süsswassers, Teil I-5 in «Die Binnengewässer», Bd. I6 (E. Schweizerbartsche Verlagshandlung I938-I96I).

[27] Huber-Pestalozzi, G., Der Walensee und sein Plankton, Schweiz. Z. Hydrol. $10, \mathrm{I}-\mathrm{I} 20$ (I946). 
[28] Järnefelt, H., und Thomas, E. A., Beitrag zur Kenntnis des Planktons des ZürichObersees und des Zürichsees, Vischr. Naturf. Ges. in Zürich 104, 403-408 (1959).

[29] JavornICKY, P., Die Revision einiger Metboden zum Feststellen der Qualität des Pbytoplanktons, Sci. Papers from Inst. Chem. Technology, Prague (I958).

[30] JøRGENSEN, E. G., Diatom periodicity and silicon assimilation, Dansk Botanisk Arkiv, Vol. I7, Bd. I8, Nr. I (I957).

[3I] KeLLER, R., Limnologiscbe Untersucbungen im Hallwilersee, Diss. (ETH, Zürich I945), I275.

[32] KUHL, F., Untersucbungen über das Zentrifugenplankton und das Netzplankton des Walchensees und Kickelsees in den Fabren 1921 bis 1923, Arch. Hydrobiol. Suppl. 6, 96-I60 (I938).

[33] LANTZSCH, K., Studien über das Nannoplankton des Zugersees und seine Beziebung zum Zooplankton, Z. wiss. Zool. 108, 63I-692 (1914).

[34] LEHN, H., Einige Frübjabrsbefunde über die Isothermen-Pbytoplankton-Relation im Bodensee, Arch. Hydrobiol. 59, I-25 (1963).

[35] Lohman.N, H., Untersucbungen zur Feststellung des vollständigen Gebaltes des Meeres an Plankton, Wiss. Meeresuntersuch. Kiel, 10, I 8I S. (I908).

[36] LoHMaNN, H., Über das Nannoplankton üd die Zentrifugierung kleinster $W$ asserproben zur Gewinnung derselben in lebendem Zustande, Internat. Rev. ges. Hydrobiol. 4, I-38 (I9II).

[37] LOZERon, H., La répurtition verticale du plancton dans le lac de Zurich, Diss. ETH, Zürich, 84 S. (I902).

[38] LUND, J. W. G., A simple counting chamber for nannoplankton, Limnol. Oceanogr. $4,57-65$ (1959).

[39] Lund, J. W. G., and TAlling, J. F., Botanical limnological metbods mith special reference to the algae, The. Bot. Rev. 23, 489-583 (I957).

[40] LUND, J. W. G., KIPLING, C., and LE CREN, E. D., The inverted microscope method of estimating algal numbers and the statistical basis of estimations by counting, Hydrobiologia 9, I43-I70 (1958).

[4I] MäRKI, E., Limnologie der scbmeizeriscben Seen und Flüsse, Schweiz. Z. Hydrol. 11, 650-707 (I949).

[42] MessiKommer, E., Eine Planktoninvasion im Pfäffikersee, Vischr. Naturf. Ges. in Zürich 92, 275-277 (1947).

[43] Messikommer, E., Weiterer Beitrag zur Planktonkunde des Pfäffkersees, Schweiz. Z. Hydrol. 3I7-346 (I943).

[44] Messikommer, E., Die Algenflora des Züricbsees bei Zürich, Schweiz. Z. Hydrol. 16, 27-63 (1954).

[45] MnNDE, L., Biologisch-chemische Untersucbungen im Züricbsee, Schweiz. Z. Hydrol: $3, \mathrm{I}-69$ ( $\mathrm{I} 926)$.

[46] Minder, L., Mungan speicbernde Organismen im Hypolimnion des Züricbsees, Verh: Internat. Verein. Limnol. 9, 303-307 (I940).

[47] Minder, L., Der Zürichsee im Licbte der Seetypenlebre, Neujahrsbl. Naturf. Ges. in Zürich, 83 S. (I943).

[48] NYDEGGER, P., Vergleichende limnologiscbe Untersucbungen an sieben Schweizerseen, Beitr. z. Geol. Schweiz, Serie B, Hydrologie Nr. 9, 80 S. (1957).

[49] PAscher, A., Die Süsswasserflora, H. 5, Chlorophyceae (I9I5), H. 4, Volvocales (I927) (Gustav Fischer Jena). 
[50] RodHE, W., The primary production in Lakes: some results and restrictions of $C_{14-}$ metbod, Rapp. Cons. Expl. Mer 144, I22-128 (1958).

[5I] RoDHE, W., Sulla produzione di fitoplancton in lagbi trasparenti di alta montagna, Mem. Ist. Ital. Idrobiol. 15, 2I-28 (1962).

[s2] RodHe, W., VollenweIdeR, R. A. and NAUwerk, A., The primary production and standing crop of phytoplankton, Perspectipes in marine biology, Symp. scrips int. of Oceanogr. 62I pp. (1956).

[53] Ruttner, F., Über die Anmendung von Filtration und Zentrifugierung bei den planktologiscben Arbeiten an den Lunzer Seen, Internat. Rev. ges. Hydrobiol. 2, I74-I 8 I (I909).

[54] RUTTNER, F., Bericbt über die Planktonuntersucbungen an den Lunzer Seen, Internat. Rev. ges. Hydrobiol. 6, 5I8-527 (1913/I4).

[55] RutTner, F., Das Plankton des Lunzer Untersees, seine Verteilung in Raum und Zeit mäbrend der Fabre 1908-1913, Internat. Rev. ges. Hydrobiol. 23, I-I 38 und I6I-287 (I929/30).

[56] RutTneR, F., Limnologische Studien an einigen Seen der Ostalpen, Arch. f. Hydrobiol. 32, 167-319 (1937).

[57] RutTneR, F., Die Metboden der quantitativen Plänktonforschung, Mikrosk. 3, 39-SI (I948).

[58] RUTTNER, F., Planktonstudien der Deutschen Limnologischen Sunda-Expedition, Arch. für Hydrobiol. Suppl. 21, I-274 (1952).

[59] RutTneR, F., Einige Beobacbtungen über das Pbytoplankton Norditalieniscber Seen, Mem. Ist. Ital. Hydrobiol. 11, 73-I I I (I959).

[60] RutTner, F., Grundriss der Limnologie (3. Auflage, Verlag Walter de Gruyter u. Co., Berlin 1962), $332 \mathrm{~S}$.

[6I] SCHröter, C., Die Schwebeflora unserer Seen, Neujahrsbl. Naturf. Ges. in Zürich, 57 S. (I 897).

[62] SKujA, H., Taxonomie des Pbytoplunktons einiger Seen in Uppland, Scbroeden, Symbolae bot. Upsaliensis 9 (3) ( 1948$), 399$ S.

[63] Skuja, H., Taxonomiscbe und biologiscbe Studien ïber das Pbytoplankton scbwediscber Binnengemässer, Nova act. Regiae soc. scientiarum Upsaliensis ser. 4, 16 (3) (1956), $404 \mathrm{~S}$.

[64] STEINER, H., Vergleichende Studien über die borizontale und pertikale Verteilung des Pbytoplanktons im Zürichsee, Veröff. Geobot. Inst. Rübel in Zürich, 3. H., 45947.5 (1925).

[65] Theiler, A., Beiträge zur Planktonkunde des Sempacher- und Baldeggersees, Vischr. Naturf. Ges. in Luzern 7, 309 (1910-1915).

[66] Thomas, E. A., Auffällige biologiscbe Folgen von Sprungscbicbtneigungen im Züricbsee, Schweiz. Z. Hydrol. 12, I-24 (1950).

[67] Thomas, E. A., Der Zürichsee, sein Wasser und sein Boden, Jb. vom Zürichsee 17, I73-208 (1956/57).

[68] Tномаs, E. A., Neue Planktonalgen des Zürichsees, Neue Zürcher Zeitung vom 5. I. I957, Nr. 29.

[69] Thomas, E. A., Das Plankton-Test-Lot, ein Gerät zum Studium des Verbaltens von Planktonorganismen im See, Schweiz. Ver. von Gas- und Wasserfachmännern, Mbull. $38, \mathrm{I}-6$ (I958). 
[70] Thomas, E. A., und MäRKI, E., Der heutige Zustand des Zürichsees, Verh. Internat. Ver. Limnol. 10, 476-488 (I949).

[7I] Thomasson, K., Die Kugelkurpen in der Planktologie, Int. Rev. Cies. Hydrobiol. 47, 627-628 (I963).

[72] THUnmaRK, S., Zur Soziologie des Sïssmasserplanktons, Folia Limnologica Scandinavica, Nr. 3, 66 S. (I945).

[73] UTERmöHL, H., Limnologiscbe Phytonplanktonstudien, Arch. f. Hydrobiol. Suppl. 5, I-527 (I925).

[74] UTERMÖHL, H., Quantitatipe Metboden zur Untersucbung des Nannoplanktons, Abderhaldens Handbuch biol. Arbeitsmethoden, Abt. 9. 2/II (I 879-1937).

[75] UTERMöHL, H., Zur Vervollkommnung der quantitatipen Pbytoplankton-Metbodik, Internat. Ver. theor. und angew. Limnol. Mitt. Nr. 9, 38 S. (1958).

[76] WILLÉN, T., The phytoplankton of Gordäln, a Bay of lake Mälaren, Oikos 10, Fasc. 2, 24I-274 (I959).

[77] WILLEN, T., The pbytoplankton of Osbysjön, Djursbolm, I. Seasonul and vertical Distribution of the species, Oikos 12 , Fasc. I. 36-69 (196I).

[78] WrLlÉN, T., The Utal lake chain central Sweden and its Pbytoplankton, Oikos Suppl. 5, I56 S. (I962).

[79] ZIMMERMANN, P., Chemische und bakteriologische Untersucbungen im unteren Züricbsee wäbrend der Fabre 1948-1957, Schweiz. Z. Hydrol. 23, 342-397 (1961).

[80] ZüLlIG, H., Beobachtungen über zunebmende Eutropbierung des Sempacbersees. Plan, Schweiz. Z. Landes-, Regional- und Ortsplanung, Nr. 3 (1958). 


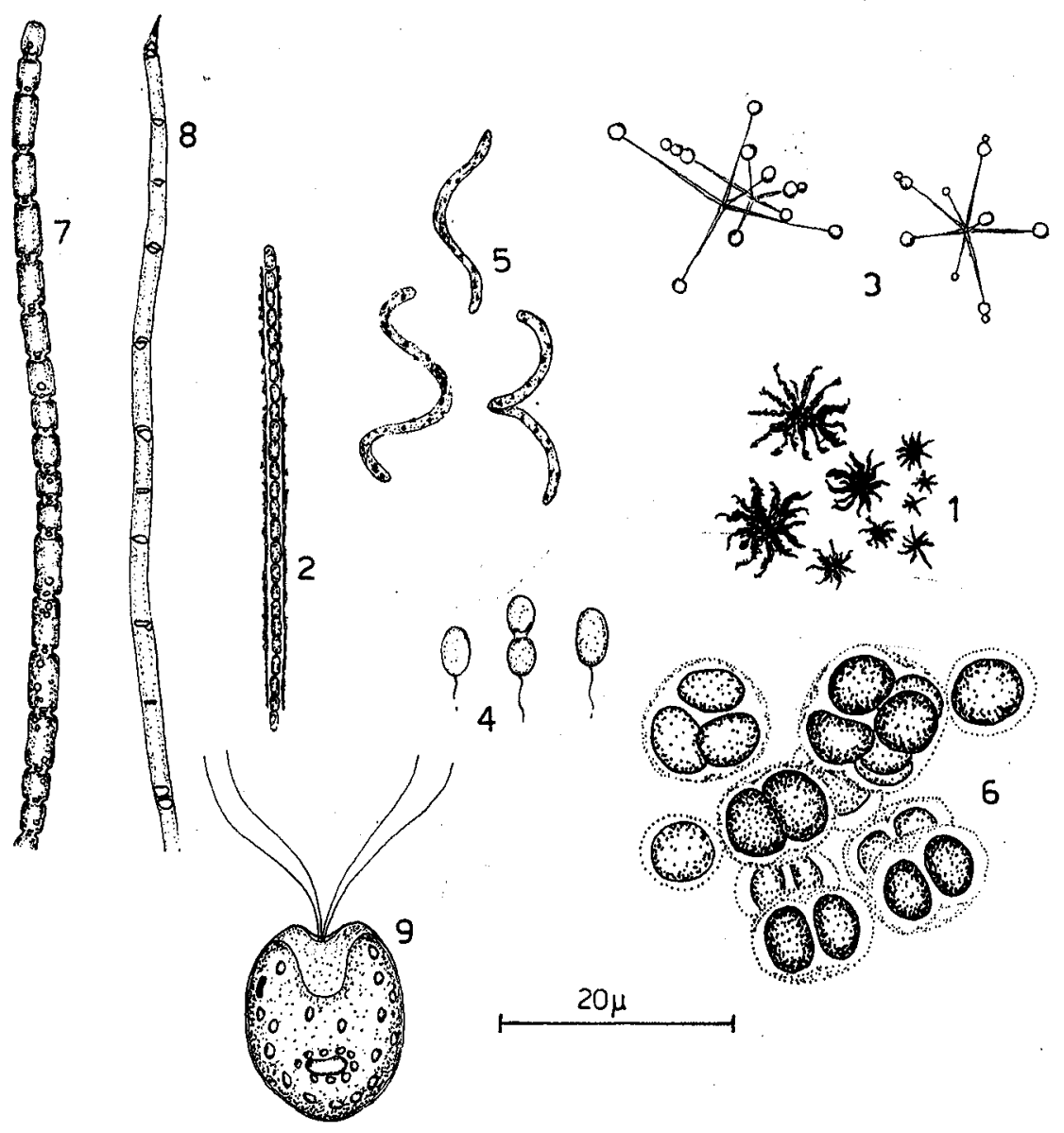

Tafel 1

5 Spirillus volutans Skuja

1 Leptothrix echinata Beger

6 Chroococcus cf. minutus (Kütz.) Näg. var.

2 Leptothrix cf. pseudovacuolata (Perfil.) Dorff.

7 Pseudanabaena catenata Lauterb.

3 Planctomyces bekefii Gimesi

8 Oscillatoria obliqueacuminata Skuja

4 Pseudomonas cf. ariston Skuja

9 Platymonas cordiformis (Carter) Korschikow 


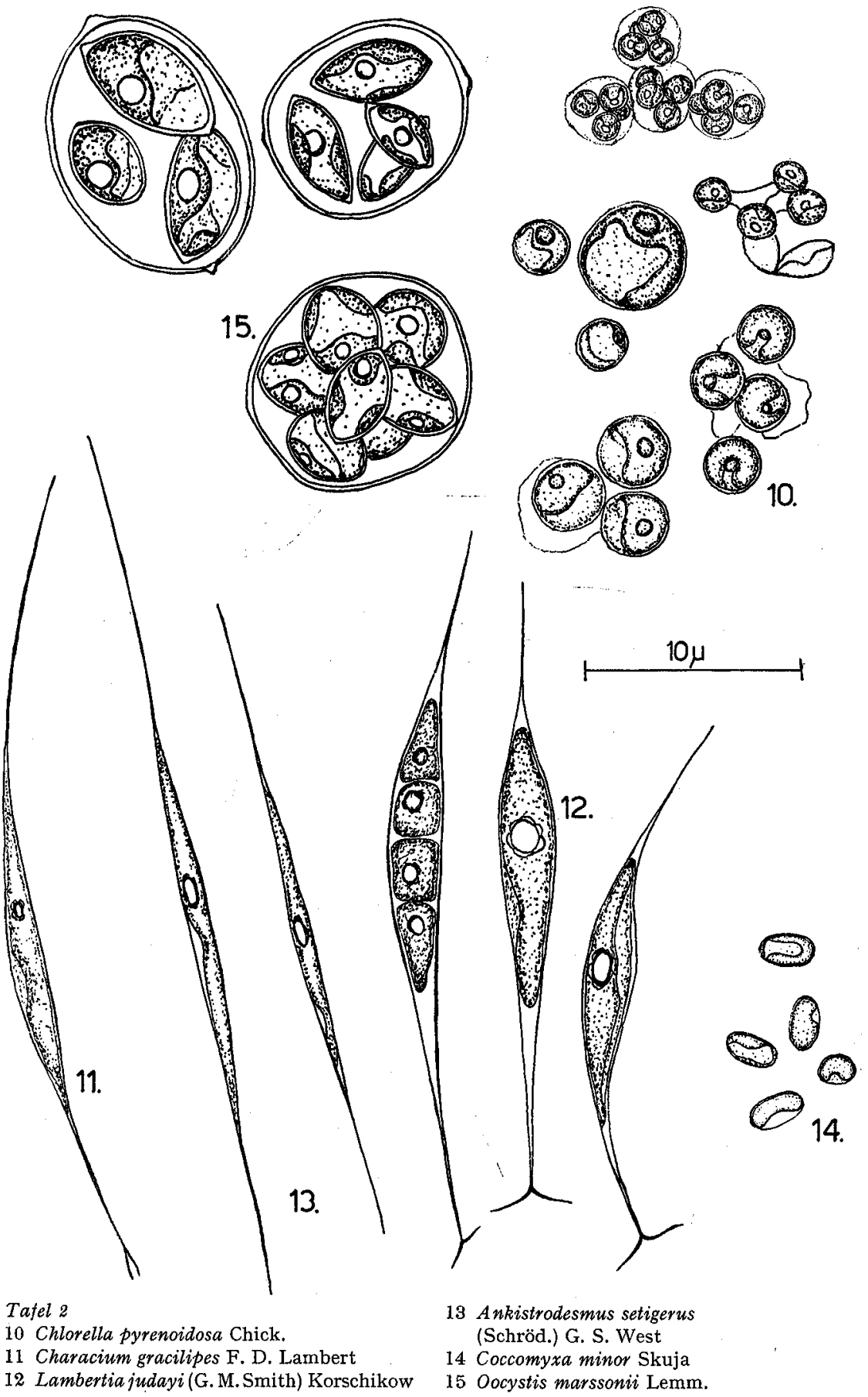



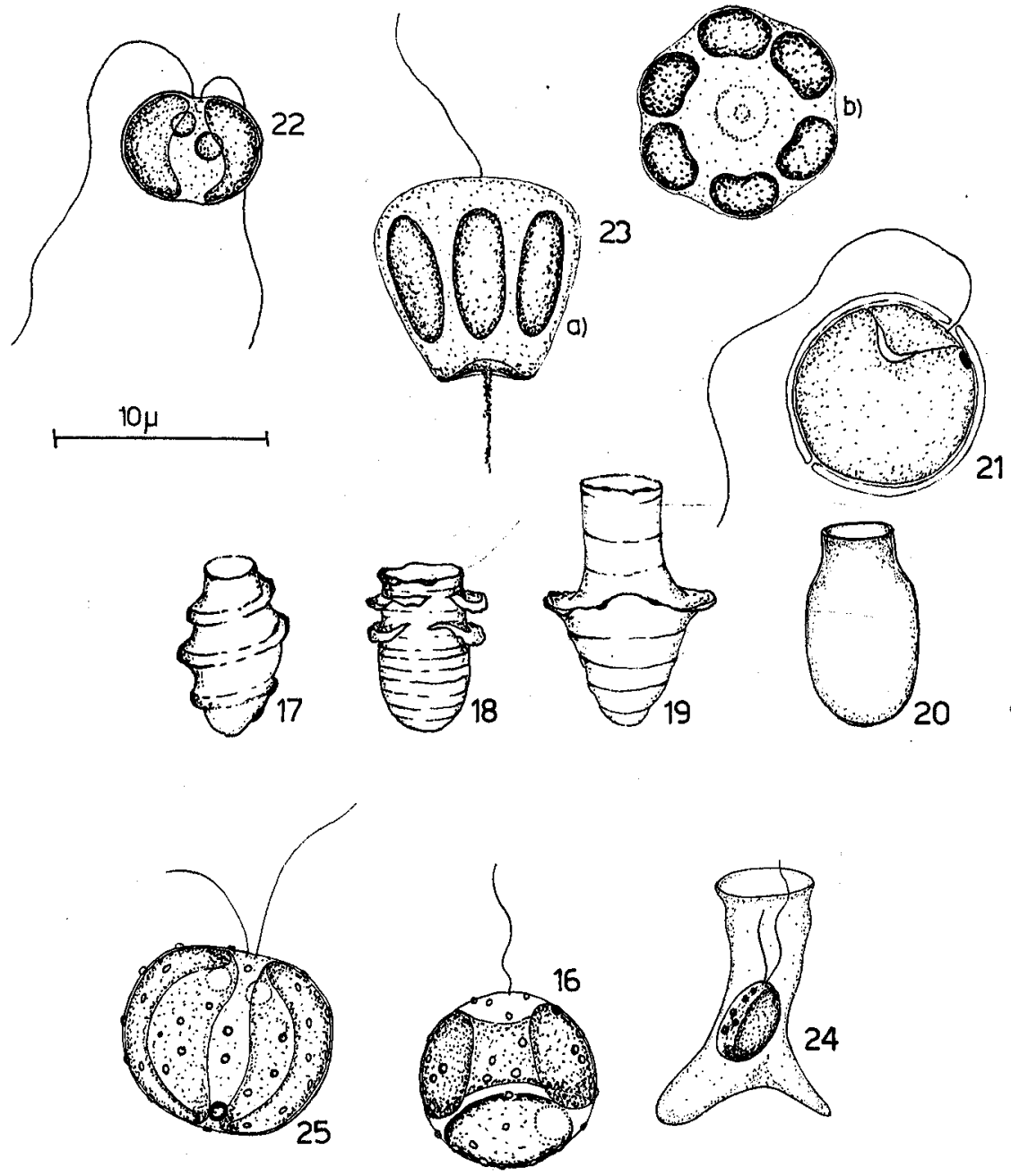

Tatel 3

21 Chrysococcus rufescens Klebs

22 Erkenia subaequiciliata Skuja

23 Pseudopedinella erkensis Skuja,

a) Lateralansicht, b) Antapikalansicht

17 Kephyrion spirale (Lack.) Conr.

18 Kephyrion inconstans (Schm.) Bourr.

19 Kephyrion moniliferum (Schm.) Bourr.

24 Chrysolykos planctonicus Mack

20 Pseudokephyrion entzii Conr.

25 Ochromonas sp. 

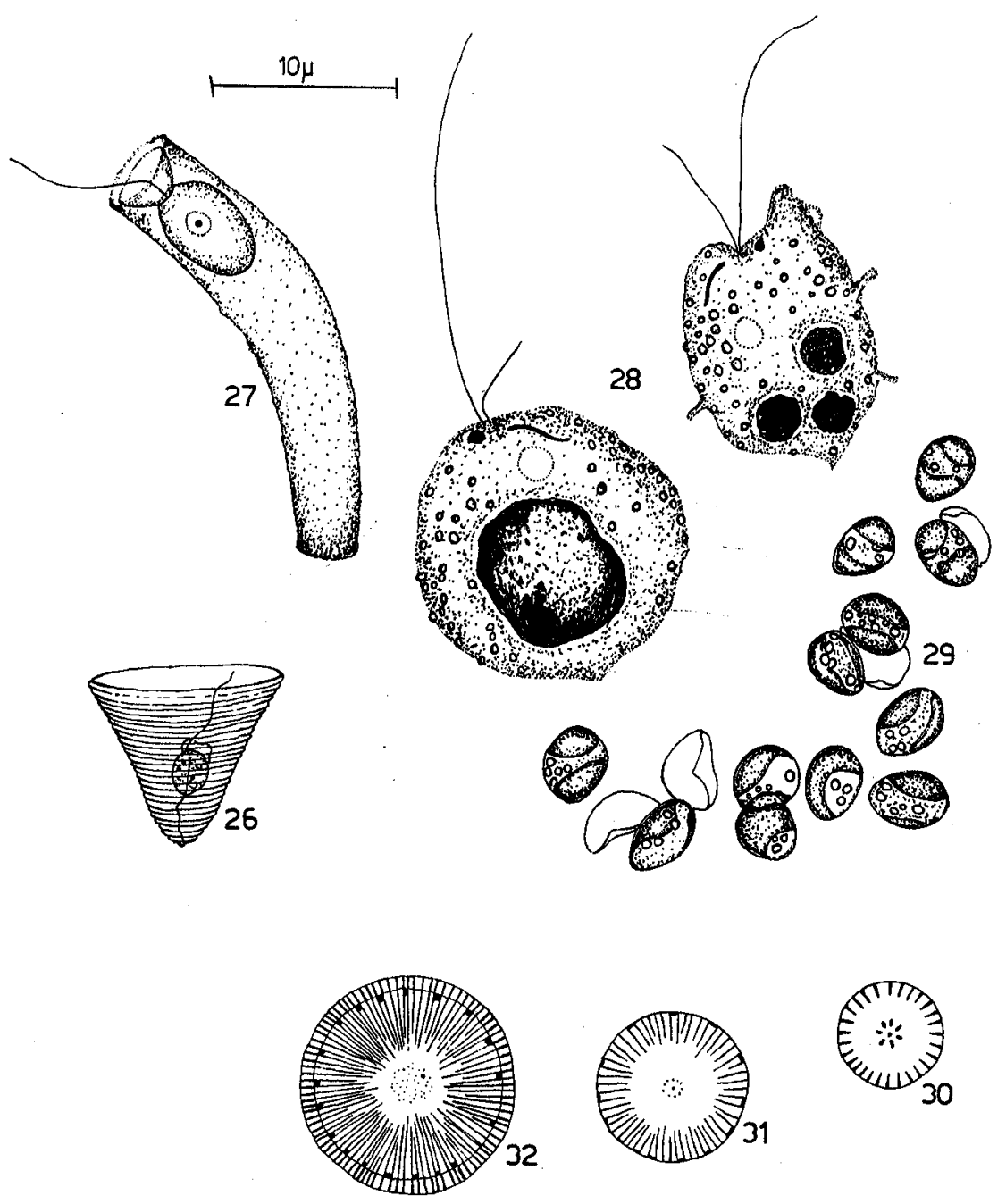

Tafel 4

26 Bicoeca multiannulata Skuja

27 Stelexomonas dichotoma Lackey

29 Ellipsoidion ef. oocystoides Pascher

30 Cydlotella stelligera Cl. et Grun.

31 Cyclotella pseudostelligeraHust.

28 Heterochromonas sp.

32 Cyclotella operculata $\left(\mathrm{Ag}_{i}\right) \mathrm{Kg}$. 


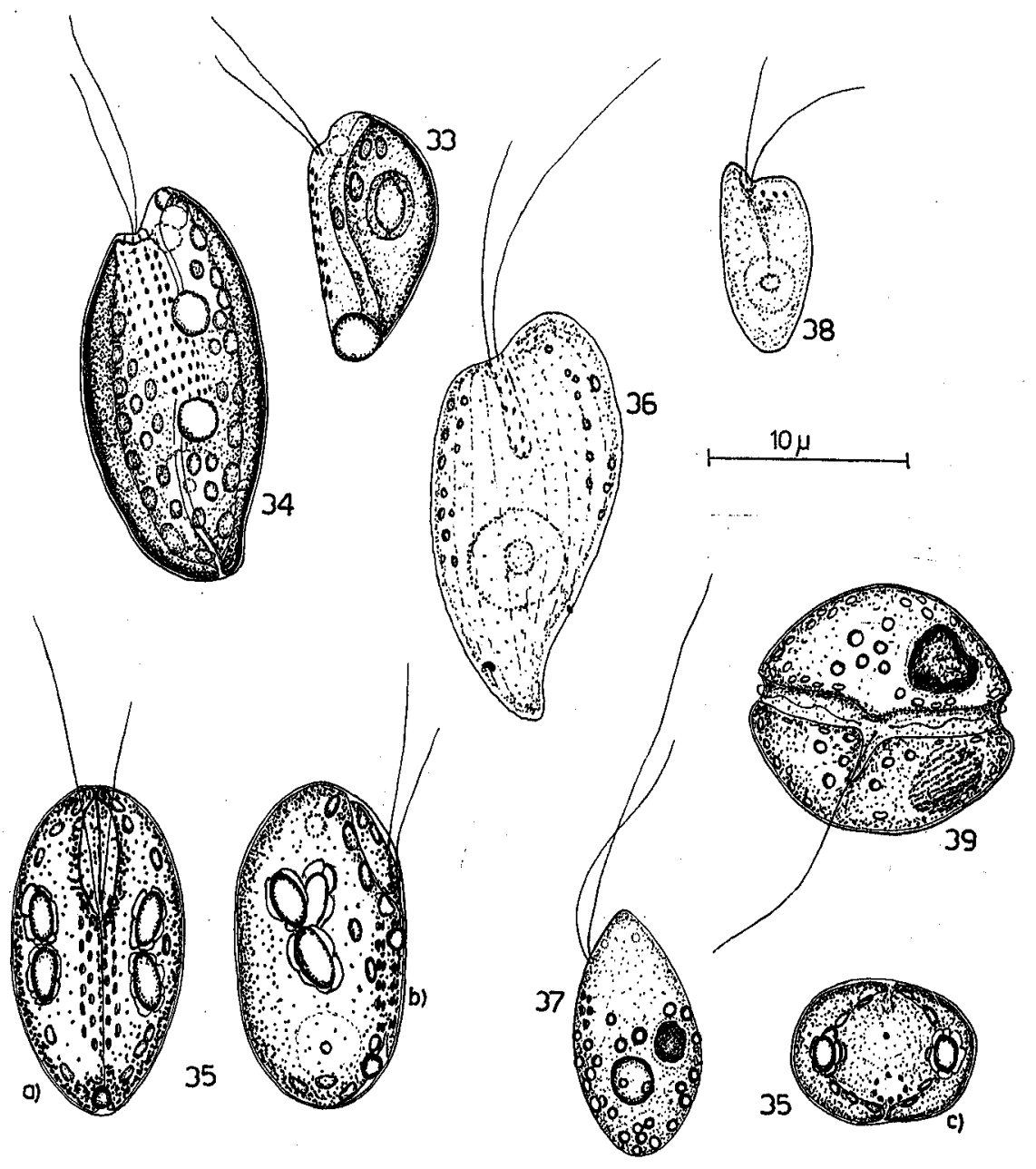

Tafel 5

33 Rhodomonas lacustris Pasch. et Rutt. 34 Cryptomonas ovata Ehrb.

36 Chilomonas cryptomonadoides Ehrb.

35 Cryptomonas tetrapyrenoidosa Skuja,

a) Ventralansicht, b) Lateralansicht, 37 Katablepharis ovalis Skuja

38 Cyathomonas truncata (Fres.) Fisch. c) Querschnitt

39 Gymnodinium lantzschii Utermöhl 